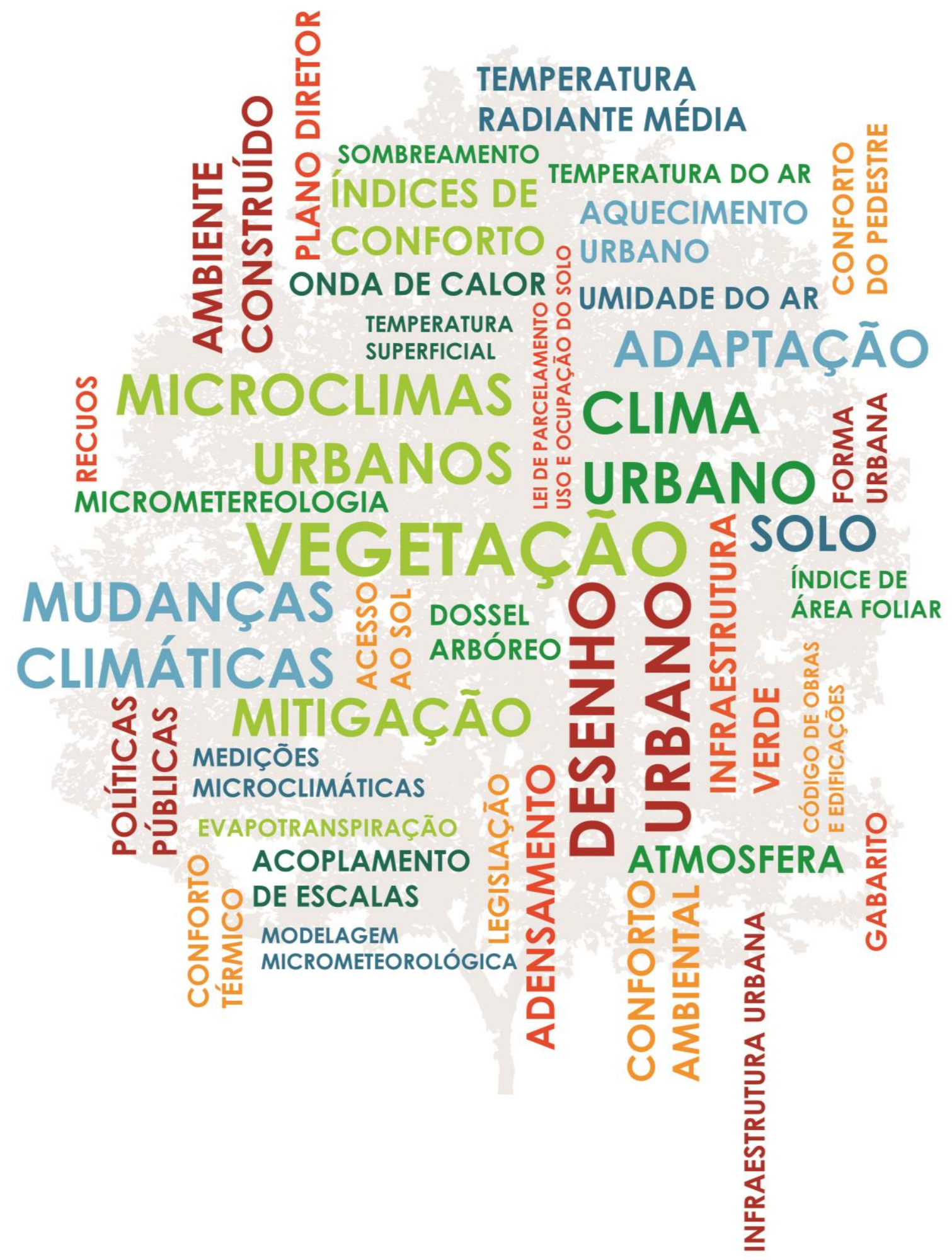



Denise Helena Silva Duarte

\section{O IMPACTO DA VEGETAÇÃO NO MICROCLIMA EM CIDADES ADENSADAS E SEU PAPEL NA ADAPTAÇÃO AOS FENÔMENOS DE AQUECIMENTO URBANO}

Contribuições a uma abordagem interdisciplinar 

Denise Helena Silva Duarte

O IMPACTO DA VEGETAÇÃO NO MICROCLIMA EM CIDADES ADENSADAS E SEU PAPEL NA ADAPTAÇÃO AOS FENÔMENOS DE AQUECIMENTO URBANO

Contribuições a uma abordagem interdisciplinar

Tese apresentada como parte dos requisitos para a obtenção do título de Professor Livre-docente no Departamento de Tecnologia da Arquitetura, da Faculdade de Arquitetura e Urbanismo da Universidade de São Paulo Edital ATAc 010/2015 
AUTORIZO A REPRODUÇÃO E DIVULGAÇÃO TOTAL OU PARCIAL DESTE TRABALHO, POR QUALQUER MEIO CONVENCIONAL OU ELETRÔNICO, PARA FINS DE ESTUDO E PESQUISA, DESDE QUE CITADA A FONTE.

E-MAIL DA AUTORA: dhduarte@me.com

Duarte, Denise Helena Silva

D812i O impacto da vegetação no microclima em cidades adensadas e seu papel na adaptação aos fenômenos de aquecimento urbano. Contribuições a uma abordagem interdisciplinar / Denise Helena Silva Duarte. --São Paulo, 2015.

167 p. : il.

Tese (Livre Docência - Departamento de Tecnologia da Arquitetura) FAUUSP.

1.Microclima urbano 2.Vegetação 3.Aquecimento 4.Mudança climática 5.Adensamento urbano I.Titulo

CDU 551.588.7 
À minha família 



\section{Agradecimentos}

Aos muitos professores que contribuíram para a minha formação.

Aos professores do grupo de disciplinas de conforto ambiental, pelo apoio à realização deste trabalho.

Aos demais professores do Departamento de Tecnologia e da FAUUSP, pelas sugestões para o encaminhamento deste trabalho.

Aos professores externos à FAUUSP, pelas discussões e contribuições para os avanços nas pesquisas do grupo.

A todos os pos-docs e alunos de pós-graduação, iniciação científica e trabalho final de graduação vinculados ao laboratório, pelas energias positivas para a realização deste trabalho.

Ao técnico de laboratório Ranieri Carvalho Higa, pelo super apoio com o parque de equipamentos, com a preparação, realização e processamento dos dados dos trabalhos de campo.

À secretaria do AUT, sempre eficiente e prestativa.

À equipe do LPG, pela produção dos exemplares.

Aos meus orientandos envolvidos na construção deste conhecimento coletivo, que ao longo de anos fizeram parte do grupo dos verdinhos, dos estudos de adensamento e de mudanças climáticas, em especial: Paula Shinzato e Erik Johansson (Pos-Docs), Carolina dos Santos Gusson, Carolina Abrahão Alves, Luciana Schwandner Ferreira, Melissa Belato Fortes (doutorandas); aos alunos de iniciação científica: Tatiana Souza, Lara del Bosco, Natalia Turri Lorenzo, Ângela Yamaguishi Madeira, Érika Osako, Bárbara Ferronato, Fernanda Camargo Barros, Denise Cordeiro Moreira, Rosane Yumi Fukuoka, Suzana Seikoyume Tateoka, Beatriz Ruiz Fernandes, Daniel Yoshida, Paulo Eduardo Ramillo e Stefani Sayuri Seki, e aos orientandos dos demais professores do grupo que se envolveram e fizeram parte das equipes de trabalho.

À Paula Shinzato, Carolina dos Santos Gusson, Carolina Abrahão Alves, Luciana Schwandner Ferreira e Eduardo Pizarro, pelo apoio mais do que incondicional para o fechamento deste trabalho. 



\section{RESUMO}

DUARTE, Denise. 0 impacto da vegetação no microclima em cidades adensadas e seu papel na adaptação aos fenômenos de aquecimento urbano. Contribuições a uma abordagem interdisciplinar. 2015. 167p. Tese (Livre-Docência) - Faculdade de Arquitetura e Urbanismo, Universidade de São Paulo, São Paulo, 2015.

O trabalho trata do impacto da vegetação no microclima em cidades adensadas e seu papel na adaptação aos fenômenos de aquecimento urbano. A hipótese é que os efeitos microclimáticos da vegetação têm um impacto positivo como parte das estratégias de adaptação aos fenômenos de aquecimento urbano, no clima atual e futuro. O objetivo é agregar os resultados das medições de campo e das simulações do efeito microclimático da vegetação numa proposta de inclusão da infraestrutura verde na cidade adensada, como parte da estratégia de adaptação aos fenômenos de aquecimento urbano. O método se inicia com levantamentos para melhor entendimento do todo e escolha das áreas de estudo; procede-se, então, ao planejamento do trabalho de campo em função dos recursos e restrições do modelo a ser adotado, neste caso o ENVI-met V4 Preview 1. Na sequência, são realizados os levantamentos de dados de solo, vegetação e atmosfera no nível do solo e no topo do modelo, essenciais ao funcionamento do mesmo. Prossegue-se com a etapa de indução, por observação dos fenômenos, essencial para a quantificação de variáveis urbanísticas e ambientais de interesse para a pesquisa. Dá-se continuidade ao estudo de forma dedutiva, por meio de comparações entre os resultados levantados nas diferentes situações. O trabalho segue com a modelagem das áreas de estudo reais, buscando a melhor representação dos fenômenos e considerando as simplificações possíveis e necessárias, dado o custo computacional envolvido. Procede-se então à simulação computacional das áreas reais de estudo, visando à calibração entre dados medidos e simulados. Após essa etapa são feitos os estudos paramétricos para selecionar as melhores estratégias para as simulações de diferentes cenários para os casos reais. A partir daí, pode-se estabelecer diretrizes para a inclusão da infraestrutura verde na cidade adensada e informar políticas públicas para o planejamento e desenho urbano. No clima atual de São Paulo, os resultados microclimáticos no nível do pedestre para um parque urbano de 1 ha com vegetação arbórea de IAF 4,6, em meio a um entorno adensado, com torres de 15 pavimentos, apresentaram uma variação dos índices de conforto da ordem de $10^{\circ} \mathrm{C}$ (TEP) e de $13,4^{\circ} \mathrm{C}$ (PET), quando comparados com o mesmo cenário sem vegetação. Em um cenário climático futuro (2045 a 2074), com o aumento da temperatura do ar segundo o IPCC AR5 RCP8.5, o mesmo parque apresenta uma redução de até $5^{\circ} \mathrm{C}$ (TEP) e $6^{\circ} \mathrm{C}$ (PET); quando se acrescentam árvores nas vias a redução é de $7^{\circ} \mathrm{C}$ (TEP) e $8,5^{\circ} \mathrm{C}$ (PET), o que é significativo para o conforto humano. A estratégia de manter uma vegetação arbórea em parques urbanos, conectada com arborização nas vias, formando uma rede de infraestrutura verde na cidade, pode contribuir diretamente para a adaptação da população aos eventos climáticos extremos, ao provocar um efeito oásis durante as ondas de calor; e também, indiretamente, para a mitigação dos fenômenos de aquecimento urbano, por diminuir as temperaturas de superfície pelo sombreamento, aumentar as perdas de calor por evaporação e, consequentemente, diminuir o armazenamento de calor no tecido urbano.

Palavras-chave: Microclima urbano. Vegetação urbana. Adensamento urbano. Aquecimento urbano. Mudanças climáticas. 



\begin{abstract}
DUARTE, Denise. The impact of vegetation in dense cities' microclimates and its role on adaptation to the urban warming effects. Contribution to an interdisciplinary approach. 2015. 167p. Tese (Livre-Docência) - Faculdade de Arquitetura e Urbanismo, Universidade de São Paulo, São Paulo, 2015.

This work deals with the impact of vegetation in dense cities' microclimates and its role on adaptation to the urban warming effects. The hypothesis is that green microclimate effects have a positive impact as part of urban warming adaptation strategies, in the current and future climate. The aim is to put together field measurements and simulation results in a proposal for the inclusion of green infrastructure in dense cities, as part of the adaptation strategy to urban warming. The method starts with data collection to understand the whole context, before choosing the study areas. Then, fieldwork is planned as a function of resources and restrictions of the computational model, in this case, the ENVI-met V4 Preview 1. Following this, soil, vegetation and atmospheric data are raised at ground level and at the top of the model, both essential for its operation. Therefore, inductive phase starts observing the phenomena, aiming to quantify the urban and environmental variables needed for the research and the deduction phase is carried out comparing the results for the various situations. Then, the study areas are modelled, aiming the better representation of the phenomena, considering the possible and needed simplifications, having in mind the computational costs involved; in doing so, simulation is carried out, aiming to calibrate measured and simulated data. After that, parametric studies help to select the better strategies for the real cases, aiming to set the recommendations to include the green infrastructure in dense cities, informing public policies for planning and urban design. Under the current climate in São Paulo, microclimate results at the pedestrian level for an urban park of 1 ha and dense trees with LAI 4,6, in the middle of a dense urban environment with 15 floors' towers, presents a difference in comfort indexes about $10^{\circ} \mathrm{C}$ (TEP) and $13,4^{\circ} \mathrm{C}$ (PET), when compared to the same urban scenario without vegetation. In a future climate scenario (2045 to 2074), with the air temperature raising according to IPCC AR5 RCP8.5, the same park presents a reduction of $5^{\circ} \mathrm{C}$ (TEP) and $6^{\circ} \mathrm{C}$ (PET); adding street trees, the reduction goes to $7^{\circ} \mathrm{C}$ (TEP) and $8,5^{\circ} \mathrm{C}$ (PET), both significant for human thermal comfort. The strategy to keep dense trees in urban parks, connected to street trees configuring a green infrastructure network in the city, can contribute directly for the adaptation to extreme climate events, creating an oasis effect during heatwaves. In addition, it can contribute indirectly to the mitigation of urban warming effects, decreasing the surface temperatures through shading, increasing heat loss by evaporation and, consequently, decreasing the heat storage in urban fabric.
\end{abstract}

Keywords: Urban microclimate. Urban vegetation. Urban density. Urban warming. Climate Change. 



\section{SUMÁRIO}

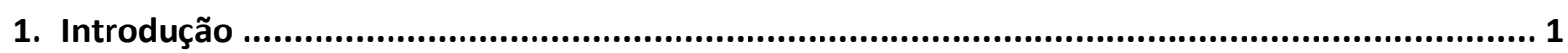

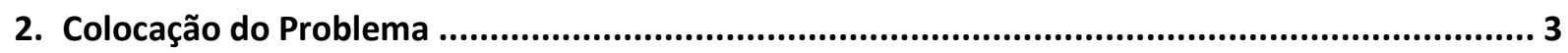

2.1. Contexto global de mudanças climáticas e o papel das cidades ............................................ 4

2.2. Contexto brasileiro de mudanças climáticas ....................................................................... 7

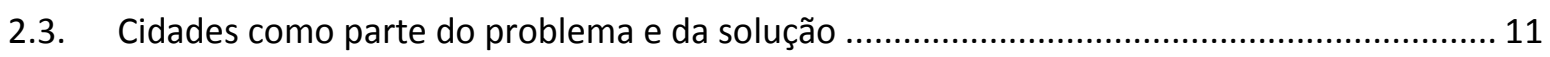

2.4. Tema do trabalho, perguntas da pesquisa, hipótese e objetivo ........................................ 14

3. Interações entre clima urbano, planejamento, desenho urbano e projeto de edifícios............. 19

3.1. Climatologia urbana: notas para uma breve perspectiva histórica ..................................... 19

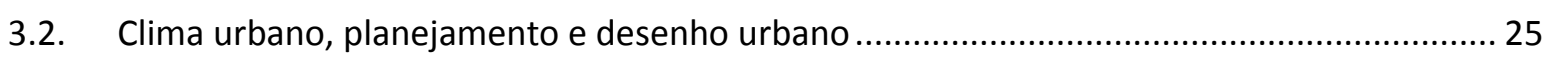

3.3. Clima urbano: abordagens, escalas e balanço de energia em áreas urbanizadas.................. 27

3.4. Interações entre o clima urbano e o ambiente construído .................................................. 28

3.4.1. Parcelamento, uso e ocupação do solo orientados aos recursos ambientais ............... 29

3.4.2. Acesso ao sol e acesso à luz natural e ventilação urbana ............................................... 30

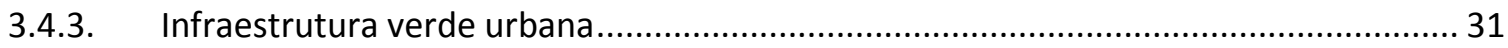

3.5. Efeitos do desenho urbano sobre o microclima urbano e sobre as edificações .................... 32

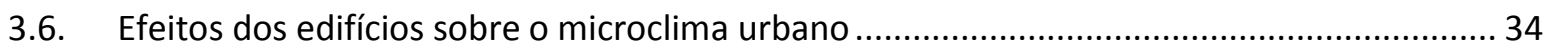

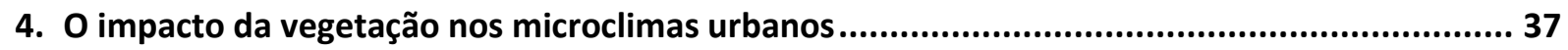

4.1. O papel da vegetação nas áreas urbanas adensadas .......................................................... 37

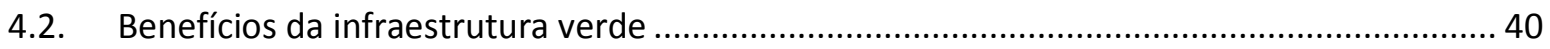

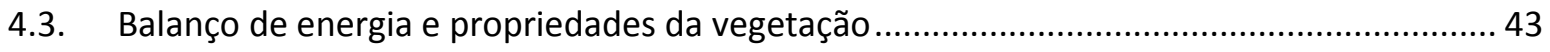

4.4. Medição e modelagem da infraestrutura verde................................................................. 46

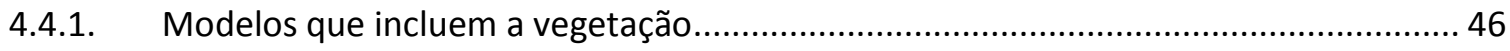

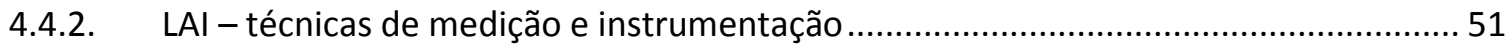

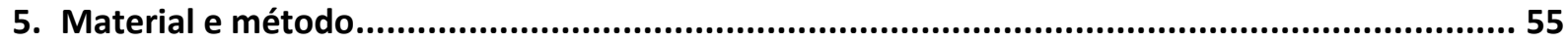

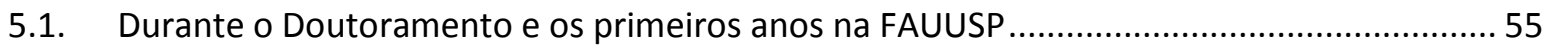

5.2. No início da formação do grupo de pesquisa na FAUUSP ................................................... 58

5.3. Mais recentemente, com a consolidação do grupo de pesquisa ........................................ 59

6. O caso de São Paulo: contexto urbano e climático, atual e futuro, e a distribuição da vegetação

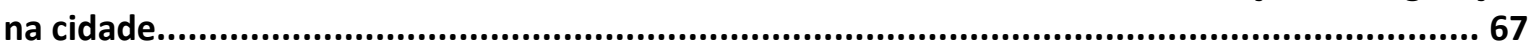

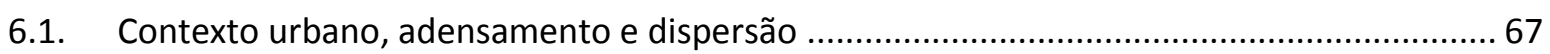

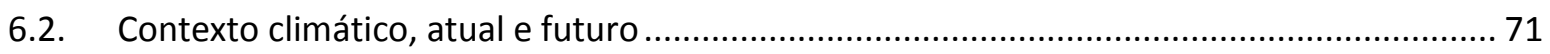

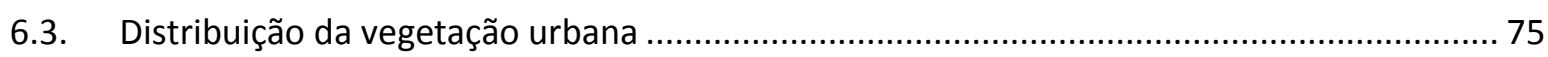


7. O que aprendemos com as medições microclimáticas e de vegetação, e com as simulações numéricas

7.1. Medições microclimáticas e de vegetação

7.2. Simulações numéricas com o ENVI-met: simulação de áreas de estudo reais, calibração entre dados medidos e simulados e simulações paramétricas .

7.2.1. Medições de campo em alta densidade construída, visando à calibração do modelo. 88

7.2.2. Simulações paraméticas no ENVI-met V4 Preview I no cenário climático atual...........90

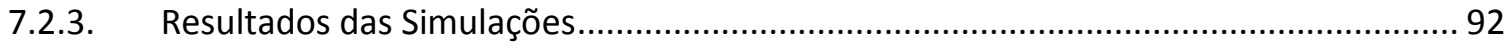

7.2.4. Considerações sobre os resultados das simulações..............................................97

7.2.5. Simulações paramétricas no ENVI-met V4 Preview I nos cenários climáticos futuros. 98

7.2.6. Resultados das simulações ........................................................................ 100

7.2.7. Considerações sobre os resultados das simulações............................................ 102

8. Infraestrutura verde: iniciativas locais e aplicações em políticas públicas .............................105

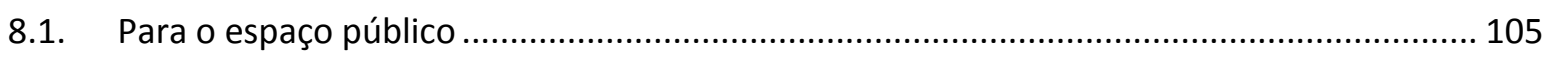

8.2. Para o espaço privado de acesso público ............................................................... 109

8.3. Para o espaço privado................................................................................... 110

8.4. Infraestrutura verde como parte da estratégia de adaptação aos fenômenos de aquecimento urbano .................................................................................. 113

9. Interações com outras áreas e atividades de pesquisa alimentando as aplicações didáticas nos currículos de graduação e pós-graduação ..............................................................119

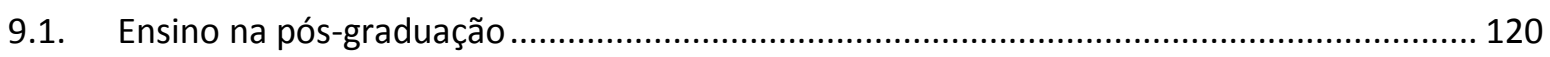

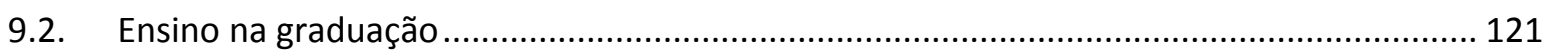

9.3. O papel dos laboratórios no ensino de graduação e pós-graduação ............................... 122

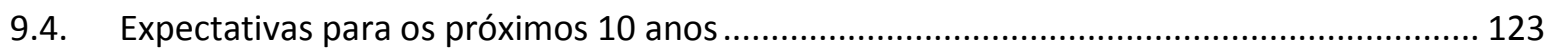

10.Considerações finais e conclusões ................................................................127

Bibliografia consultada e referenciada ..................................................................133 


\section{Introdução}

Buscando atender à exigência do Edital ATAc 010/2015 para a apresentação de tese original ou texto que sistematize criticamente a obra do candidato ou parte dela, percebe-se que cada trabalho de livre-docência apresenta uma trajetória profissional que é única, e não há um formato que contemple o universo de contribuições possíveis em arquitetura e urbanismo e, em particular, na FAUUSP. O trabalho também se diferencia de uma tese de doutoramento pela premissa de apresentar uma reflexão que demonstre o conjunto das atividades didáticas e de sua contribuição para o ensino.

Sendo assim, a intenção deste trabalho é reunir o escopo das pesquisas com as quais estive envolvida nos últimos anos, somando resultados e fazendo conexões entre os diferentes trabalhos, que foram sendo articulados em benefício de uma construção do conhecimento necessariamente interdisciplinar.

O trabalho reflete a consolidação das pesquisas e o amadurecimento profissional desde o doutoramento, quando ainda havia pouco desenvolvimento do tema clima urbano em arquitetura e urbanismo. Nessa época as principais referências vinham da meteorologia e da geografia, ainda de difícil tradução e assimilação na área.

As interações entre as atividades de pesquisa, docência e orientação são interligadas, resultando em uma produção de conhecimento conjunta com os orientandos e parceiros, internos e externos à FAUUSP, enriquecidas pela experiência didática com alunos de diferentes formações e, ao mesmo tempo, retroalimentando as atividades didáticas para a graduação e a pós-graduação.

Dentro desse contexto, a opção para este concurso foi contextualizar os estudos de microclima urbano no cenário atual e futuro de mudanças climáticas, com um peso maior no impacto microclimático da vegetação, compatível com o adensamento urbano, que acredito ser a melhor solução socioambiental, tendo a vista a somatória dos muitos fatores para a melhoria das condições de vida nas cidades. $O$ trabalho descreve a construção do conhecimento no tema ao longo dos anos, apontando erros e acertos, ressaltando as questões de interdisciplinaridade, e apontando alguns caminhos para o atendimento a algumas questões socioambientais cada vez mais prementes.

O resultado é apresentado aqui sob o título $O$ impacto da vegetação no microclima em cidades adensadas e seu papel na adaptação aos fenômenos de aquecimento urbano. Contribuições a uma abordagem interdisciplinar.

Dessa forma, este documento foi estruturado da seguinte forma:

O capitulo 2 traz a colocação do problema, à guisa de introdução e justificativa, a formulação das perguntas de pesquisa e da hipótese e os objetivos pretendidos.

O capítulo 3 trata da interação entre clima urbano, planejamento, desenho urbano e edifícios.

O capítulo 4 aborda especificamente o impacto da vegetação nos microclimas urbanos, com destaque para o papel da vegetação nas cidades adensadas, os benefícios da infraestrutura verde, as propriedades da vegetação, bem como as técnicas de medição e modelagem.

O capítulo 5 apresenta material e método, que se inicia com a intenção de mostrar a evolução dos mesmos ao longo das diversas fases desta trajetória profissional, com mais detalhes para os métodos adotados atualmente no grupo de pesquisa e neste trabalho, em particular.

O capítulo 6 apresenta o estudo de caso de São Paulo, com seu contexto urbano e climático, atual e futuro, baseado em projeções, e a distribuição da vegetação na cidade.

O capítulo 7 apresenta sequencialmente o que se aprendeu com as medições microclimáticas e de vegetação ao longo do tempo, em função das restrições e recursos de cada fase do trabalho, e com mais detalhes nas últimas medições de campo realizadas, em parques urbanos e áreas densamente 
urbanizadas. Apresenta também os progressos realizados nas simulações numéricas com o modelo ENVI-met, detalhando-se as etapas de calibração entre dados medidos e simulados, e apresentando os resultados das simulações paramétricas realizadas, no cenário climático atual e futuro.

No capítulo 8 são exemplificadas algumas experiências na implementação de espaços de amenidade climática em diferentes cidades, no espaço público e no espaço privado, e também no espaço privado de acesso e uso público. Ao final, são tratados alguns planos municipais para ocorrências de calor extremo, quando é ressaltado o papel do planejamento e do desenho urbano na criação de espaços apropriados a essas ações.

O capítulo 9 discute as interações com outras áreas do conhecimento, as atividades de pesquisa alimentando as atividades didáticas de graduação e pós-graduação, destacando-se o papel dos laboratórios e as expectativas para os próximos 10 anos.

O capítulo 10 apresenta as considerações finais e conclusões. 


\section{Colocação do Problema}

Este trabalho tem como pano de fundo a intersecção entre dois dos mais importantes temas socioambientais do século 21: a constatação da cidade como contexto geográfico dominante para as atividades humanas na Terra (The Worldwatch Institute, 2007; UN/DESA, 2014), e a emergência da mudança climática como uma ameaça real e já em curso no planeta (IPCC, 2013; 2014a; 2014b) e também como uma potente, se não, dominante força de mudanças urbanas, conforme discutido pelos editores While e Whitehead (2013), no número especial da revista Urban Studies intitulado Cities, Urbanisation and Climate Change.

Em 2007, pela primeira vez na história, a população urbana excedeu a população rural. Em 2014, 54\% da população mundial vive em áreas urbanas. Em 1950 eram 30\%, e em 2050 são esperados $66 \%$, adicionando 2,5 bilhões de habitantes urbanos à situação atual. Hoje as regiões mais urbanizadas incluem a América do Norte ( $82 \%$ urbano), América Latina e Caribe (80\%) e Europa (73\%). Tóquio é hoje a maior aglomeração urbana com 38 milhões de habitantes, seguida por Nova Deli com 25 milhões, Shangai com 23 milhões, depois Cidade do México, Mumbai e São Paulo com cerca de 21 milhões de habitantes cada. Décadas atrás as maiores aglomerações urbanas estavam nas regiões mais desenvolvidas, e hoje estão mais concentradas no hemisfério sul. Hoje são quatro megacidades na América Latina (Buenos Aires, Cidade do México, Rio de Janeiro e São Paulo. O Brasil como um todo tem 173 milhões de pessoas vivendo em cidades. "As the world continues to urbanize, sustainable development challenges will be increasingly concentrated in cities, particularly in the lower-middle-income countries where the pace of urbanization is fastest. Integrated policies to improve the lives of both urban and rural dwellers are needed." (UN/DESA,2014). ${ }^{1}$

Eram 700 milhões de habitantes no planeta no início da Revolução Industrial, agora já são 7 bilhões e esse número continua crescendo, principalmente na África e na Ásia. Há que se pensar nas dimensões sociais das mudanças climáticas, já que a vulnerabilidade é maior em áreas densamente povoadas. E pouco se sabe sobre a avaliação de impactos, são poucos os estudos propondo métricas para tal. Um dos poucos setores a levar esse fator em consideração é o das seguradoras, por razões óbvias, mas muitas são as perguntas ainda não respondidas.

Considerando-se os gases de efeito estufa, as emissões de $\mathrm{CO}_{2}$ excederam a barreira de $400 \mathrm{ppm}$ (número de moléculas de gás por milhão de moléculas de ar seco) pela primeira vez no Ártico em 2012, e essa marca já se repetiu algumas vezes localmente desde então. Em abril de 2014, as concentrações mensais de $\mathrm{CO}_{2}$ na atmosfera ultrapassaram 400 ppm no Hemisfério Norte. Em março de 2015, pela primeira vez desde que a Agência Nacional Oceânica e Atmosférica (NOAA) mede a concentração de dióxido de carbono na atmosfera global, a concentração média mensal deste gás de efeito estufa ultrapassou 400 ppm. ${ }^{2}$

Com relação ao clima, conforme pré-anunciado em dezembro de 2014, em janeiro de 2015 a World Meteorological Organization (WMO, 2015) confirmou o ano de 2014 como o mais quente já registrado, e como parte de uma tendência de continuidade no aquecimento, que é mais preocupante do que o ranking de um ano específico. Catorze dos quinze anos mais quentes já registrados ocorreram no século 21 , e a WMO prevê a continuidade do aquecimento global, dadas a elevação dos níveis de gases de efeito-estufa na atmosfera e do aumento de temperatura nos oceanos. Um dado agravante em relação à 2014 é que:

[...] the high 2014 temperatures occurred in the absence of a fully developed EI Niño. [...] High temperatures in 1998 - the hottest year before the 21st century occurred during a strong El-Niño year. (...) In 2014, record-breaking heat combined

\footnotetext{
${ }^{1}$ Disponível em: <http://esa.un.org/unpd/wup/Highlights/WUP2014-Highlights.pdf>. Acesso em 16/01/15.

2 Disponível em: <https://www.climate.gov/news-features/featured-images/monthly-carbon-dioxide-levels-hit-newmilestone>. Aacesso em 11/05/2015.
} 
with torrential rainfall and floods in many countries and drought in some others consistent with the expectation of a changing climate (WMO, 2015). ${ }^{3}$

Somados a esses dois fatores, dentre os riscos globais para 2015 estão:

1) Extreme weather events (e.g. floods, storms, etc.), where major property, infrastructure and environmental damage as well as human loss caused by extreme weather events, and 2) Failure of climate-change adaptation. Governments and businesses fail to enforce or enact effective measures to protect populations and to help businesses impacted by climate change to adapt (WORLD ECONOMIC FORUM, 2015). ${ }^{4}$

Segundo o relatório anual da Agência Internacional de Energia (IEA, 2013) o objetivo climático de limitar o aumento da temperatura a $2^{\circ} \mathrm{C}$ está se tornando cada vez mais difícil e oneroso, à medida que os anos passam pois aproximadamente $80 \%$ das emissões de $\mathrm{CO}_{2}$ admissíveis em 2035 já estão irremediavelmente determinadas pelas emissões das centrais elétricas, das fábricas, dos edifícios existentes, entre outros. Um meio para adiar este cenário é a implementação rápida de tecnologias de maior eficiência energética, conferindo um prazo adicional para se atingir o tão necessário acordo mundial de redução das emissões de gases de efeito estufa.

Para contextualizar o trabalho, vai se discutir brevemente a abordagem urbana na mudança climática, incluindo o último relatório do International Panel on Climate Change - IPCC AR5 (REVI et al., 2014), depois trazer o tema para o caso brasileiro, especialmente em megacidades como São Paulo (NOBRE; YOUNG, 2011), além do recém-lançado relatório completo do Painel Brasileiro de Mudanças Climáticas (PBMC, 2015), discutindo estratégias de mitigação e adaptação, bem como o papel das cidades como parte do problema e da solução.

\subsection{Contexto global de mudanças climáticas e o papel das cidades}

As cidades não foram consideradas nos primeiros relatórios do IPCC; o fenômeno urbano era visto como uma anomalia, com eventuais estações meteorológicas urbanas como fontes distorcidas de medições climáticas. A resolução de modelos atmosféricos globais é baixa para se sensibilizar com efeitos regionais e mais ainda urbano; sendo assim, mudanças na ocupação do solo urbano sequer eram vistas pelos modelos em escala global. As cidades também não foram mencionadas no protocolo de Kyoto. Atualmente, o aumento expressivo da resolução dos modelos climáticos globais permite que as cidades sejam, pela primeira vez, visíveis nos sistemas gerais de circulação atmosférica. O ambiente urbano, com sua geometria tridimensional, materiais absorvedores de calor, superfícies impermeáveis e concentração de poluição está começando a ser resolvido nesses modelos (HEBBERT, JANKOVIC, 2013).

A urbanização entrou pela primeira vez como uma consideração nas mudanças climáticas no $4^{\circ}$ relatório do IPCC (AR4), em 2007 (HEBBERT, JANKOVIC, 2013), e o 50 relatório, lançado em novembro de 2014, tem um capítulo especialmente dedicado às cidades que traz uma avaliação do seu papel nas mudanças climáticas, na poluição e discute o seu potencial de adaptação aos riscos climáticos.

Segundo o IPCC AR5, grande parte da população afetada por eventos climáticos extremos está nos centros urbanos.

Resilience to extreme weather for urban dwellers is strongly influenced by factors already mentioned - the quality of buildings, the effectiveness of land use planning, and the quality and coverage of key infrastructure and services. (...) Adaptation of

\footnotetext{
${ }^{3}$ Disponível em <https://www.wmo.int/media/?q=content/warming-trend-continues-2014>. Acesso em 02/02/2015.

${ }^{4}$ De acordo com o décimo relatório Global Risks, do World Economic Forum - WEF, que define risco global como sendo "an uncertain event or condition that, if it occurs, can cause significant negative impact for several countries or industries within the next 10 years." Global Risks, 10th edition. WEF, Genebra, 2015. Disponível em: <www.weforum.org/risks $>$. Acesso em $15 / 01 / 15$
} 
infrastructure and building stock often depends on changes in the institutions and governance framework, for example, in planning regulations and building codes. (REVI et al., 2014)

Uma série de incertezas e prioridades de pesquisa emergem a partir da revisão da literatura para o capitulo de áreas urbanas. Uma das prioridades é o desenvolvimento de métricas para medir e monitorar o sucesso das estratégias de adaptação em centros urbanos; "other modelling efforts define building density and design and the scale of urban development as important local determinants of the influence of urbanization on local temperature shifts". (REVI et al., 2014)

Ainda hoje as projeções de climas futuros são feitas excluindo-se os efeitos de aquecimentos locais, como da ilha de calor urbana. O AR5 ainda aponta incertezas sobre o efeito das mudanças climáticas sobre os fenômenos de aquecimento nas cidades, com alguns mostrando resultados divergentes. ${ }^{5}$ Porém, tudo indica que o aumento da frequência de dias quentes e períodos quentes pode exacerbar os efeitos da ilha de calor urbana, causando problemas de saúde relacionados ao calor e, possivelmente, aumento na poluição do ar, assim como aumento na demanda de energia elétrica para resfriamento (REVI et al., 2014).

Cidades em países emergentes têm a oportunidade de implantar o que o IPCC chama de climate smart infrastructure planning, considerando as necessidades de desenvolvimento já com estratégias de mitigação e adaptação às mudanças climáticas, o que seria até mais difícil em cidades com infraestruturas antigas e mais consolidadas. Neste ponto é preciso deixar clara a distinção entre mitigação e adaptação, bem como a relação entre as duas aproximações, mais especificamente no caso de áreas urbanas.

Mitigation refers to approaches that regulate the functions that generate the emissions of $\mathrm{CO}_{2}$. Adaptation accepts that climate change will occur and focuses on altering urban form in response. Of course, the two could be related - modifying urban form could be used to regulate urban metabolism. However, a simple translation of strategies based on global concerns to urban scales may not be correct or appropriate. (MILLS, 2011)

Apesar da crescente aceitação da importância das questões urbanas envolvidas, há algumas razões para a relativa falta de políticas de adaptação urbana. Primeiro, as políticas nacionais de mudanças climáticas geralmente dão pouca atenção às questões urbanas, quando comparadas à agricultura, por exemplo. E de fato, agricultura é a exceção em adaptação no Brasil, sem dúvida, a mais desenvolvida. Um outro fator é o foco inicial de muitas cidades na mitigação, ao invés da adaptação, com compromissos de redução de GEE, em parte por causa do apoio internacional. Tomadores de decisão locais frequentemente consideram a mudança climática um assunto marginal, "but adaptation usually ranks lower than mitigation on the agenda." (REVI et al., 2014)

Acontece o mesmo em São Paulo; o novo Plano Diretor Estratégico aborda principalmente a redução de emissões (SÃO PAULO, 2014), o que não é o nosso foco nas cidades, apesar das emissões a partir de veículos e principalmente das emissões de $\mathrm{CO}_{2}$ do setor elétrico, para geração de energia, virem crescendo nos últimos anos, com o uso constante de centrais térmicas, antes acionadas somente

\footnotetext{
5 "Olesen (2012) discusses how urban and rural areas might respond differently to changes in climate. The average UHI at the end of the twenty-first century is similar to present day in RCP2.6 and RCP4.5, but decreases in RCP8.5. Both the daytime and nocturnal UHIs decrease in RCP8.5, but the decrease in the daytime UHI is larger and more uniform across regions and seasons than in the nocturnal UHI. This is caused by changes in evaporation that warm the rural surface more than the urban. There is significant spatial and seasonal variability in the response of the nocturnal UHI caused mainly by changes in the rural surface. In Europe, the response to climate change of rural leaf-stem area in summer and clouds and rural soil moisture in winter explains the majority of this variability. Climate change increases the number of warm nights in urban areas substantially more than in rural areas. These results provide evidence that urban and rural areas respond differently to climate change. Thus, the unique aspects of the urban environment should be considered when making climate change projections, particularly since the global population is becoming increasingly urbanized." (OLESEN, 2012 apud REVI et al., 2014).
} 
para os picos de demanda (CBCS, PNUMA, MMA, 2014). E assim mesmo, esse aumento só não foi maior pela conjuntura econômica de desaceleração pela qual passa o país.

Existe ainda pouca literatura em adaptação para as cidades brasileiras (OJIMA, 2009). Em São Paulo, adaptação é limitada a declarações sobre ações necessárias, mesmo sofrendo com inundações, deslizamento de terra e escassez de água (PUPPIM DE OLIVEIRA, 2009; NOBRE et al., 2010; MARTINS, FERREIRA, 2011). De qualquer forma, o interesse em adaptação em áreas urbanas é crescente, pelo engajamento de redes municipais transnacionais e agências financiadoras.

O Centro de Ciência do Sistema Terrestre do Instituto Nacional de Pesquisas Espaciais (CSST/INPE) e - Núcleo de Estudos de População da Universidade Estadual de Campinas (NEPO/UNICAMP) elaboraram um estudo no qual um dos pontos altos foi a ênfase na vulnerabilidade e nas ações de adaptação. A adaptação, nesse contexto, envolve o conjunto de ações que as cidades e as instituições terão que enfrentar em busca de soluções para os impactos e perigos que sofrerão. Conhecer os perigos e seus impactos, portanto, é fundamental para propor medidas de adaptação que tornem as cidades mais resilientes. $O$ estilo de vida urbano é um dos principais motores da mudança climática. A fragmentação da paisagem, o uso intensivo de energia, a pressão sobre os ecossistemas, a expansão urbana e do consumo são fatores que colocam as cidades no topo da lista de preocupações quando se pensa em políticas de mitigação para os efeitos das mudanças no clima. A estruturação do espaço urbano, a forma do desenvolvimento e da expansão do tecido urbano merecem atenção no planejamento urbano de médio e longo prazo, para que haja um potencial de minimização das consequências de mudanças ambientais (NOBRE, YOUNG, 2011).

Governos locais podem implementar medidas de adaptação e mitigação usando instrumentos e políticas públicas já existentes, como códigos de edificações, zoneamento, planejamento da infraestrutura de transporte, etc. Há iniciativas, ainda que pontuais, de cidades que estão revisando seus planos diretores, códigos de edificações e demais legislações pertinentes. Regulamentações urbanas em Nova lorque e Boston estão sendo atualizadas para incluir riscos climáticos (CITY OF BOSTON, 2011; CITY OF NEW YORK, 2011). Os planos de adaptação de Londres e Melbourne consideram estratégias combinando infraestrutura verde e intervenções no setor habitacional (GLA, 2010; UN/HABITAT, 2011).

Há uma preocupação com a adaptação de ecossistemas, indo além da arborização de rua e parques urbanos para um entendimento mais abrangente dos ecossistemas locais, e de como se pode reduzir a vulnerabilidade dos mesmos nos cenários de mudanças climáticas, e como incentivar a sua manutenção nos processos de requalificação de áreas urbanas.

Planos urbanos estratégicos com um horizonte de dez anos ou mais podem incorporar riscos climáticos e vulnerabilidades, e avaliações precisam estar disponíveis para planos dessa natureza. Porém, um aspecto crítico para a governança das mudanças climáticas urbanas é a integração do conhecimento científico à tomada de decisão, com uma cooperação entre cientistas e políticas públicas e a população exposta ao risco.

Elevação no nível do mar e risco de inundações costeiras, saúde e recursos hídricos estão entre os temas mais estudados; energia, transporte e infraestrutura urbana de modo geral ainda tem muito por fazer. Há uma lacuna de estudos e propostas no ambiente construído, seja na escala urbana ou na escala dos edifícios, que se configura como uma urgência a ser enfrentada e uma oportunidade de pesquisa a ser explorada.

O clima já está mais variável, e vai ficar cada vez mais. Dois anos seguidos de seca do Sudeste já é algo anômalo, não há registros anteriores. O sistema climático parece ser mais sensível do que pensávamos ao aquecimento global, a esse aumento de temperatura que foi de cerca de $0,8^{\circ} \mathrm{C}$ no planeta, $1^{\circ} \mathrm{C}$ nos continentes. Recado para a infraestrutura do país: não se pode mais basear os investimentos em séries históricas, no clima do passado; há que se projetar para os extremos cada vez mais frequentes, seja para planejar energia, abastecimento de água, irrigação. São Paulo está se 
aquecendo, ao se comparar o clima dos anos 1930, por exemplo, e agora, é outro clima, é o que se chama de mudança climática sub-regional. A cidade está $3^{\circ} \mathrm{C}$ a $4^{\circ} \mathrm{C}$ mais quente na parte mais urbanizada, com $30 \%$ mais chuvas decorrentes do aquecimento, com tempestades acima de $50 \mathrm{~mm}$. Para saber o que vai acontecer se o planeta se aquecer $3^{\circ} \mathrm{C}-4^{\circ} \mathrm{C}$ no cenário de mudanças climáticas, e com qual severidade, basta olhar para o que está acontecendo em São Paulo. E tende a acontecer o mesmo em outras grandes cidades; só não acontece de forma tão intensa no Rio, por exemplo, por causa do oceano, lá as temperaturas não sobem tanto (informação verbal). ${ }^{6}$

\subsection{Contexto brasileiro de mudanças climáticas}

Mudanças climáticas já estão em curso, em muitas regiões do planeta, com impactos graves também em áreas urbanizadas. As ondas de calor são cada vez mais frequentes e intensas, ${ }^{7}$ o que já não é incomum no Brasil. ${ }^{8}$

Além do aumento da temperatura média, um aumento na ocorrência dos eventos extremos é esperado, com a intensificação das chuvas intensas, ${ }^{9}$ das ondas de calor, com consequências na saúde e mortalidade. Megacidades como São Paulo são vulneráveis ao aquecimento global e efeitos de aquecimento local, provocados pela urbanização. Mortes decorrentes de ondas de calor estão relacionadas a doenças cardiovasculares, cerebrovasculares e respiratórias e se concentram, principalmente, entre pessoas idosas e indivíduos com doenças preexistentes (SALDIVA, 1994). $\mathrm{Na}$ Baixada Santista, no estado de São Paulo, em fevereiro de 2010, as temperaturas atingiram $39^{\circ} \mathrm{C}$ com a sensação térmica de até $45^{\circ} \mathrm{C}$, com registro de morte de mais de 50 pessoas. De acordo com o Departamento de Regulação da Secretaria de Saúde de Santos, provavelmente, essas mortes ocorreram por causa do calor. Essas pessoas, de faixa etária entre 60 e 97 anos, já sofriam de

\footnotetext{
${ }^{6}$ Carlos Nobre (informação verbal) em entrevista a Mirian Leitão, Globonews Painel 29/01/15.

${ }^{7}$ Até o momento, não há consenso nem mesmo entre os meteorologistas sobre a definição exata de onda de calor. Uma das definições encontradas é adotada pelas Nações Unidas (UN, 2015), "Heat or hot weather that lasts for several days, often referred to as a "heatwave", is a pervasive natural hazard that can exact a heavy toll on human systems, affecting health, livelihoods and infrastructure. Natural systems can also be severely affected by the impacts sustained beyond the duration of a heatwave. Although there is no universally acceptable definition of heatwaves (...) they are understood to be periods of unusually hot and dry or hot and humid weather that have a subtle onset and cessation, a duration of at least two to three days and a discernible impact on human activities. During such periods of hot weather, not only do daytime temperatures reach high values but nocturnal temperatures and humidity levels may also rise well beyond their long-term mean. Heatwaves are relative to a location's climate; the same meteorological conditions can constitute a heatwave in one place but not another. Similarly, not all heatwave events are the same as their spatial extent, and intensity may vary considerably across a region."
}

Outra definição, adotada pelo New York City Office of Emergency Management - NWS, define onda de calor como sendo "at least three consecutive days with maximum surface air temperatures above $32.2^{\circ} \mathrm{C}$ ". Pela mesma fonte, "extreme heat is defined by temperatures that hover 10 degrees or more above the average high temperature for the region, last for prolonged periods of time, and are accompanied by high humidity." NYC hazards: Extreme heat basics, 2008. Disponível em: <http://www.nyc.gov/html/oem/html/hazards/heat_basics.shtml>. Acesso em 11/05/2015.

8 "Temperatures were particularly high in the south of Brazil and in northern Argentina. In Argentina the average temperature anomaly for the year to October would place it second highest on record. (...) The heatwave also affected southern Brazil, Bolivia and Paraguay. Monthly average temperatures in the region were the warmest on record for October" (WMO, 2014).

9 "Significant positive trends are found in the evolution of daily rainfall extremes in the city of São Paulo (Brazil) from 1933 to 2010. Climatic indices (...) and the sea surface temperature at the coast near São Paulo explain $85 \%$ of the increasing frequency of extremes during the dry season. During the wet season the climatic indices and the local sea surface temperature explain a smaller fraction of the total variance when compared to the dry season indicating that other factors such as the growth of the urban heat island and the role of air pollution in cloud microphysics need to be taken into account to explain the observed trends over the almost eight decades." (Silva Dias et al., 2013). 
hipertensão, diabetes, cardiopatias e problemas renais que possivelmente foram agravados pelo aumento de temperatura do ar e as limitações temo-regulatórias dos idosos. ${ }^{10}$

Ao longo dos últimos anos, o Brasil avançou pouco na adaptação. Entre os setores econômicos do país, a agricultura é um dos poucos que vêm se adiantando para se adaptar aos impactos das mudanças climáticas (informação verbal) ${ }^{11}$ mas, de modo geral, o país achou que o único caminho ou o mais viável era a mitigação, e é preciso avaliar impactos e trabalhar soluções de adaptação, para tornar as nossas cidades mais resilientes, e inverter a lógica do Brasil investir principalmente em reconstrução, ou seja, de ser mais reativo do que proativo (informação verbal) ${ }^{12}$

A dificuldade na comunicação entre cientistas e tomadores de decisão pode ser atribuída em parte a falhas na tradução dos resultados científicos em opções de ação estratégicas e/ou políticas viáveis. A proposta do Índice de Vulnerabilidade Sócioclimática ou SCVI, acrônimo do inglês Socio-Climatic Vulnerability Index, é traduzir a complexidade e quantidade dos dados produzidos e compilados por cientistas do clima e da sociedade de maneira clara e confiável possibilitando um melhoramento na comunicação entre os cientistas e os tomadores de decisão. O SCVI combina o Regional Climate Change Index - $\mathrm{RCCl}$ com densidade populacional e IDH; ambos foram mapeados pelo IBGE para o Brasil (Figura 1). A primeira versão do SCVI publicada no ano de 2012 foi calculada a partir da combinação numérica de indicadores sociais referentes ao ano 2000 e projeções climáticas do Painel Intergovernamental sobre Mudança do Clima (IPCC), publicados em 2007. Diante da divulgação de novos resultados, tanto em termos de indicadores sociais (novos dados de IDH para o ano de 2010) como de projeções climáticas (Quinto Relatório do IPCC), faz-se necessária e estratégica uma atualização do SCVI. A comparação entre uma versão atualizada do índice com aquela desenvolvida anteriormente será relevante para identificar eventuais mudanças no padrão espacial de vulnerabilidade socioclimática no país. Isso por sua vez pode ter implicações para a identificação de regiões prioritárias em termos de políticas de adaptação às mudanças climáticas projetadas para as próximas décadas no país (TORRES et al., 2012).

O Brasil adotou como compromisso nacional voluntário quatro ações de mitigação das emissões de gases de efeito estufa, com vistas a reduzir entre $36,1 \%$ e 38,9\% suas emissões projetadas até 2020 . Para alcançar os objetivos do Plano Nacional de Mudanças Climáticas, essa decisão, apresentada na COP 15, foi instituída através da Lei no 12.187, de 29 de dezembro de 2009, sobre a Política Nacional sobre Mudança do Clima (NOBRE, YOUNG, 2011). Carlos Nobre ressalta, entretanto, que a adaptação ficou desassistida; a estratégia não é só mitigar, mas é preciso também se adaptar às mudanças climáticas (informação verbal). ${ }^{13}$

\footnotetext{
10 LIMA, Rejane. Calor aumenta o número de mortes na Baixada. O Estado de São Paulo. São Paulo. 11 fev. 2010. Disponível em: <http://www.estadao.com.br/noticias/cidades,calor-aumenta-numero-de-mortes-na-baixada,509652,0.htm>. Acesso em: 23 fev. 2013.

11 Apresentação Eduardo Delgado Assad, no evento INCLINE "Mudanças Climáticas: perspectivas e desafios sociais", realizado no auditório István Jancsó da Biblioteca Brasiliana Guita e José Mindlin, Rua da Biblioteca, s/no, na Cidade Universitária, em 22/11/2013.

12 Apresentação José Antonio Marengo Orsini, idem.

13 Disponível em: <http://agencia.fapesp.br/mudancas_no_clima_do_brasil_ate_2100/17840>. Acesso em: 8/5/15.
} 

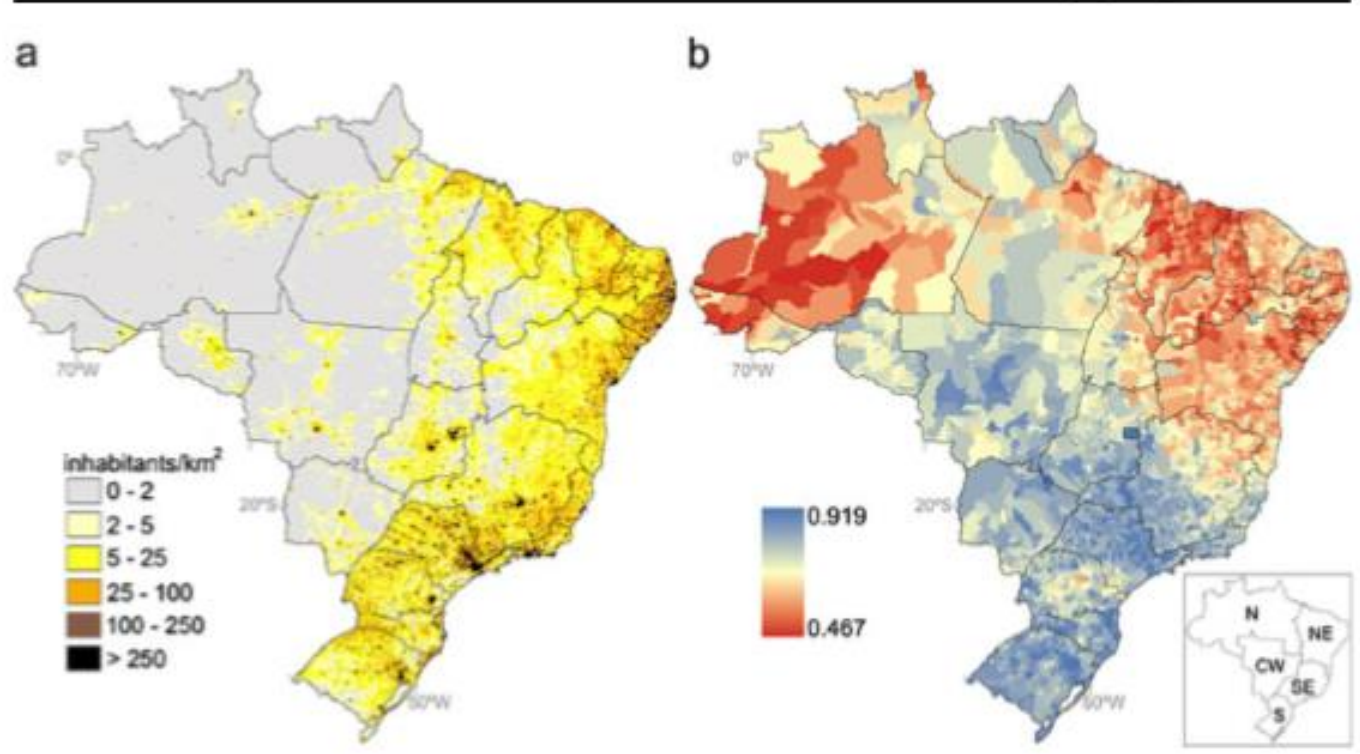

Fig. 1 Year 2000 (a) Brazilian population density (inhabitants per $\mathrm{km}^{2}$ ) and (b) Human Development Index (dimensionless). The bottom right-hand panel shows Brazil's 5 macro regions: North (N), Northeast (NE), Centre-West (CW), South (S) and Southeast (SE)
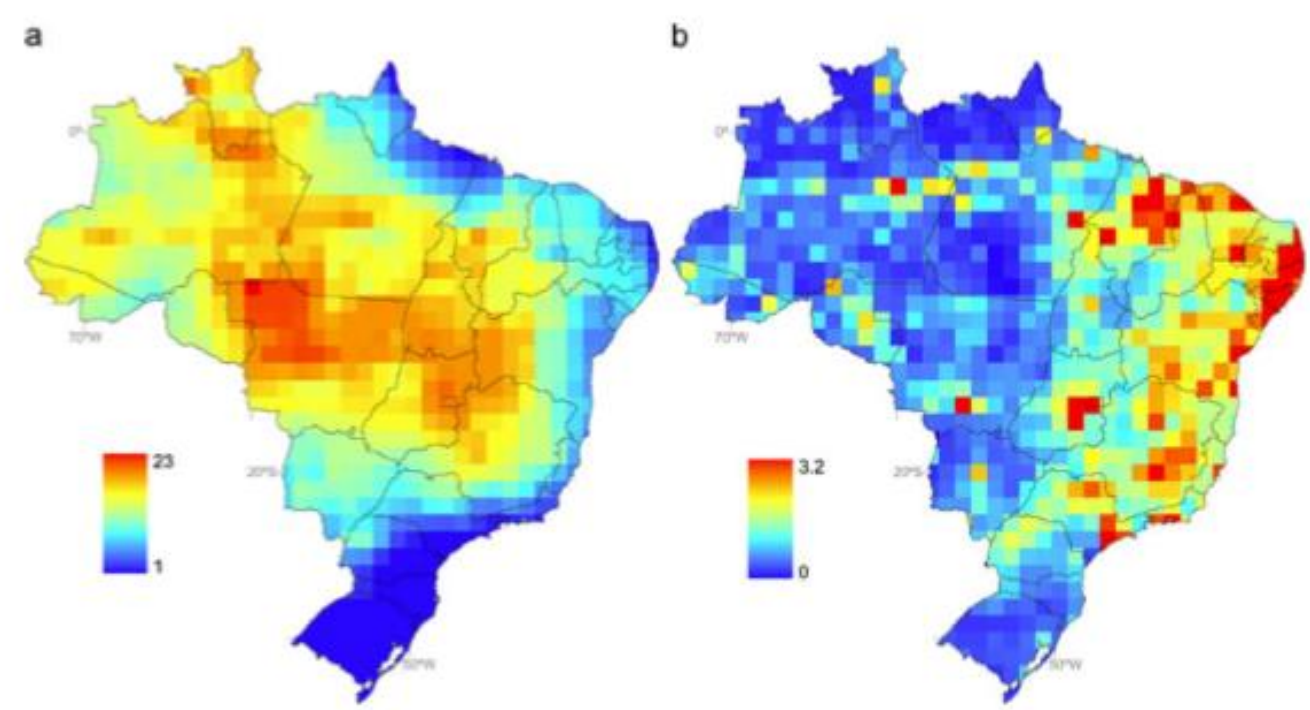

Fig. 2 (a) Regional Climate Change Index (RCCI) and (b) Socio-Climatic Vulnerability Index (SCVI) for Brazil (both dimensionless)

Figura 1 - Índice de Vulnerabilidade Sócioclimática - SCVI (acima, à direita), acrônimo do inglês Socio-Climatic Vulnerability Index, que combina o Regional Climate Change Index - RCCl (acima, à esquerda) com densidade populacional (no alto, à esquerda) e índice de Desenvolvimento Humano - IDH (no alto, à direita), ambos mapeados pelo IBGE para o Brasil. Destaque no SCVI para a vulnerabilidade das áreas mais urbanizadas, incluindo São Paulo (Torres et al., 2012)

Com relação às emissões, Brasil ocupa uma posição diferenciada no contexto energético mundial por possuir uma forte base hidráulica para produção energética, já que atualmente $77 \%$ da rede elétrica brasileira ainda é baseada em hidroeletricidade (BRASIL, 2013). Essa matriz envolve questões ambientais e sociais polêmicas e sua emissão de gases de efeito estufa não é, ainda, completamente conhecida pela ciência (VIANNA et al., 2009). Ainda assim, pode-se afirmar que suas emissões são bastante reduzidas se comparadas a outras fontes energéticas. Nos últimos anos, houve um aumento da participação das termelétricas no total da produção nacional, segundo a International Energy 
Agency (IEA, 2013); até essa data, e ainda que o Brasil estivesse passando por um período de transição com aumento de seu consumo energético, incluindo o acesso universal à eletricidade, o país continuava a ter uma das menores intensidades de carbono no mundo. Porém, um levantamento recente do CBCS, PNUMA, MMA (2014) apresenta tendência de mudanças nesse cenário, com dados das emissões aumentando a partir da geração de energia elétrica.

No início, o IPCC praticamente omitia a América do Sul porque não havia dados e muito menos um volume de trabalhos suficientes. A resposta brasileira veio com a criação do PBMC - Painel Brasileiro de Mudanças Climáticas, com a compilação crítica dos dados produzidos pelos estudos mais recentes no Brasil, ainda com regiões sobre as quais quase não há estudos, como o Centro-Oeste (informação verbal). ${ }^{14}$

O PMBC é um organismo científico composto por 345 pesquisadores, que foi criado em 2009 pelos ministérios da Ciência e Tecnologia e do Meio Ambiente para reunir, sintetizar e avaliar informações científicas sobre os impactos relevantes das mudanças climáticas no Brasil. Seu primeiro relatório, lançado em 9 de setembro de 2013, divulgado na 1a Conferência Nacional de Mudanças Climáticas Globais - CONCLIMA, organizada pela Fapesp, é um retrato dos impactos que o aquecimento global terá no País. ${ }^{15}$

São 20 modelos globais até agora desenvolvidos, e o Brasil é hoje o único país do hemisfério sul a contar com um modelo próprio, o Modelo Brasileiro do Sistema Terrestre (BESM), que vem sendo desenvolvido desde 2008 por pesquisadores da Rede Brasileira de Pesquisa sobre Mudanças Climáticas Globais (Rede Clima). ${ }^{16}$ Com esse modelo, pode-se produzir cenários para futuras mudanças ambientais e representar processos importantes para o Brasil, mas que poderiam ser considerados secundários em outros modelos; é uma forma de incorporar conhecimento sobre as florestas e os oceanos tropicais no quebra-cabeça das mudanças climáticas globais. O BESM roda no supercomputador Tupã da Rede Clima/PFPMCG, e inaugura a participação do Brasil no IPCC como nação fornecedora de projeções em escala planetária das mudanças climáticas. O modelo tem resolução espacial de $200 \mathrm{Km} \times 200 \mathrm{Km}$, enquanto o modelo regional do Inpe, que por ora roda dentro do modelo global do Centro Hadley, Reino Unido, é usualmente de $40 \mathrm{Km} \times 40 \mathrm{Km}$ e pode chegar a $5 \mathrm{Km} \times 5 \mathrm{Km}$.

De acordo com o PBMC (2013a, 2013b, 2013c), a intensificação do calor é evidente; os dados indicam um Brasil mais quente em quase todas as latitudes, com uma variação gradual no aumento das temperaturas médias de $1^{\circ} \mathrm{C}$ a $6^{\circ} \mathrm{C}$ até 2100 , comparadas aos registros do final do século XX. O Brasil assumiu compromissos voluntários para a redução de emissões, como parte da Política Nacional de Mudanças Climáticas, mas medidas de adaptação para as áreas urbanas ainda deixam a desejar. 0 uso e a ocupação do solo como parte da estratégia de mitigação, especialmente em áreas urbanas, ainda são pouco explorados, o que é essencial para maior resiliência das cidades.

O PMBC prevê impactos na infraestrutura, principalmente transportes. O relatório traz um alerta especial ao impacto a megacidades, como São Paulo e Rio de Janeiro, principalmente no que se refere à questão de mobilidade urbana. As reformas pensadas para o sistema de transporte têm de considerar, além de seu potencial de mitigar as emissões de gases de efeito estufa, as adaptações que ele terá de sofrer para se adequar às mudanças do clima das cidades.

\footnotetext{
${ }^{14}$ Apresentação de Carlos Nobre no evento INCLINE "Mudanças Climáticas: perspectivas e desafios sociais", realizado no auditório István Jancsó da Biblioteca Brasiliana Guita e José Mindlin, Rua da Biblioteca, s/no, na Cidade Universitária, em 22/11/2013.

${ }^{15}$ Disponível em: <http://www.pbmc.coppe.ufrj.br/pt/>. Acesso em: junho de 2015.

16 Disponível em: <http://agencia.fapesp.br/modelo_brasileiro_do_sistema_terrestre_e_apresentado_na_china/18950/>. Acesso em: junho de 2015.
} 
Porém, o aquecimento urbano também é função dos padrões de urbanização, e não somente do aquecimento global provocado pelas emissões. Os gases de feito estufa não são o único agente do aquecimento e as ações de mitigação não podem ser somente nesta fronteira. "Because of the greater prevalence of mineral-based building materials, such as stone, slate, concrete, and asphalt, cities absorb and retain substantially more heat than rural areas characterized by more vegetative cover" (STONE, 2012). Na Região Metropolitana de São Paulo - RMSP, o aquecimento global gerado pelo aumento na concentração de gases de efeito estufa parece ser secundário, se comparado com o efeito da ilha de calor (NOBRE, YOUNG, 2011). Ao contrário da estratégia colocada pelo novo Plano Diretor Estratégico - PDE de São Paulo, que enfatiza a mitigação, com a redução de emissões de gases de efeito estufa - GEE, as estratégias de adaptação do ambiente construído, incluindo questões de adensamento, drenagem, permeabilidade ao vento, distribuição de vegetação dentro da malha urbanizada, etc., tem um efeito preponderante.

Para o caso de megacidades o PMBC também traz uma preocupação com a supressão da pouca vegetação que resta no entorno das médias e grandes cidades brasileiras. As megacidades estão se expandindo sobre os remanescentes de áreas verdes sem considerar os serviços ecossistêmicos, incluindo a regulação do clima. O PMBC está especialmente preocupado com a rápida supressão de vegetação em São Paulo, tanto nos espaços entre os edifícios assim como nos arredores da cidade.

\subsection{Cidades como parte do problema e da solução}

Stone (2007), pesquisando várias cidades americanas, constatou que no 1961 a 2010, Phoenix, Atlanta e Greensboro vivenciaram o aquecimento urbano mais rápido dos Estados Unidos, com taxas de aquecimento várias vezes maior do que o aquecimento global. O mesmo autor aponta também que a forma de ocupação dos subúrbios, com baixa densidade de ocupação, mas com grandes áreas pavimentadas e supressão da vegetação, está aquecendo Atlanta, provocando o que se pode chamar de "desbalanço" de energia nas cidades, com a parcela de calor latente diminuindo cada vez mais. $O$ mesmo autor ressalta o papel da umidade como um crítico regulador do clima urbano, argumentado que a importância da umidade para arrefecer o corpo humano não é diferente do seu papel para regular o ambiente urbano, contrabalançando os ganhos de calor pela evaporação.

Pensando no balanço de energia, o fator mais determinante não é o tamanho da cidade, mas a ocupação do solo como um todo. E não é porque a densidade é baixa que não contribui para o aquecimento. Pode ser tão ruim quanto ou até pior. Helmut Landsberg, em 1947, já apontava as consequências microclimáticas do padrão de ocupação dos subúrbios americanos: "how new residential suburbs 'consciously or otherwise ... violate every climatic principle, producing a microclimate much like that of a desert" (LANDSBERG, 1947 apud HEBBERT, MACKILLOP, 2013). Voltando ao balanço de energia em áreas urbanas:

The surface energy balance can thus be understood as a terrestrial valve that
controls the flow of solar energy back to the atmosphere" (...) In combination, the
surface properties of albedo and energy balance play a significant role in the
warming of the atmosphere. If human modifications to the landscape are serving to
reduce albedo and the availability of moisture for evaporative cooling, a larger
quantity of intercepted solar energy will be returned to the atmosphere in the form
of longwave radiation, driving temperatures higher even without an increase in the
atmospheric concentration of greenhouse gases. In addition, such changes will
bring about higher temperature at the Earth's surface through the increased
emission of sensible heat. (STONE, 2012, p.54)

Stone (2012) explora a dramática amplificação do aquecimento global em curso nas cidades e as ações que podem ser tomadas para diminuir o avanço do aquecimento global. Segundo o autor, "cities do not cause heat waves - they amplify them", e a principal estratégia adotada para mitigar a mudança climática - a redução dos gases de efeito estufa, não será suficiente para desacelerar o rápido avanço do aquecimento nas cidades. A razão para isso é que o principal motivo do 
aquecimento das cidades não é o efeito estufa global, mas a perda de vegetação e as emissões antropogênicas, de veículos, indústrias e edifícios. Nas cidades, mudanças no uso do solo e emissões de calor antropogênico são mais significativos para as tendências de aquecimento do que as emissões de gases de efeito estufa.

Na tentativa de explorar diferentes opções, Stone (2012) sugere comparar a redução de emissões, estabelecida no Protocolo de Quioto, com outras estratégias. Muitas cidades criaram planos de ações climáticas (climate action plans) para identificar estratégias de redução de gases na área urbana; Los Angeles foi uma delas, e São Paulo também tem. No longo prazo, a redução de emissões acoplada com sequestro de carbono talvez possa reverter o aquecimento global. Porém, "at the scale of cities, only land-based mitigation can yield measurable improvements during the period of our own or our children's lifetime." (STONE, 2012, p.104).

Pensando nas cidades como parte das soluções, é evidente o crescimento da climatologia urbana e sua significância, estudada por muitas disciplinas e diferentes pontos de vista, com uma ampla variedade de escalas espaciais: da escala da rua e do bairro até a escala das cidades como um todo e das regiões onde elas se inserem. "Cities are also part of the solution - as they have the ability, capacity and will to lead. The way they are built and run further provides a crucial contribution to efficient global resource use and waste disposal" (ROTH, 2013).

Uma gama de aplicações usa informações meteorológicas para arquitetura e urbanismo, da escala do edifício até a escala urbana, conforto e saúde. Precisam ser exploradas as várias estratégias de adaptação, tais como a compatibilidade do adensamento com verde, estratégias para aumentar a umidade, não somente como reação, mas como proativos nas áreas urbanizadas, esse é o papel da arquitetura e do urbanismo, além do desempenho dos edifícios. $O$ foco está na adaptação das áreas urbanas e dos edifícios, uma ciência nova a ser explorada (informação verbal). ${ }^{17}$

No caso da adaptação, as medidas não visam propriamente a redução dos impactos causados ao sistema e sim a assimilação destes. A adaptação pressupõe medidas imediatas que permitam conviver com os impactos causados por determinado evento. Em certa medida, os impactos também serão reduzidos porque seus efeitos deverão ser minimizados, mas o evento continuará a existir (NOBRE, YOUNG, 2011).

Outro aspecto fundamental é reconhecer que a adaptação é construída por indivíduos, grupos e governos, e depende da escala e do contexto. Pode ser entendida como uma ação do indivíduo (autoproteção) ou ações do governo e entidades públicas que visem proteger os cidadãos. Para isso, é necessário se estabelecer objetivos claros e consequentemente estratégias de adaptação bem definidas. Adaptação envolve uma sequência de decisões interconectadas constituídas por agentes da sociedade civil, esfera pública e governos em diferentes níveis (locais, estaduais e nacionais). Esse processo envolve a criação de leis e regulamentações que vão dar origem à capacidade de adaptação visando a operacionalização das ações. Três aspectos são relevantes para a adaptação: redução da sensibilidade do sistema à mudança climática, alteração da exposição do sistema (ou dos níveis de exposição) e aumento da resiliência do sistema para o enfrentamento das mudanças. Os critérios para o sucesso da ação devem se basear em questões de eficácia (capacidade de se colocar em prática e tornar efetivo) e eficiência (capacidade de fazer operar/funcionar de acordo com as especificações), examinando-se antes a equidade e a legitimidade das ações de adaptação (NOBRE, YOUNG, 2011).

A matriz de decisão proposta por Nobre e Young (2011), por exemplo, no que se refere ao aumento da temperatura, ondas de calor e períodos de seca, não contempla o ambiente construído urbano, menciona somente os edifícios, em especial de moradia, talvez pelo impacto que pode causar na saúde das pessoas, mas não inclui nem mesmo ambientes de trabalho, talvez supondo todos

17 Palestra Carlos Nobre, no evento INCLINE - Mudanças Climáticas: perspectivas e desafios sociais, realizado no auditório István Jancsó da Biblioteca Brasiliana Guita e José Mindlin, Rua da Biblioteca, s/no, na Cidade Universitária, em 22/11/2013. 
climatizados e passíveis de adaptação dessa forma, ainda que dependentes do consumo de energia para refrigeração, o que também pode ser uma limitação em momentos críticos, eventualmente com racionamento no uso de energia ou mesmo com interrupções de fornecimento, em cenários climáticos de estiagem prolongada, por exemplo.

Aponta-se aqui a necessidade de incluir não só os edifícios residenciais, mas espaços de trabalho, espaços abertos, públicos e privados, considerando-se as condições de conforto ou stress térmico em escala urbana. E mais ainda, estratégias de adaptação a serem exploradas pela arquitetura e urbanismo devem incluir não só a adaptação dos edifícios, mas também dos espaços urbanos, de uso público, e acessíveis à população. ${ }^{18}$

Faz diferença se o usuário tem a oportunidade ou não de modificar comportamentos e rotina para se adaptar melhor às temperaturas extremas, o que nos leva a estudar a criação de espaços de amenidade climática nos bairros, incluindo parques e demais espaços públicos, abertos ou semiconfinados, incluindo principalmente estratégias de distribuição do verde na cidade (ROSENTHAL, 2014). Um aspecto importante da adaptação aos fenômenos de aquecimento urbano se refere ao balanço de água no solo ou balanço hídrico. A chuva e o orvalho dependem do clima da região (interação com a atmosfera), enquanto as demais entradas no sistema hídrico dependem do tipo de solo, do relevo e da presença de vegetação (TOMASELLA et al., 2005). Considerando-se o balanço de energia de áreas urbanas, a perda de calor latente é a chave do balanço (informação verbal), ${ }^{19}$ a única variável que é sempre de perda de calor; as demais trocas de calor sensível são de perda ou ganho, dependendo de cada caso.

De acordo com o IPCC AR5 (Revi et al. 2014), o que contribui para a resiliência de áreas urbanas são:

- Estudos mais detalhados das respostas do ambiente construído para promover a adaptação;

- Mais estudos de caso de adaptação local em comunidades, suas contribuições potenciais e limitações;

- Maior consideração do papel dos serviços ecossistêmicos e da chamada infraestrutura verde (land) e azul (water) na adaptação.

Considerando-se os itens listados acima, sobre respostas do ambiente construído, incluem-se os estudos sobre adensamento e clima urbano, nos aspectos que envolvem a massa construída, o acesso ao sol ou o envelope de sombreamento, o papel da vegetação urbana, dos tetos verdes, dos tetos e pavimentos frios, etc. $O$ foco deve estar em análises locais com a distribuição da cobertura de árvores de forma compatível com o adensamento, e de tratamento adequado da cobertura de solo, em diferentes zonas e categorias de uso na cidade, compartilhando projetos com diferentes departamentos da administração municipal e com a comunidade.

O aquecimento urbano provocado por Los Angeles foi uma das motivações para Heat Island Group, no Lawrence Berkeley National Laboratory, University of California, ${ }^{20}$ explorar o potencial de mitigação do fenômeno ilha de calor por mais de vinte anos, combinando estratégias de plantio massivo de árvores e uso de materiais reflexivos em coberturas e pavimentos urbanos. Em função desse projeto, programas de arborização massiva e substituição de coberturas e pavimentos foram implementados em diversas cidades nos Estados Unidos, como Atlanta, Sacramento, Los Angeles, Baton Rouge, etc.

Para diferentes autores, a reintrodução de cobertura vegetal densa é a principal estratégia de adaptação para áreas urbanas.

\footnotetext{
${ }^{18}$ Ver Heatwaves and Health: Guidance on Warning-System Development (UN, 2015) que será discutido mais adiante.

19 Expressão utilizada pela Prof. Dra. Eleonora Sad de Assis (UFMG) em palestra na disciplina de pós-graduação AUT 5823 Conforto Ambiental em Espaços Urbanos Abertos, na FAUUSP/LABAUT, em 06/10/2010.

20 Disponível em <https://heatisland.lbl.gov/>. Acesso em 1/06/2015.
} 
[...] none is more effective or less energy intensive than planting trees [...] more valuable than the absorption of water during rain events is the retention of moisture by trees and other vegetation between periods of rain [...] moisture availability within cities is often the single most important variable governing the pave and extent of warming over time. (STONE, 2012).

De acordo com Oleson (2012), estudando os contrastes entre o ambiente rural e urbano em modelos mesoclimáticos em cenários de mudanças climáticas,

a key example [...] is the significant increase in the summer nocturnal UHI in Europe under RCP8.5. This is attributed to increased leaf-stem area of the rural surface which keeps the rural surface cooler than it would otherwise be under climate warming. The urban area does not benefit from this mechanism and so the UHI increases. This suggests that increasing vegetation within cities may be one way of counteracting warming, an approach suggested by other studies. (OLESON, 2012)

Para Zhou e Shepherd (2010), estudando o caso de Atlanta sob condições climáticas extremas e potencial de mitigação, também afirmam que "increased vegetation seems to be a more likely choice for mitigating surface temperature."

E, por fim,

None of these options will reverse long-term warming trends but, if pursued aggressively, combinations of these strategies can slow the pace of warming over time and substantially moderate the extremely of climate events - events not limited to extreme heat alone. Although cities in different climatic regions require different approaches, all management approaches are born of a common theme: land-surface changes are the single most effective option available to cities to counteract the very threats of climate change during the next half-century." (STONE, 2012, p.99)

\subsection{Tema do trabalho, perguntas da pesquisa, hipótese e objetivo}

Tendo em vista a colocação do problema acima, e buscando atender à exigência do edital para a apresentação de tese original ou texto que sistematize criticamente a obra do candidato ou parte dela, este trabalho descreve uma trajetória didática e de pesquisa, com suas interdependências e realimentações ao longo de todo o processo, centrada do tema do impacto dos padrões de ocupação urbana e, particularmente, da vegetação em cidades adensadas, sobre os microclimas urbanos, tendo como pano de fundo o entendimento dos processos socioambientais que fazem da cidade parte do problema e da solução para as alterações climáticas, no cenário climático atual e futuro, tendo em vista as mudanças climáticas previstas já em curso há alguns anos.

Essa trajetória aqui descrita foi sendo construída ao longo do tempo com o aprimoramento da fundamentação teórica, com a ampliação do escopo para a inclusão absolutamente necessária de áreas afins que tornaram o trabalho interdisciplinar, com o aprimoramento de métodos e técnicas de pesquisa, incluindo medições de campo e simulação computacionais com instrumentos e modelos mais sofisticados e cada vez mais complexos. Nesse percurso, destaca-se o peso decisivo da interdisciplinaridade para a solução de problemas dessa natureza, agregando as vantagens dessa ampliação do escopo e o ônus da maior complexidade decorrente disso.

O campo disciplinar Clima Urbano foi e continua sendo enriquecido pela pesquisa interdisciplinar, que foi impulsionada após a criação da International Association for Urban Climate - IAUC, formada em 2001, a partir de uma decisão tomada em 1999, no International Conference on Urban Climate ICUC, realizado em Sydney, Austrália. Inicialmente liderada por Timothy Oke, a IAUC agregou 
diferentes áreas do conhecimento em torno do tema clima urbano. A associação promove conferências regulares a cada três anos, além de manter um boletim trimestral para a divulgação de projetos e pesquisas, de manter atualizada uma bibliografia no tema, e de divulgar publicamente na internet textos históricos de referência no tema, antes de difícil acesso. ${ }^{21}$

Nessa interdisciplinaridade, dentre inúmeras contribuições, destacam-se: 1) a meteorologia, que contribui com o entendimento dos fenômenos de interação solo, vegetação, ambiente construído, atmosfera e com o aumento da resolução espacial dos modelos meso e microclimáticos; 2) a mecânica de fluidos, que contribuiu com modelos CFD; 3) a silvicultura urbana, que contribuiu com o entendimento e a quantificação de variáveis da vegetação que impactam no potencial microclimático da infraestrutura verde; 4) a geografia, que contribuiu com técnicas de mapeamento e de sensoriamento remoto e com leituras próximas da escala urbana, que são familiares a arquitetos e urbanistas; 5) a biometeorologia, que contribuiu com índices de conforto humano para espaços abertos; e, por fim, e não menos importante, 6) a arquitetura e o urbanismo que, por sua vez, contribui com a leitura qualitativa e quantitativa do papel da cidade e dos edifícios nas alterações climáticas urbanas, integrando diferentes escalas até chegar ao edifício, com seus processos físicos e socioambientais envolvidos. Parte dos pesquisadores na área, quase sempre ligados aos grupos de conforto ambiental, contribuem ainda com as medições in loco e uso de modelos microclimáticos para estudos preditivos de diferentes cenários para o planejamento e o desenho urbano, cumprindo, portanto, com um papel que vai muito além dos estudos de computer aided design, como apontado de maneira muito reducionista por Hebbert e Jankovic (2013). ${ }^{22}$

Em arquitetura e urbanismo destaca-se, ao longo desse processo, o papel fundamental das medições de campo das variáveis urbanísticas e ambientais envolvidas, com equipamento adequado, seguindo protocolos de medição, na escala do pedestre (diferentemente das medições da meteorologia) para se entender corretamente os fenômenos e as diferenças encontradas aqui em relação à literatura internacional, vinda quase sempre de climas temperados ou frios. O suporte dos modelos é fundamental, mas o que se confia é aquilo que se mede, de fato, em determinadas circunstâncias, cujos resultados são a base para os estudos exploratórios, para a calibração dos modelos, etc. As medições in loco também têm uma enorme importância didática, na graduação e na pós-graduação; é quando 'as fichas caem' para os alunos, e torna-se possível medir a contribuição de diferentes variáveis para um determinado fenômeno.

Na construção desse conhecimento, ao final, a meta é avançar nos estudos preditivos de diferentes cenários que possam contribuir para a assimilação dos resultados em políticas públicas, e que possam se traduzir em benefícios socioambientais para a população. Pensando no stress térmico, cada vez mais frequente e mais intenso durante as ondas de calor vivenciadas em São Paulo e outras regiões do país nos verões de 2014 e 2015, em edifícios e espaços abertos, é cada vez mais importante proporcionar acesso a espaços de amenidade climática distribuídos por toda a cidade, principalmente nos espaços públicos, para que as pessoas possam se recuperar em condições microclimáticas mais favoráveis. Sendo assim, pergunta-se: quantitativamente, como a vegetação contribui? Como esses espaços de amenidade podem ser distribuídos e conectados na cidade? Como equacionar o adensamento necessário das cidades com uma infraestrutura urbana que contemple vegetação, água, mobilidade, etc.?

Apresenta-se, portanto, neste trabalho os resultados de estudos locais desenvolvidos para: 1) quantificar o impacto dos padrões de ocupação urbana e, particularmente, da vegetação, nos microclimas urbanos, e 2) quantificar as possibilidades de adaptação no cenário climático atual e futuro, tendo em vista os fenômenos de aquecimento urbano e as mudanças climáticas previstas e já

\footnotetext{
${ }^{21}$ Disponível em <http://www.urban-climate.org/>. Acesso em: 01/6/2015.

22 Mesmo no Brasil, em recente publicação, o Prof. Carlos Augusto Monteiro ressalta a incorporação do tema pelos pesquisadores em Arquitetura e Urbanismo, de forma significativa (MONTEIRO et al., 2015)
} 
em curso. Cientes de que as ferramentas para estudos preditivos são complexas, os modelos microclimáticos demandam tempo e capacidade computacional, colocam-se as seguintes perguntas de pesquisa:

1) Tendo em vista as aplicações em arquitetura e urbanismo, o que é necessário para se fazer estudos preditivos em microclimas urbanos? Quais simplificações são possíveis? O que trazer das outras áreas correlatas e que é fundamental para o entendimento das questões microclimáticas urbanas, incluindo as ondas de calor e o futuro próximo das mudanças climáticas? E em qual medida? Mais especificamente, qual o potencial da vegetação para a adaptação aos cenários climáticos acima citados?

Visando à aplicação didática desse conhecimento, para a formação de arquitetos e urbanistas, pergunta-se:

2) O que deveria entrar no currículo da FAUUSP e dos cursos de Arquitetura e Urbanismo em geral, como conteúdo de disciplinas obrigatórias e optativas de graduação e de pósgraduação? O que é útil para a escola? Quais as interações pertinentes e possíveis com outras disciplinas, em especial com planejamento, desenho urbano e estudos da paisagem?

Visando à aplicação em políticas públicas, vontade política à parte, falta a disseminação de tecnologia na escala urbana para interagir com o planejamento, o desenho urbano e com o paisagismo viabilizando estudos preditivos de diferentes cenários do ponto de vista ambiental, essenciais ao desenvolvimento de projetos urbanos. Não tem número mágico nem fórmula única, mas com base nos resultados obtidos ao longo desta trajetória, calçados em muitas medições de campo e simulações custosas computacionalmente e bastante complexas, pode-se estabelecer ordens de grandeza das principais variáveis envolvidas no impacto da vegetação no clima e nos índices de conforto urbano resultantes disso, e seu papel na adaptação aos fenômenos de aquecimento urbano, tão importante quanto a mitigação das emissões de gases de efeito-estufa, colocado como principal estratégia pelo PDE em São Paulo (SÃO PAULO, 2014). Para facilitar essa disseminação de conhecimento, pergunta-se:

3) O que a política pública precisa saber a respeito? Como pode incorporar esse conhecimento à legislação e aos planos urbanos? Quais ações o poder público deveria tomar para adaptação aos fenômenos de aquecimento urbano, além das estratégias de mitigação propostas?

Tendo em vista os fenômenos de aquecimento urbano já conhecidos, no clima atual e futuro, e as mudanças climáticas previstas já em curso e as que ainda estão por vir, estratégias de adaptação na escala urbana precisam ser consideradas. As estratégias de mitigação não serão suficientes, pelo menos até que se tenha as alternativas tecnológicas adequadas em curso, ainda assim com um passivo ambiental de emissões na atmosfera que pode levar dezenas ou mesmo centenas de anos para ser compensado. Nas palavras de Carlos Nobre (informação verbal), ${ }^{23}$ a adaptação ficou desassistida e é uma ciência nova a ser explorada. E para essa empreitada, deixa um recado claro para a infraestrutura urbana, principalmente no que diz respeito às questões ligadas à água e energia, alertando os pesquisadores e tomadores de decisão para não se basear somente em séries históricas de dados ambientais, mas sim, em dados do presente e dados projetados para o futuro, dado que tudo indica que está havendo uma antecipação dos cenários climáticos previstos em cerca de vinte anos, pelo menos.

Alertas recentes das Nações Unidas, divulgadas em 01 de julho de 2015, através de publicação conjunta de duas de suas importantes agências, World Meteorological Organization - WMO e World

\footnotetext{
${ }^{23}$ Palestra Carlos Nobre, no evento INCLINE - Mudanças Climáticas: perspectivas e desafios sociais, realizado no auditório István Jancsó da Biblioteca Brasiliana Guita e José Mindlin, Rua da Biblioteca, s/no, na Cidade Universitária, em 22/11/2013, e Carlos Nobre em entrevista a Mirian Leitão, Globonews Painel 29/01/15.
} 
Health Organization - WHO, intitulada Heatwaves and Health: Guidance on Warning-System Development (UN, 2015), ${ }^{24}$ sobre maior frequência e intensidade de ondas de calor, atestam que:

[...] ] heatwaves are becoming more frequent and intense on a global scale, largely due to the acceleration of climate change [...]. Growing concerns over climate change have brought to the fore three important aspects: adaptation, disaster-risk reduction and the need for climate information and services to support these (UN, 2015)

Tendo em vista os argumentos colocados, fica claro que as estratégias de mitigação apenas não serão suficientes, e os reflexos da redução de emissões de gases de efeito estufa levam tempo, no mínimo, décadas, e as ações de adaptação tornam-se imprescindíveis e decisivas, inclusive para se evitar mortes, como aconteceram às centenas em junho de 2015 na Índia e no Paquistão.

People living in urban areas may be at greater risk from the effects of a prolonged heat wave than people living in rural regions [...]. Most deaths occur in urban areas where concrete, asphalt, and physical structures raise temperatures in urban heat islands, and nighttime temperatures remain above average. (UN, 2015)

Há uma preocupação clara com pessoas que moram sozinhas e que saem pouco de casa, especialmente idosos e crianças. As causas de morte apontadas são, principalmente:

1. Illnesses caused by exposure to high temperatures include heat cramps, fainting, heat exhaustion, heatstroke, and death. 2. Population at increased risk especially older and younger people, risk of dehydration, low fitness/excessive exertion, etc. 3. Another reason of death during heat wave is because of living alone. Studies designed to investigate why some people died during the 1995 and 1999 heat waves in Chicago found that the strongest risk factor was living alone, particularly for those who did not leave home daily. (UN, 2015)

Sendo assim, esse é mais um argumento para se tratar os espaços públicos como espaços de amenidade climática, onde as pessoas possam descansar e se recuperar dos extremos climáticos. Vários estudos apontam a necessidade de se fazer pausas para descanso ao longo do dia em locais mais amenos; com a onda de calor que atingiu a Europa em junho de $2015,{ }^{25}$ Paris e outras cidades colocaram os edifícios de acesso público com ar-condicionado à disposição da população neste verão para que possam fazer uma pausa nos dias de calor extremo e se recuperar. A própria ONU recomenda que as pessoas passem os horários mais quentes do dia em bibliotecas, escolas, cinemas e centros comunitários, muitas vezes mais preparados para o calor, com sistemas de refrigeração) do que as residências, principalmente em países de clima temperado e frio. No Brasil, muitos edifícios públicos ou de acesso público não são condicionados artificialmente, e essa rede de espaços de amenidade climática precisa incluir espaços públicos ou de acesso público abertos ou semiconfinados, sombreados, arborizados, que proporcionem o alívio necessário às pessoas, espalhados por toda a cidade.

A hipótese colocada aqui é que os efeitos microclimáticos da vegetação têm um importante papel a desempenhar como parte das estratégias de adaptação aos fenômenos de aquecimento urbano, no clima atual e futuro, considerando-se as mudanças climáticas previstas já em curso. Para tanto a

\footnotetext{
${ }^{24}$ Disponível em <https://www.wmo.int/media/content/wmo-who-issue-guidance-heat-health-warning-systems>. Acesso em: $17 / 07 / 2015$.

25 Disponível em https://www.wmo.int/media/content/widespread-heatwave-affects-europe-wildfires-northamerica, <http://www.weather.com/forecast/news/europe-heat-wave-record-highs-june-july-2015.>, http://www.theguardian.com/uk-news/live/2015/jul/01/heatwave-live-britain-hottest-day-2015, Acesso em 19/07/2015.
} 
vegetação precisa ser espacialmente distribuída, formando uma rede de infraestrutura urbana para a criação de uma sucessão de espaços abertos e semi-confinados de amenidade climática, especialmente públicos ou de acesso público, que proporcionem melhorias às condições ambientais urbanas, não somente dentro de seus limites, mas também no seu entorno imediato, e de forma que seja compatível com a cidade adensada.

O objetivo é agregar o conhecimento acumulado em funções das muitas medições de campo, das possibilidades mais recentes de simulação do efeito microclimático da vegetação no cenário climático atual e futuro numa proposta de inclusão da infraestrutura verde, compatível com a cidade adensada, que, além dos muitos serviços ecossistêmicos, passa a desempenhar um papel como parte da estratégia de adaptação aos fenômenos de aquecimento urbano.

Em outras palavras, este trabalho propõe o aproveitamento dos efeitos microclimáticos da vegetação como parte das estratégias de adaptação em áreas urbanas, de forma compatível com as estratégias de adensamento populacional e construído, configurando uma rede de infraestrutura urbana, com consequente diminuição das condições de desconforto e mesmo de stress térmico para a população, seja durante os eventos ainda episódicos de ondas de calor, que devem se tornar mais severos e mais frequentes, ou mesmo nos cenários previstos de mudança climática, se mantidos os cenários de emissões atuais. 


\section{Interações entre clima urbano, planejamento, desenho urbano e projeto de edifícios}

\subsection{Climatologia urbana: notas para uma breve perspectiva histórica}

Recentemente foram publicados diversos trabalhos com perspectivas históricas acerca da climatologia urbana, da relação entre clima urbano e planejamento (MILLS, 2014; HEBBERT et al., 2011; HEBBERT; MACKILLOP, 2013; HEBBERT, 2014), alguns deles abordando a emergência das mudanças climáticas dentro desse contexto (HEBBERT; JANKOVIC, 2013; CITY OF STUTTGART, 2010). Esses textos registram momentos marcantes nessa trajetória, com uma clara predominância da escola alemã de climatologia urbana desde o início do século XX.

Também foram disponibilizados nos últimos anos versões eletrônicas de textos clássicos dificilmente acessíveis anteriormente, na página da International Association of Urban Climate - IAUC, ${ }^{26}$ tais como o trabalho de Luke Howard (1833), "The Climate of London. Volume 1", de Albert Kratzer (versão em inglês de 1956), "The Climate of Cities" e de Tony Chandler (1965) "The Climate of London".

Os estudos de climatologia urbana se iniciam com Luke Howard, no final século XIX, dentro e nos arredores de Londres, e que resultam na publicação de The Climate of London. A primeira edição foi publicada em 1818 e a segunda, expandida e em três volumes, publicada em 1833 (HOWARD, 1833), ${ }^{27}$ e que representa o início científico dos estudos de clima urbano (MILLS, 2014). Howard faz as primeiras análises de dois fenômenos distintos, porém, inter-relacionados: a contaminação dos dados meteorológicos urbanos pela urbanização e a magnitude e as causas da ilha de calor urbana, e ele já identifica corretamente muitas das causas do aquecimento urbano que são estudadas hoje: calor antropogênico, múltiplas reflexões, indisponibilidade de água para evaporação e diminuição dos ventos pela rugosidade urbana (MILLS, 2008). Muitos efeitos urbanos na temperatura do ar observados por Howard foram confirmados (OKE, 1982).

Depois surge a primeira edição em alemão de Climate near the ground, de Geiger, em 1927, que só foi publicada em inglês em 1965 (MILLS, 2014), com tradução posterior para o português como Manual de microclimatologia: o clima da camada de ar junto ao solo, em edição da Fundação Calouste Goubenkian, de Portugal (GEIGER, 1980).

Dez anos após Geiger, vem a contribuição do meteorologista e geógrafo também alemão Albert Kratzer (1937), intitulada The Climate of Cities (Das Stadtklima), resultante da tese de doutoramento do autor, e que só foi traduzida para o inglês em 1956. O livro é considerado como representativo da escola alemã de climatologia da paisagem (landscape climatology). ${ }^{28}$

Nascido na Alemanha, o geofísico Helmut Landsberg, então diretor do Taunus Observatory em Frankfurt, foi para os EUA em 1934 ministrar o primeiro curso de pós-graduação em bioclimatologia. Atuou em distintas universidades americanas, trabalhou para as forças armadas dos Estados Unidos como meteorologista na 2 a guerra mundial, foi diretor de climatologia do US Weather Bureau, e desempenhou importante papel na WMO. Landsberg ajudou a construir a climatologia urbana como campo disciplinar e definia a microclimatologia como "a big word for the study of small-scale weather". Décadas depois, publicou o livro The Urban Climate (LANDSBERG, 1981), considerado um sucessor do livro de Kratzer (HEBBERT; MACKILLOP, 2013).

\footnotetext{
${ }^{26}$ Disponível em: http://www.urban-climate.org/resources/classic-texts/. Acesso em 10/04/15.

${ }^{27}$ Idem.

28 Idem.
} 
Nos anos 1960 o geógrafo Tony Chandler publicou The Climate of London (1965), um verdadeiro tratado com uma quantidade extraordinária de dados e análises e que descreve de forma sistemática o efeito da área urbana em cada propriedade atmosférica (MILLS, 2014).

Um pouco mais tarde, nos anos 1970, os estudos de Oke (1973) relacionando a ilha de calor urbana ao tamanho da cidade, apontaram possíveis generalizações para cidades norte-americanas. De início o parâmetro população foi usado como uma métrica empírica de forma e função urbanas, que mais tarde se demonstrou falho para captar informações relevantes das cidades, tais como materiais, cobertura do solo e geometria. Quase uma década depois, Oke (1981) substituiu o parâmetro população pela relação $\mathrm{H} / \mathrm{W}$ ou, alternativamente, pelo fator de visão de céu, como descritor da geometria urbana, com uma relação universal baseada em dados para diferentes cidades em diferentes climas.

Até então, apesar de todo o progresso realizado, a climatologia urbana ainda não havia assumido a tarefa de medir e modelar os mecanismos das causas do aquecimento urbano propriamente ditos. Em função disso, Mills (2014) faz uma distinção do desenvolvimento da climatologia urbana desde 1900 em duas fases. Antes de 1970, a maior parte das pesquisas era dominada por estudos descritivos e baseada em observações dos elementos do tempo, especialmente temperatura e umidade do ar, na escala urbana. Depois disso, a climatologia física, com a ênfase nos princípios da conservação de energia, massa e momento, veio à tona. A partir daí o foco da pesquisa mudou da descrição dos efeitos (respostas) para a busca das causas (processos), ligando estes estudos à escala da meteorologia da camada limite.

O primeiro evento da WMO com um foco urbano foi um simpósio organizado com a WHO em Bruxelas, em 1968. Nessa ocasião, foi marcante uma colocação de Helmut Landsberg que, segundo Chandler (1970a: 367 apud HEBBERT, MacKILLOP, 2013) "challenged planners for their ignorance of climate issues and meteorologists for their neglect of living environments and their one-sided orientation towards aviation."

Mesmo contando com referências da meteorologia e da geografia, as particularidades do clima tropical ainda eram um capítulo à parte, tratado nas conferencias da WMO específicas sobre climas tropicais realizadas em 1986, na Cidade do México, "the first international conference oriented to the global South and the urban poor" (HEBBERT, MacKILLOP, 2013), e 1994, em Dhaka, Bangladesh. A conferência de 1986 contava com Baruch Givoni, em meio aos climatologistas, no painel Urban Design. Do Brasil registra-se a contribuição do Prof. Dr. Carlos Augusto de Figueiredo Monteiro, da Faculdade de Filosofia, Letras e Ciências Humanas da Universidade de São Paulo, departamento de Geografia - FFLCH/USP/GEO. Na conferência de 1994, as contribuições para arquitetura e planejamento já eram mais expressivas, como na Session D: The Impact of Climate on Planning and Architecture, com trabalhos pioneiros do brasileiro Prof. Dr. Leonardo Salazar Bittencourt, Universidade Federal de Alagoas - UFAL, e dos latino-americanos John Martin Evans (inglês radicado na Argentina) e Silvia de Schiller, ambos da Facultad de Arquitectura, Diseño y Urbanismo, Universidad de Buenos Aires - FADU, na Session E: Urban Design and Climate.

Nessa ligação entre clima, planejamento e arquitetura, além dos clássicos como Design with Climate. Bioclimatic Approach to Architectural Regionalism (OLGYAY, 1963) e Man, Climate and Architecture (GIVONI, 1969), ambos fazendo uma ponte inestimável com a arquitetura e o urbanismo, as referências estavam principalmente nos textos mais recentes de Baruch Givoni, em artigos científicos e no documento técnico de sua autoria para a WMO intitulado Urban Design in Different Climates (GIVONI, 1989), com edição esgotada em pouco tempo. Nove anos depois, o mesmo autor publicou Climate Considerations in Urban and Building Design (GIVONI, 1998), que trazia uma ampla discussão de climatologia urbana e as implicações do desenho urbano e do impacto de áreas verdes no clima urbano, inédita na área com aquela riqueza de detalhes e com uma abordagem voltada para arquitetura e urbanismo. 
Oke também atuou muito nessa integração entre as áreas, mostrando aos alunos o grau de aceitação da Alemanha às práticas de planejamento orientadas pelo clima, algo impensável na América do Norte. Por outro lado, Tim Oke criticava a disciplina:

for failing to provide what decision makers needed - practical predictive tools that would enable them to configure green space, orient roads and buildings, and optimize the height-width ratio of street canyons in relation to climatic objectives such as thermal comfort, energy conservation or pollutant dispersal (OKE, 1984).

A Alemanha, com centros de excelência em Munique, Karlsruhe, Kassel e Freiburg produziu várias monografias em clima urbano, e os conhecimentos foram aplicados em cidades de várias escalas, tais como Berlin, Bochum, Freiburg, Kassel, Heidelberg e Munique. O conhecimento foi incorporado à VDI 3787-1 - Environmental meteorology - Methods for the human biometeorological evaluation of climate and air quality for urban and regional planning at regional level - Part I: Climate, ${ }^{29}$ uma norma nacional promulgada pelo Institute of German Engineers, largamente aplicada no país (HEBBERT, WEBB, 2011).

As circunstâncias locais que facilitaram a aplicação desse conhecimento na Alemanha, Suíça e Áustria raramente são encontradas em outros lugares. A orientação da maioria dos serviços de tempo e clima é voltada para aviação, agricultura, defesa e previsão do tempo. Na verdade, por esses motivos, vários autores apontam um viés antiurbano na maioria dos registros:

The very basis of meteorological data collection had an anti-urban bias, since weather measurements came from level grass-covered sites away from the distorting influence of buildings [...] failure to apply the discipline of climatology to the built environment could be attributed to the continuing disconnection between national meteorological services and the planning, design and construction professions. [...] The verdict was clear. While climate science continued to advance, supported by progressively more sophisticated measuring, monitoring and modelling technologies, its application to urban planning, Germany excepted, had stalled. (HEBBERT, MACKILLOP, 2013).

Sobre a afirmação:

Scientific progress in UC seems assured but two major challenges remain: acquiring information on the climates of cities in less prosperous regions, which are growing rapidly and many of which have Tropical climates in which there have been few studies and; transferring urban climate knowledge into routine planning/design practice. (MILLS, 2014).

cabem duas colocações, uma de ordem local e outra de caráter geral. A primeira delas é que em São Paulo, a quarta maior aglomeração urbana do mundo, com mais de 21 milhões de habitantes, aproximadamente a mesma população da Cidade do México e Mumbai, depois de Tóquio, Nova Délhi e Shangai (UN/DESA, 2014), a rede de estações meteorológicas precisa aumentar e melhorar dramaticamente. Com longas séries históricas, a cidade conta com a estação IAG/Água Funda (WMO 83004), que atua desde 1933, e INMET Mirante de Santana, que atua desde 1943 (WMO 86910, INMET A701). As demais são mais recentes, da rede METAR, nos aeroportos de Congonhas, Campo de Marte e Guarulhos (esta última na RMSP), algumas estações CETESB que, além de qualidade do ar, monitoram variáveis climáticas, e, mais recentes ainda, estações do Centro de Gerenciamento de Emergências - CGE, algumas delas com cerca de dois anos ou menos de registros atualmente, mas em maior número e mais distribuídas pela área urbanizada. Há mais algumas estações para fins acadêmicos na Cidade Universitária (dentre elas a plataforma IAG/USP, IEE/USP, FFLCH/USP/GEO,

\footnotetext{
${ }^{29}$ Disponível em: <http://www.vdi.eu/nc/guidelines/vdi_3787_blatt_2-

umweltmeteorologie_methoden_zur_human_biometeorologischen_bewertung_von_klima_und_lufthygiene/> Acesso em 19/07/2015.
} 
EP/USP), outra no alto de um edifício na Sé, região central da cidade (IAG Ministério da Fazenda) e uma rural em Itutinga (IAG Itutinga, no Parque Estadual da Serra do Mar), ambas operando há apenas alguns anos, e outras da ECOVIAS, no entorno da RMSP. Portanto, não há uma estação meteorológica na área mais densamente urbanizada já com uma série histórica razoável, que permita o estudo do clima urbano de forma sistemática, até o momento (Figura 2).

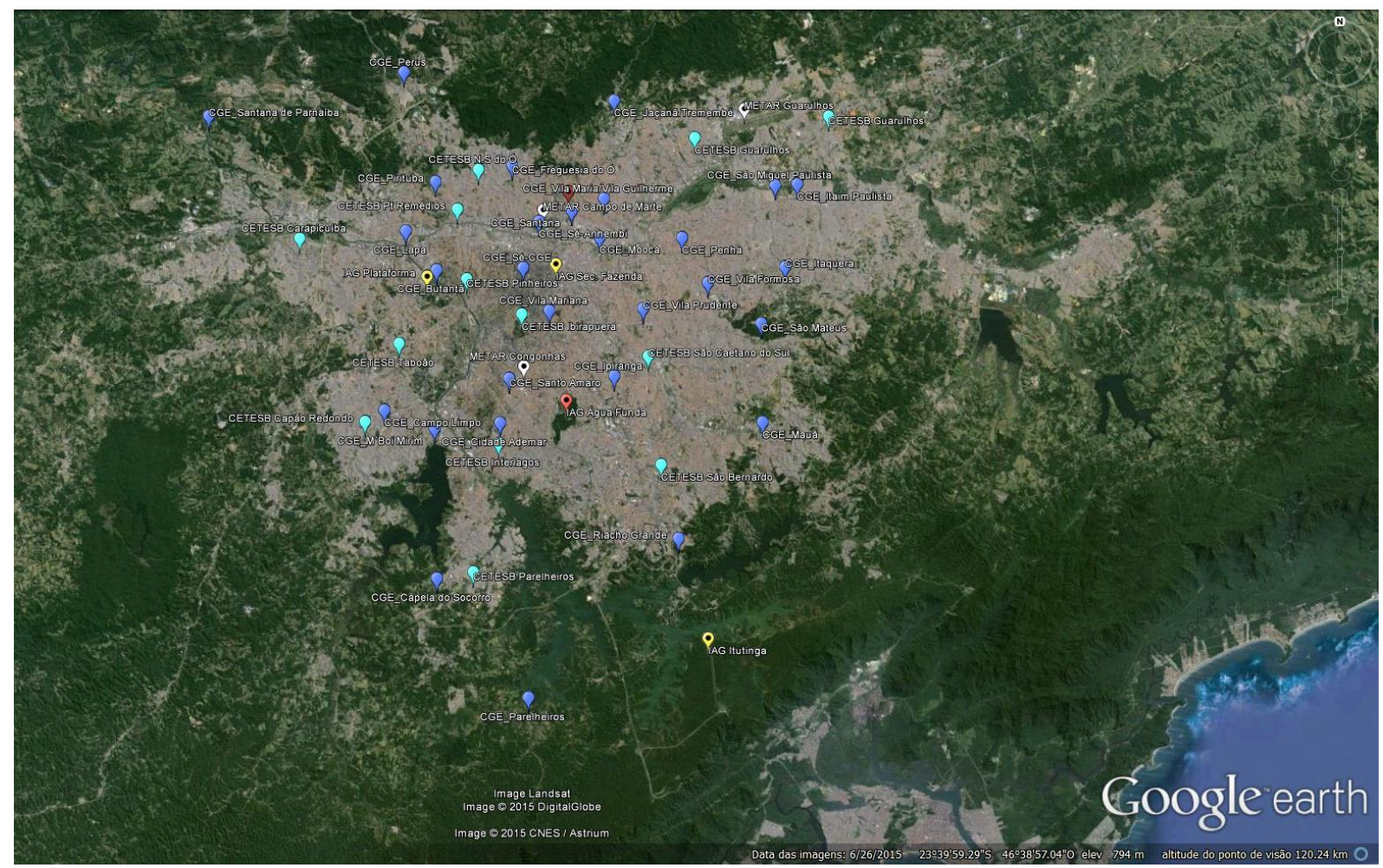

Figura 2 - Localização das estações meteorológicas em São Paulo, de diferentes bases e períodos de monitoramento. Em vermelho, IAG/Agua Funda, na zona sul de São Paulo, e INMET Mirante de Santana, na zona norte da cidade. Em branco, os aeroportos Congonhas, Guarulhos e Campo de Marte. Em amarelo, estações IAG/USP na Cidade Universitária, Ministério da Fazenda (Sé) e Itutinga (Serra do Mar). Em verde algumas das estações CETESB que medem variáveis climáticas e, em azul, as novas estações do CGE (Elaboração: Luciana S. Ferreira, julho de 2015)

A segunda colocação é que, para a arquitetura e o urbanismo, deve-se mudar o foco de uma mera transferência de conhecimento da climatologia para o planejamento. Arquitetos e urbanistas enxergam a cidade de outra forma, entendem outras dinâmicas que não são familiares aos climatologistas. Arquitetos e urbanistas precisam interagir mais e colocar outro ponto de vista em pauta, colocar suas demandas junto à climatologia para aproximar as duas escalas e cobrir essa lacuna que ainda distancia as duas áreas. ${ }^{30}$ Por sua vez:

[...] urban climatologists saw the need to reach beyond the confines of meteorological science and speak directly to those who shaped the urban environment. [...] The failure of knowledge transfer in urban climatology has contemporary relevance and deserves to be more widely known. The application of science is a process of translation. It depends upon intermediaries to demonstrate potential, entrepreneurs to extend networks into fresh territory, and legal, political and economic incentives to consolidate the application. [...] Tried and tested German precedents of applied climatology were not widely considered as part of state-of-the-art town planning. They were not taught or researched in planning schools. Most actors remained unaware of them. [...] How do things stand today? Brazel and Quatrocchi (2005: 778) describe the application of research findings of

\footnotetext{
30 Este tema é retomado no capítulo 9.
} 
urban climatology in building design and urban environmental planning as 'beginning to emerge but not yet widespread'. German-speaking cities still set the benchmark, other European cities lag, the fast-growing settlements of the global South have hardly begun to define the issue (Emmanuel, 2005). But certain factors that worked against the urban climatology actor-network may now be shifting in its favour. On the science side of the equation, the creation of IAUC has given the discipline a single network and the capacity to act and influence. The methodological basis of meteorology continues to advance. Lightweight sensors that capture and transmit data are bringing down the cost of weather observation. Multi-scalar computer models linked to GIS systems and three-dimensional modelling of urban form facilitate high-resolution climate mapping. Biometeorological modelling now provides a methodological link to the demographic base and to assessment of public health impacts (Erell et al., 2010; Hebbert et al., 2011)....At the same time, there has been a shift on the demand side. (HEBBERT, MacKILLOP, 2013).

Nos últimos anos, surgiram algumas iniciativas importantes nessa aproximação entre as áreas. Uma delas é uma iniciativa da WMO e da United Nations Educational, Scientific and Cultural Organization UNESCO, que assim como outras organizações governamentais e não-governamentais reuniu especialistas e publicou os resultados dessas discussões que resumem os dois pontos de vista Climate Information for Improved Planning and Management of Mega Cities - Needs Perspective (MILLS et al., 2010) e Climate and More Sustainable Cities: Climate Information for Improved Planning and Management of Cities - Producers/Capabilities Perspective (GRIMMOND et al., 2010).

Outro evento, City Weathers Workshop, realizado em 2011 na University of Manchester (HEBBERT et al., 2011), foi financiado pela agência britânica Economic and Social Research Council - ESRC, com a finalidade discutir a aplicação da climatologia no urbanismo, trazem uma gama de trabalhos incluindo:

a) a representação das cidades nos modelos regionais e a exclusão das estações urbanas das bases de dados. Hoje os modelos têm maior resolução e buscam uma melhor representação das trocas de calor, umidade e momento entre as superfícies urbanas e a atmosfera; o autor lembra também que a magnitude da ilha de calor urbana como fator isolado não dá a exata magnitude dos impactos que pode causar, mas sim, que ela é mais sentida quando acoplada a eventos extremos: "An extreme heat island event duing relatively cool conditions will be less significant for human comfort than a small heat island during a heat wave for example." (McCARTHY, 2011);

b) o clima urbano como resultante da forma e das funções da cidade, assim como as diferentes perspectivas dentro e fora (indoors and outdoors), para o projeto de edifícios e o ambiente externo (MILLS, 2011);

c) a revisão de quatro décadas de estudos em mapeamento climático, mostrando claramente a predominância da Alemanha e do Japão, com alguns estudos expressivos em outros países europeus e a China, os poucos trabalhos latino-americanos no Brasil e no Chile, e praticamente a ausência de trabalhos nos EUA e na África (REN et al., 2011).

No Brasil, em paralelo, dentre os estudos de clima urbano em arquitetura e urbanismo, destacam-se os mestrados das professoras Dra. Anésia Barros Frota (1983), Clima Local e Micro-Clima na Cidade Universitária, orientado pelo Prof. Dr. Ualfrido Del Carlo na FAUUSP, e da Dra. Eleonora Sad de Assis (1990), Mecanismos de Desenho Urbano Apropriados à Atenuação da llha de Calor: análise de desempenho de áreas verdes urbanas em clima tropical, com orientação do Prof. Dr. Pierre Fernandez na UFRJ. Alguns anos depois, Assis (2000), precursora nessa área de pesquisa no Brasil, concluiu a sua tese de doutoramento Impactos da Forma Urbana na Mudança Climática: método 
para a previsão do comportamento térmico e melhoria de desempenho do ambiente urbano, já sob a orientação da Prof. Dr. Anésia Barros Frota, na pós-graduação da FAUUSP. Entre um trabalho e outro, foi fundamental o seu texto Bases teóricas para a aplicação da climatologia ao planejamento urbano, publicado no Encontro Nacional de Conforto no Ambiente Construído - ENCAC 1997, abordando teorias sobre o clima urbano e sobre as cidades, as escalas climáticas e níveis de planejamento urbano, bem como os meios de representação para a integração de ambos (ASSIS, 1997).

Também no ENCAC 1997, em Salvador, aconteceu a primeira mesa redonda no tema no encontro bienal dos 'conforteiros', com a presença da Prof. Dra. Magda Adelaide Lombardo, geógrafa da UNESP/Rio Claro e também orientadora do Programa de Pós-Graduação em Geografia, na FFLCH/USP. O evento contou também com outros especialistas no tema, como Matthews Santamouris, Grécia, e Lutz Katzschner, Alemanha, que passou a interagir com os grupos de conforto ambiental das universidades brasileiras, particularmente a Universidade Federal da Bahia - UFBA, com as professoras Tereza Moura, Jussana Nery e Telma Andrade, e Universidade Federal de Minas Gerais - UFMG, com a Prof. Dra. Eleonora Assis.

Os estudos de ventilação urbana, ainda nas primeiras versões dos modelos CFD ou com modelos físicos em túnel de vento, surgiram no Brasil também nos anos 1990, com os professores Leonardo Bittencourt, da UFAL, e Francisco de Assis Gonçalves da Silva, da Universidade Federal da Paraíba UFPB, respectivamente.

Além dos já citados, outros grupos de conforto ambiental nas escolas de arquitetura e urbanismo no Brasil também foram desenvolvendo trabalhos em escala urbana, na época, em particular, a Prof. Dra. Virgínia Araújo, na Universidade Federal do Rio Grande do Norte - UFRN, Prof. Dra. Lúcia Mascaró e Prof. Dr. Juan Mascaró, na Universidade Federal do Rio Grande do Sul - UFRGS, Prof. Dra. Lucila Chebel Labaki, na Universidade Estadual de Campinas - UNICAMP, Prof. Dra. Marta Adriana Bustos Romero e Prof. Paulo Marcos de Oliveira, na UnB, Prof. Dra. Denise Duarte e Prof. Dra. Márcia Alucci, na FAUUSP, Prof. Léa Cristina de Souza e Prof. Dr. João Gomes Faria, na UNESP/Bauru.

No início dos anos 2000, foram publicados $A$ inclusão de questões de conforto térmico urbano nas regulamentações municipais no Brasil (DUARTE, 2000) e Estado da Arte em Clima Urbano e Planejamento (DUARTE, 2002). Alguns anos depois, uma reunião da área foi coordenada pela Prof. Dra. Eleonora Assis no ENCAC 2005, em uma mesa redonda com os pesquisadores interessados no tema, com o objetivo de fazer um balanço do mesmo no evento e para organizar uma agenda de atividades. Nessa ocasião foram publicados $A$ abordagem do clima urbano e aplicações no planejamento da cidade: reflexões sobre uma trajetória (ASSIS, 2005) e Aplicações da climatologia urbana no planejamento das cidades: revisão dos estudos brasileiros (ASSIS, 2006; 2007), importantes textos de revisão no tema, sistematizando o estado da arte no tem até então.

Por ocasião dos trinta anos da proposta teórica de Monteiro (1976), para os estudos de clima urbano, tratada mais à frente neste mesmo capítulo, o mesmo concede uma entrevista à Prof. Dra. Eleonora Assis, publicada na Revista de Arquitetura e Urbanismo - RUA. ${ }^{31}$ Recentemente também foi publicada A construção da climatologia geográfica no Brasil, de Monteiro et al. (2015), que permite ao leitor uma excelente retrospectiva histórica dos avanços da área no Brasil, e as distinções no tratamento do tema entre a meteorologia e a climatologia geográfica. Monteiro também comenta a difusão e o interesse pelo tema entre os arquitetos, a aplicação do seu modelo em trabalhos da arquitetura desde o início dos anos oitenta, principalmente no Nordeste do Brasil, e menciona pontualmente alguns trabalhos na área.

\footnotetext{
${ }^{31}$ Revista RUA, v.7. n.1, p. 100-107, Salvador, 2006. Entrevista concedida à Prof. Dra. Eleonora Sad de Assis em 27/11/2006.
} 


\subsection{Clima urbano, planejamento e desenho urbano}

A principal razão para se considerar o clima urbano é criar ambientes construídos que interajam com a atmosfera criando microclimas nos quais as pessoas se sintam confortáveis (BROWN; GILLESPIE, 1995). Se o espaço não oferece condições de conforto, não atrai as pessoas. Se houver alternativa, o usuário, com certeza, vai em busca de um espaço mais confortável do ponto de vista térmico, luminoso, acústico, tátil, etc. Se o objetivo é melhorar a qualidade ambiental das cidades, temos que melhorar as condições que favoreçam o uso dos espaços públicos onde as pessoas vão circular a pé, de transporte público ou por outros meios não motorizados de transporte. A fim de que as pessoas possam passar mais tempo nos espaços públicos, essa vivência precisa ser prazerosa (ROBINSON, BRUSE, 2011). O outro objetivo é minimizar o consumo de energia em edifícios (BROWN; GILLESPIE, 1995). Por isso é importante conhecer os elementos do microclima que mais afetam o conforto humano, o consumo de energia, e conhecer os elementos do microclima que podem ser alterados pelo planejamento e pelo desenho urbano.

O microclima urbano é incrivelmente complexo e está sempre mudando. Na escala microclimática é possível observar os efeitos locais do clima urbano, em sua distribuição espacial e temporal: 1) a ilha de calor urbana, em suas várias manifestações; ${ }^{32} 2$ ) as modificações no balanço de energia em comparação com os sítios naturais do entorno e 3) a interação com as mudanças globais aumentando os riscos sociais e ambientais em eventos extremos.

As variáveis ambientais podem, até certo ponto, ser controladas pela atividade de planejamento e projeto, tanto na escala urbana quanto na do edifício, por meio das legislações de uso e ocupação do solo e códigos de edificações, de modo que há, a princípio, potencial para agregar objetivamente informações da climatologia ao planejamento e gestão das cidades, por meio de um planejamento urbano climaticamente responsável, pelo desenho urbano e pelo entendimento do papel dos edifícios na estratégia de climatização das cidades.

Entretanto, embora se reconheça a importância da consideração do clima no planejamento urbano, constata-se que muito pouco do conhecimento disponível da climatologia urbana é usado no planejamento das cidades. Na década de 1980, Oke (1984) apontava que parte do problema estava na natureza da pesquisa em climatologia urbana, essencialmente descritiva, e na sua dificuldade em traduzir seus resultados em subsídios e ferramentas úteis para aplicação em planejamento. De fato, Taesler (1986) observa que, do ponto de vista da climatologia, o principal objetivo reside em estudar o impacto da área urbana sobre a atmosfera, mas que para o planejador urbano e para o projeto de edificações, ao contrário, o interesse está em avaliar os impactos do clima sobre as funções, a economia e a segurança do ambiente construído, bem como sobre a saúde e bem-estar da população, de modo a tomar decisões para a preservação da qualidade desse ambiente.

Obviamente, o processo de tomada de decisão em planejamento e projeto não pode estar baseado em critérios puramente qualitativos e em princípios gerais; é necessário desenvolver metodologias para a análise quantitativa e integrada de atributos da forma urbana e do clima, em suas várias escalas, baseadas em critérios de conforto ambiental e eficiência no uso de recursos energéticos e de materiais, de maneira a diminuir a pressão das áreas urbanas sobre os recursos naturais, contribuindo para a sustentabilidade do ambiente construído. Monteiro (1986) já chamava a atenção para a necessidade do desenvolvimento de modelagem para a simulação, a partir de situações observadas, fortalecendo as bases de previsão para subsidiar o planejamento urbano.

Nos últimos anos o cenário está mudando; há recursos de modelagem numérica que permitem estudos preditivos de clima urbano na camada ao nível das coberturas (Urban Canopy Model - UCM), ainda que bastante complexos. Também começam a acontecer acoplamentos entre modelos de diferentes escalas (ROBINSON et al., 2011). Nos estudos microclimáticos urbanos em Arquitetura e

\footnotetext{
32 Abordada no capítulo 6.
} 
Urbanismo, o mais utilizado é o ENVI-met, ${ }^{33}$ um modelo microclimático tridimensional para simular as interações entre o solo, a superfície (vegetação, área urbana) e a atmosfera na micro-escala urbana (BRUSE; FLEER, 1998), baseado nos princípios da mecânica dos fluidos e nas leis fundamentais da termodinâmica. Considera as caraterísticas dos processos da macro e mesoescalas para fornecer dados da microescala. $\mathrm{O}$ uso do modelo exige conhecimentos de micrometeorologia que não são abordados na formação de arquitetos e urbanistas, o que o torna bastante complexo para aplicações na área.

Esse é um dos poucos modelos em microescala que tentam descrever a maior parte dos processos climáticos que acontecem no meio urbano, incluindo turbulência, transporte de calor sensível e latente, fluxos de radiação em estruturas urbanas e a influência da vegetação (JANSSON, 2006). O modelo considera não apenas o efeito de sombreamento das árvores, mas também o processo fisiológico de fotossíntese e abertura dos estômatos (BRUSE, 1998), o que é fundamental para o correto entendimento do impacto da vegetação no clima. A fim de se avaliar os benefícios da vegetação, o modelo considera os principais processos relacionados à vegetação: transpiração, evaporação, fluxo de calor sensível, fluxos turbulentos de calor e vapor; balanço de energia da folha e balanço de água do sistema solo-vegetação. Também determina as temperaturas de superfície (pisos e envoltória dos edifícios), as trocas de água e calor no solo, um parâmetro de conforto, o PMV adaptado de Fanger (1972) por Jendritzky e Nübler (1981) para uso em espaços externos e o BOT pedestrian agent (BRUSE, 2007).

Um outro ponto a ser incluído na agenda é o desempenho ambiental dos edifícios no cenário de mudanças climáticas. Alterações nos padrões de clima têm sido verificadas nos últimos anos, o desempenho dos edifícios depende do clima ao qual eles estão expostos, agora e nos cenários de mudança climática, e o conforto dos usuários também. Um impacto adicional no clima das cidades é o efeito da ilha de calor urbana (WILDE, COLEY, 2012; UNEP, 2007), em suas diversas manifestações. Novas condições climáticas impõem novos impactos aos edifícios e cidades, assim como aos seus usuários. ${ }^{34} \mathrm{Na}$ constatação da ocorrência de mudanças climáticas, vários estudos apontam que elas são ocasionadas por atividades humanas, principalmente com a emissão de gases de efeito estufa para consumo energético, e os edifícios são responsáveis por boa parte desse consumo. Neste contexto, existe um importante trabalho de adaptação e mitigação a ser realizado, incluindo diversos setores, inclusive o da construção civil, da arquitetura e do urbanismo. Nesses setores, adaptação diz respeito aos estudos dos impactos das mudanças climáticas e da previsão de suas prováveis consequências para as áreas urbanas, para os edifícios e para as pessoas que neles habitam. Remete ao desempenho das construções frente às alterações dos principais parâmetros climáticos e à redução da sua vulnerabilidade a essas mudanças. Por outro lado, a mitigação das causas das mudanças climáticas, decorrentes das emissões de gases de efeito estufa implica na redução dessas emissões pela diminuição do consumo de energia.

Ainda que exista certo grau de incerteza quanto às projeções das alterações, grande parte dos pesquisadores aceita sua relação com o aumento de emissões de gases de efeito estufa (GUAN, 2012), resultantes do modelo de ocupação humana. Os edifícios, responsáveis por parte do consumo energético e de matéria-prima contribuem, deste modo, com parcela significativa das emissões de gases de efeito estufa.

\footnotetext{
${ }^{33}$ Autoria Michael Bruse e equipe. Software gratuito disponível em http://www.envi-met.com/. Abordado com mais detalhes nos capitulos 5 e 7.

${ }^{34} \mathrm{Em}$ andamento no grupo o doutoramento da Arq. MSc. Carolina Abrahão Alves, estudando o desempenho térmico da produção recente de edifícios residenciais no contexto das mudanças climáticas, com avaliação e proposição de estratégias de adaptação visando ao conforto e à eficiência energética, com orientação da Prof. Dra. Denise Duarte e co-orientação da Prof. Dra. Joana Carla Soares Gonçalves.
} 


\subsection{Clima urbano: abordagens, escalas e balanço de energia em áreas urbanizadas}

Os estudos de clima urbano têm fundamentos na climatologia e na meteorologia, com duas abordagens distintas: a geográfica e a meteorológica.

No Brasil, a abordagem geográfica, com base em Monteiro (1976) tem uma perspectiva humanista e está baseada nos canais de percepção humana do clima, com subdivisões no subsistema termodinâmico (canal do conforto térmico), subsistema físico-químico (canal da qualidade do ar) e subsistema hidro-meteórico (canal de impacto meteórico). Essa abordagem dá ênfase na dimensão espacial horizontal, as escalas vertical e temporal dos fenômenos não estão bem definidas, e aí está a principal fragilidade do modelo. A análise é feita com base na identificação da dinâmica do clima local, desde a escala sinótica, aplicando técnicas da análise rítmica (sucessão de estados atmosféricos).

A abordagem meteorológica traz uma perspectiva física, fenomenológica e estatística do comportamento das variáveis do clima, tendo como base os fluxos de energia e massa, e seus balanços na interação da atmosfera com a superfície. A abordagem meteorológica é quadridimensional (espaço e tempo) e integra as escalas de cima para baixo (downscaling). A preocupação é preditiva com relação ao comportamento do clima, e não necessariamente gera subsídios ao planejamento e desenho urbanos. A climatologia traz uma visão geral do que acontece dentro do sistema; já a abordagem meteorológica é mais fenomenológica, mais preditiva do comportamento das variáveis do clima, em última instância, mais útil para o projeto (informação verbal). ${ }^{35}$

Tanto na abordagem geográfica quanto na meteorológica, a definição das escalas do fenômeno em estudo é fundamental para identificar as bases de dados necessárias, identificar o tamanho da área de estudo e identificar os meios, métodos e técnicas observacionais mais adequados. Não se pode perder de vista a hierarquia de escalas, típica da abordagem ecológica, e fundamental para que se possa identificar adequadamente as bases de dados, o tamanho da área de estudo, os meios métodos e técnicas mais adequados.

A melhor maneira de se entender o microclima urbano é pelo balanço de energia. $O$ tecido urbano altera o balanço de energia introduzindo um termo de calor antropogênico e diminuindo o termo de calor latente. A forma como a energia é particionada afeta fortemente o microclima: a radiação solar pode ser usada para aquecer o solo ou evaporar a água, pode ser refletida para a atmosfera, e o saldo é usado para aquecer o ar. A proporção de energia usada em cada uma dessas funções irá afetar o microclima. Por exemplo, se o local é seco, a energia não vai ser usada para evaporar a água, portanto mais energia está disponível para aquecer superfícies e, consequentemente, $\mathrm{o}$ ar. Temperatura e umidade do ar geralmente não são significativamente afetadas pelo desenho, mas radiação e vento, sim (BROWN; GILLESPIE, 1995).

O mesmo conceito de balanço aplica-se a uma pessoa ou a um edifício. $\mathrm{O}$ uso de energia em um edifício pode ser estimado considerando-se todos os fluxos de energia para e a partir do edifício (balanço de energia). Dependendo da tipologia dos edifícios (forma, orientação solar, envoltória, etc.) eles reagem de forma diferente ao microclima (BROWN; GILLESPIE, 1995). O controle da radiação solar é o mecanismo mais importante para determinar os ganhos de calor pelo edifício, daí a importância da forma, da orientação solar e da proteção da envoltória onde necessário.

Toda a matéria emite energia radiante. Algumas superfícies se aquecem mais sob a radiação solar direta do que outras, porque elas interagem com a radiação de maneira diferente. A fração da radiação solar que é refletida por uma superfície é chamado albedo dessa superfície. Quanto maior o albedo, mais energia é refletida e menos é absorvida. A transferência de energia do sol para a Terra é

\footnotetext{
35 Palestra da Prof. Dra. Eleonora Sad de Assis (UFMG) na disciplina de pós-graduação AUT 5823 - Conforto Ambiental em
} Espaços Urbanos Abertos, na FAUUSP/LABAUT, em 06/10/2010. 
uma transferência de calor radiante de ondas curtas; igualmente importante, porém menos intuitiva, é a perda de energia radiante de onda longa da Terra para o espaço, caso contrário, o calor acumulado faria a temperatura da Terra aumentar continuamente, se ele não fosse removido. A temperatura resultante é influenciada por um arranjo complexo de fatores como vento, evaporação e precipitação, além do calor emitido por outras fontes antropogênicas (SASS, [s.d]).

Tanto as áreas rurais quanto as áreas urbanas recebem energia solar por processos radiativos, ganhando energia de onda curta do sol, e perdem energia de onda longa para a atmosfera. A superfície da Terra se aquece durante o dia e se resfria durante a noite principalmente por esses processos. As variáveis climáticas resultam diferentes por causa dos diferentes albedos entre o ambiente rural e urbano, por causa da perda de calor por evapotranspiração, geralmente maior nos ambientes rurais, pela presença de vegetação e solo permeável, pelas fontes de calor antropogênico nas cidades, etc., tudo isso resultando em maior ou menor calor estocado no sistema (solo, pavimentos, edifícios, etc.) (SASS, [s.d]).

Tendo em mente as trocas de calor envolvidas no balanço, as formas possíveis de se amenizar as condições microclimáticas urbanas em climas tropicais incluem: manter os corredores de vento onde necessário para favorecer as trocas convectivas, aumentar o albedo das superfícies urbanas para reduzir o calor estocado, incluir a vegetação e o solo permeável em locais estratégicos para aumentar as perdas por evapotranspiração, minimizar a geração de calor antropogênico nos transportes, nas indústrias, nos sistemas de ar-condicionado, etc.

\subsection{Interações entre o clima urbano e o ambiente construído}

A eficiência energética em cidades não pode ser alcançada ignorando-se as condições de mobilidade e transportes (EMMANUEL, 2005). São largamente conhecidos os efeitos do espalhamento urbano, da baixa densidade de ocupação, com o aumento dos gastos com infraestrutura urbana, dos deslocamentos feitos por automóveis e, consequentemente, da poluição do ar das cidades. Nesse contexto, cria-se a necessidade do uso do carro para distâncias perfeitamente caminháveis se houvesse um percurso viável.

Além da mobilidade, são muitas as consequências da escala e do desenho da cidade para uma maior qualidade ambiental. As dimensões das ruas, das quadras, as distâncias entre os pontos para as diferentes atividades cotidianas determinam o tempo de percurso e as formas de deslocamento. Isso influencia o uso de energia para o transporte, o uso de recursos não renováveis, assim como a saúde humana (BOSSELMANN, 2008). Em climas tropicais, além das necessidades comuns a qualquer aglomeração urbana, um cuidado especial precisa ser tomado provendo amenidades climáticas como sombreamento nos percursos para pedestres e ciclistas (EMMANUEL, 2005).

Por essas razões, uma série de trabalhos sobre a sustentabilidade das cidades colocam que uma das necessidades atuais das aglomerações urbanas é uma maior densidade de ocupação (ROGERS, 1997, GIRADET, 2003, EDWARDS, 2002), inclusive nas cidades latino-americanas (DUARTE, 2012; GONÇALVES et al., 2011, GONÇALVES, 2011). Precisamos pensar um novo modelo de cidade, assim como os arquitetos e planejadores dos séculos XIX e XX também o fizeram. Por mais que haja críticas, a cidade modernista foi uma solução para os problemas do final do século XIX, e boa parte do século $X X$. Hoje as demandas são outras. Estamos de novo em um ponto de inflexão, e desta vez enfrentando a iminência de escassez de recursos, de mudança de matriz energética, de mudanças climáticas, etc. Além de envolver muitas outras questões sociais e econômicas, a cidade também é um ecossistema, e o fator humano introduziu um grau de complexidade para o qual a natureza também não tem experiência. ${ }^{36}$ ${ }^{36}$ Vivemos a primeira confrontação do planeta com um limite global com a constatação do buraco na camada de ozônio no
final do século XX; limites locais já vêm sendo superados há muito mais tempo (MEADOWS, et al., 2004). Agora vivemos 
Com o programa habitacional 'Minha Casa, Minha Vida' em curso no país, vamos construir como? Com qual padrão de ocupação urbana? Na maioria dos municípios brasileiros, se mantidos os padrões atuais, isso significa construir residências unifamiliares, principalmente, em áreas distantes, aumentando cada vez mais a dispersão das cidades e suas consequências já tão conhecidas e, mais do que isso, vivenciadas nas cidades brasileiras.

É possível pensar uma São Paulo adensada, policêntrica, conectada por bons serviços de transporte público, com usos mistos em lugar das muitas áreas monofuncionais existentes hoje na cidade, e, principalmente, onde o imenso estoque construído desocupado das áreas centrais possa ser reabilitado e ocupado principalmente pelo uso habitacional, contemplando unidades de diversos tamanhos, para comportar diferentes arranjos familiares. $O$ desafio maior para o adensamento nas cidades latino-americanas é a qualidade do espaço público, dos espaços de transição entre os edifícios, a mobilidade, a poluição, etc. Nas cidades latino-americanas a maior densidade de ocupação precisa ser resolvida com novas propostas, pois a dispersão não pode persistir. 0 adensamento traz vantagens e os impactos negativos decorrentes disso podem ser minimizados, desde que haja planejamento, infraestrutura adequada e excelência no desenho urbano e no projeto dos edifícios.

\subsubsection{Parcelamento, uso e ocupação do solo orientados aos recursos ambientais}

Partindo-se do consenso que se deve viabilizar ambientes urbanos compactos, adensados, e uma vez entendida a necessidade e a premência do adensamento urbano, a discussão muda de devemos adensar? para como devemos adensar? A questão que se coloca agora é: como compatibilizar adensamento e qualidade ambiental. Adensar quanto? Com qual arranjo? Sob quais condições? Com qual padrão de ocupação das quadras? Torres? Lâminas? Ocupação perimetral? Há uma relação entre densidade e morfologia urbana que precisa ser explorada com critérios de desempenho ambiental qualitativos e quantitativos que possam subsidiar políticas públicas, decisões de projeto urbano e de projeto de edifícios (GONÇALVES et al., 2011). E nessa relação entre densidade e morfologia, a aceitação das pessoas aos arranjos de alta densidade depende da percepção que elas têm sobre os espaços propostos (CHENG, 2010), daí a importância ainda maior de um bom planejamento e da excelência no desenho urbano e no desenho dos edifícios.

São muitos os pontos a serem tratados: adensamento e acesso ao sol e à luz natural (para iluminação natural, conforto térmico, aquecimento de água e geração de energia), adensamento e ventilação urbana (para conforto térmico e dispersão de poluentes), adensamento e mobilidade (por razões óbvias), adensamento e resíduos sólidos, adensamento e qualidade do ar, adensamento e ruído urbano, além das muitas questões sociais e econômicas advindas da maior concentração e diversidade de pessoas, tais como os conflitos que podem surgir em áreas residenciais com diversidade de renda.

Esses temas ambientais precisam ser tratados em diversas escalas:

- no zoneamento, que inclui o parcelamento do solo, o adensamento, o controle do uso do solo, a mobilidade, inclusive ciclovias e vias para pedestres, o controle de ocupação nas margens de cursos d'água, etc.;

- nos códigos de edificações, com a orientação dos lotes e dos edifícios, forma, envoltória, tratamento do térreo para passeios permeáveis ao fluxo de pessoas e sombreamento dos percursos, altura das edificações, exigências de sombreamento, monitoramento do consumo de energia, etc.;

com frequência cada vez maior eventos climáticos antes desconhecidos, talvez inéditos, em várias partes do mundo, verdadeiras catástrofes climáticas, inclusive no Brasil. 
- no tratamento da paisagem como infraestrutura urbana (infraestrutura verde ${ }^{37}$ ): tipo e densidade de vegetação, distribuição espacial, permeabilidade à água, espaços públicos conectados com boas opções de mobilidade para as pessoas, etc.

Para o tratamento das questões ambientais, é preciso fazer uma distinção entre densidade construída e densidade de ocupação. Para o balanço de energia em áreas urbanas, por exemplo, o que importa é a densidade construída, que pode ter $n$ tipologias e arranjos diferentes para comportar a mesma densidade de ocupação. Nesse caso, a pergunta é: quais são os efeitos microclimáticos de diferentes arranjos de quadra possíveis com alta densidade e com diferentes tipologias construtivas?

Dentre as razões para as alterações no clima provocadas pela urbanização estão o armazenamento de calor, o aumento da rugosidade e a menor evaporação, fenômenos que são vistos em qualquer cidade do mundo, em menor ou maior grau, mas que são mais evidentes em megacidades densamente construídas (KATZSCHNER, 2010).

O desconforto térmico em regiões tropicais está estreitamente relacionado à radiação; o controle da radiação em edifícios é a maneira mais eficiente, mais impactante, de minimizar os ganhos de calor pela envoltória; portanto, a acumulação de calor nas superfícies urbanas e nos edifícios deve ser minimizada (EMMANUEL, 2005). No desenho urbano os mecanismos de controle desse armazenamento de calor estão principalmente relacionados ao desenho das vias, à densidade construída, à altura dos edifícios, às diferenças de altura entre eles, às tipologias dos edifícios (forma, orientação, envoltória), à infraestrutura verde, etc.

Em áreas adensadas, o desenho faz tão ou mais diferença do que em outras situações, até o último detalhe. Nessas áreas o cuidado deve ser redobrado com o tratamento dos térreos e com o embasamento dos edifícios altos; nas calçadas, no nível do pedestre, fachadas cegas para a rua não ajudam, edifícios cercados por muros intermináveis também não. Especial cuidado deve ser tomado também ao se mesclar áreas de alta densidade com a área urbana existente, com um gradiente de alturas dos edifícios em direção aos edifícios mais baixos pré-existentes.

Excelência e diversidade no desenho urbano e no projeto dos edifícios é fundamental, ao contrário do que ocorre nas extensas áreas de baixa densidade ocupadas pelas habitações populares no Brasil (FERREIRA, 2012), que infelizmente tendem a se repetir no extenso programa habitacional federal em curso no país.

\subsubsection{Acesso ao sol e acesso à luz natural e ventilação urbana}

Quanto à insolação e ventilação, os impactos podem ser muito diversos em diferentes climas. Os estudos de acesso ao sol e de ventilação urbana precedem qualquer avaliação de desempenho térmico e luminoso dos edifícios inseridos na área urbanizada e fazem toda a diferença nos ganhos e perdas de calor, no acesso à luz natural e no consumo de energia do edifício. As condições externas de ventilação e de insolação (ou de sombreamento) precisam necessariamente ser consideradas nos modelos BES - Building Energy Simulation.

Para o controle de acesso da radiação solar, são bastante conhecidos os conceitos de envelope solar (KNOWLES, 2003) e shadow umbrella (EMMANUEL, 1993; 2005), cada um dentro do seu contexto

\footnotetext{
${ }^{37} \mathrm{O}$ termo Infraestrutura Verde pode ser entendido como o uso da paisagem como rede de infraestrutura urbana, assim como o sistema viário, de energia ou de abastecimento de água; é um enfoque no projeto urbano que enfatiza espaços multifuncionais conectados e baseia-se no aproveitamento dos muitos serviços ambientais dos ecossistemas urbanos (BENEDICT; MCMAHON, [s.d.]). Da mesma forma, a infraestrutura verde pode atuar conjuntamente com outros sistemas, no atendimento da mobilidade e da acessibilidade, da drenagem das águas pluviais, do lazer, da recreação e do convívio social, da manutenção dos processos ecológicos, da biodiversidade e da sustentabilidade dos ecossistemas (Paulo Pellegrino, FAUUSP, informação verbal).
} 
climático, quando se busca garantir o acesso ao sol ou prover a sombra (ASSIS, 1995; BRANDÃO, 2004; DUARTE et al., 2006).

Com base em estudos paramétricos, para áreas adensadas, edifícios altos com diferentes alturas são mais vantajosos para o acesso ao sol e à luz natural. Para o mesmo volume construído, em média, a disponibilidade de luz natural nos edifícios pode ser até 40\% maior (NG; WONG, 2004).

No contexto das densas cidades asiáticas, o acesso ao sol propriamente dito é algo muito restrito. Em Hong Kong a preocupação, regulamentada inclusive pelo código de edificações local, é garantir a área de visão desobstruída (UVA - Unobstructed vision area) e o acesso à luz (e não necessariamente ao sol) que essa área pode prover (NG, 2010).

Para a ventilação, irregularidades naturais ou construídas modificam a velocidade do vento, a direção e a intensidade da turbulência. A irregularidade do terreno implica necessariamente em maior complexidade. Do rural ao urbano, o vento se ajusta às novas condições de camada limite definidas pela área urbanizada (topografia, geometria e dimensões dos edifícios, traçados das vias, vegetação, etc.), e os efeitos se sobrepõem, do impacto de um único edifício no solo até os impactos em larga escala de áreas urbanizadas.

Ao contrário de climas temperados ou frios, em climas tropicais a preocupação é incrementar o fluxo do vento, mesmo em áreas altamente adensadas. Os estudos de ventilação urbana precedem o estudo de soluções de ventilação nos edifícios por ação dos ventos. Mesmo para edifícios que, por diferentes razões, operam com climatização artificial durante o período diurno, ressalta-se a importância da ventilação noturna para o esfriamento da massa construída. Edifícios selados ou ainda edifícios que apesar de possuírem aberturas operáveis, funcionam com climatização por todo o tempo de operação, deixam de aproveitar esse valioso recurso, e estocam calor de um dia para o outro desnecessariamente, em contrassenso com o que se busca para um melhor desempenho do edifício.

A diferença de alturas entre os edifícios mencionada anteriormente para melhor acesso ao sol e à luz natural é também uma estratégia mais vantajosa do ponto de vista da ventilação em climas tropicais, como demonstram trabalhos recentes que vêm sendo feitos no Brasil (BITTENCOURT, 1997; PRATA, 2005; LEITE, 2010) e na Ásia (NG, 2010; NG, 2011; YUAN; NG, 2012), principalmente. Quando se projeta edifícios altos, as diferenças de altura são mais vantajosas do ponto de vista da ventilação, por causa das diferenças de pressão induzidas pelo desenho (NG, 2004; 2010).

Por outro lado, sem levar em conta as diversas questões ambientais, um arranjo de alta densidade sem o planejamento necessário pode criar uma série de problemas, não somente de desconforto, mas de stress térmico e saúde pública. Muitas cidades asiáticas estão revendo os seus critérios em função dos problemas que surgiram. Após um grave episódio de poluição que provocou a Severe Acute Respiratory Syndrome (SARS) em 2003, a administração de Hong Kong, Hong Kong Special Administrative Region (HKSAR) decidiu implementar medidas para melhorar as condições de ventilação para uma melhor qualidade de vida urbana (YUAN; NG, 2012; NG, 2011).

Além das considerações de qualidade ambiental do ponto de vista físico propriamente dito, pesquisas recentes demonstram que arranjos de edifícios mais altos e com menores taxas de ocupação são percebidos como de menor densidade quando comparados a arranjos com menor altura e maior taxa de ocupação (CHENG, 2010), isso porque a nossa percepção não corresponde exatamente à densidade física, expressa geralmente por taxa de ocupação e coeficiente de aproveitamento em muitas legislações municipais.

\subsubsection{Infraestrutura verde urbana}

Muitos são os serviços ambientais diretos ou indiretos da vegetação, dentre os quais: o aumento na umidade do ar, a diminuição da temperatura do ar, o menor aquecimento das superfícies urbanas, a 
melhoria da qualidade do ar, o resfriamento passivo de uma edificação, o manejo das águas, além do valor estético e da influência na saúde das pessoas.

No século XX, o crescimento das metrópoles reduziu os espaços para as áreas verdes e o ambiente urbano criou vários obstáculos para o plantio de novas mudas como, por exemplo, a compactação do solo, o pouco espaço para crescimento das raízes, as instalações da rede elétrica e a falta do manejo adequado das árvores.

As consequências da negligência com a vegetação e com o manejo das águas, sendo estes elementos que modulam o clima na paisagem urbana, são evidentes: enchentes recorrentes cada vez mais severas, aquecimento das superfícies urbanas, baixa qualidade do ar e aumento do efeito de ilha de calor em suas diversas manifestações, efeitos esses ligados à escassez de vegetação e água, dentre outros fatores. Um aumento na taxa de evaporação em áreas urbanizadas pressupõe um aumento de vegetação e dos corpos d'água, assim como uma maior retenção da água de chuva, e esse armazenamento pode ser incrementado também com superfícies urbanas mais porosas, seja em solo natural ou construído (EMMANUEL, 2005).

\subsection{Efeitos do desenho urbano sobre o microclima urbano e sobre as edificações}

É clara a interdependência o entre edifício e o ambiente urbano, e como um afeta o outro, ou seja, não há como pensar o edifício ambiental fora do seu contexto urbano e climático. E mais ainda, nessa interação, não há como pensar o edifício sozinho inserido em um ambiente urbano, mas sim, pensar um grupo de edifícios, minimamente em uma escala de nove quadras, para levar em consideração o que acontece no entorno imediato de uma determinada quadra (de referência), entendida aqui como a unidade mínima de projeto (Figura 3).
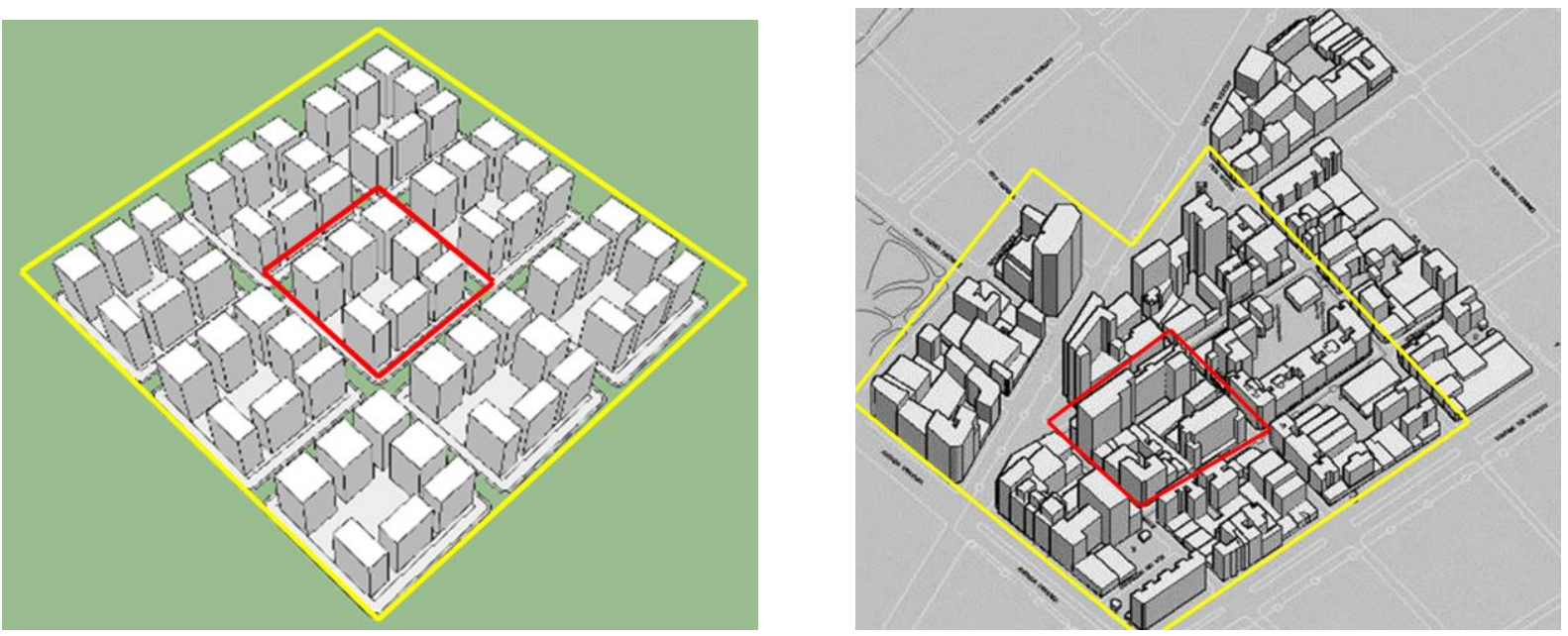

Figura 3 - Quadra de referência como unidade mínima de projeto e mais oito quadras no entorno imediato (à esquerda, uma versão simplificada do contexto existente de um bairro no centro da cidade de São Paulo para estudos paramétricos; à

direita, exemplo de um caso real, no distrito da República, em São Paulo). Fonte: Edificação e Desenho Urbano com adensamento e qualidade ambiental: habitação de interesse social na recuperação de áreas urbanas degradadas (Fonte: LABAUT/LabHab, CAPES/PNPD)

O canyon urbano é largamente utilizado nos modelos microclimáticos como uma estrutura que se repete na Urban Canopy Layer - UCL, afetado diretamente pelo balanço de radiação. O canyon é definido como o espaço tridimensional conformado pela rua e pelos edifícios lindeiros à via. Os canyons urbanos restringem a visão da abóbada celeste, caracterizada pelo fator de visão de céu, causam múltiplas reflexões da radiação solar e geralmente restringem o movimento do ar. Por outro lado, em climas tropicais, edifícios em canyon urbanos podem se beneficiar do sombreamento mútuo. 
Na estrutura do canyon, a radiação solar é absorvida e transformada em calor sensível, atingindo principalmente as coberturas e as superfícies verticais dos edifícios. Paredes, coberturas e solo emitem radiação de onda longa para o fundo de céu, e a intensidade depende do fator de visão de céu. $O$ saldo líquido entre ganhos solares e perda de calor devido à emissão de radiação de ondas longas determinam o balanço térmico de áreas urbanas. Como a perda de calor radiante é mais lenta em áreas urbanizadas, o balanço líquido é maior do que nos arredores e, portanto, as temperaturas são mais altas; diversos trabalhos estabeleceram correlação entre temperaturas do ar e fator de visão de céu sob condições atmosféricas estáveis, com baixa velocidade do vento.

As temperaturas superficiais no canyon são determinadas pelo balanço térmico; as superfícies absorvem radiação de onda curta em função do albedo e de sua exposição à radiação solar; as mesmas superfícies absorvem e emitem radiação de onda longa em função da temperatura, da emissividade e do fator de visão de céu. Ao final, a temperatura do ar no canyon é influenciada pela temperatura das superfícies do canyon, porque a energia também é transferida por processos convectivos.

Muitos modelos de simulação energética de edifícios (Building Energy Simulation - BES) trabalham com o edifício isolado, considerando apenas o sombreamento do entorno. No entanto, para resolver corretamente o balanço de energia, as múltiplas reflexões da radiação solar entre os edifícios e a troca de radiação de onda longa entre eles deveria ser considerada. Os coeficientes de convecção adotados para a envoltória do edifício geralmente são os mesmos padrões adotados para edifícios isolados, e na verdade eles são influenciados pelos edifícios vizinhos, pelas temperaturas mais altas das superfícies, especialmente devidas à radiação solar. Um primeiro fator a ser considerado são os dados climáticos de estações meteorológicas em áreas próximas, urbanizadas, e não em locais afastados, rurais, para que os efeitos do aquecimento urbano sejam considerados e para que o potencial de ventilação noturna seja corretamente avaliado. Um segundo passo consiste em levar melhor em consideração os fluxos de calor radiativos, e terceiro, levar em consideração os fluxos de ar locais, por exemplo, acoplando modelos BES com modelos de mecânica de fluidos (Computer Fluid Dynamics - CFD), (ALLEGRINI et al., 2012).

Também devem ser considerados os efeitos das superfícies no ofuscamento em espaços urbanos, em função das reflexões. O ofuscamento urbano, ainda pouco estudado, provoca desconforto no espaço externo, na maioria das vezes por reflexões dos raios solares nas fachadas polidas ou envidraçadas.

O ofuscamento provocado pelo desenho, pela localização e pela orientação de envoltórias envidraçadas implica em desconforto e comprometimento da segurança no ambiente externo, especialmente para o trânsito, bem como no aumento da carga térmica e no consumo de energia de edifícios afetados, que recebem uma concentração de radiação que provoca ganhos de calor indesejados (SCHILER, 2009).

Há, portanto, um conflito entre a necessidade ou a conveniência de reflexão pela envoltória para diminuir os ganhos de calor nos edifícios ou o aquecimento das superfícies urbanas, por um lado, e o ofuscamento no espaço externo, por outro (SCHILER; VALMONT, 2006).

Dessa forma, o desenho, a localização e o impacto de superfícies refletivas devem ser considerados no desenho urbano, no projeto do edifício e devem ser objeto de regulamentação urbana. Além dos benefícios microclimáticos e de consumo de energia, os edifícios pintados com cores claras para absorver menos radiação ou com grandes fachadas envidraçadas podem incluir soluções mitigadoras para o ofuscamento urbano. Dentre essas soluções estão o tratamento das superfícies, a inclusão de peles externas de sombreamento e o tratamento da paisagem. O acabamento irregular, por exemplo, cria pequenas sombras e reduz o ofuscamento na rua; pode-se também optar por um acabamento jateado em superfícies aluminizadas ao invés do acabamento especular; o uso de proteções externas também diminui o ofuscamento e as peles externas de sombreamento podem também incluir vegetação, nos fechamentos verticais e horizontais (Figuras 4 e 5). 


\subsection{Efeitos dos edifícios sobre o microclima urbano}

Edifícios influenciam o clima urbano (EMMANUEL, 2005; WONG; CHEN, 2009) substituindo solo exposto, solo gramado e árvores por asfalto, concreto e vidro; substituindo volumes arredondados e resilientes ocupados pela vegetação por superfícies rígidas e angulosas dos edifícios; emitindo calor gerado pelos edifícios, pelos sistemas de ar condicionado, indústria e automóveis; e conduzindo a água da chuva para os sistemas de drenagem, diminuindo drasticamente a infiltração no solo.

Por sua vez, os edifícios também podem ser tratados de diversas maneiras como parte da estratégia de climatização urbana. Com as escolhas feitas para a envoltória e demais superfícies do entorno, alteram-se as condições no meio externo, impactando positiva ou negativamente o balanço de energia das áreas urbanas e, por consequência, o microclima exterior e o conforto dos usuários no meio externo. ${ }^{38}$

O tratamento da interface (indoors/outdoors) entre espaço público e privado no nível da rua depende do desenho urbano e do projeto do edifício como um todo, incluindo a volumetria, a orientação, o projeto de fachadas ou a criação de espaços de transição interior/exterior ao longo das mesmas (YEANG, 2002) ou ainda ao longo da altura do edifício (Figura 6). Podem ainda ser exploradas a incidência da radiação solar na forma e no projeto de fachadas ou o aproveitamento dos ventos para resfriamento noturno da massa construída do edifício. Além das vantagens evidentes para a redução do consumo de energia do edifício propriamente dito, isso tudo resulta em menor carga térmica acumulada e em menos calor reirradiado para a cidade no período noturno, contribuindo para a mitigação do aquecimento urbano (DUARTE, 2002).

As regulamentações municipais geralmente incentivam o estabelecimento de limites muito rígidos entre o espaço público e o privado, e com isso eliminam os tão desejáveis espaços de transição, mas existem alternativas ligadas tanto ao tratamento dos espaços abertos propriamente ditos, como também ao desenho dos edifícios que podem criar espaços de transição climática e de uso. Em áreas comerciais, de lazer ou onde mais se quiser incentivar o uso de espaços públicos, e atrair as pessoas para os espaços ao ar livre, a proteção ao sol e à chuva para os pedestres é um dos requisitos mais importantes. $O$ recuo do andar térreo com a permissão de se avançar com a projeção de um ou dois andares sobre a calçada pode compensar economicamente o proprietário e incentivar o uso desse elemento no projeto. Os demais pavimentos voltam a seguir o recuo original, ou um recuo progressivo com a altura, para não prejudicar a ventilação no nível da rua (DUARTE, 2001).

Para YEANG (2002), os edifícios podem ser projetados não somente com concentrações de material inorgânico. Eles precisam ser balanceados com elementos naturais, não só para a melhoria das condições do seu microclima imediato, mas para produção de ar limpo e filtragem de poluentes, com aspersão de água nas fachadas para promover evaporação e resfriamento das superfícies e da camada de ar mais próxima. O autor pesquisa a incorporação de materiais orgânicos e biodegradáveis nos espaços de transição nas fachadas, suavizando o impacto dos edifícios na cidade e criando espaços semi-confinados mesmo em edifícios altos. Esses espaços permitem a abertura das janelas para um ar mais limpo e um ambiente menos ruidoso, além das vantagens estéticas e de maiores possibilidades de escolha para o usuário, como o simples fato de poder abrir as janelas, por exemplo. Com o desenho de átrios ventilados, a ideia é que as possibilidades de ventilação e iluminação natural recriem nos edifícios altos as possibilidades externas existentes no nível da rua. Com essa concepção as fachadas mudam com a orientação e têm diferentes possibilidades de operação em função das condições ambientais locais.

\footnotetext{
${ }^{38}$ Estudo em andamento no grupo, com o doutoramento da Arq. MSc. Carolina dos Santos Gusson, estudando o impacto da densidade construída no microclima a partir do desenho urbano e do comportamento térmico das superfícies urbanas, e da iniciação científica de Beatriz Ruiz Fernandes (PIBIC/CNPq), ambas com orientação da Prof. Dra. Denise Duarte.
} 

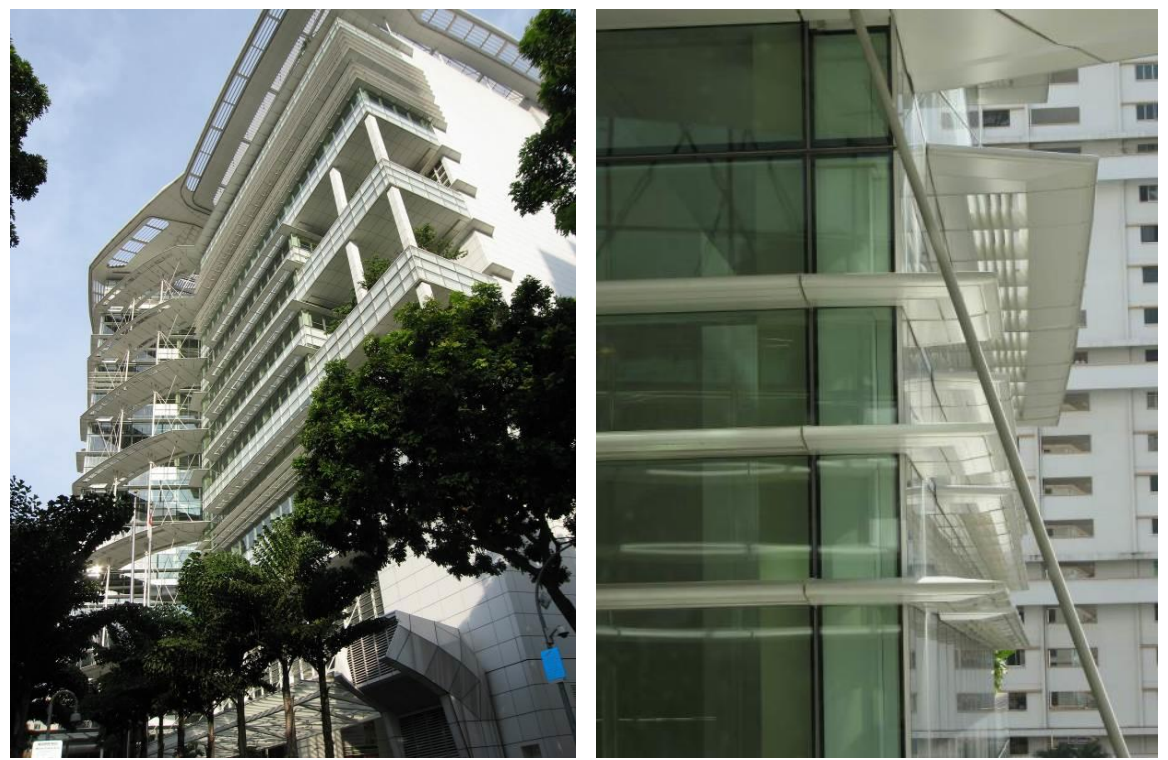

Figura 4 - Biblioteca Nacional de Cingapura. Recortes e detalhes das fachadas que contribuem para minimizar o ofuscamento provocado pelas cores claras, além de outros benefícios microclimáticos para o edifício e para o entorno (foto: Denise Duarte, nov. 2007)
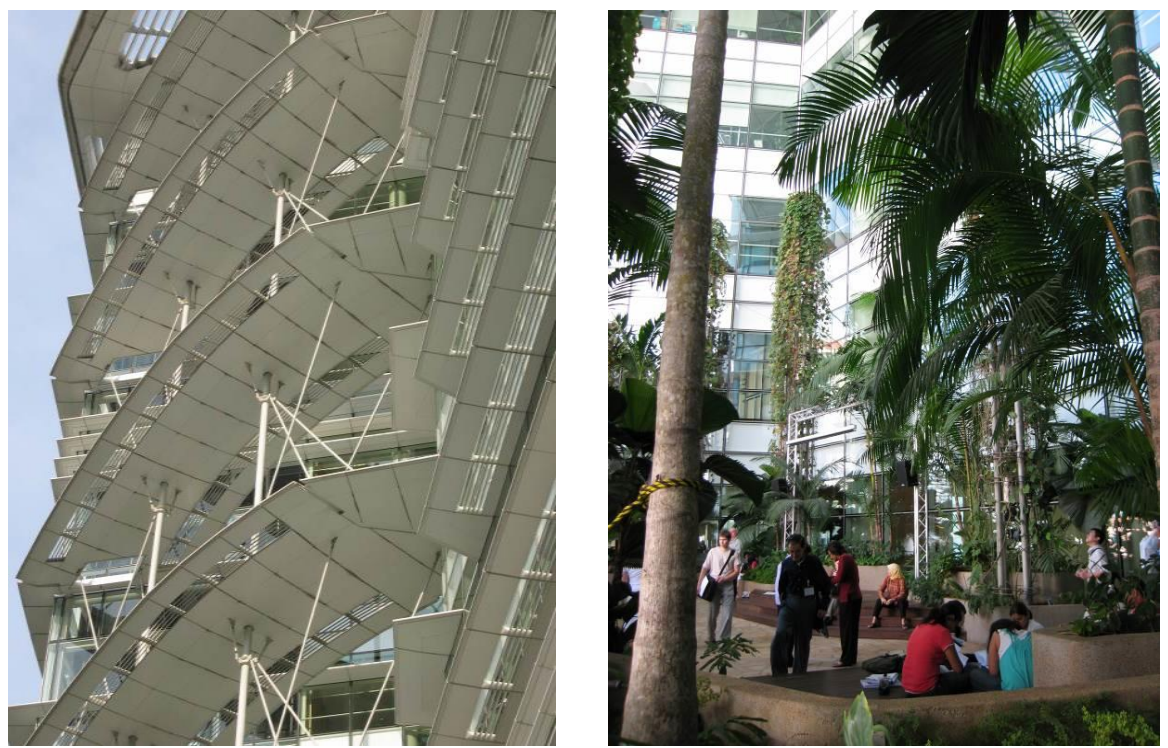

Figura 5 - Biblioteca Nacional de Cingapura. Recortes e detalhes do tratamento das fachadas e do tratamento paisagístico nos jardins em altura que contribuem para minimizar o ofuscamento provocado pelas cores claras, além de benefícios microclimáticos para o edifício e para o entorno (foto: Denise Duarte, nov. 2007)
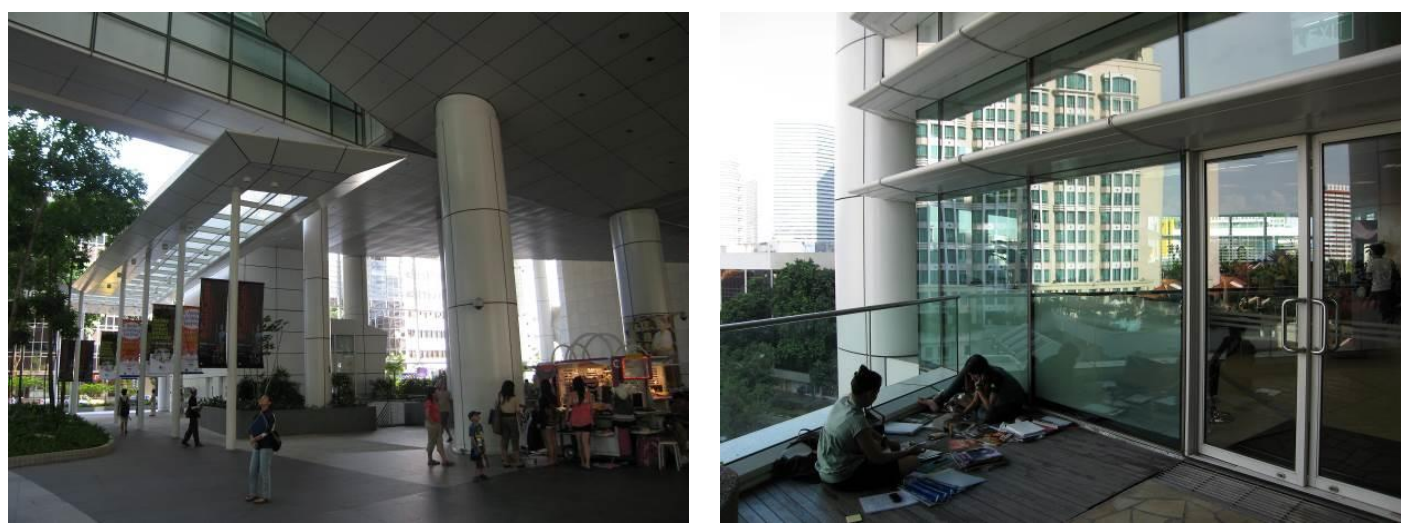

Figura 6 - Biblioteca Nacional de Cingapura. Espaços de transição interior/exterior no térreo e ao longo da altura do edifício (foto: Denise Duarte, nov. 2007) 
Uma variável importante para o microclima exterior (mas que afeta e muito as condições internas dos edifícios também), é a temperatura das superfícies (fachadas, coberturas, pisos e demais superfícies urbanas). Ela é resultado de uma série de processos tais como trocas radiativas, armazenamento de calor nos materiais e componentes, evaporação (se houver) e fluxos de calor turbulentos. Observações da temperatura de superfície podem revelar uma série de informações úteis para os estudos de clima urbano. No entanto, a complexidade das superfícies urbanas leva a uma dificuldade de obtenção de medidas representativas por causa do grande número de superfícies a serem levantadas. Esse levantamento passa a ser viável com o uso de sensoriamento remoto, em instrumentos portáteis a partir do nível do solo ou do topo de edifícios altos, acoplados a aviões ou satélites, com as correções necessárias em função de efeitos atmosféricos na transmissão de radiação para o instrumento e na refletividade da superfície à radiação (VOOGT, OKE, 2003), (Figura 7).
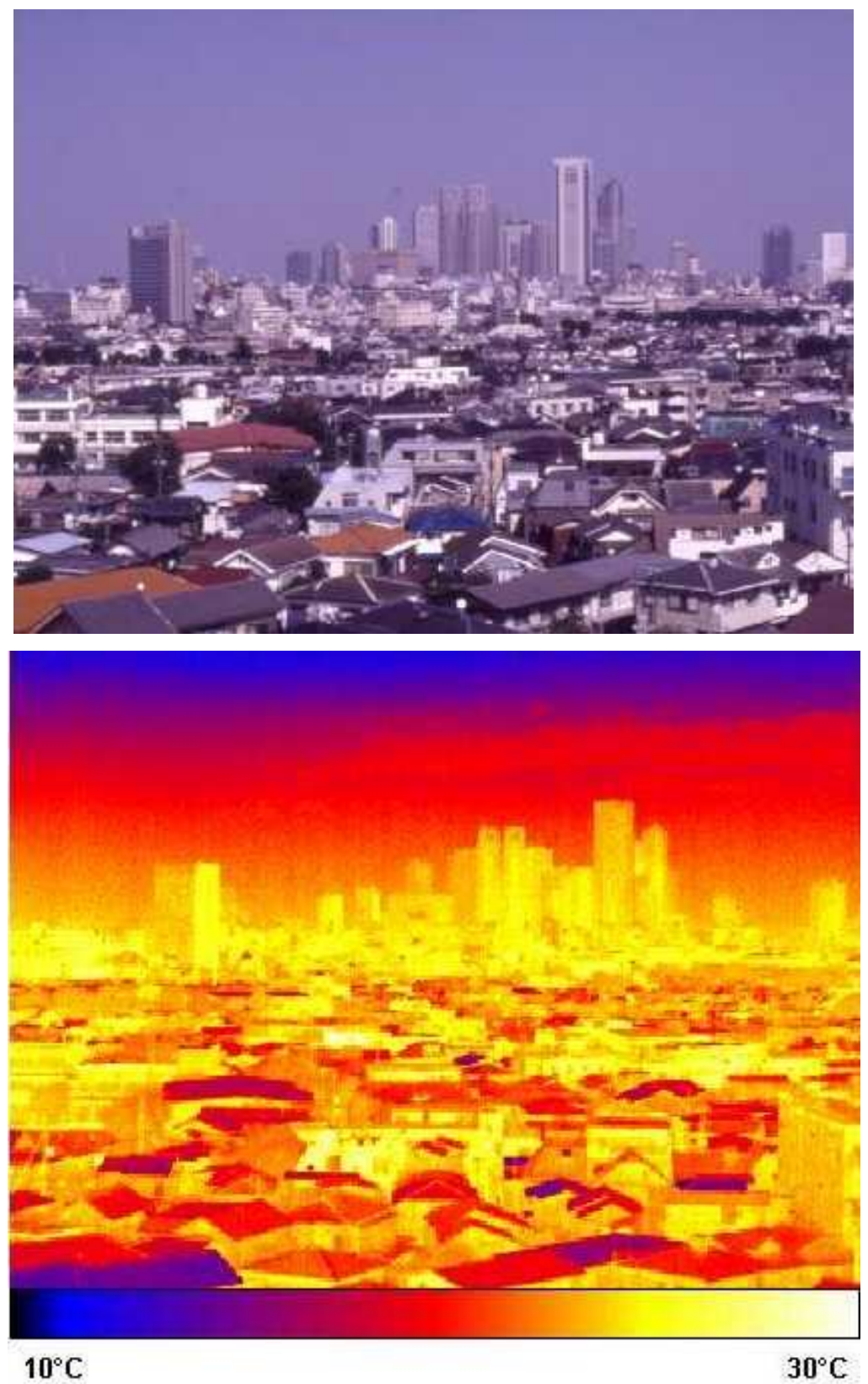

Figura 7 - Foto e imagem termal de um bairro residencial em Tóquio, Japão, com o skyline ao fundo. A imagem foi captada no final da tarde, quando as superfícies urbanas começam a se resfriar (Fotos: M. Roth, National University of Singapore). Disponível em: < http://publish.uwo.ca/ javoogt/urban\%20climate\%20.htm>. Acesso em: 24 de julho de 2015. 


\section{O impacto da vegetação nos microclimas urbanos}

\subsection{O papel da vegetação nas áreas urbanas adensadas}

Em geral, o crescimento urbano diminui o espaço para a vegetação nas cidades, e o ambiente urbano cria obstáculos ao plantio de novas árvores. Entre eles a compactação do solo, falta de espaço para as raízes, alocação de serviços na superfície e no subterrâneo, e a falta de gestão adequada da vegetação arbórea. Por essas razões, a vegetação é quase sempre escassa, mesmo em cidades tropicais, com a tendência de se substituir a vegetação natural e os solos permeáveis por superfícies impermeáveis, como asfalto e concreto, o que leva a um maior fluxo de calor sensível em relação ao calor latente.

Consequências da negligência quanto à infraestrutura verde e das águas, fatores estes que moderam o clima urbano, são evidentes: inundações severas e recorrentes, aquecimento excessivo das superfícies urbanas, baixa qualidade do ar e intensificação dos fenômenos de aquecimento urbano. Para um aumento na taxa de evaporação nas zonas urbanas é necessário o aumento da vegetação e dos cursos d'água, bem como a retenção de água da chuva (EMMANUEL, 2005).

A situação se agrava onde a terra é escassa e há pouca oferta de espaço para a incorporação da vegetação urbana; pressões sobre o uso do solo e o mercado imobiliário aquecido limitam o potencial para uma infraestrutura verde em larga escala (ONG, 2012). A integração da vegetação nos edifícios e em espaços urbanos densos enfrentam muitas restrições (CHEN; WONG, 2010), apesar de existir alguns casos de sucesso, como em Cingapura, com a adoção do Green Plot Ratio pela legislação local (ONG, 2002).

Em relação à cidade densa e informal, 29\% da população urbana global (quase 1 bilhão de pessoas) reside em assentamentos informais (DAVIS, 2007), sem condições mínimas de saúde, saneamento, serviços urbanos e qualidade nos espaços públicos. No Brasil, a população residente em assentamentos informais representa 6\% dos 190 milhões da população total, ou seja, mais de 11 milhões de pessoas (IBGE, 2010), o que corresponde à população do município de São Paulo. Na capital, 1,6 milhões de pessoas vivem em favelas, sendo aproximadamente 400.000 habitações (SÃO PAULO, 2010), em condições precárias de acesso solar, ventilação e falta de serviços públicos. Mesmo assim, é possível identificar iniciativas da população para incluir a vegetação de alguma forma, mesmo que em áreas muito pequenas, dispersas pelas comunidades (Figura 8).

$\mathrm{Na}$ cidade formal e informal, a vegetação pode estar presente em pequenos parques, hortas e pomares comunitários, parques lineares, parklets, paredes verdes, terraços e jardins, mesmo em ruas estreitas, becos e vielas. Além disso, a vegetação pode estar presente nas ruas, compondo espaços públicos de forma efetiva para os pedestres, ainda que com um caráter temporário em feiras, celebrações comunitárias ou práticas esportivas. Outros espaços de transição, tais como varandas e escadarias urbanas podem ser usados para incrementar a vegetação nos espaços entre os edifícios, sejam de uso público, semi-público ou privado, etc., sendo todos importantes do ponto de vista urbano e ambiental, como espaços de uso efetivo nas cidades, aumentando a presença da vegetação de caráter permanente ou temporário.

Quatro características das cidades contribuem para elevar as temperaturas: redução de resfriamento evaporativo, reabsorção da radiação refletida pelas superfícies verticais de edíficios/canyons urbanos, baixa refletividade das superfícies e emissão de calor entropogênico, sendo que as duas primeiras podem ser diretamente mitigadas por meio da vegetação. 

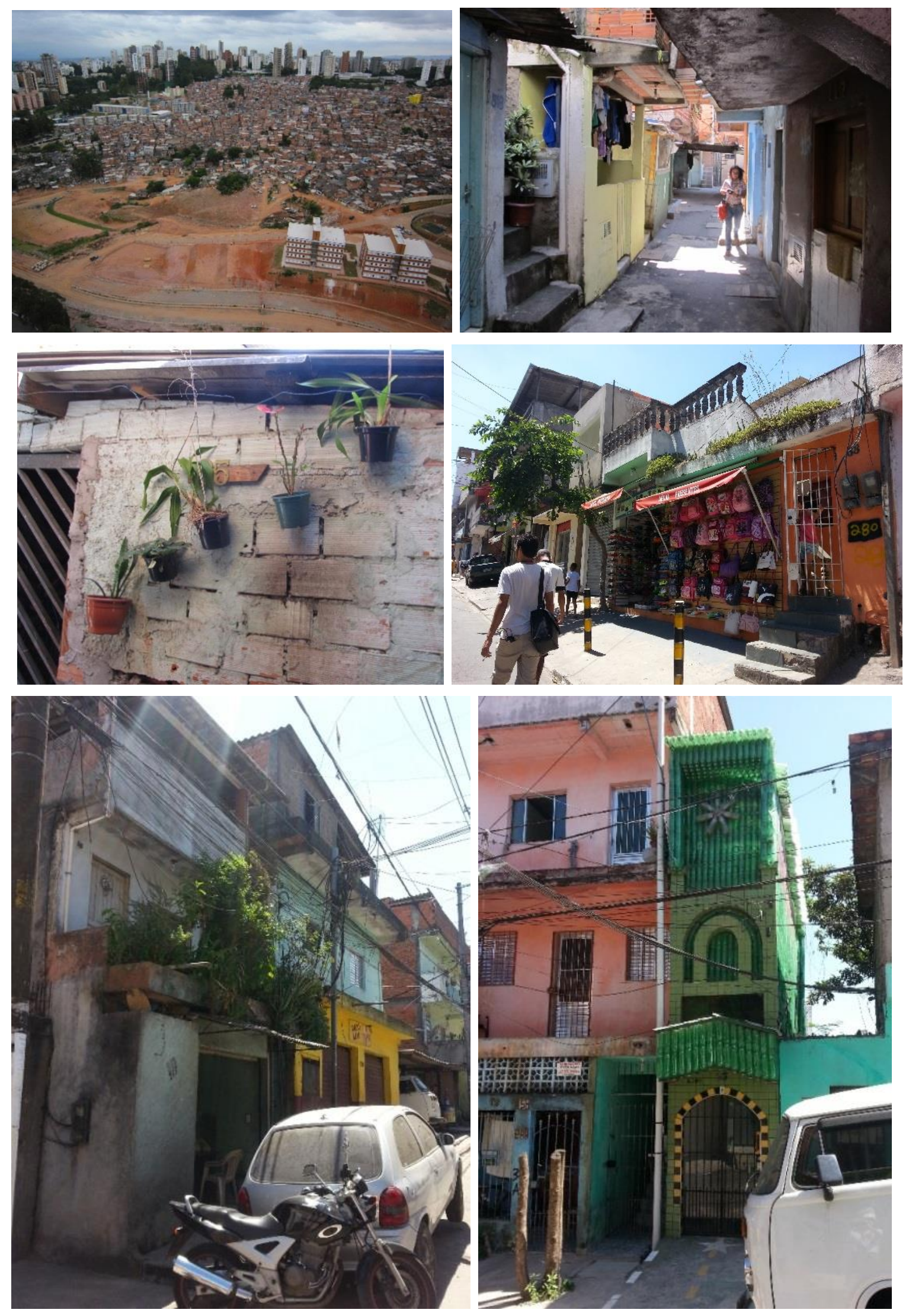

Figura 8 - No alto, à esquerda, desigualdades na distribuição do verde, contrastando a favela de Paraisópolis com o bairro do Morumbi, em São Paulo. Nas demais, percebe-se a inclusão do verde, de alguma forma, pelos moradores da comunidade. Na última imagem (à direita), de acordo com o morador, a intenção era sentir-se mais perto da natureza, usando garrafas PET verdes para construir parte da casa (Fotos: vista aérea de Luciana Ferreira, 2010; de dentro da comunidade, Eduardo Pizarro, 2013/2014) 
A presença de vegetação em áreas urbanas tende a reduzir as temperaturas máximas durante o dia, reduzindo as trocas radiativas na superfície do solo. O efeito da vegetação nos fenômenos de aquecimento urbano não se manifesta apenas indiretamente, sob a forma de uma redução do fluxo de calor sensível a partir das superfícies mais frias, mas também diretamente por meio do resfriamento evaporativo. A maioria dos estudos na área defendem o argumento de que a falta de vegetação na cidade tende a resultar na elevação da temperatura do ar durante o dia e, que concomitantemente, uma campanha de plantio de árvores em larga escala pode levar a uma redução do aquecimento diurno (ERELL et al., 2010).

Do ponto de vista microclimático, o problema não está relacionado ao tamanho da cidade em si, mas nos padrões de ocupação do solo, não apenas em cidades de alta densidade, pois as áreas de baixa densidade podem ser ainda piores para o aquecimento urbano. De acordo com Stone (2012), os dias extremamente quentes nas cidades americanas mais dispersas estão aumentando mais do que o dobro se comparados às cidades mais compactas, e as áreas urbanizadas de baixa densidade de ocupação podem ter uma influência significativa na formação da ilha de calor urbana, se estas apresentam grandes áreas pavimentadas, por exemplo.

De acordo com Wong e Chen (2009), o efeito de aquecimento urbano pode ser entendido como um resultado do conflito entre edifícios e clima urbano; considerando-se o impacto positivo da vegetação sobre este conflito, um modelo conceitual foi proposto pelos autores para se entender as interações entre o três componentes críticos no ambiente construído: clima, edifícios e vegetação. Sendo assim, a fim de se verificar os benefícios de vegetação no ambiente construído, os efeitos microclimáticos deveriam ser quantificados. Do ponto de vista do planejamento, pequenas áreas com vegetação, dispostas estrategicamente ou agrupadas em torno dos edifícios poderiam ser amplamente adotadas. Isso não significa que grandes parques urbanos não sejam eficazes em termos de melhoria do clima urbano, mas muitas vezes eles são considerados um 'luxo' em uma cidade adensada, especialmente nos casos em que a urbanização foi muito rápida.

Além disso, outras variáveis urbanas têm um efeito sobre o tipo, o tamanho e a qualidade da infraestrutura verde. Por exemplo, o padrão de ocupação e a topografia são fatores importantes para a disponibilidade e a qualidade dos espaços verdes urbanos. A rede viária e o índice de ocupação do solo pelos edifícios contribuem negativamente para a extensão do espaço verde (DAVIES et al., 2008); é por isso que outras formas de inserção da vegetação devem ser consideradas.

Nas cidades de alta densidade, uma outra possibilidade a ser explorada é a compatibilização da infraestrutura verde com diferentes formas de estacionamento nas vias e fora delas. Além disso, a distribuição e as formas de compartilhamento e do uso misto do sistema viário podem oferecer uma 'perspectiva verde,' incorporando a vegetação e outras formas de retenção de água da chuva, por exemplo. Nessa compatibilização, a infraestrutura verde agrega valor à cidade favorecendo a mobilidade urbana, incentivando as caminhadas, o uso de bicicletas e um sistema de transporte mais eficiente, como o exemplo do East London Green Grid em Londres ou o Green Cycle Routes de Copenhague, gerando uma rede interligada de ciclovias e caminhos para pedetres. ${ }^{39}$

Outro benefício da infraestrutura verde é a redução do consumo de energia nos edifícios, aumentando as possibilidades de operação em modo passivo e modo misto de climatização, especialmente em climas tropicais e subtropicais. As propriedades físicas e o balanço de energia e água da vegetação necessitam ser compreendidos e apropriadamente associados a modelos de simulação térmica e energética em edifícios (Building Energy Simulation - BES models). Por sua vez, esses modelos precisam incluir algumas variáveis da vegetação, como o Índice de Área Foliar - IAF, a

\footnotetext{
${ }^{39} \mathrm{Em}$ andamento no grupo, o doutoramento da Arq. MSc. Melissa Belato Fortes, investigando a necessária mudança de paradigma da mobilidade em prol do desenho urbano e do conforto do pedestre, sob orientação da Prof. Dra. Denise Duarte e co-orientação do Prof. Dr. Marcelo Giacaglia.
} 
geometria das árvores e as características do substrato, em conjunto com as demais trocas entre o edifício e o ambiente urbano.

\subsection{Benefícios da infraestrutura verde}

Bowler et al. (2010) apresentam uma revisão sistemática utilizada para investigar se as intervenções em áreas verdes, por meio do plantio de árvores, criação de parques ou colocação de telhados verdes, afetariam a temperatura do ar de uma área urbana. A maioria dos estudos investigou a temperatura do ar dentro dos parques e abaixo das copas das árvores, e os resultados indicaram que as áreas com vegetação apresentaram temperaturas do ar mais baixas. Em síntese, os resultados mostraram que, em média, um parque urbano é $0,94^{\circ} \mathrm{C}$ mais frio durante o dia, com base em dados observados nas áreas verdes existentes. Portanto, os autores sugerem que essa hipótese deve continuar sendo testada por meio do monitoramento dos programas de arborização urbana, incluindo a coleta de dados microclimáticos antes e depois da implementação da vegetação, incluindo localidades sem vegetação como 'grupo de controle.'

Um aspecto crucial sobre o valor microclimático dos parques urbanos é verificar se existe qualquer efeito sobre a temperatura do ar para a área do entorno, além dos limites do parque (BOWLER et al., 2010). Aqui é preciso distinguir o impacto acima e abaixo do dossel arbóreo, e também os benefícios para a meso e a microescala. Abaixo do nível da copa, os efeitos de sombreamento das árvores estão restritos aos limites do parque, e parte do efeito de redução da temperatura do ar e aumento da umidade pode ser estendido para poucos metros além do parque, dependendo da direção e da velocidade do vento. Chen e Wong (2006) estudaram dois grandes parques em Cingapura com temperaturas medidas a diferentes distâncias, até cerca de 500 metros da borda dos parques e, para ambos, as temperaturas aumentaram gradualmente com o aumento da distância dos limites do parque.

De acordo com Jauregui (1990-1991) os contrastes térmicos entre um grande parque ( $\sim 50$ hectares) e uma área urbana nas proximidades da Cidade do México apresentaram significativas taxas de resfriamento na área verde, com temperaturas de no mínimo $3-4^{\circ} \mathrm{C}$ mais baixas no parque, e sua influência atingiu uma distância aproximadamente igual à largura do parque (neste caso, de $2 \mathrm{~km}$ ).

Para pequenas áreas verdes em Tel-Aviv, Israel, o efeito de resfriamento estimado por Shashua-Bar e Hoffmann (2000) foi perceptível até aproximadamente $100 \mathrm{~m}$ de distância nas ruas do entorno e o efeito de resfriamento foi relativamente pequeno, cerca de $0,5^{\circ} \mathrm{C}$, em relação a uma redução média de até $3^{\circ} \mathrm{C}$ ao meio-dia, dentro do parque.

Estudos de Spronken-Smith e Oke (1998) em Vancouver (British Columbia, Canadá) e Sacramento (California, EUA), durante as condições de verão, adotaram uma combinação de temperatura da superfície medida por sensoriamento remoto e temperatura do ar a partir de uma estação fixa, além de transectos móveis (carro e bicicleta) para caracterizar a magnitude do resfriamento proporcionado pelo parque, chamado de 'park cool island' (PCl). Em Vancouver, os parques ficaram cerca de $1^{\circ} \mathrm{C}$ a $2^{\circ} \mathrm{C}$, e em condições ideais quase $5^{\circ} \mathrm{C}$, mais frios do que os seus arredores. $\mathrm{O}$ maior $\mathrm{PCl}$ foi possível em Sacramento, onde áreas verdes irrigadas podem ficar de $5^{\circ} \mathrm{C}$ a $7^{\circ} \mathrm{C}$ mais frias, devido ao contraste com as condições locais mais quentes e mais áridas. A influência dos parques na temperatura do ar nos arredores parece estar restrita a uma distância de cerca de uma vez a largura do parque, mas esses são efeitos de borda, sujeitos a incertezas.

Spronken-Smith e Oke (1998) concluem que a magnitude dos efeitos térmicos em parques irá variar dependendo do seu tipo e tamanho, da irrigação, da natureza do uso da terra no entorno e do clima em macroescala. A natureza desses controles não foi estudada de forma sistemática. Sabe-se relativamente pouco sobre a variação diurna de resfriamento dos parques. A maioria dos estudos vem de cidades com climas temperados, sendo que as aplicações mais urgentes seriam em climas tropicais e subtropicais. 
Estudos anteriores também mostram os efeitos de diferentes tipos de vegetação, particularmente a vegetação rasteira e a arbórea. O sombreamento das árvores é, sem dúvida, mais efetivo para a redução das temperaturas do ar; no entanto, as temperaturas de superfície também apresentam-se inferiores em áreas verdes não sombreadas mas com vegetação rasteira, o que sugere que o resfriamento por evaporação pode desempenhar um papel importante nesses casos. Uma caminho para a pesquisa é investigar a distância e quantificar os efeitos microclimáticos das áreas verdes, permitindo previsões futuras para diferentes extensões de vegetação e configurações espaciais (BOWLER et al., 2010).

De acordo com Spronken-Smith e Oke (1998) parques com árvores de copas densas têm o efeito PCI máximo no período da tarde. Jardins e parques do tipo savana têm o efeito PCl logo após pôr do sol, enquanto gramados abertos têm um $\mathrm{PCl}$ máximo próximo ao nascer do sol, devido à perda de radiação de onda longa para o fundo de céu. Estas observações sugerem que as árvores durante o dia podem desempenhar um papel importante no estabelecimento de um efeito de resfriamento pela vegetação, por meio da combinação de sombreamento e resfriamento evaporativo. À noite, verifica-se que o conteúdo de umidade no ar e a maior ou menor cobertura do dossel arbóreo são importantes fatores de controle para o resfriamento das superfícies. ${ }^{40}$

Giridharan et al. (2008) investigaram o impacto de variáveis locais sobre a influência da vegetação na redução da temperatura do ar em espaços abertos, em áreas de alta densidade em Hong Kong, e concluiram que a mera introdução de vegetação em áreas de alta densidade construída e com arranha- céus não leva a uma redução significativa da temperatura do ar em espaços abertos. A introdução de vegetação terá de ser cuidadosamente combinada com outras variáveis locais, tais como fator de visão do céu, para se alcançar resultados tangíveis. Os autores sugerem que qualquer futura pesquisa sobre o impacto da vegetação no efeito de ilha de calor em áreas de alta densidade deverá incorporar jardins suspensos e coberturas verdes na amostra. Tais estudos devem considerar a combinação de plataformas, jardins suspensos intermediários e coberturas verdes como mudanças necessárias em diferentes alturas para roporcionar melhor conforto térmico em áreas com arranhacéus e demais configurações de alta densidade. Modelos futuros também devem levar em conta variáveis fora do local, tais como densidade do entorno imediato e emissão de calor antropogênico. O estudo concluiu que o aumento da cobertura arbórea de $25 \%$ para $40 \%$ nos pocket parks em empreendimentos residenciais na costa de Hong Kong poderia reduzir a intensidade diurna da temperatura do ar em até $0,5^{\circ} \mathrm{C}$. À noite, o bloqueio de radiação de onda longa pela vegetação urbana é insignificante, segundo os autores, em comparação com o efeito de resfriamento provocado pelas plantas, mas indicam que essa questão precisa ser melhor investigada.

$\mathrm{Ng}$ et al. (2012), estudaram o impacto da vegetação no conforto térmico em um ambiente urbano de alta densidade como Hong Kong, realizando medições e estudos paramétricos para investigar quais os melhores locais, quantidade e tipos de vegetação para o contexto local. Para uma cidade como Hong Kong, que tem um índice elevado da relação entre altura das edificações e a largura de vias (height/width - H/W), o estudo revela que a vegetação nas coberturas é ineficaz para o conforto térmico humano próximo do solo. A vegetação arbórea também é indicada como mais eficaz do que as áreas gramadas para o resfriamento no nível do pedestre. Os autores concluíram que a proporção de área com vegetação arbórea necessária para diminuir a temperatura do ar em cerca de $1^{\circ} \mathrm{C}$ no nível do pedestre é de aproximadamente $33 \%$ da área urbana, quando a taxa de ocupação dos edifícios for de $44 \%$, que é o valor médio da cidade. Por outro lado, percebe-se que nem o plantio de árvores ou grama nas coberturas, nem a inclusão de gramados no nível do solo são soluções eficazes para o resfriamento do ambiente para os pedestres, em meio aos arranha-céus e à alta densidade urbana de Hong Kong. Na melhor das hipóteses, eles podem ser benéficos na medida em que contribuem menos para aquecimento do ambiente urbano, se comparados aos materiais artificiais. A altura dos edifícios tem uma implicação sobre os benefícios na redução da temperatura do ar com o

40 Discutido com mais detalhes no capítulo 7. 
plantio no topo dos edifícios. Quando a relação entre a altura do edifício sobre a largura da via for superior a 1, o benefício obtido pelo efeito do resfriamento é pequeno. É importante, portanto, que o plantio de árvores seja feito o mais próximo possível do nível onde as atividades humanas se concentram.

Medições de campo por Shashua-Bar e Hoffman (2004) mostraram que algumas ruas e bulevares arborizados na área de Tel-Aviv, Israel, apresentavam temperaturas do ar de 1 a $2,5^{\circ} \mathrm{C}$ menores do que as ruas sem vegetação, no período mais quente do dia, às $15 \mathrm{~h}$. Aplicando o modelo ENVI-met para o clima de Thessaloniki, na Grécia, Chatzidimitriou et al. (2005) encontraram uma pequena diminuição da temperatura do ar para ruas arborizadas (menos de $1{ }^{\circ} \mathrm{C}$ ), mas até $20^{\circ} \mathrm{C}$ nas temperaturas de superfície e mais de $40^{\circ} \mathrm{C}$ nas temperaturas radiantes médias. Constatou-se que o efeito de resfriamento foi proporcional ao número de árvores. No clima quente e seco de Ghardaia, Argélia, Ali-Toudert e Mayer (2007) verificaram que o sombreamento das árvores poderia melhorar consideravelmente o conforto térmico nas ruas. Em outro estudo de simulação de diferentes cenários de vegetação usando o ENVI-met para o Rio de Janeiro, Spangenberg (2004) estimou que um aumento da quantidade de vegetação urbana (cobertura arbórea de $30 \%$ do solo e $100 \%$ de coberturas verdes) poderia quase que recriar as condições confortáveis de uma floresta natural.

Combinando o modelo de mesoescala BRAMS e do modelo de microescala ENVI-met, Johansson et al. (2013) simularam o microclima de seis tecidos urbanos diferentes em um dia típico de verão em São Paulo. A temperatura do ar simulada e a umidade relativa do ar foram semelhantes em todas as áreas, enquanto que a velocidade do vento e a temperatura radiante média variou significativamente entre as áreas e seu interior. O desconforto térmico foi especialmente ruim em áreas não sombreadas; por outro lado, áreas com solo natural e um fechamento completo pela copa das árvores foi a situação mais confortável. Ficou demonstrado que a arborização nas vias melhorou significativamente o conforto térmico em áreas edificadas e com vegetação, e a diferença entre áreas de gabarito baixo e as de edifícios mais altos foi diminuída. O sombreamento melhorou nas áreas sem vegetação, especialmente nos locais dos edifícios altos; no entanto, para áreas com árvores nas ruas, a orientação solar teve menor importância.

Considerando-se valores diferentes para o índice de área foliar (IAF), que é um importante parâmetro biofísico da vegetação que será discutido mais adiante neste capítulo, Shinzato e Duarte (2012) investigaram o efeito da densidade de folhas na temperatura do ar e de superfície no nível do pedestre em São Paulo. Com base em medições de IAF no Parque do Ibirapuera, três valores de IAF $(1,3,5)$ foram selecionados para a simulação no modelo de microescala ENVI-met nos cenários paramétricos. $O$ modelo considera que o IAF é conhecido e a densidade de área foliar (DAF) pode ser calculada através da integração de valores do IAF. Árvores densas (IAF = 5) mostraram uma redução média de $14,7^{\circ} \mathrm{C}$ para a temperatura de superfície entre a área verde e a rua, bem como $10^{\circ} \mathrm{C}$ para árvores com $\mathrm{IAF}=3$, e $5^{\circ} \mathrm{C}$ para árvores com $\mathrm{IAF}=1$. Em relação à temperatura do ar, as diferenças abaixo das árvores densas (IAF $=5)$ e sobre a rua são de até $1,3^{\circ} \mathrm{C}$, similar à diminuição da temperatura local registrada em levantamentos de campo.

Em São Paulo, os microclimas de um parque, uma praça e um canyon no centro da cidade foram medidos em um dia de verão. O objetivo foi estudar o efeito do sombreamento das árvores com diferentes densidades foliares no microclima, e o conforto térmico em espaços públicos. A medição de campo mostrou que o parque ficou até $2^{\circ} \mathrm{C}$ mais frio do que a praça e o canyon. $\mathrm{O}$ efeito do sombreamento das árvores para o canyon foi simulado para o mesmo dia, utilizando o ENVI-met. Os resultados mostraram que a incorporação de árvores nas vias do canyon teve um efeito de resfriamento limitado na temperatura do ar (até $1,1^{\circ} \mathrm{C}$ ), mas obteve uma redução significativa na temperatura superfície (até $12^{\circ} \mathrm{C}$ ), bem como uma grande redução na temperatura radiante média no nível do pedestre (até $24^{\circ} \mathrm{C}$ ). Os resultados mostram que, entre os três casos simulados, o canyon coberto com copas menos densas (IAF $=1$ ) e mais densas (IAF $=5$ ) apresenta, em média, $0,5^{\circ} \mathrm{C}$ e $1,1^{\circ} \mathrm{C}$, respectivamente, na redução das temperaturas do ar, em relação ao caso base, sem árvores. Embora as árvores tenham reduzido a velocidade do vento em até $45 \%$ dos valores máximos, o 
conforto térmico teve uma melhora considerável, uma vez que o índice Physiologically Equivalent Temperature - PET (HÖPPE, 1999a; 1999b) foi reduzido em até $12^{\circ} \mathrm{C}$ (SPANGENBERG et al., 2008).

Diferenças dessa magnitude para a temperaturas do ar e de superfície são percebidas pelo corpo humano, e podem afetar positivamente a sensação de conforto térmico em climas tropicais e subtropicais. A sensação térmica pode ser estimada com a aplicação de índices de conforto para espaços abertos, tais como PET ou Temperatura Equivalente Percebida - TEP (MONTEIRO; ALUCCI, 2011), desenvolvido empiricamente para as condições locais da cidade de São Paulo, indicando uma redução de aproximadamente $10^{\circ} \mathrm{C}$ ou mais por meio do sombreamento de árvores.

Em resumo, pode-se concluir que o efeito microclimático da vegetação abaixo do dossel e na área do entorno pode parecer pequeno e espacialmente restrito, mas é significativo para o microclima urbano e o conforto humano; verifica-se que áreas verdes menores, conectadas, ainda que separadas por pequenos intervalos, são preferíveis para um resfriamento mais eficaz do ambiente urbano do que poucas áreas verdes de maior porte, porém, mais espaçadas entre si.

\subsection{Balanço de energia e propriedades da vegetação}

A presença de vegetação influencia dois mecanismos que buscam contrabalançar o aquecimento urbano: sombreamento e evapotranspiração (AKBARI et al., 2001; WONG; CHEN, 2009.). Para ser mais preciso, a vegetação mitiga o aquecimento urbano não por resfriar o ar, mas por se aquecer menos do que as superfícies inertes.

As árvores podem provocar uma diminuição da temperatura do ar, devido ao efeito combinado de sombreamento e evapotranspiração. Normalmente, reduções da temperatura do ar variam de $1^{\circ} \mathrm{C}$ a $3^{\circ} \mathrm{C}$ e podem ser alcançadas abaixo do dossel das áreas verdes, dependendo das condições climáticas e do solo. As maiores diferenças nos efeitos do resfriamento podem ser explicadas quando ocorre um maior resfriamento pela evapotranspiração, devido às condições climáticas mais secas do entorno.

Do ponto de vista do microclima, a vegetação é importante devido às suas propriedades no balanço de energia. Para se avaliar os efeitos da vegetação no microclima urbano, a interação entre solo, vegetação e a atmosfera deve ser entendida por meio da dinâmica associada entre clima e vegetação (BONAN, 2010). Apenas dessa forma é possível responder a perguntas aparentemente simples (mas que exigem interações muito complexas), tais como: Qual é a magnitude dos efeitos da vegetação no microclima urbano? Como o efeito é distribuído espacialmente? Qual é o tamanho da área de influência de um parque urbano? A que distância das áreas verdes poderiam os benefícios microclimáticos ser sentidos? Como quantificar o impacto do sombreamento, das aberturas na copa (gap fraction) por passa a radiação solar, da geometria da árvore e das características do solo?

Geralmente, a disponibilidade da água e o aumento da evaporação resultam na redução das temperaturas superficiais. No entanto, o efeito da vegetação é bastante complexo, e varia com o tipo de planta, condições meteorológicas e hora do dia. Sob certas condições, um parque urbano pode até ser um pouco mais quente do que a área urbana no entorno. $O$ armazenamento de energia nas plantas, ao contrário do ocorre nas superfícies inertes, tem duas componentes distintas: de armazenamento de calor físico e de armazenamento de calor bioquímico, devido ao processo de fotossíntese e a troca de $\mathrm{CO}_{2}$ (ERELL et al., 2010).

O efeito global depende do balanço hídrico e energético da vegetação, e as trocas de energia e de massa entre a vegetação e a atmosfera têm reguladores associados a aspectos da estrutura e da fisiologia. A taxa de evapotranspiração pelas plantas está diretamente relacionada à quantidade de estômatos na superfície das folhas. Os estômatos estão localizados na superfície das folhas, e fazem a ligação entre a atmosfera e o interior das plantas. O processo de fotossíntese é resultado da abertura dos estômatos, uma vez que, durante o dia, estes estão abertos para receber e eliminar $\mathrm{CO}_{2}$, funcionando como válvulas, expondo, assim, a umidade no interior das folhas (OKE, 1987). 
Relações energéticas que originam e mantêm o calor, a umidade e as trocas bioquímicas são movidas por uma fonte primária de energia - a radiação solar, complementada pela radiação de onda longa a partir de estruturas da vegetação e outras superfícies adjacentes. Além disso, a troca de calor latente ocorre não apenas como resultado da evaporação ou condensação na superfície do solo, mas, em grande parte devido à transpiração das folhas da copa.

Sombreamento e evapotranspiração dependem da estrutura física do dossel, e da interação entre solo / vegetação / atmosfera. Resultados do sombreamento na atenuação da radiação solar sob a copa das árvores são determinados pela geometria da árvore e sua densidade de folhas, que constituem a base dos principais métodos indiretos de caracterização da cobertura vegetal. A densidade das folhas é um indicador de troca gasosa (oxigênio e dióxido de carbono), bem como a perda de vapor de água pela transpiração.

Muitos dos benefícios ecológicos de plantas surgem de seus processos biológicos. A intensidade destes processos biológicos está ligada à densidade de folhas, muitas vezes expressa pelo IAF. Este é um parâmetro dinâmico que indica a taxa de crescimento de uma planta, com mudança nos valores de acordo com as estações. É um índice que prevê variações, visto que a densidade foliar difere de planta para planta dentro de uma mesma espécie e durante seu crescimento; e até mesmo de um lugar para outro ao longo do dossel da planta durante os períodos de medição (ONG, 2015).

Diferentes definições de IAF foram revisadas por Jonckheere et al. (2004), a partir do conceito de Watson (1947) que definiu o IAF como sendo: "one-half of the total leaf area per unit ground surface area," sendo uma variável adimensional $\left(\mathrm{m}^{2} / \mathrm{m}^{2}\right)$. Para Chen e Black (1992), o IAF é: "half the total intercepting (non-projected) area per unit of ground surface area." Jonckheere et al. (2004) também observaram que as variações entre as definições podem resultar em diferenças significativas entre os valores de IAF calculados.

O IAF influencia o microclima dentro e abaixo da copa, determinando a intercepção de água, a extinção de radiação e as trocas gasosas no dossel. O IAF é um parâmetro chave em modelos que descrevem a troca de fluxos de energia, massa (como, por exemplo, água e $\mathrm{CO}_{2}$ ), e momentum entre a superfície e a camada limite planetária.

O IAF mede a quantidade de material foliar (tecido fotossintético) em um ecossistema, o que define controles importantes sobre fotossíntese, respiração, interceptação da chuva e outros processos que relacionam a vegetação ao clima. Consequentemente, o IAF aparece como uma variável-chave em muitos modelos descrevendo as interações vegetação/atmosfera, particularmente no que diz respeito aos ciclos de carbono e água. $O$ interesse nas informações sobre a distribuição do IAF e suas mudanças tem crescido substancialmente nas últimas décadas, devido à sua importância e a capacidade de se estimar esse índice em grandes áreas utilizando medições por satélite (FAO, 2009).

A importância do uso do IAF está no fato dele ser um denominador comum em muitos dos efeitos ecológicos das plantas. A chave para entendê-lo encontra-se primeiro no entendimento do papel da IAF na intercepção da luz solar por meio da copa das árvores. A quantidade de radiação solar interceptada por um dossel é representada matematicamente pela lei de Beer-Lambert, que modela a transmissão de luz através da copa, utilizando uma função exponencial ligando o IAF e o coeficiente de extinção da copa - K. O valor de $\mathrm{K}$ depende de vários fatores, incluindo a transparência da folha e o ângulo da folha em relação à luz do sol. O produto k.IAF é aplicado para calcular a taxa de fluxo de energia através das folhas. Esta relação exponencial pode ser considerada como uma equação geral que descreve a absorção de um fluxo (energia - por exemplo, luz, vento, chuva) passando por um meio permeável (dossel). Isto não só descreve a quantidade de luz solar que penetra na copa, mas também permite o cálculo do efeito de resfriamento do ar pela transpiração das folhas. A maior parte da energia térmica utilizada pela planta é absorvida através da transpiração, uma vez que envolve o calor latente de evaporação da água, que é de cerca de seis vezes a energia necessária para aquecer a mesma quantidade de água de $0^{\circ} \mathrm{C}$ até o ponto de ebulição. Uma quantidade muito 
menor de energia é absorvida pela massa da planta, de modo que, em geral, a temperatura resultante na superfície da folha é próxima da temperatura do ar (ONG, 2015).

A copa das plantas tem um gradiente vertical de luz solar relacionada com a quantidade de folhas. A luz solar que atinge uma folha individualmente é absorvida, refletida ou transmitida pela folha. Como a copa torna-se mais densa com as folhas, mais radiação solar é absorvida ou refletida e menos é transmitida no interior do dossel. Um modelo simples de transferência radiativa mostra que a radiação solar diminui numa função exponencial do índice de área foliar. $\mathrm{O}$ coeficiente de extinção $\mathrm{k}$ depende, em parte, da folha e do ângulo de orientação zenital. Estes afetam o ângulo em que o feixe solar atinge uma folha, e a radiação recebida por unidade de área é maior quando o feixe está perpendicular em relação à superfície. Apenas para se ter uma ideia geral, um IAF típico para uma floresta produtiva é 4-6 (BONAN, 2010). Valores típicos de IAF estão presentes nas Tabelas 1 e 2, e foram levantados adotando-se duas técnicas diferentes, detalhadas posteriormente neste capítulo.

Tabela 1 - Valores de IAF quantificados com o analisador de dossel (LAI 2000 Plant Canopy Analyser, Li-Cor)

Fonte: dados compilados por Shinzato

\begin{tabular}{|l|c|c|}
\hline \multicolumn{1}{|c|}{ Tipologias de vegetação } & IAF & Referências \\
\hline Arbustos em Cingapura & $3.5-4.0$ & Tan, Sia (2010) \\
\hline Palmeiras isoladas em Cingapura & $2.5-4.0$ & Tan, Sia (2010) \\
\hline Árvores isoladas na Alemanha & 4.5 (valor médio) & Barclay et al. (2000) \\
\hline Árvores isoladas em Cingapura & $2.5-4.0$ & Tan, Sia (2010) \\
\hline Parque em São Paulo & 2.5 (valor médio) & Shinzato et al. (2013) \\
\hline Floresta de Eucaliptos no Brasil & 2.86 (valor médio) & Xavier et al. (2002) \\
\hline Floresta de Eucaliptos em Kerala, India & 2.75 (valor médio) & Kallarackal, Somen (1997) \\
\hline Floresta de Eucaliptos na Austrália & 4.1 (valor médio) & Vertessy et al. (1995) \\
\hline Floresta de Coníferas no Canada & $3.32-4.06$ & Barclay et al. (2000) \\
\hline Floresta de Coníferas no Canada & $3.1-6.7$ & Chen et al. (2006) \\
\hline
\end{tabular}

Tabela 2 -- Valores de IAF quantificados com a técnica de fotos hemisféricas

Fonte: dados compilados por Shinzato

\begin{tabular}{|l|c|c|}
\hline \multicolumn{1}{|c|}{ Tipologias de vegetação } & IAF & Referências \\
\hline Cultura (milho) na França & $0.4-2.9$ & Demarez et al. (2008) \\
\hline Cultura (trigo) na França & $0.2-3.4$ & Demarez et al. (2008) \\
\hline Floresta de Eucaliptos na Austrália & 4.4 (valor médio) & Vertessy et al. (1995) \\
\hline Floresta de Coníferas no Canadá & -3.2 to 4.8 & Zhang et al. (2005) \\
\hline Floresta de Coníferas no Canadá & -3.5 to 4.0 & Chen et al. (2006) \\
\hline Parque em São Paulo & 2.1 (valor médio) & Shinzato et al. (2013) \\
\hline Floresta Tropical em Sumatra, Indonésia & $3.9-6.1$ & Trichon et al. (1998) \\
\hline Floresta Tropical em Borneo, SE Asia & $4.8-6.8$ & Kumagai et al. (2004) \\
\hline Floresta Amazônica no Brasil & $3.6-6.6$ & Aragão et al. (2005) \\
\hline
\end{tabular}

O IAF não é a única variável que determina o comportamento das plantas no ambiente. Outros fatores como a orientação das folhas e a geometria do dossel afetam a extinção da radiação na copa (JONES, 2014) e, consequentemente, os impactos sobre o microclima. Além da própria árvore, o microclima resultante depende do entorno, edificado ou não, artificial ou natural, considerando-se as interações entre solo, superfície (natural ou construída) e atmosfera. 


\subsection{Medição e modelagem da infraestrutura verde}

\subsubsection{Modelos que incluem a vegetação}

No campo meteorológico, alguns modelos de balanço de energia urbanos incorporam a vegetação na paisagem urbana, a fim de modelar as interações locais (LEMONSU et al., 2012). Um desses modelos é o Vegetated Urban Canopy Model - VUCM (LEE; PARK, 2008), que leva em conta a presença e efeitos da vegetação nos cálculos dinâmicos, de radiação e energia. Bons resultados foram obtidos através da avaliação do modelo para experimentos de campo para Vancouver e Marselha. VUCM é um modelo de dossel urbano desenvolvido para modelagem meteorológica em mesoescala. A geometria urbana é composta de edifícios simples homogêneos caracterizados pela relação entre altura e largura do canyon urbano $(\mathrm{H} / \mathrm{W})$, bem como do canyon com vegetação, caracterizado pela quantidade de folhas e o perfil de densidade de área foliar.

Mais recentemente uma versão do Town Energy Budget - TEB (MASSON, 2000) foi desenvolvido considerando-se a vegetação, o TEB-Veg (LEMONSU et al., 2012). A vegetação é inserida diretamente dentro do canyon, permitindo o sombreamento da grama pelos edifícios. As trocas da superfície em relação à vegetação são integradas, a fim de se considerar as interações entre coberturas naturais e construídas, tornando possível utilizar qualquer tipo de vegetação. Baseiam-se pela primeira vez em novos cálculos de radiação para um canyon composto por uma parte do sistema viário e parte da vegetação. A orientação da via e o comportamento térmico das fachadas também foram introduzidos no modelo. Esta abordagem leva em conta os efeitos do sombreamento pela vegetação. As trocas de superfície entre a vegetação e a atmosfera são, então, calculadas, considerando-se a radiação de ondas curtas e longas de fato recebidas pela vegetação, bem como as condições microclimáticas (temperatura, umidade e vento) dentro do canyon, em lugar das condições acima da copa. Por outro lado, o microclima dentro do canyon é resolvido incluindo-se as contribuições da vegetação nas trocas de calor, umidade e momentum. Os resultados demonstram o valor da combinação entre superfícies impermeáveis e verdes para ambientes urbanos, que incluem uma parcela significativa de vegetação.

Novos avanços melhoraram a primeira versão, levando em conta outros tipos de vegetação urbana. Além da parametrização voltada à vegetação de pequeno porte em canyons urbanos (LEMONSU et al., 2012) a versão TEB-Veg agora inclui coberturas verdes (MUNCK et al., 2013), em um módulo chamado GREENROOF para avaliar o desempenho hidrológico e de energia. Estudos em andamento de Redon et al. (2014) sobre os efeitos termorradiativos e aerodinâmicos das árvores nas vias, interagindo com os edifícios, estão sendo desenvolvidos para uma parametrização no TEB-Veg, a partir da escala do bairro até a escala da cidade.

A partir do modelo Cluster Thermal Time Constant Model - CTTC (SWAID, HOFFMAN, 1990), ShashuaBar e Hoffman $(2002,2004)$ propuseram o modelo Green CTTC, incluindo os efeitos térmicos do sombreamento das árvores no modelo analítico CTTC, provenientes das trocas da radiação solar. Esse modelo investiga o impacto climático das árvores em relação às propostas alternativas de desenho urbano. No modelo CTTC, a temperatura do ar prevista de um cluster é calculada por meio da contribuição do calor recebido a partir de fontes externas. O cluster é definido no modelo como um agrupamento entre edifícios, vias, pátios, praças e espaços arborizados. Os efeitos microclimáticos referem-se particularmente ao resfriamento da temperatura do ar na presença de árvores durante os dias de verão. Usando uma abordagem do balanço de energia, o processo térmico é obtido principalmente por meio das mudanças na insolação do espaço aberto urbano, expressa por: (1) redução do ganho solar devido à obstrução da radiação pela copa das árvores; (2) consumo de energia pela evapotranspiração na copa das árvores; e (3) alteração no calor armazenado na área com vegetação, que durante o dia é expressa pelo aumento da temperatura da superfície das folhas.

Um projeto internacional, realizado em duas fases, avaliou trinta e dois tipos de superfície do solo urbano, desenvolvidos com diferentes abordagens. Para modelar as trocas para um ambiente 
urbano, o Land Surface Models - LSMs varia de uma representação relativamente simples do ambiente urbano como uma laje impermeável, a modelos que levam em conta a geometria 3D de edifícios com diferentes alturas e as características dos materiais. O local da fase 1, uma área industrial em Vancouver, British Columbia, no Canadá, teve uma área de vegetação muito menor que o local da fase 2, em Preston, subúrbio de Melbourne, na Austrália. As conclusões mostraram que considerar ou não a cobertura vegetal resulta em um impacto significativo no desempenho do modelo, indicando que mais pesquisas precisam ser feitas para melhorar as simulações do fluxo de calor latente (GRIMMOND et al., 2010; GRIMMOND et al., 2011).

Todos esses modelos meteorológicos de mesoescala trazem grandes avanços, mas ainda estão distantes de arquitetos e urbanistas. Conforme apontado por Wong et al. (2011), também é bastante difícil para os planejadores tentar conceber projetos sem envolver os cientistas voltados para os estudos do clima urbano. As prioridades atuais voltadas para o desenvolvimento urbano sustentável têm incentivado os planejadores urbanos a examinar os vários parâmetros da modelagem do clima urbano e incorporá-las no planejamento e desenho das cidades. Mesmo compreendendo a importância das interações entre a morfologia e a condição do microclima nas cidades, falta ainda, para muitos, o conhecimento básico da climatologia urbana. Engajar cientistas voltados ao estudo do clima urbano para avaliar diferentes alternativas tem contribuído para os trabalhos de projeto e planejamento, mas, até o momento, o processo de projeto urbano tem sido, em muitos casos, dissociado do processo de avaliação de impacto e análise dos resultados.

Para superar esta lacuna, Wong et al. (2011) propuseram uma plataforma de desenho urbano de fácil utilização, com o objetivo de gerar um mapa de conforto térmico urbano em que a temperatura do ar, ventos e as camadas expostas à radiação solar são analisadas em conjunto com uma plataforma de Sistemas de Informação Geográfica - SIG. Planejadores poderiam, então, analisar os níveis de conforto esperados e fazer mudanças no projeto nos locais onde existe o desconforto térmico.

Uma abordagem mais simples em estudos exploratórios na área de planejamento urbano é baseada na análise de regressão simples ou múltipla que busca compreender os fenômenos - entre eles as variáveis da vegetação. Os modelos de regressão normalmente conectam as variáveis microclimáticas às variáveis urbanas, tais como coeficiente de aproveitamento, taxa de ocupação, porcentagem de áreas verdes (geralmente descrita como a projeção horizontal de copa das árvores) e superfícies com água. Um desses estudos foi realizado para o clima tropical continental no Brasil, sob condições quentes muito severas. Com base nas correlações, um indicador empírico foi proposto (DUARTE, 2000; DUARTE; SERRA, 2003; DUARTE, 2010), a fim de orientar a proporção entre áreas edificadas e áreas verdes, visando à amenização de condições microclimáticas urbanas, para o caso de Cuiabá - MT.

Giridharan et al. (2008) adotaram uma técnica de regressão múltipla que abrange seis variáveis críticas locais: albedo da superfície, fator de visão do céu, altitude, cobertura arbustiva, cobertura arbórea e H/W, para efetuar análises em cinco conjuntos de dados para edifícios altos e adensados em empreendimentos residenciais na costa de Hong Kong, com o objetivo de avaliar a influência da vegetação na redução da temperatura do ar em espações abertos. A cobertura das árvores ou arbustos indicados nesse estudo é a área de folhagem visualmente projetada de cobertura arbustiva ou arbórea no plano horizontal e expressa como uma porcentagem de $1000 \mathrm{~m}^{2}$ de área no entorno dos pontos de medição.

Com base em análise de regressão múltipla (WONG; JUSUF, 2008a; WONG; JUSUF, 2008b; WONG; JUSUF, 2009) foi proposto um modelo empírico denominado Screening Tool for Estate Environment and Evaluation - STEVE, calibrado para as condições de Cingapura, considerando o ponto de vista da arquitetura e do desenho urbano. Inicialmente integrada como um plug-in no ESRI ${ }^{\oplus}$ ArcGIS Desktop, a versão atual usa o Trimble Sketch-up, com o objetivo de preencher a lacuna entre um modelo de previsão complexa e a linguagem dos planejadores urbanos (JUSUF; WONG; TAN, 2014). STEVE é um aplicativo web que calcula as temperaturas mínima, média e máxima do ar de um ponto de interesse, 
para a condição existente e condição futura. É possível se alterar a quantidade de vegetação, de superfícies inertes e de edifícios e, consequentemente, calcular a temperatura do ar prevista. Quando usado junto com SIG, mapas de temperatura do ar podem ser gerados e os pontos mais quentes podem ser identificados, permitindo que o aplicativo seja utilizado por arquitetos, planejadores urbanos e órgãos governamentais; permite também avaliar os ganhos de calor de um edifício como critério na certificação Singapore Greenmark. ${ }^{41}$

As variáveis independentes do STEVE podem ser classificadas em (JUSUF; WONG, 2009):

- Descritores do clima: Temperatura mínima diária (Ref Tmin), média (Ref Tavg) e máxima (Ref Tmax) num ponto de referência; média de radiação solar diária (SOLAR). Para o SOLAR, foi utilizada a média do total da radiação solar diária (SOLARtotal) em modelos Tavg, enquanto a média da radiação solar máxima diária (SOLARMAX) foi utilizado no modelo de Tmax. O SOLAR não é aplicável para o modelo de Tmin.

- Descritores da morfologia urbana: porcentagem de área pavimentada acima de 50m (PAVE), índice médio da relação altura/ área construída (HBDG), área total da superfície da fachada (WALL), Green Plot Ratio (GnPR), fator de visão do céu (sky view fator - SVF) e albedo médio da superfície (ALB).

A velocidade do vento foi excluída no desenvolvimento do modelo, uma vez que ele se limita a condições de calmaria, evitando as questões de turbulência.

Entre as abordagens anteriores, muitos estudos sobre o impacto da vegetação no microclima urbano foram possíveis por meio do modelo ENVI-met (BRUSE; FLEER, 1998), que teve as versões iniciais criadas em 1994. O ENVI-met é um dos modelos micrometeorológicos mais promissores e um dos que mais se aproxima das aplicações no planejamento urbano, especialmente na versão atual, ENVIMET V4 Preview. No entanto, o uso do modelo requer algum conhecimento sobre micrometeorologia, e pode demandar muitos recursos computacionais, dependendo da área simulada e da heterogeneidade urbana.

O ENVI-met é um modelo não-hidrostático tridimensional para a simulação das interações entre superfície-vegetação-atmosfera, não exclusivamente para, mas especialmente destinado a ambientes urbanos, com uma abordagem avançada para interações entre plantas e atmosfera. 0 ENVI-met é um dos poucos modelos que procura descrever os processos climáticos mais importantes que atuam no ambiente urbano, incluindo turbulência, transporte turbulento de calor sensível e latente, fluxos de radiação dentro das estruturas urbanas e a influência da vegetação. Com base na posição do sol, na geometria urbana, na vegetação, no solo e nos materiais de construção, o modelo simula aerodinâmica, termodinâmica e o balanço de radiação em estruturas urbanas complexas, com resolução de $0,5 \mathrm{~m}$ a $10 \mathrm{~m}$, por meio da resolução de equações termodinâmicas e fisiológicas da planta (BRUSE; FLEER, 1998; HUTNNER, 2012). Tem um período de tempo típico de $24 \mathrm{~h}$ a $48 \mathrm{~h}$ com um intervalo de tempo de 10 segundos, no máximo. Esta resolução permite a análise das interações em pequena escala entre edifícios, superfícies e vegetação. Usa a Densidade de Área Foliar (DAF) em vez do IAF para calcular a fisiologia das plantas, e o modelo considera que o IAF é conhecido e a DAF pode ser calculada através da integração de valores do IAF (JONCKHEERE, 2004).

No que diz respeito à avaliação do efeito de sombreamento das plantas, o ENVI-met considera vegetação como um meio turvo e calcula a transmitância da vegetação em função do percurso óptico do feixe do raio solar através das folhas e do índice de área foliar (YANG et al., 2013). Avanços no módulo de vegetação ALBERO foram apresentados na V4 Preview, lançada recentemente em uma fase de testes.

\footnotetext{
41 Disponível em: http://www.stevetool.com/. Acesso em: junho de 2015.
} 
O ENVI-met simula a influência da vegetação no microclima, considerando não apenas o efeito do sombreamento pelas copas, mas também o processo fisiológico da evapotranspiração pelas plantas, cujo efeito pode ser calculado no modelo por meio dos seguintes métodos: uma abordagem simples baseada nos estudos de Deardorff (1978) e outra abordagem mais sofisticada chamada modelo A-gs proposto por Jacobs (1994). O método por Deardorff estima o valor máximo da resistência estomática com relação à entrada de radiação solar e disponibilidade de água no sistema, enquanto o modelo A-gs calcula a taxa de fotossíntese das plantas, de acordo com a concentração de $\mathrm{CO}_{2}$ na atmosfera e no interior das folhas (BRUSE, 2015).

O modelo considera o parâmetro Densidade de Área Foliar - DAF para descrever a densidade e a distribuição das folhas na copa, sendo também a variável utilizada para se estimar a fisiologia das plantas. O DAF é um parâmetro definido como: "the total one-sided leaf area $\left(\mathrm{m}^{2}\right)$ per unit layer volume $\left(\mathrm{m}^{3}\right)$ in each horizontal layer of the tree crown" (LALIC; MIHAILOVIC, 2004). A distribuição do DAF pode ser obtida por medições de campo e abordagens analíticas, especialmente se o Índice de Área Foliar - IAF é conhecido (BRUSE, 2015). O perfil dos valores de DAF no ENVI-met pode ser calculado integrando-se os valores de IAF, conforme Lalic e Mihailovic (2004).

Dentre vários novos recursos apresentados na V4 Preview, o modelo de cálculo inclui a representação em 3D da vegetação, incluindo a modelagem do balanço hídrico dinâmico das espécies. O ENVI-met define plantas verticais simples, mas também permite geometrias complexas de vegetação 3D, como árvores de grande porte. Todas as plantas são tratadas como espécies individuais com um controle no balanço hídrico integrado, dentro do conceito de reação ao calor e estresse hídrico. A temperatura das folhas é calculada por meio da resolução do balanço de energia da superfície da folha em relação às condições meteorológicas e fisiológicas de plantas reais para cada ponto da grade de modelagem (grid box) do dossel da planta. Dentre outros fatores, o estado de saúde da planta e o fornecimento de água pelo solo regulam a taxa de transpiração, assim como a temperatura da folha.

O ENVI-met usa um sofisticado modelo para simular o comportamento dos estômatos da vegetação em resposta ao microclima, disponibilidade de $\mathrm{CO}_{2}$ e o nível de estresse hídrico. A vegetação interage de várias formas com o meio ambiente: calor e vapor são trocados entre as folhas e a atmosfera. A água perdida pela transpiração é extraída do solo pelo modelo hidráulico utilizando a distribuição do sistema radicular da planta. Um algoritmo de raytracing complexo é usado para analisar o impacto das plantas na radiação solar (projeção de sombra) e nas trocas da radiação de onda longa (proteção térmica). Os efeitos da vegetação são incluídos como forças de arrasto no campo de vento. Esses efeitos são considerados em todos os fluxos radiativos. Paredes e coberturas de edifícios atuam principalmente como superfícies trocando calor com a atmosfera, mas também podem atuar como fontes de umidade se for aplicada vegetação na fachada ou na cobertura. ${ }^{42}$

No ENVI-met V4 Preview, a ferramenta forcing foi incorporada e agora é possível se definir a variação diurna das condições de contorno atmosféricas e da radiação incidente. O Simple Forcing permite que os perfis de temperatura e umidade do ar sejam incorporados em vinte e quatro valores horários. Ele também permite o desenvolvimento de cenários climáticos muito mais detalhados, com a finalidade de testar o modelo, e verificar se os resultados gerados estão de acordo com as medições de campo.

Embora já tenha sido aplicado para diferentes climas com bons resultados, a calibragem do modelo com medições microclimáticas e dados da vegetação local é necessária para se compreender melhor as questões relacionadas às particularidades do clima e do padrão de urbanização, e para se obter resultados mais confiáveis.

O ENVI-met V4 Preview também pode fazer uma estimativa aproximada do desempenho energético do edifício. No entanto, essa estimativa seria adequada apenas para o projeto conceitual de edifícios,

42 Disponível em:<www.envi-met.com>. Acesso em 22 de julho de 2015. 
pois seu principal domínio de análise está voltado para o efeito externo (YANG et al., 2013). As saídas adicionais do modelo incluem dados climáticos dinâmicos ao longo das fachadas e coberturas, trocas de energia nas fachadas do edifício e termodinâmica das paredes. O modelo calcula de forma dinâmica a variação da temperatura interna do edifício como um resultado dos fluxos de entrada e de saída por meio dos segmentos associados de parede e de teto. Esta simulação energética do edifício é executada paralelamente à simulação do microclima exterior para cada edifício dentro da modelagem, de forma que um feedback constante entre as condições climáticas exteriores e interiores e das interações entre edifícios é informado. A versão atual também permite que seja elaborado um modelo de zoneamento inicial para se definir seções do edifício e zonas térmicas. ${ }^{43}$

Outra abordagem possível é associar o ENVI-met com modelos de simulação de desempenho térmico e energia de edifícios, os Building Energy Simulation (BES) models, tais como o Energy Plus em uma plataforma de acoplamento do tipo Building Controls Virtual Test Bed (BCTVB). Esta simulação de acoplamento unidirecional poderia beneficiar o desenvolvimento contínuo de ambos os modelos. No entanto, dados os custos computacionais do ENVI-met, é necessário escolher uma resolução do modelo apropriada de acordo com os objetivos da pesquisa ou das fases de concepção, levando-se em conta as disparidades entre os modelos com diferentes configurações numéricas e as diferenças entre os modelos físicos (YANG et al., 2013).

Outros esforços para se considerar a vegetação em modelos BES estão começando a surgir e de fato incorporando as propriedades da vegetação ou tentando emular o seu efeito, principalmente nas coberturas e fachadas. Um exemplo é um modelo de base física do balanço energético de uma cobertura com vegetação integrado ao Energy Plus. Esse módulo inclui opções de projeto do telhado verde, incluindo propriedades do substrato e sua profundidade, bem como características da vegetação, como, por exemplo, o tipo da vegetação, sua altura e o índice de área foliar (SAILOR, 2008).

Esse modelo considera: troca radiativa de onda longa e onda curta no dossel da planta, efeitos do dossel vegetal sobre a transferência de calor por convecção, evapotranspiração do solo e das plantas, condução de calor e armazenamento do mesmo na camada de solo. A capacidade de monitorar propriedades térmicas dependentes de umidade ainda não foi implementada devido a problemas de instabilidade no esquema Conduction Tranfer Function - CTF, mas está em desenvolvimento para uso com o sistema de solução de diferenças finitas disponibilizado no Energy Plus a partir da versão 2. 0 usuário pode especificar vários aspectos da construção do teto verde, incluindo profundidade do substrato, propriedades térmicas, densidade da copa, altura da planta, condutância estomática (capacidade para transpiração) e as condições de umidade do solo, incluindo irrigação. A formulação do modelo inclui: 1) o balanço de umidade simplificada que considera a precipitação, a irrigação e o transporte de umidade entre duas camadas de solo, na parte superior e na zona de raiz; 2) balanço de energia do solo e do dossel da planta; 3 ) equações da superfície do solo e temperatura das folhas são resolvidas simultaneamente a cada time step, invertendo a CTF para se extrair informações de fluxo de calor para o cálculo do balanço de energia (EnergyPlus, 2014). ${ }^{44}$

As diversas tentativas de simular o efeito da vegetação em edifícios sem considerar suas propriedades incluem mudanças no albedo, ou valores estimados de resistência térmica $(R)$ do componente construtivo para as coberturas verdes com base em medições de campo. Wong et al. (2003) utilizaram o DOE-2 para simular o impacto de um terraço jardim no consumo de energia dos edifícios, combinando dados de campo medidos para calcular a resistência térmica do componente construtivo coberto com três tipos de vegetação: turfas, arbustos e árvores. A estimativa dos valores

\footnotetext{
43 Idem.

44 Disponível em:< http://apps1.eere.energy.gov/buildings/energyplus/pdfs/engineeringreference.pdf>. Acesso em 22 de julho de 2015. Atualizado em 25 de setembro de 2014.
} 
de $R$ equivalentes foi baseada em dados coletados nas medições de campo de um jardim no terraço de um edifício comercial de baixa altura em Cingapura.

Mais tarde, Wong et al. (2007) usaram o TAS - Thermal Analysis Software (EDSL) para avaliar o desempenho de um jardim no terraço em relação à economia de energia para o resfriamento do edifício, introduzindo os valores de R calculados anteriormente para os mesmos tipos de vegetação, baseados em medições de campo.

\subsubsection{LAI - técnicas de medição e instrumentação}

Existem dois principais procedimentos para obtenção do IAF: métodos diretos e métodos indiretos. $O$ primeiro grupo mede a área foliar de forma direta, enquanto o segundo grupo calcula o IAF de parâmetros mais facilmente mensuráveis, considerando-se o tempo dispendido, o trabalho necessário e a tecnologia disponível. Os métodos diretos são utilizados como fonte de calibração para técnicas de medição indiretas, principalmente, porque eles são extremamente demorados e, portanto, o que torna a sua implementação em larga escala praticamente inviável (JONCKHEERE et al., 2004;. GOWER et al., 1999;. JONES, 2014).

Métodos indiretos em que a área foliar é inferida a partir de observações de outra variável são geralmente mais rápidos, passíveis de automação e, assim, permitem que uma amostra espacial maior seja obtida. Por razões de conveniência, quando comparados com os métodos diretos, estes estão se tornando cada vez mais utilizados. Métodos indiretos de determinação do IAF in situ podem ser divididos em duas categorias: (1) medições de IAF de contato indireto; (2) medições indiretas sem contato. As medições de campo em geral são aplicadas para uma única árvore (Jonckheere et al., 2004).

Métodos ópticos são métodos indiretos sem contato, e são os mais utilizados. Baseiam-se na medição por transmissão de luz e radiação através da copa. Estes métodos aplicam a lei de BeerLambert, já mencionada anteriormente, considerando que a quantidade total de radiação interceptada por uma camada do dossel depende da irradiância incidente, da estrutura da copa e de suas propriedades ópticas. Envolvem medidas de campo da transmissão total, transmitância direta e/ou difusa da radiação que chega até a superfície do solo (JONCKHEERE et al., 2004).

A medição do IAF por transmissão de luz através da copa pode ser obtida por fotos hemisféricas ou sensores portáteis. Estes métodos ainda podem ser divididos em dois grupos, dependendo se medem a distribuição do gap fraction (proporção em área das manchas iluminadas por radiação solar direta abaixo do dossel) ou a distribuição do gap size (a distribuição do tamanho dessas manchas). Os instrumentos fornecem dados que representam a distribuição do IAF de um ponto específico, ao longo de uma linha, ou referente uma área, conforme ocorre para as medições com as imagens hemisféricas (FAO, 2009).

Para a distribuição de gap fraction, que é a proporção do dossel em que o raio solar não é bloqueado pelas folhas, os instrumentos existentes empregam técnicas de análise da imagem ou medições com diferenças de luz e radiação acima e abaixo do dossel. O IAF máximo medido é geralmente mais baixo para esses equipamentos de medição por gap fraction do que os métodos diretos, e atingem um nível de saturação no IAF próximo a 5. A causa provável para isso é uma saturação do gap fraction conforme o IAF se aproxima de 5 ou 6 . Uma ampla pesquisa comparando medições diretas e indiretas de IAF foi apresentada nos estudos de Gower et al. (1999).

Para a distribuição de gap size, os instrumentos disponíveis medem as dimensões das aberturas na superfície da copa que são diretamente iluminadas pela radiação solar. Procedimentos analíticos e de medidas de apoio são utilizados para converter as medições em valores de IAF. O método por fotos hemisféricas é uma dessas técnicas. Entre os sensores, alguns instrumentos disponíveis são comercializados pela Accupar, Demon e Li-Cor, que calculam o IAF comparando medições de luz acima e abaixo da copa. 
As medições indiretas sem contato não distinguem tecido foliar fotossinteticamente ativo de outros elementos da planta, tais como tronco, galhos ou flores, e as correções são, portanto, necessárias. Outro fator importante que deve ser considerado é a sobreposição das folhas que leva a um IAF subestimado; métodos de correção também têm sido desenvolvidos para compensar este efeito (WEISS et al., 2004; JONCKHEERE et al., 2004).

Embora os dispositivos ópticos sejam muitas vezes utilizados para se estimar o IAF, a sua quantificação é feita a partir do gap fraction e de um modelo de distribuição do ângulo das folhas; o gap fraction é a medida básica destes instrumentos ópticos e o cálculo do IAF a partir do gap fraction é outra questão importante na determinação por modelos indiretos de medição (JONCKHEERE et al., 2005). A maioria dos instrumentos baseados no gap fraction determinam o que chama de IAF efetivo (Effective $L A l$ ) com a suposição de uma distribuição espacial aleatória das folhas, que não é válida para todos os casos, e subestimam o IAF quando as folhas na copa não são aleatoriamente distribuídas, ou seja, estão agrupadas (clumped). Chen e Black (1992) usaram o termo IAF efetivo para descrever o IAF estimado opticamente. Esta nomenclatura parece ser mais adequada porque reconhece que os modelos convencionais são incapazes de medir a área de superfície composta unicamente pelas folhas e, também, de compensar o posicionamento não-aleatório de elementos do dossel (JONCKHEERE et al., 2004).

O registro de imagens hemisféricas do dossel é uma outra técnica para se estudar a copa das plantas, por meio de uma lente grande angular (fish-eye lens) abaixo do dossel (orientada para o zênite) ou colocada acima do dossel, fotografando para baixo. Além disso, o uso de lentes grande angular permite que o gap fraction seja avaliado em todas as direções, o que aumenta a precisão do IAF gerado, e existe um potencial para caracterizar a distribuição azimutal das folhas e as variações para o arranjo não aleatório das folhas. Além disso, também é possível obter estimativas do índice de área foliar para árvores que crescem em terrenos inclinados (JONCKHEERE et al., 2005). De início, a câmera e a lente são calibrados para se definir o centro ótico e a função de projeção. Em seguida, cada imagem é tratada e pré-processada no modelo. Os valores de brilho no pixel para a banda azul são extraídos de cada imagem RGB para se alcançar o máximo de contraste entre a folha e o céu, porque a absorção pelas folhas é máxima e a dispersão pelo céu tende a ser maior nessa faixa (JONCKHEERE et al., 2005; GONSAMO, PELLIKKA, 2009). Procedimentos adicionais devem ser aplicados a fim de se identificar o nível de contraste ideal para distinguir a vegetação do céu (WEISS, 2010).

Em resumo, os vários métodos in situ de obtenção do IAF e os resultados obtidos têm sido descritos nas referências bibliográficas da área, e vários testes de comparação para inter-relacionar os estudos já foram realizados. Cada método tem seus pontos fortes e fracos e, portanto, são mais aplicáveis em algumas circunstâncias do que outras. Embora um consenso pareça existir sobre a utilidade e aplicabilidade das diferentes abordagens, não há padrões definidos ou aceitos; no entanto, as diretrizes comuns têm sido muitas vezes desenvolvidas e utilizadas por equipes de pesquisa colaborando em programas mais amplos de investigação em vários países (FAO, 2009).

Cada sistema tem seus detalhes específicos de medição e a escolha deve considerar as condições locais para os estudos. Os equipamentos portáteis conhecidos como analisadores de dossel são mais adequados para árvores isoladas, ao passo que as imagens hemisféricas são mais adequadas para uma configuração de um grupo de árvores. Neste último caso é obtido o IAF médio para uma determinada área, e não apenas para uma única árvore. Outro fato a ser considerado é que, quando se usam os analisadores de dossel, mesmo com as capas restritoras para mascaramento das áreas indesejadas, pode ocorrer um IAF superestimado se comparado com o IAF obtido a partir da imagem hemisférica, uma vez que a leitura do analisador de dossel considera não apenas as folhas, mas outros elementos, tais como galhos e tronco (SHINZATO, DUARTE, 2013).

Além dos métodos ópticos acima referidos, podem ser adotadas técnicas de sensoriamento remoto. Os sensores registram diferenças espectrais entre vegetação e solo, expressa, por exemplo, pelo 
Índice de Vegetação por Diferença Normalizada (Normalized Difference Vegetation Index - NDVI), que registra as diferenças de refletância espectral entre o vermelho e o infravermelho próximo, e que pode ser usado como uma métrica para se obter a cobertura vegetal ou para estimar o índice de área foliar (JONES, 2014).

Quando o IAF é obtido a partir das medições por sensoriamento remoto, ao se inverter um modelo de transferência de radiação, o seu valor corresponde a um valor efetivo ligado à resolução espacial particular dessas medidas. A conversão de medidas geométricas para valores efetivos torna-se um passo essencial e requer informação adicional sobre a estrutura e arquitetura da copa, como por exemplo, as distribuições do gap size, nas resoluções espaciais (FAO, 2009).

Devido à variabilidade espacial e temporal do IAF, as informações necessárias para estudos de mudanças climáticas só podem ser obtidas através de medições de sensores ópticos de satélite. A experiência acumulada ao longo da última década mostra que os sensores com pelo menos uma banda espectral no domínio azul (além do usual vermelho e infravermelho próximo) proporcionam produtos de qualidade muito superior porque permitem correções atmosféricas mais precisas (FAO, 2009). Como a resolução espacial varia entre bandas de satélites (amostragem espacial de cerca de 1 km ou mais), esta técnica é geralmente adequada para grandes áreas, mas não é capaz de inferir o IAF para árvores urbanas individuais ou até mesmo pequenos parques urbanos. 


\section{Material e método}

Ao longo dessa trajetória foram utilizadas individualmente ou, principalmente, de forma combinada, diferentes estratégias de pesquisa e, consequentemente, diferentes materiais e métodos, em função das restrições e recursos materiais e humanos disponíveis em cada etapa (SERRA, 2006).

Visando à uma finalidade didática, descreve-se aqui, brevemente, em uma perspectiva histórica, os materiais e métodos utilizados em três períodos distintos da pesquisa ao longo do percurso profissional e acadêmico descritos neste trabalho, bem como o encadeamento entre eles, que reflete a evolução dos mesmos, sendo:

- no início desta trajetória de pesquisa, ainda durante o doutoramento e os primeiros anos na FAUUSP;

- em um segundo momento, no início da formação do grupo de pesquisa;

- mais recentemente, já com o grupo mais consolidado, e que expressa os materiais e métodos adotados na atualidade, podendo o leitor ir diretamente a este tópico.

\subsection{Durante o Doutoramento e os primeiros anos na FAUUSP}

Esta construção do conhecimento se iniciou na pesquisa para o doutoramento Padrões de Ocupação do Solo e Microclimas Urbanos. Estudo de caso em clima tropical continental, realizada de 1996 a 2000 (DUARTE, 2000), usando a estratégia de estabelecer correlações para melhor entendimento dos fenômenos, quando as variáveis de interesse (urbanísticas e microclimáticas) foram observadas e medidas/quantificadas em áreas urbanas sob determinadas circunstâncias que ocorreram naturalmente, neste caso, sob os pontos de vista climático e do padrão de urbanização. Para este primeiro estudo, dentro da região de clima tropical continental, que predomina no Centro-Oeste do Brasil, optou-se por trabalhar com amostras de condições ambientais urbanas da cidade de Cuiabá MT por diversos motivos, incluindo o conhecimento prévio da pesquisadora e do então orientador sobre a cidade, e a condição climática quase que de laboratório a céu aberto, com trocas convectivas minimizadas pelo clima local, o que realçava ainda mais o papel do padrão de ocupação sobre o clima urbano, além dos seguintes fatores:

- localização em área tropical continental, sem influência marítima, onde já foi detectada a influência do uso do solo urbano na ocorrência de ilhas de calor no trabalho de Maitelli (1994);

- o fato da zona urbana estar situada em uma depressão geográfica faz com que a frequência e a velocidade média dos ventos seja extremamente baixa, minimizando o efeito das trocas térmicas por convecção e ressaltando ainda mais a influência do espaço construído sobre a temperatura do ar, o que acaba gerando condições praticamente ideais para este tipo de experimento;

- o porte médio da cidade e suas altas taxas de crescimento. Em 2000 o aglomerado urbano Cuiabá / Várzea Grande totalizava 698.644 habitantes (IBGE, 2003);

- em Cuiabá encontram-se amostras de desenho urbano acompanhando cada período de sua história, gerando uma grande variedade de padrões de ocupação. É um exemplo de cidade do período colonial que foi se modernizando e se adaptando às suas novas funções, diferentemente de outras antigas capitais de estado como Ouro Preto e Goiás Velho, por exemplo, que foram substituídas por novas capitais planejadas - Belo Horizonte e Goiânia - respectivamente.

Em estudos exploratórios, para o estabelecimento de correlações observam-se variáveis que ocorrem naturalmente, quando as variáveis de interesse não podem ser manipuladas, mas sim, observadas e medidas (GROAT, WANG, 2013). Pela natureza do trabalho envolvido, foi adotada uma amostragem não probabilística, e sim, uma amostragem orientada, buscando-se representar os diferentes padrões de ocupação urbana na cidade. Foi feita uma análise tipológica de padrões de 
ocupação da cidade expressos por coeficiente de aproveitamento, taxa de ocupação, projeção horizontal de copas de arvores e superfícies d'água, tendo como variável dependente a temperatura do ar externo. Na época havia limitações no número de equipamentos disponíveis, de equipe para as medições ainda com equipamentos analógicos e dependentes de leituras visuais, sujeitas a eventuais erros. Foram monitoradas temperatura e umidade do ar em sete áreas de estudo, sendo duas no entorno de estações fixas, do Instituto Nacional de Meteorologia e da Universidade Federal de Mato Grosso, e cinco com instrumentos analógicos abrigados, com um par de termômetros de mercúrio formando um psicrômetro, durante uma semana cada, no verão e no inverno.

Partindo-se de diferentes densidades construídas na cidade afetam os microclimas e, pelo seu efeito cumulativo, determinam a modificação do clima regional pela urbanização. É conveniente, então, substituir o parâmetro população usado em alguns modelos para tratar os fenômenos climáticos urbanos (OKE, 1973a) por densidade construída, por esta apresentar uma relação causal mais forte com o aquecimento urbano (GIVONI, 1998), e por ser mais permanente e possível de ser quantificada.

$\mathrm{Na}$ tentativa de resolver algumas destas questões, os primeiros estudos propostos por esta autora foram concluídos em 2000, para as condições climáticas da região tropical continental brasileira (DUARTE, 2000; DUARTE, SERRA, 2001; DUARTE, SERRA, 2002; DUARTE, SERRA, 2003), estabelecendo correlações lineares simples entre a temperatura do ar e algumas variáveis de planejamento que podem ser regulamentadas pela legislação municipal (taxa de ocupação, coeficiente de aproveitamento, arborização e superfícies d'água) e fazendo a proposição de um indicador a fim de orientar as medidas necessárias para amenizar o rigor climático nas cidades da região tropical continental.

A proposta era o estabelecimento de correlações lineares simples entre a temperatura do ar e algumas variáveis de planejamento que poderiam ser regulamentadas pela legislação municipal (taxa de ocupação, coeficiente de aproveitamento, arborização e superfícies d'água). Por fim, foi feita a proposição de um indicador visando orientar as medidas necessárias para amenizar o rigor microclimático de áreas urbanas. $O$ indicador proposto é compatível com altas densidades urbanas, necessárias a qualquer proposta de planejamento mais sustentável. A ideia é equilibrar a maior densidade construída com os elementos naturais (vegetação e água), espalhados por toda a cidade, adicionando trocas de calor latente, em oposição ao predomínio de trocas sensíveis que caracterizam o balanço de energia da maioria das áreas urbanizadas, e atuando, assim, como amenizadores das condições microclimáticas locais.

Após ser testado em outras cidades e validado, esse indicador poderia ser usado para ajustar a proporção recomendada entre o espaço construído e os elementos naturais (vegetação e água) em cidades existentes ou para o planejamento de novas áreas de ocupação, bairro a bairro.

O estabelecimento de tal correlação já havia sido tentado por Sampaio (1981), cujo objetivo era sistematizar metodologicamente um caminho que permitisse aferir e explicitar possíveis correlações entre as variáveis do uso do solo e as ilhas de calor para o caso de Salvador, verificando a existência da correlação e determinando o grau de associação entre as variáveis. Sampaio usou como variável dependente a temperatura do ar e como variáveis independentes o uso do solo e as condições do meio físico. Pelos resultados encontrados, Sampaio concluiu que a intensidade de uso do solo não poderia ser apontada como tendo uma correlação linear com a variação de temperatura na cidade de Salvador, invalidando a hipótese inicial em termos de significação numérica; o autor afirma ainda que Salvador não se encaixa no modelo de Oke (1973a) para relacionar a intensidade da ilha de calor à população. Apesar disso, Sampaio conseguiu comprovar contrastes entre áreas edificadas e áreas livres nas temperaturas máximas e médias.

O resultado do trabalho de Sampaio (1981) mostrava a dificuldade de se isolar a variável uso do solo para demonstrar a ocorrência da ilha de calor. Na época o autor não conseguiu comprovar a hipótese para o caso de Salvador com os dados de microclimas urbanos medidos e os índices urbanísticos 
utilizados, talvez por condições climáticas atípicas durante o curto período de medições, por ter medido somente no período diurno e, principalmente, pelo fato de que cidades litorâneas, sujeitas a ventos de grande intensidade que aumentam as trocas térmicas por convecção, são menos sujeitas à influência da forma urbana sobre a temperatura do ar, o que acontece com muito menor intensidade em cidades tropicais continentais, sob condições de céu claro e calmaria. Com o aumento da velocidade do vento diminui a tendência da temperatura na zona urbana ser superior à dos arredores.

Algumas críticas a este trabalho foram levantadas na época, questionando a inadequação do uso de modelos empíricos frente aos modelos de balanço de energia, propostos pela meteorologia desde a década de 1970. Concordei plenamente com o maior rigor dos modelos baseados no balanço de energia, mas que na época ainda eram muito distantes da arquitetura e do urbanismo. Naquele momento, o papel do trabalho era explorar outras possibilidades, principalmente se estas contribuíssem para a aproximação entre as áreas da meteorologia e do planejamento urbano. Esse distanciamento entre as duas áreas é, com certeza, uma das grandes lacunas a serem preenchidas neste campo do conhecimento. Essas críticas faziam também uma analogia com o uso de modelos de balanço em recintos fechados. Acredita-se, porém, que não se pode também fazer uma comparação sem ressalvas entre os modelos de balanço de energia usados para conforto em edifícios e para conforto urbano, pois as duas áreas estavam em estágios bem diferentes de pesquisa e desenvolvimento. O conforto térmico em edifícios tem décadas de pesquisa, com um grau de compreensão dos fenômenos e de amadurecimento superiores aos estudos para áreas urbanas dentro da arquitetura e do planejamento, que são muito mais recentes e, em muitos casos, incipientes.

Por outro lado, o estabelecimento de correlações simples, como as que foram levantadas na primeira etapa deste estudo, é uma prática de pesquisa encontrada na produção de diversos autores, como Givoni (1998), Taha (1988), Mizuno (1990/91), Santos, Lima e Assis (2003), só para citar alguns, na exploração de novas possibilidades.

Na época, a opção em se utilizar variáveis comuns ao planejamento e às legislações municipais foi consciente, principalmente depois de algumas experiências de trabalho junto às prefeituras. A opção final por estas variáveis foi um dos pontos mais discutidos de todo esse trabalho porque, ao mesmo tempo em que se procurava representar da maneira mais fiel possível as relações causais entre o tecido construído e o fenômeno de aquecimento urbano, buscava-se uma linguagem mais acessível às equipes de planejamento das prefeituras, para que o resultado fosse compreendido por arquitetos e planejadores e pelos demais agentes envolvidos nos processos de decisão sobre as legislações municipais. Essa busca por uma linguagem comum entre as partes visa exatamente à assimilação dos fenômenos envolvidos para uma posterior incorporação desses conceitos nos instrumentos de planejamento e gestão das nossas cidades.

Excelentes trabalhos oriundos da meteorologia e da climatologia geográfica são encontrados nas bibliotecas das prefeituras, mas, infelizmente, sem nenhuma aplicação prática, simplesmente pela falta de 'tradução' em termos mais palpáveis, em variáveis conhecidas pelos envolvidos com o processo de decisão na esfera municipal; isso mostra aos pesquisadores a necessidade de diálogo e entendimento com o sistema político-institucional. Apesar dos valiosos e muitíssimo bem-vindos estudos da meteorologia e da climatologia geográfica, a fusão entre essas duas áreas ainda está em construção.

Dando continuidade ao estabelecimento de correlações, já estudando o caso de São Paulo, foram cruzados dados de estações meteorológicas locais com o padrão de urbanização no entorno, desta vez com recursos de modelos computacionais para correlações lineares múltiplas. Posteriormente, em uma reflexão sobre o modelo proposto durante o doutoramento, ele foi aplicado à cidade de São Paulo e foram feitos mais alguns testes envolvendo correlações lineares múltiplas para se avaliar o efeito conjunto dessas mesmas variáveis (DUARTE, 2009). Foram utilizados dados climáticos de 2003, 
e as médias foram calculadas a partir de dados horários ou coletados a cada 30 minutos, dependendo da estação. Foram selecionados os meses de julho e dezembro como representativos dos períodos de inverno e verão, respectivamente. As estações meteorológicas fixas utilizadas foram: Cidade Universitária e Água Funda (estações IAG/USP), Parque do Ibirapuera, a região central no entorno do parque D. Pedro II e o bairro de São Miguel Paulista (estações CETESB) e Aeroporto de Congonhas (estação METAR). A estação do INMET - Instituto Nacional de Meteorologia, localizada no Mirante de Santana, na zona Norte da cidade, e apontada por Tarifa e Azevedo (2001) como a estação representativa do clima local na cidade de São Paulo, não dispunha de dados horários, e as medições eram realizadas três vezes ao dia, às $9 \mathrm{~h}, 15 \mathrm{~h}$ e $21 \mathrm{~h}$. Na Av. Paulista, por falta de uma estação fixa, foram feitas medições de verão e inverno em um dia estável de julho e dezembro no ano de 2003, no canteiro central, pelo interesse de se estudar as condições ambientais desse padrão de ocupação. Houve uma razoável correspondência entre as variáveis de ocupação e a temperatura do ar. De início foi estabelecida uma correlação linear simples entre cada uma das variáveis de ocupação, individualmente, e a temperatura do ar, utilizando-se a média mensal dos horários $9 \mathrm{~h}, 15 \mathrm{~h}$ e $18 \mathrm{~h}$, para os meses de julho e dezembro, respectivamente. No caso do ponto na Av. Paulista foram utilizadas medidas pontuais, nos mesmos horários, em dias estáveis. Em um segundo teste, foi estabelecida uma correlação linear múltipla, com a finalidade de estabelecer o efeito conjunto das variáveis em questão. Como uma primeira aproximação, as equações foram testadas para os três horários, individualmente, para verão e inverno. Os coeficientes de correlação encontrados foram bastante significativos, demonstrando uma correspondência bastante razoável entre as variáveis envolvidas.

\subsection{No início da formação do grupo de pesquisa na FAUUSP}

Após a conclusão do doutoramento, no início da formação do grupo de pesquisa, com as primeiras orientações de iniciação científica, foram feitas medições exploratórias na cidade de São Paulo, com o objetivo de leitura e representação gráfica das condições ambientais na Av. Paulista, agora dispondo dos primeiros equipamentos digitais portáteis e pequenas estações meteorológicas, de aplicação quase doméstica em outros contextos, ainda de baixa resolução e com uma série de limitações. A leitura foi feita com medições de variáveis ambientais em transectos móveis, no verão e no inverno, percorridos a pé, com instrumentos portáteis, ao longo do canteiro central da avenida, cruzando esses dados com a leitura das fachadas, fator de visão de céu, parque, vegetação de rua, etc. A intenção era representar graficamente as condições ambientais urbanas ao longo da avenida, relacionando-as aos padrões de ocupação do solo, principalmente a configuração do canyon, a presença de vegetação, as fachadas dos edifícios, etc. (SOUZA, DUARTE, 2003; SOUZA, DUARTE, 2004). Nesse momento concluí as primeiras orientações de IC, com bolsa CNPq e Fapesp.

Em novembro de 2005, foram realizadas novas medições na Barra Funda, em São Paulo, já como parte da disciplina de pós-graduação AUT 5823 - Conforto Ambiental Urbano, proposta e oferecida pela autora desde $2005 .{ }^{45} \mathrm{Com}$ uma equipe maior, agregando não só os alunos da disciplina, mas outros da FAUUSP e do IAG/USP/Ciências Atmosféricas, de graduação e pós-graduação, eram 18 pessoas no total, incluindo medições microclimáticas e acústicas no ambiente urbano. A partir de um extenso levantamento prévio da área, realizado pelo grupo, foram monitorados um total de 7 pontos fixos e dois transectos. Foram dois pontos fixos ao norte da estação Barra Funda, próximos ao Tribunal Regional do Trabalho - TRT, um terceiro no Memorial da América Latina, o quarto na calçada em frente ao Parque da Água Branca, o quinto próximo à entrada do parque, o sexto na arena do parque e o sexto na área mais verde e úmida do parque, além de dois transectos móveis percorridos a pé ligando as diferentes áreas. Ao fim, foi um estudo exploratório com objetivo de leitura das condições ambientais urbanas, basicamente com os mesmos equipamentos utilizados na Av. Paulista, mas cobrindo uma área bem maior e muito mais heterogênea (DUARTE, GONÇALVES,

\footnotetext{
45 Juntamente com a Prof. Marcia Peinado Alucci até a sua aposentadoria, em março de 2013.
} 
2006; DUARTE, GONÇALVES, MONTEIRO, 2007). ${ }^{46}$ Nesse momento, estava em andamento uma orientação de mestrado no tema, com bolsa Fapesp, estudando o impacto da vegetação no clima, dando início aos estudos preditivos do impacto da vegetação no microclima urbano.

A partir desta fase, depois da experiência com alguns estudos exploratórios e descritivos, intensificase a busca por modelos preditivos, viáveis para a arquitetura e o urbanismo, em escala e complexidade, a fim de superar uma barreira e prognosticar cenários futuros, como nas palavras de Echenique (2010), de forma extrapolativa, quando se manifesta a continuação das tendências atuais diagnosticadas no modelo descritivo, ou condicional, onde os mecanismos de causa e efeito que governam as variáveis são discretizados.

\subsection{Mais recentemente, com a consolidação do grupo de pesquisa}

A partir do surgimento de modelos micrometeorológicos implementados computacionalmente para a Urban Canopy Layer, a camada no nível das coberturas, mais viáveis para aplicações em arquitetura e urbanismo em função da complexidade e de uma escala compatível com a resolução da área urbana minimamente necessária, ${ }^{47}$ o grupo começou a explorar as possibilidades de simulação computacional para estudos preditivos, de validação do modelo para as condições climáticas locais, e as limitações do mesmo, inclusive para representar a heterogeneidade do tecido urbano das cidades brasileiras.

Dada a complexidade do modelo escolhido, o ENVI-met, ${ }^{48}$ na época em versões anteriores à atual, a busca pela interdisciplinaridade se intensificou, como uma condição sine qua non para a continuidade deste trabalho, sem a qual não seria possível avançar em estudos preditivos. Em um modelo complexo como esse, que lida com a interação solo, superfície (ambiente construído e vegetação) e atmosfera, passar por cada uma das etapas do File Editor, entendendo cada dado de entrada é indispensável, o que aprendemos a duras penas com erros e acertos ao longo do processo, e assim continua com nova versão lançada em outubro de 2014, depois substituída em janeiro de 2015, ainda como preview, e que é constantemente atualizada pelos autores. Esse conhecimento do modelo é imprescindível, não só para executar a simulação propriamente dita, como também para planejar o trabalho de campo, e registrar os dados necessários em base horária, pelo menos, em ciclos de $24 \mathrm{~h}$ ao longo de dias, semanas, ou meses, para que possa 'janelar' o período mais adequado para a calibração do modelo (informação verbal), ${ }^{49}$ que será explicada mais à frente.

Ao mesmo tempo em que uma mudança significativa foi implantada em decorrência do uso do novo modelo, aconteceu também o aprimoramento do trabalho de campo, com instrumentos e protocolos de medições mais precisos, mais confiáveis. Sensores de melhor qualidade foram sendo adquiridos com recursos de sucessivos auxílios-pesquisa dos membros do laboratório e, eventualmente, do uso da reserva técnica de alunos bolsistas vinculados aos projetos, e que foram doados e incorporados ao patrimônio da FAUUSP ao término de cada trabalho. Os protocolos para medições urbanas ainda não são tão voltados para as necessidades da arquitetura e do urbanismo, e sim, para a micrometeorologia, portanto, ainda demandam adaptações e interpretações do pesquisador a cada caso. Porém, muitos avanços foram feitos desde Oke (2004; 2006), ambos

\footnotetext{
${ }^{46} \mathrm{~A}$ área também era objeto de estudo de uma pesquisa maior, da qual o LABAUT participou, com o Prof. Koen Stemeers, do The Martin Centre for Architectural and Urban Studies, University of Cambridge, e a Prof. Susannah Hagan, da University of East London, financiada pela British Academy.

47 Até então os modelos computacionais disponíveis eram da meteorologia, em mesoescala, como o RAMS-TEB, por exemplo, mas inviáveis para aplicação em arquitetura e urbanismo. Para uma aplicação desse modelo em área urbana, ver, por exemplo: FREITAS, Edmilson Dias de. Circulações Locais em São Paulo e sua Influência Sobre a Dispersão de Poluentes. Tese (Doutorado em Meteorologia). IAG/USP, 2003.

48 Disponível em http://www.envi-met.info/ Acesso em 29/01/15.

49 Informação verbal, em conversa com a Prof. Dra. Eleonora Sad de Assis, UFMG, em janeiro de 2013.
} 
documentos técnicos para a WMO, que precederam a incorporação do capítulo Urban Observations ao Guide to Meteorological Instruments and Methods of Observation (WMO, 2008). ${ }^{50}$

Nessa época, por diversas razões, vários trabalhos do grupo interessados na compatibilidade entre adensamento populacional e construído com qualidade ambiental, envolvendo outros orientadores e pos-docs, foram concentradas em uma área de estudo no bairro da Luz, centro de São Paulo, antes do projeto Nova Luz, encampado pelo poder público a partir do final de 2006 . Nessa região era possível medir e posteriormente simular diferentes possibilidades para um parque urbano de vegetação relativamente densa, o Parque da Luz, um canyon urbano sem nenhuma vegetação, na Rua dos Andradas, paralela à Rua Santa Efigênia, e uma praça pavimentada com pouca vegetação, em frente à Sala São Paulo. Com os equipamentos que dispúnhamos no momento, e com o suporte da administração do Parque da Luz e da Sala São Paulo, conseguimos ir a campo com um grupo grande de alunos, incluindo dois pesquisadores estrangeiros que já tinham uma experiência anterior com o ENVI-met, desenvolvendo na ocasião doutoramento sanduíche e pós-doutoramento no grupo, para avaliar o potencial da vegetação no microclima urbano e realizar testes de sensibilidade no modelo em clima tropical, respectivamente. Juntamente com uma mestranda e, de início, uma aluna de IC, deu-se início à formação do grupo dos verdinhos, como nos autodenominamos informalmente.

Dessa forma, mesmo com avanços no modelo, a simulação computacional nunca foi adotada como única técnica de pesquisa, mas sim, usada em conjunto com as medições no real para alimentar a fase de calibração do software para as condições locais e só então passar aos estudos paramétricos e cenários preditivos para casos reais, colocando em pratica o que Groat e Wang (2013) chamam de "power of combined strategies", incluindo estudos de caso enriquecidos por medições, simulações, etc.

Uma das grandes vantagens da simulação computacional, além da agilidade no teste de soluções, é antever cenários que não seriam possíveis de outra forma, mostrando "how things could be" (GROAT, WANG, 2013). E as simulações nem sempre foram ou continuam sendo computacionais, haja vista a riqueza didática e as sofisticadas possibilidades de simulação com modelos físicos em arquitetura e e urbanismo, para estudos de insolação, iluminação e ventilação, por exemplo; "[...] the computer itself is not integral to simulation as a strategy. Modelling scenarios to learn from them [...] is something humans were doing long before computers come along. Nothing about this changes with regard to simulation at the level of strategy." (GROAT, WANG, 2013, p.363).

Ao abordar o uso de simulação para a pesquisa, Groat e Wang (2013) apontam quatro fatores importantes: "completeness of data input, accuracy of the replication, 'programmed spontaneity', and cost/workability. These concerns also reveal the limitations of simulation research, and ways to overcome them are a large part of the tactics of this research strategy."

De fato, a demanda computacional para modelos micrometeorológicos é considerável. Simulações de áreas urbanas reais no ENVI-met, por exemplo, ainda que numa escala de cerca de nove quadras, que se considera mínima para estudos urbanos (DUARTE, 2015a), com a complexidade e heterogeneidade das nossas cidades, levam cerca de cinco dias para rodar um período de $48 \mathrm{~h}$, em um bom microcomputador. E a cada eventual queda de energia além do que suporta um no-break de pequena capacidade, a simulação precisa recomeçar.

Par e passo com a sofisticação do modelo, trabalha-se muito pela otimização nesse processo, agilizando a seleção das melhoras estratégias em cenários paramétricos simplificados geometricamente, para que sejam testadas como cenários preditivos sobre as áreas reais somente aqueles cenários mais promissores.

\footnotetext{
${ }^{50}$ A primeira proposição foi feita por Oke (2004), como technical document para a WMO; depois uma nova versão no mesmo formato em Oke (2006), também para a WMO e finalmente, foi incorporada ao Guide to Meteorological Instruments and Methods of Observation (WMO, 2008), Part II. Observing Systems, Chapter 11 - Urban Observations. Essa versão teve algumas atualizações em 2010, e uma nova versão em fase de elaboração é esperada.
} 
Recentemente o grupo começou a testar um modelo mais simples, correlacional, chamado STEVE (JUSUF, WONG, 2009; WONG, YUSUF, TAN, 2011), ${ }^{51}$ calibrado para as condições ambientais de Cingapura, cientes de todas as suas limitações, também para essa primeira etapa de simulações com a finalidade de agilizar a seleção das estratégias mais promissores que valham a pena serem testadas em modelos mais complexos e que demandam muito mais tempo e capacidade computacional.

O modelo STEVE continuou agregando ao estabelecimento de correlações uma estratégia de simulação que envolve controle e manipulação de variáveis, mantendo o trabalho de campo como ponto fundamental para simulação do caso real com a finalidade de calibração prévia dos modelos computacionais adotados, conforme feito pelos autores em Cingapura.

Sobre o número de estudos de caso necessários para cada trabalho, que serão medidos e simulados,

"[...] there is no quick and easy formula for making the choice between single - and multiple-case design, or about the number of cases necessary for a multiple-case design. [...] Since there are no hard and fast rules about the number of cases to select, each researcher must assess the degree of depth versus comparative breadth that best suits the research question(s) he or she has posed." (GROAT, WANG, 2013). ${ }^{52}$

Para essa tomada de decisão dois princípios são primordiais: 1) a natureza das questões teóricas envolvidas e 2) a necessidade da replicação para testar ou confirmar os resultados do estudo.

Para ajudar a responder a essas questões, ao longo dos muitos trabalhos conduzidos no grupo, as medições de campo e a simulação computacional foram realizadas em mais de um ponto ou local, sempre que a disponibilidade de instrumentos e pessoal permitiu, para se obter propositalmente um contraste, por exemplo, em locais com e sem vegetação, em locais com alta de baixa densidade construída, etc., para a obtenção de resultados medidos em situações contrastantes e também para se verificar a validade do modelo computacional ao tentar reproduzir ambas as situações na fase de calibração.

De forma sucinta, posteriormente à revisão bibliográfica, o método adotado atualmente para as pesquisas do grupo em escala urbana inclui:

1. Levantamentos e/ou produção de mapeamentos quando pertinente, por exemplo cruzando dados do IBGE e SEMPLA (GUSSON, MADEIRA, DUARTE, 2012), produzindo imagens a partir de dados de satélite ou mapeando dados da PMSP sobre a distribuição de vegetação na cidade, com o valioso apoio do CESAD/FAUUSP (DUARTE, 2015b); esses mapeamentos são essenciais ao entendimento do todo, à identificação dos pontos de interesse para a pesquisa, à escolha das áreas de estudo, dos pontos de medição que tem que sem compatíveis com os pontos receptores do modelo computacional para a fase de calibração a posteriori, etc.

2. Após a escolha das áreas de estudo, com base nos levantamentos de dados secundários ou primários mencionados no item 1 , procede-se ao planejamento do trabalho de campo em função dos recursos e restrições do modelo analítico ou computacional a ser adotado, mais recentemente o ENVI-met V4 (DUARTE, SHINZATO, GUSSON, ALVES, 2014a e 2014b; GUSSON, 2014), pesando aqui também o custo computacional para o dimensionamento do modelo e o grau de detalhamento a ser adotado, os efeitos de borda para delimitação das áreas, o

\footnotetext{
51 Para o qual consegui duas licenças por cooperação acadêmica junto à National University of Singapore - NUS, em dezembro de 2014, após contato pessoal com o Prof. Wong, no evento Third Urban Heat Island Countermeasures, 2014, realizado em Veneza.

${ }^{52}$ Ainda assim, na tentativa de propor um índice empírico com as correlações encontradas durante o doutoramento, e com medições simultâneas em sete locais com padrões de ocupação bastante distintos, ouvi dos estatísticos: "mas a senhora só mediu em sete bairros?" Com todas as dificuldades da obtenção de instrumentos, confecção dos abrigos, disponibilidade dos locais para medição, de segurança e de equipe para medições simultâneas, dependentes de leitura visual em cada ponto, a distinção no entendimento dessas questões entre as áreas de conhecimento é evidente.
} 
levantamento das áreas no entorno do modelo necessárias à configurações das áreas de aninhamento (nesting grids).

3. Levantamento de dados de solo, de vegetação e da atmosfera no nível do solo e no topo do modelo, essenciais ao funcionamento do mesmo, para que haja de fato a interação das trocas entre solo, vegetação, ambiente construído, atmosfera.

Os dados de solo incluem a descrição das variáveis em várias camadas, informação de difícil acesso em áreas urbanas (GUSSON, 2014).

Os dados de vegetação são principalmente a quantificação do índice de área foliar realizada na grupo por métodos indiretos, como por fotos hemisféricas e pós-processamento da imagem, ou por medições indiretas com o analisador de dossel (SHINZATO, DUARTE, MOREIRA, BARROS, 2013a; 2013b). Em função das últimas medições realizadas, foi feita uma distinção entre IAF verdadeiro e IAF efetivo e, em função disso, as métricas e os resultados estão sendo revistos; os resultados preliminares são apresentados em Shinzato, Yoshida, Duarte (2015).

Os dados de atmosfera, simultâneos às medições de campo, incluem variáveis de estações meteorológicas fixas, no nível do solo, ${ }^{53}$ e variáveis no topo do modelo, como umidade específica a $2500 \mathrm{~m}$ acima do nível do mar, que só podem ser obtidos a partir de sondagens com balões meteorológicos. Para São Paulo, essas leituras são disponíveis para as 9h (12h UTC) e 21h (Oh UTC) ${ }^{54}$ e procura-se sempre iniciar as simulações no período noturno, para minimizar erros de convergência devido à presença de radiação de onda curta nas primeiras horas da simulação; portanto, recomenda-se o início da simulação no ENVI-met às $21 \mathrm{~h} .{ }^{55}$ Velocidade e direção do vento a $10 \mathrm{~m}$ de altura podem ser obtidos a partir dos valores médios das condições iniciais obtidos das estações meteorológicas do INMET - Mirante Santana e IAG - Água Funda (SHINZATO, 2014; GUSSON, 2014).

4. Indução, por observação dos fenômenos durante as medições de campo. Essa etapa é essencial para a quantificação de variáveis urbanísticas e ambientais de interesse para pesquisa (DUARTE, 2015a, 2015b; DUARTE, SHINZATO, GUSSON, ALVES, 2014a, 2014b; SHINZATO, 2014; GUSSON, 2014), muitas vezes em mais de um ponto, buscando-se avaliar o desempenho do modelo na calibração a posteriori em situações contrastantes, por exemplo, com e sem vegetação, vegetação com diferentes configurações, alta e baixa densidade construída, etc. As variáveis ambientais incluem radiação solar global no plano horizontal, temperatura de globo, temperatura de solo, temperatura do ar, umidade relativa do ar, direção e velocidade dos ventos, além de medições pontuais de emissividade e temperatura superficial. A temperatura de solo da camada superior pode ser medida diretamente, e a umidade de solo é estimada com o Simple Biosphere Model - SIB2, ${ }^{56}$ por falta de equipamento que ainda não dispomos no laboratório.

Quando possível, dependendo das condições de segurança e permissões necessárias, essas medições acontecem ao longo de dias ou mesmo meses, para que se possa 'janelar' o período mais adequado para a calibração do modelo, em condições atmosféricas estáveis, geralmente

\footnotetext{
53 Em São Paulo, geralmente a partir do Aeroporto de Congonhas, do IAG/USP/Água Funda, do INMET Mirante de Santana, das estações da USP Cidade Universitária (IAG, IEE e FFLCH/GEO), ou da CETESB. Para a escala da cidade, a cobertura das estações ainda é muito pequena ou de períodos ainda muito curtos de registro, e faltam dados principalmente de áreas densamente urbanizadas.

${ }^{54}$ Dados de balões meteorológicos para São Paulo são obtidos a partir do Campo de Marte e acessados pela University of Wyoming. Disponível em: http://weather.uwyo.edu/upperair/sounding.html. Acesso em: junho de 2013.

55 Informação verbal, Prof. Dra. Eleonora Assis, janeiro de 2013. Uma descrição detalhada pode ser encontrada em Francisco (2012).

${ }^{56}$ Com a colaboração do Prof. Dr. Humberto Ribeiro da Rocha, IAG-USP.
} 
com céu claro e pouco vento, ressaltando a influência do padrão de ocupação urbana sobre o microclima, e minimizando as trocas turbulentas para este tipo de estudo.

Para as medições de campo, de alguns anos para cá o laboratório dispõe de duas estações meteorológicas Campbell, com os seguintes sensores (Figura 9):

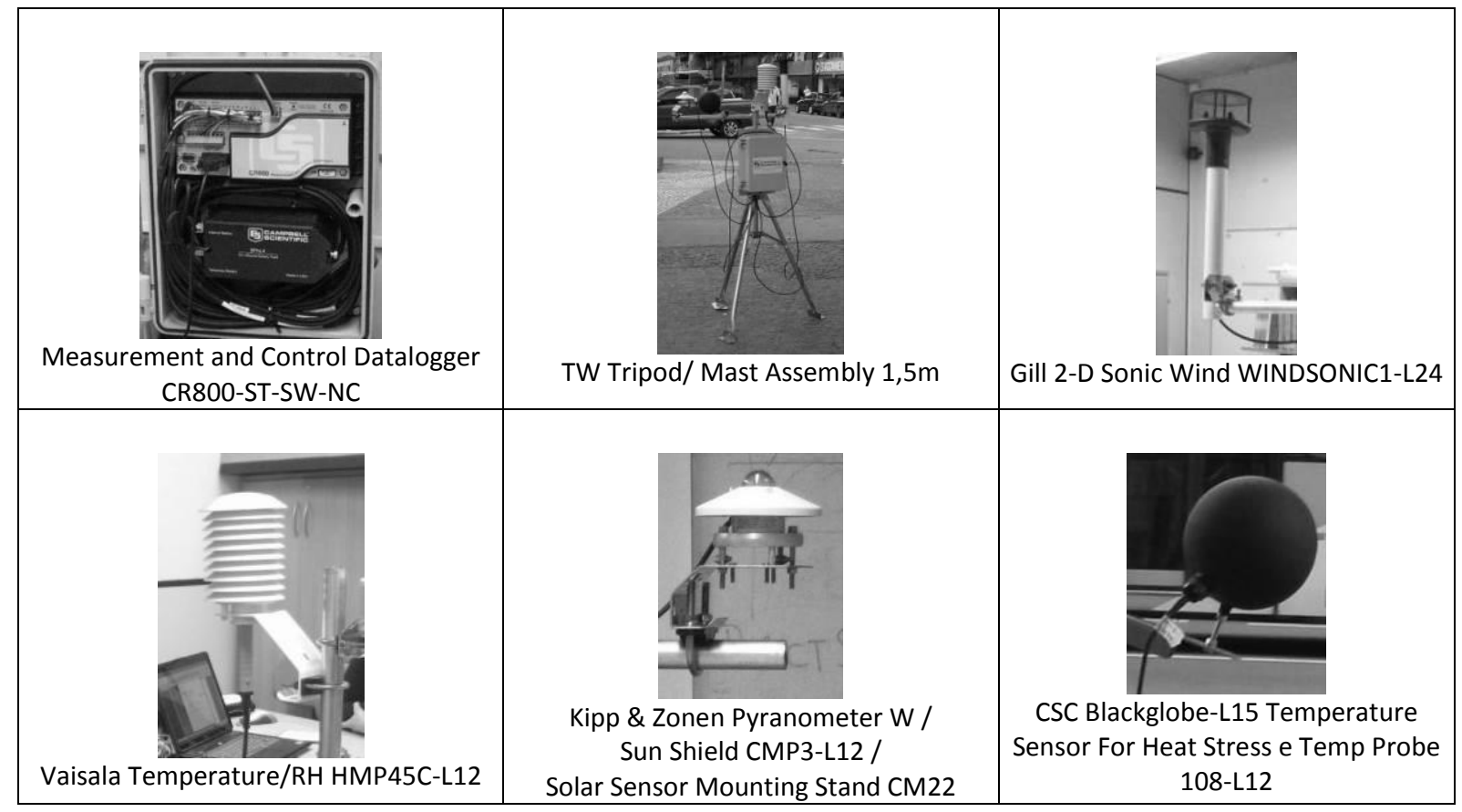

Figura 9 - Sensores da estação meteorológica Campbell.

Além desses, o laboratório dispõe de câmera termográfica, câmera digital com lente angular, sensores externos de temperatura e umidade com solar shields para radiação direta e difusa, dentre outros como, por exemplo, um emissômetro, de patrimônio IAG/USP, mas de uso compartilhado por projeto conjunto.

Para as condições de exposição dos sensores em área urbanizada, não há como se manter as condições padrão WMO, como já era apontado por OKe (2005). Depois da primeira proposição de Oke (2004), como technical document para a WMO, depois uma nova versão no mesmo formato em Oke (2006), finalmente foi incorporada ao Guide to Meteorological Instruments and Methods of Observation (WMO, 2008), Part II. Observing Systems, um capítulo sobre observações urbanas Chapter 11 - Urban Observations. Essa versão teve algumas atualizações em 2010, e uma nova versão em fase de elaboração é esperada. Mesmo sendo voltado para observações urbanas, ainda é um padrão da micrometeorologia, e nem sempre é possível atender a todas recomendações, para os estudos em arquitetura e urbanismo na escala da rua, da praça, etc. Portanto, são necessários cuidados com a proximidade de superfícies urbanas aquecidas, de fontes de calor antropogênico como veículos e ar-condicionado, com a turbulência nas esquinas, etc. Além disso, em espaços abertos públicos, ainda há toda a questão da segurança dos equipamentos pra ser administrada. Muitas vezes torna-se impossível completar um ciclo de $24 \mathrm{~h}$ com alguma segurança, dependendo da área de interesse para a pesquisa, o que compromete e muito uma coleta de dados consistente para a calibração do modelo.

5. Dedução, por meio de comparações entre os resultados levantados nas diferentes situações medidas e posterior tratamento dos dados, buscando contrastar alta e baixa densidade construída, diferentes configurações de vegetação, diferentes índices de área foliar, cobertura de solo, etc. 
6. Modelagem das áreas de estudo reais, buscando a melhor representação dos fenômenos envolvidos, incluindo a topografia a partir do ENVI-met V4 Preview, e considerando-se as simplificações possíveis e necessárias da configuração urbana, dado o custo computacional com o aumento do grau de detalhamento e heterogeneidade das áreas estudadas. Em áreas urbanizadas, a modelagem muitas vezes inclui nove quadras, e considera a quadra central como objeto de medição e quantificação pelo modelo, para que se possa considerar a influência do entorno e desprezar os efeitos de borda (DUARTE, 2015a; GUSSON, 2014). Quando possível e pertinente, a modelagem pode incluir mais de um ponto medido, e as considerações sobre a área de aninhamento ${ }^{57}$ e efeitos de borda precisam ser feitas em conjunto.

Uma vez identificada a janela mais adequada durante o período medido, geralmente com cerca de $48 \mathrm{~h}$ de estabilidade atmosférica, ${ }^{58}$ procede-se à simulação computacional das áreas reais de estudo, visando à calibração entre dados medidos e simulados. Para tanto, alocam-se os pontos receptores (receptors) coincidindo com os pontos medidos em campo e, eventualmente, em outros pontos de interesse. Os dados de entrada precisam então ser informados, e algumas verificações importantes precisam ser feitas, como por exemplo, o ajuste de radiação em função dos dados medidos. A radiação solar calculada em função da latitude pode ser ajustada aos dados medidos, para nuvens baixas, médias e altas, ${ }^{59}$ e testada no Preview da condição de radiação solar. Esse ajuste já era disponível na V3.1 Beta 5, mas não foi disponibilizado da mesma forma na V4 Preview até o momento. Uma alternativa é fazer o ajuste na V3.1 Beta 5, com mais recursos de controle, e adotar esses valores na V4 Preview (Gusson, 2014), como o procedimento realizado para este trabalho. As condições de turbulência também precisam ser especificadas. ${ }^{60}$

No ENVI-met V4 Preview, a ferramenta forcing foi incorporada, tornando possível definir a variação diurna das condições atmosféricas e a entrada de radiação. Isso permite a construção de cenários climáticos muito mais detalhados para testar hipóteses e gerar resultados mais de acordo com as medições de campo (JANSSON, 2006). Porém, ainda não se sabe exatamente as interferências que essa assimilação de dados, inexistente nas versões anteriores do modelo, pode provocar nos resultados.

A umidade especifica a $2500 \mathrm{~m}$ acima do nível do mar é registrada por sondagens em balões atmosféricos a partir do Campo de Marte, no caso de São Paulo, à zero hora UTC ou $12 \mathrm{~h} \mathrm{UTC,}{ }^{61} \mathrm{o}$ que significa $21 \mathrm{~h}$ ou $9 \mathrm{~h}$ para São Paulo, a menos $3 \mathrm{~h}$ de Greenwich.

\footnotetext{
${ }^{57} \mathrm{~A}$ área de aninhamento serve para aclimatar os dados de entrada até a chegada no modelo (informação verbal, Eleonora Assis, 29/01/2013).

580 modelo se aquece após 48h de simulação (informação verbal, Prof. Dra. Eleonora Assis, 29/01/2013).

59 O Brasil não mede nebulosidade; os dados, quando existentes, não obtidos por observação visual do meteorologista, em décimos; já o ENVI-met pede esse dado em octas; a alternativa é fazer uma regra de três para conversão. Quanto mais alta a nuvem, mais radiação é espalhada na atmosfera. No Brasil a maior parte das nuvens são baixas, principalmente no verão. A recomendação é começar o ajuste pela radiação difusa no plano horizontal, ajustando o dado de nebulosidade do meio dia solar. Faz-se uma proporção de nuvens baixas, médias e altas ao longo do dia e insere-se como dado de entrada no ajuste de nuvens do modelo; em seguida verifica-se a coincidência ou não com os dados de radiação global e difusa para aquele dia. Se os dados de radiação difusa coincidirem, só com o ajuste de nuvens e a radiação global, não é necessário se fazer o solar adjustment no programa. O ENVI-met V4 4 tem a opção de ajuste de radiação, mas sem a visualização que havia na V3.1. Por essa razão, no momento, faz-se o ajuste na V3.1 para melhor visualização dos dados e transcrevem-se os dados para a V4 preview (informação verbal, Prof. Dra. Eleonora Assis, 29/01/2013).

${ }^{60} \mathrm{Na}$ opção simple forcing, o modelo determina a condição de turbulência, Turbulence Model, e o usuário pode adotar o default do modelo. Fora do forcing, para as condições de turbulência, as opções são open, cyclic e closed ou forced: para o caso de São Paulo, em área densamente urbanizada, melhor utilizar a opção cyclic. A opção open é geralmente mais adequada para o litoral, com vento vindo do mar, e o closed ou forced para situações intermediárias (informação verbal, Prof. Dra. Eleonora Assis, 29/01/2013). O próprio modelo alerta o usuário para só alterar essas configurações com muita certeza entre as diferentes opções.

61 Disponível em: http://weather.uwyo.edu/upperair/sounding.html. Acesso em: junho de 2013.
} 
Para as simulações, o dia inicial é definido com base em dados pluviométricos coletados em estações fixas de referência, buscando-se o período mais estável, e em um momento sem ganho de radiação, ou seja, em atmosfera neutra. ${ }^{62}$

Para atender as duas condições anteriores, quando há o dado de umidade especifica a $2500 \mathrm{~m}$ acima do nível do mar em atmosfera neutra, a única possibilidade é iniciar o modelo às $21 \mathrm{~h}$, horário local em São Paulo.

7. Calibração do modelo. As curvas medidas e simuladas são, então, sobrepostas para verificação da fidelidade da representação do modelo, incluindo uma resposta satisfatória em situações contrastantes, quando pertinente. Em função das diferenças encontradas, é possível e necessário proceder-se ao ajuste dos dados de entrada, agora com mais recursos da ferramenta simple forcing, disponível no ENVI-met V4 Preview. Até a V3.1 Beta 5, o modelo não assimilava dados, e essa calibração era feita apenas manualmente até então, consumindo muito tempo e diversas simulações por tentativa e erro até que se chegasse a uma configuração de dados de entrada satisfatória a cada trabalho (JOHANSSON, 2008; SHINZATO, 2009; 2014).

8. Somente após essa etapa de calibração, com maior confiabilidade na representação pretendida, é que são feitos os estudos paramétricos, geometricamente mais simples e bem mais rápidos para serem simulados e, a partir dos resultados encontrados, são selecionadas as melhores estratégias para as simulações de diferentes cenários para os casos reais, que novamente vão demandar mais tempo e maior custo computacional. Esses estudos paramétricos podem ser feitos sobre dados medidos, do período usado para a calibração ou mesmo de outros períodos de interesse, como durante as ondas de calor que ocorreram em São Paulo nos verões de 2014 e 2015, ou mesmo sobre projeções de dados futuros, desde que se disponha das variáveis necessárias. ${ }^{63}$

9. A partir dos resultados obtidos nos estudos paramétricos e nos diferentes cenários para os casos reais, pode-se estabelecer diretrizes para informar políticas públicas e estratégias de infraestrutura verde e desenho urbano, por exemplo.

Para a obtenção de dados futuros, a serem também utilizados para as simulações, um longo caminho foi percorrido, em paralelo, em projeto conjunto com o IAG, intitulado Biometeorologia humana: análise dos efeitos de variáveis ambientais (meteorológicas, conforto térmico e poluição atmosférica) e das mudanças climáticas na população geriátrica da cidade de São Paulo. Trata-se de um projeto temático FAPESP processo 2010/10189-5, coordenado pelo Prof. Dr. Fábio Luiz Teixeira Gonçalves (IAGUSP). O projeto envolve IAGUSP, FMUSP, POLIUSP e FAUUSP, com a equipe do LABAUT Laboratório de Conforto Ambiental e Eficiência Energética, com vigência de 01/07/2011 a 30/06/2015, recentemente prorrogada até setembro de 2015.

Os dados futuros deveriam representar as variações esperadas para a cidade de São Paulo, e a princípio foram acoplados para a simulação em outro modelo, o Thermal Analysis Software TAS/EDSL, um Building Energy Simulation model - BES, que utiliza dados horários em base anual para simuação térmica e energética de edifícios, para o trabalho de Alves (2015), na FAUUSP.

Para tanto, dois conjuntos de dados foram sistematizados: o primeiro, de dados efetivamente medidos na estação IAG/Água Funda desde 1933, quando a estação foi implementada, até 2014, para uma leitura do comportamento climático desde então (ALVES, 2015; ALVES, DUARTE,

\footnotetext{
${ }^{62}$ A temperatura potencial, usada pelo ENVI-met, só é igual à temperatura do ar no momento da transição da atmosfera neutra (informação verbal, Prof. Dra. Eleonora Assis, 29/01/2013).

63 Estudo em andamento no grupo, com o acoplamento de dados dos modelos de mesoescala para simulações micrometeorológucas no ENVI-met. As primeiras aproximdações são apresentadas no capítulo 7.
} 
GONÇALVES, 2015a; 2015b); ${ }^{64}$ e o segundo, de dados simulados com modelos atmosféricos por Llopart et al. (2014), para o prognóstico de períodos futuros, descritos mais adiante, também elaborados sobre a base de dados da estação IAG/Água Funda.

Os períodos futuros simulados por Llopart et al. (2014) foram cedidos pela Prof. Dra. Rosmeri P. da Rocha (IAG/USP). As simulações foram feitas a partir dos modelos: regional RegCM4 e global MPI (Max-Planck Institute for Meteorology), de acordo com o cenário RCP 8.5 (Representative Concentration Pathways), o mais pessimista do $5^{\circ}$ relatório do IPCC (AR5), com o maior nível de emissões estimadas pelo Painel, representando as médias para os seguintes períodos: presente (1975-2005), futuro próximo (2015-2044), futuro intermediário (2045-2074) e futuro distante (20762096).

Das simulações de Llopart et al. (2014) foram utilizadas as variáveis temperatura e umidade do ar; a partir daí as demais variáveis necessárias à simulação, inicialmente para o TAS, foram compostas por Alves (2015), e o procedimento foi descrito resumidamente em Alves, Duarte, Gonçalves (2015a; 2015b; 2015c). Nessa composição, as demais variáveis (radiação solar global e difusa, nebulosidade e direção e velocidade do vento), foram extraídas de um banco TMY (Test Meteorological Year) para São Paulo, ${ }^{65}$ cujo ano base é 1984 e a fonte dos dados é a estação do aeroporto de Congonhas.

De acordo com simulações futuras realizadas por Llopart et al. (2014) e Pessacg et al. (2014), o estado de São Paulo está na fronteira de previsões entre aumento e diminuição de precipitação e cobertura de nuvens. Não há um sinal claro dos modelos atmosféricos para estas variáveis, e nem para radiação total e radiação líquida, já que a radiação solar não varia na maioria dos modelos prognósticos para o futuro. Com relação ao vento, as simulações de Rocha et al. (2015) revelam que os resultados do modelo também não são conclusivos para dados de superfície.

Pela oportunidade do trabalho conjunto com esse projeto temático, os dados futuros foram retomados e revistos para simulações no ENVI-met. Partiu-se dos mesmos dados de temperatura e umidade relativa do ar simulados pelo IAG/USP e as demais variáveis foram mantidas constantes em todos os períodos, obtidas de um arquivo climático TMY existente para a cidade de São Paulo, sendo estas radiação global e difusa, nebulosidade e velocidade e direção de vento. Os resultados são apresentados no capítulo 7.

\footnotetext{
${ }^{64}$ Apresentados e discutidos no capítulo 6.

${ }^{65}$ Arquivo TMY para São Paulo disponível na página eletrônica do Laboratório de Eficiência Energética em Edificações, LabEEE, da Universidade Federal de Santa Catarina, UFSC.
} 


\section{O caso de São Paulo: contexto urbano e climático, atual e futuro, e a distribuição da vegetação na cidade}

\subsection{Contexto urbano, adensamento e dispersão}

A região metropolitana de São Paulo é uma megacidade formada por 39 municípios, com mais de 21 milhões de habitantes, e atualmente a $4^{\text {a }}$ maior aglomeração urbana no mundo (Figuras 10 e 11), com aproximadamente a mesma população da Cidade do México e Mumbai, depois do Tóquio, hoje

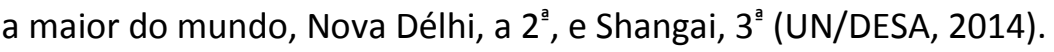

Projeções indicam que, caso o padrão de expansão da RMSP seja mantido conforme registros históricos, em 2030 a mancha urbana será aproximadamente 38\% maior do que a atual (Figura 12), aumentando os riscos de desastres naturais como enchentes, inundações e deslizamentos de massa em encostas, atingindo cada vez mais a população como um todo e, sobretudo, os mais vulneráveis (NOBRE, YOUNG, 2011). ${ }^{66}$

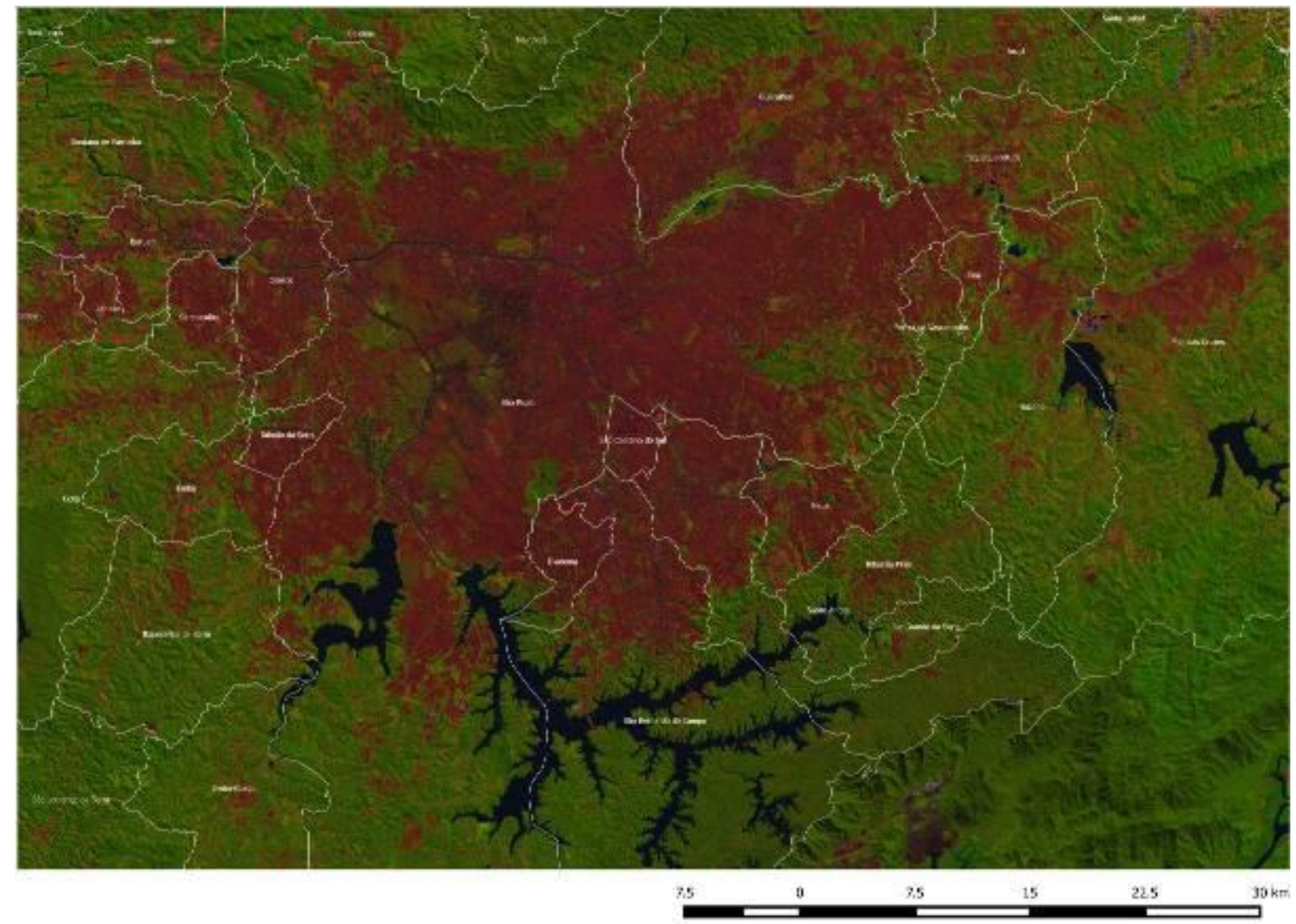

Figura 10 - Parte da região metropolitana de São Paulo, com seus 39 municípios, mostrando a área urbanizada com a vegetação mais preservada nos arredores e reservatórios ao sul. Dentro da área mais urbanizada, pontos significativos de vegetação urbana são mais evidentes na zona Oeste, contrastando com as áreas centrais e a zona Leste. Fonte: composição colorida das bandas espectrais 5, 4 e 3 do Landsat-5, em 23 de maio de 2011 (CESAD-FAU/USP).

\footnotetext{
${ }^{66}$ Segundo Nobre e Young (2011), “Cenários de risco são apresentados neste relatório e se referem a análises que mostram os impactos e vulnerabilidades atuais e futuras, com projeções para 2030, através da aplicação de um modelo de projeção da mancha urbana associado ao modelo HAND (Height Above the Nearest Drainage). Esse estudo permitiu identificar quais seriam as possíveis áreas ocupadas no futuro e seu risco potencial, caso o padrão de uso e ocupação do solo atual se perpetue sem nenhuma alteração e controle. Se esse processo de expansão urbana se concretizar, mais de $20 \%$ da área total em 2030 será suscetível e poderá eventualmente ser afetada por acidentes naturais provocados pelas chuvas.
} 

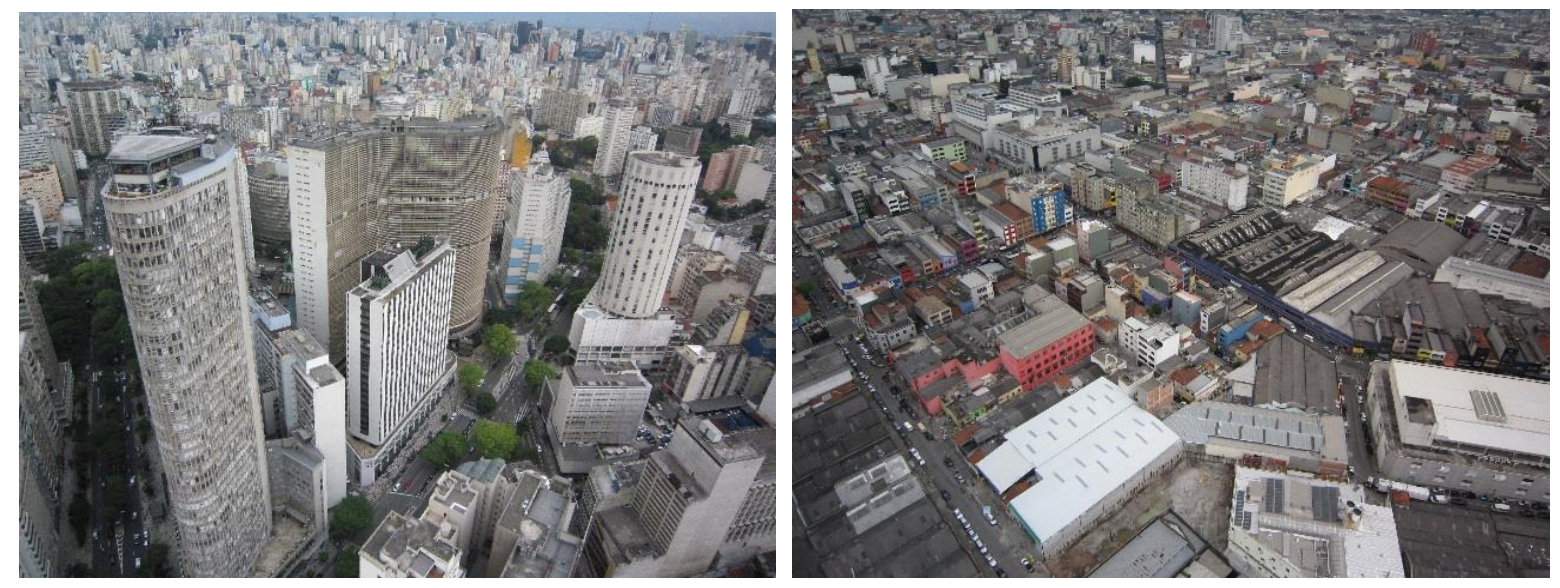

Figura 11 - São Paulo vista do alto: à esquerda, distrito da República (o mais denso construtivamente do município) em direção à Bela Vista (o mais denso populacionalmente do município), com pequenos oásis de vegetação; à direita, o Brás, antiga área industrial atualmente abrigando principalmente comércio e serviços, com praticamente nenhuma vegetação (fotos aéreas: Luciana S. Ferreira, novembro de 2010).

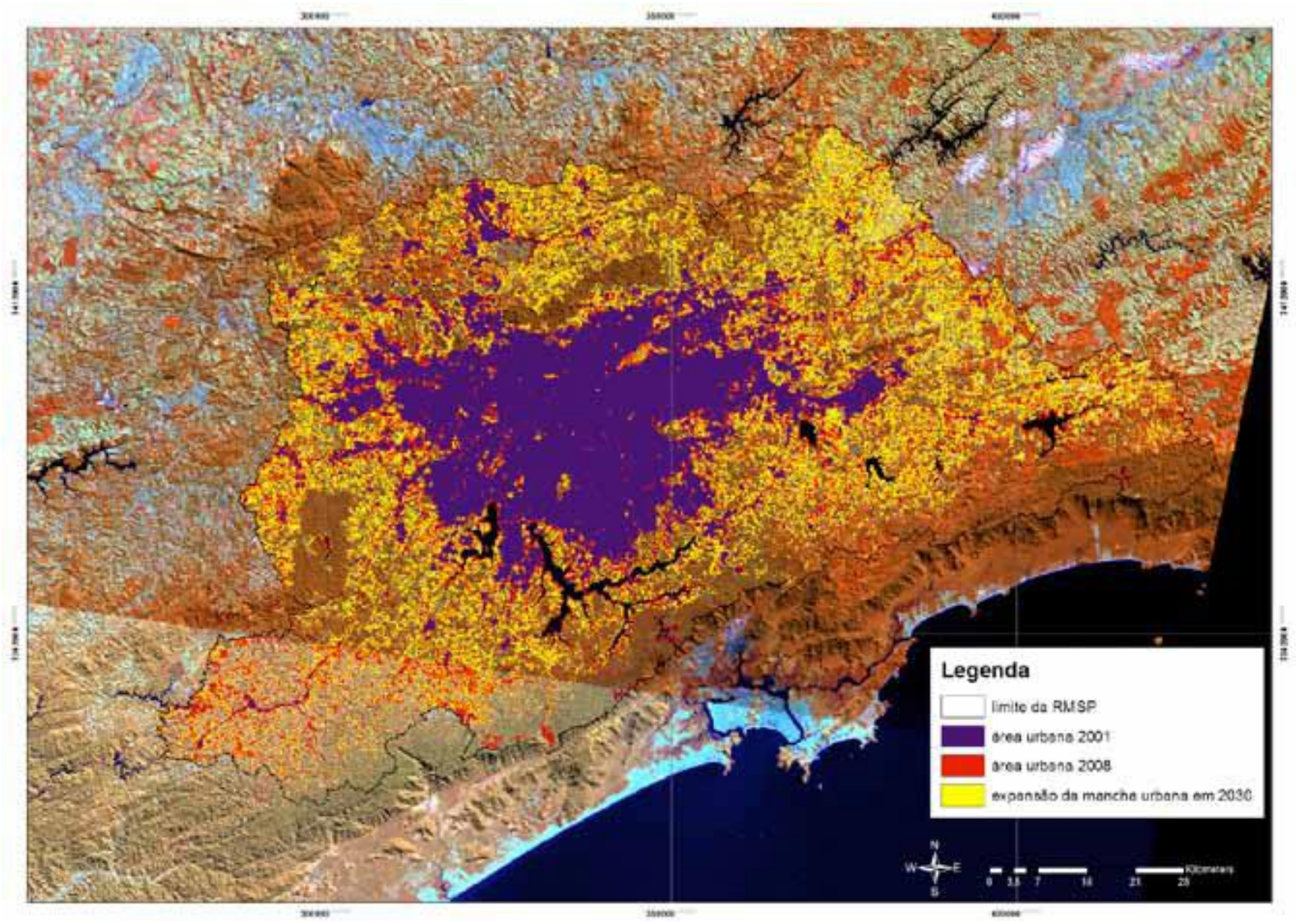

Figura 12 - Expansão da mancha urbana da RMSP em 2030. Imagem de satélite Landsat 7 ETM+ (órbita 219-076, resolução 30x30m (Nobre, Young, 2011).

Por décadas, a região central sofreu um processo de degradação e foi sendo abandonada por seus moradores, com uma dispersão cada vez maior pelas periferias e perda de população nas áreas centrais. O último Censo (IBGE, 2010), porém, mostrou um aumento de população em todos os distritos, incluindo os centrais, mas mantendo as diferentes proporções de população entre distritos centrais e periféricos. Esse aumento de população nos bairros centrais parece ser motivado por melhor infraestrutura, especialmente de transporte público, e proximidade do trabalho, considerando-se as horas perdidas no transito da vida diária. 
Comparando-se a densidade populacional da cidade de São Paulo com outras cidades no mundo (Figura 13), pode-se observar que mesmo com uma densidade populacional média em torno de 74 hab/ha (IBGE, 2010), similar a outras grandes cidades no mundo, a densidade do seu distrito mais denso é uma das menores. Sendo a disponibilidade de transporte e infraestrutura diretamente ligada à densidade urbana, pode-se pensar que há uma equidade na distribuição destas infraestruturas pela cidade, o que não é verdade. São Paulo apresenta áreas com infraestruturas razoáveis de transporte que não tem necessariamente altos valores de densidade populacional e vice-versa (GUSSON, MADEIRA, DUARTE, 2012).

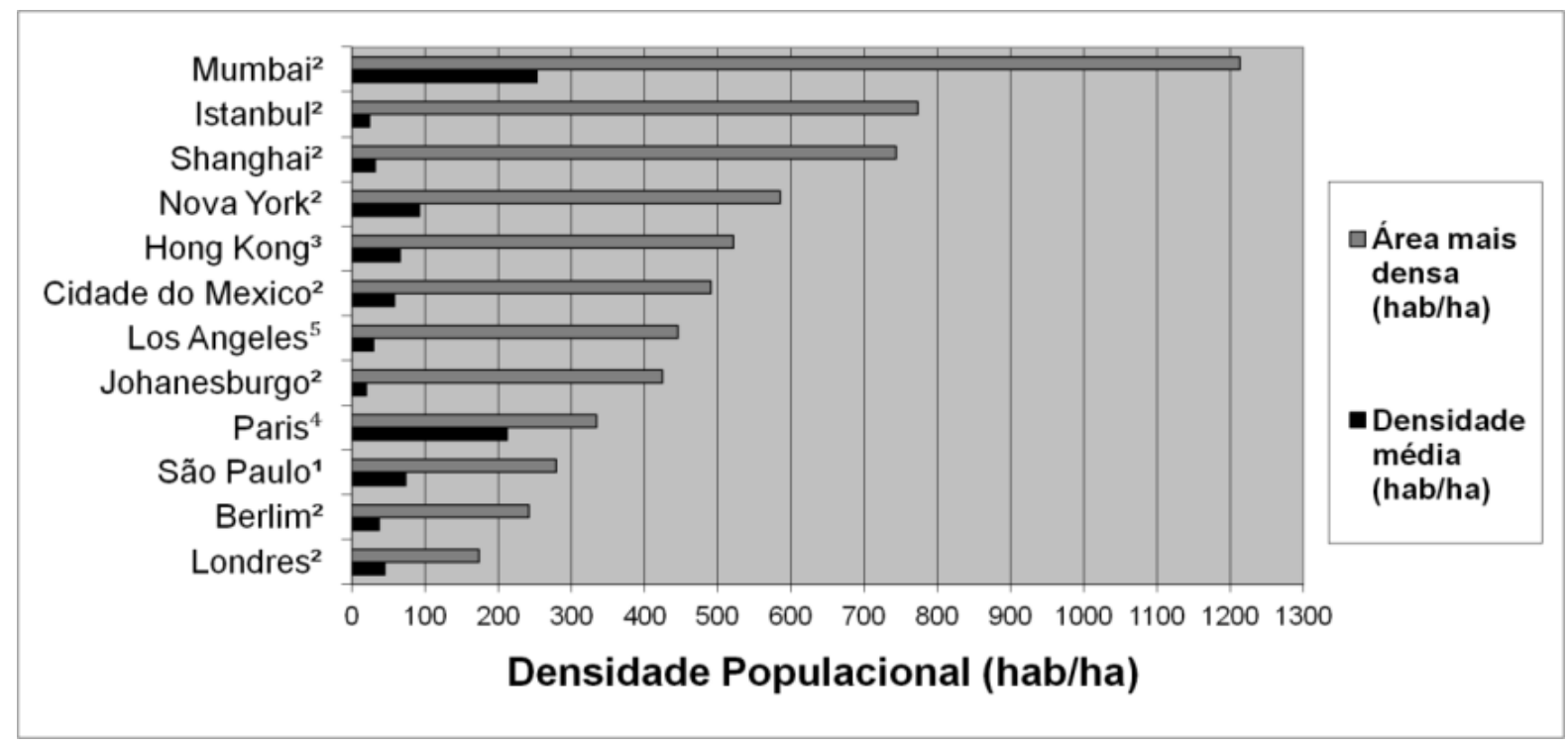

Figura 13 - Grandes cidades, com suas densidades médias e áreas mais densas. (Fonte: GUSSON, MADEIRA, DUARTE, 2012, sobre dados do ${ }^{1}$ IBGE (2010), ${ }^{2}$ BURDETT; SUDJIC (2011), ${ }^{3}$ Hong Kong Special Administrative Region (2012), ${ }^{4}$ INSEE (2009), ${ }^{5}$ CAMPOLI; MacLEAN (2007).

De um total de 97 distritos analisados, com exceção dos primeiros mais densos, verifica-se que, de forma geral, a densidade demográfica não é diretamente relacionada com a densidade construída. A cidade de São Paulo não tem uma alta densidade construída, já que o coeficiente de aproveitamento (CA) médio é 1 . Valores de CA maiores do que 5 podem ser encontrados em alguns distritos nas áreas centrais, embora uma densidade populacional mais alta apareça também nos distritos periféricos, explicando um fenômeno que foi bastante pronunciado nas últimas décadas, a dispersão da população (Figura 14).

Uma alta densidade construída não significa necessariamente uma alta densidade populacional. No município de São Paulo é possível se verificar essas discrepâncias e, para isso, dentre os 97 distritos, alguns distritos foram selecionados para uma leitura mais detalhada. Os distritos da Bela Vista, Santa Cecília e Moema tem em comum a predominância do uso residencial vertical. Os valores de densidade construída e populacional, no entanto, variam muito (Figura 15). De acordo com os resultados encontrados, uma alta taxa de verticalização não significa necessariamente altos valores de densidade construída. Em Moema, por exemplo, mesmo sendo um distrito onde a predominância tipológica seja de edifícios residenciais verticais de alto padrão, o coeficiente de aproveitamento médio é inferior a 2. As razões para isso estão relacionadas a fatores como a classe social predominante, ao tamanho das unidades habitacionais e ao padrão de ocupação dos lotes (GUSSON, MADEIRA, DUARTE, 2012). 


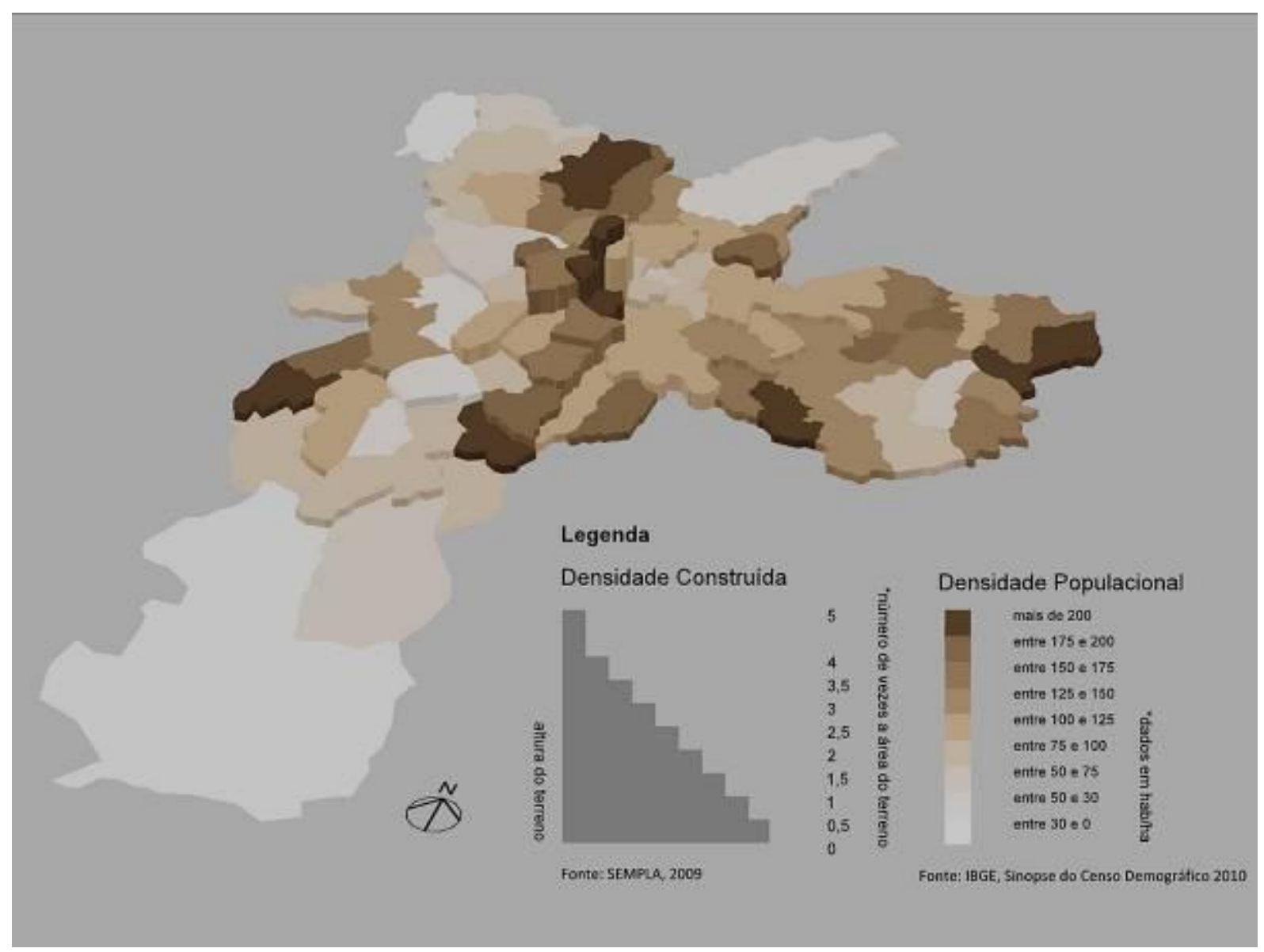

Figura 14 - Densidade construída e densidade populacional, por distritos, na cidade de São Paulo (GUSSON, MADEIRA, DUARTE, 2012 sobre dados da Sempla (2009) e IBGE (2010)).

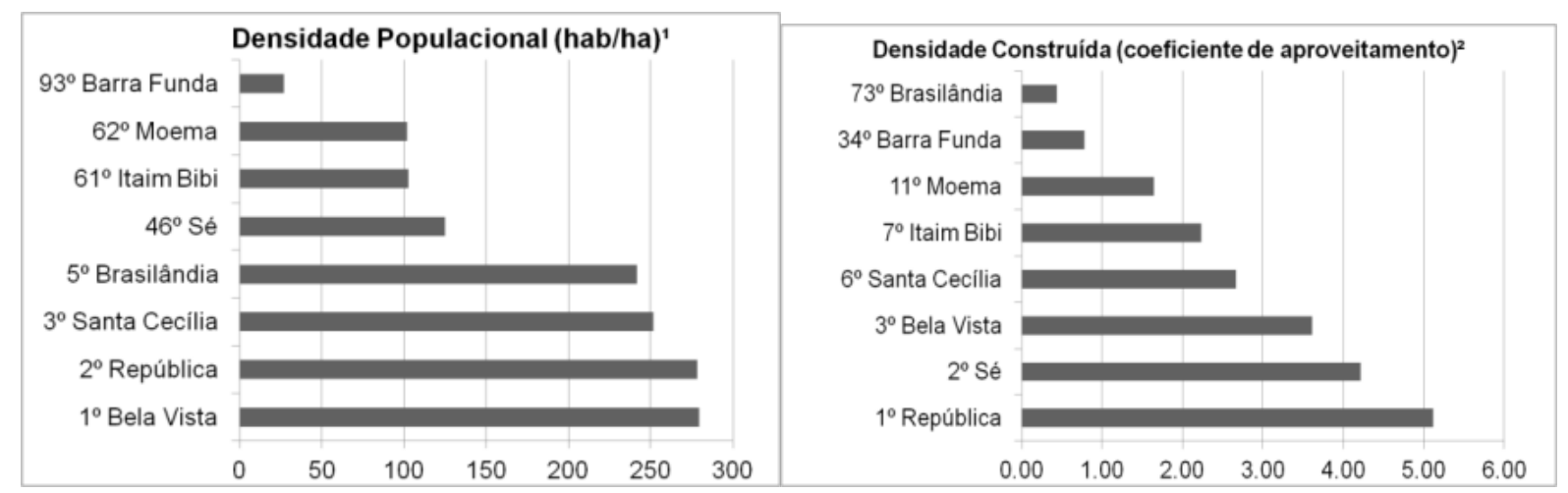

Figura 15 - Densidade populacional e construída nos distritos selecionados (GUSSON, MADEIRA, DUARTE, 2012)

Altos valores de densidade urbana podem ser alcançados com diferentes tipologias edificáveis, não só a vertical, mas também tipologias horizontais de média altura. Em São Paula, as favelas podem chegar a ter mais do que 1000 hab/ha (Figura 16), como já apontado por Samora (2010), mas sem qualidade de vida e em regiões pobres de infraestrutura. Essa mesma densidade pode ser alcançada em áreas centrais, com mais qualidade ambiental, pois as mesmas já possuem uma infraestrutura adequada para atender essa demanda (GUSSON, MADEIRA, DUARTE, 2012). 


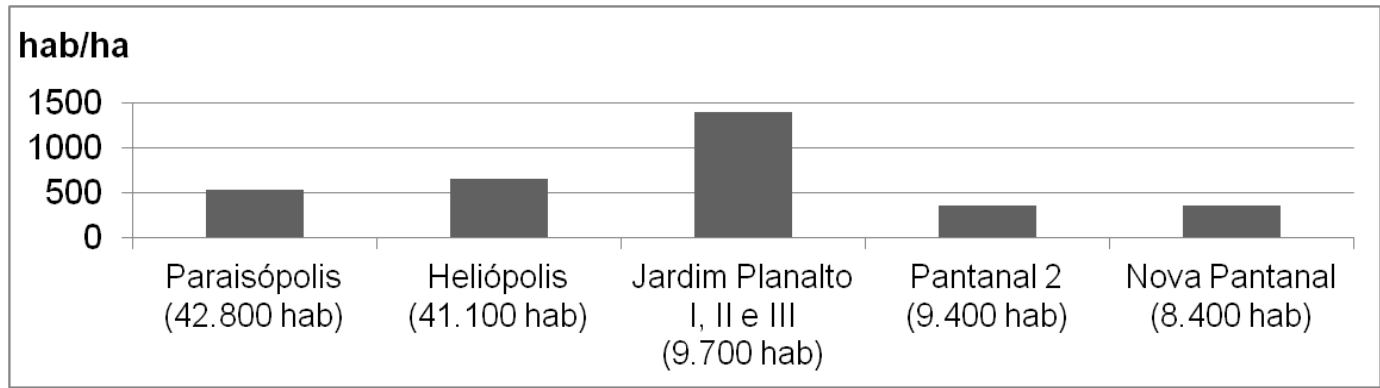

Figura 16 - Densidade populacional nas favelas de São Paulo (GUSSON; MADEIRA; DUARTE, 2012, elaborado sobre dados do IBGE (2011) e São Paulo/HABISP (2009))

Com o cruzamento desses dados, conclui-se que nem sempre há uma relação direta entre densidade construída e densidade populacional em São Paulo, confirmando que a verticalização não está necessariamente associada à alta densidade populacional. Pelo contrário, a mesma tipologia pode ser encontrada em muitos distritos com densidades muito diferentes, porque o CA máximo determinado pela legislação municipal assume diferentes significados dependendo da renda média da população daquele distrito, o que se reflete no tamanho das unidades habitacionais, por exemplo (GUSSON, MADEIRA, DUARTE, 2012).

\subsection{Contexto climático, atual e futuro}

São Paulo localiza-se na região Sudeste do Brasil, na latitude $23^{\circ} 32^{\prime} \mathrm{S}$, longitude $46^{\circ} 37^{\prime} \mathrm{W}$, a $60 \mathrm{Km}$ do mar. A altitude varia de $720 \mathrm{~m}$ a $850 \mathrm{~m}$. O clima é subtropical (Köppen Cfa) com temperaturas amenas. A cidade tem verões quentes e úmidos, com temperaturas do ar variando entre $22^{\circ} \mathrm{C}$ e $30^{\circ} \mathrm{C}$, e verões amenos com temperaturas entre $10^{\circ} \mathrm{C}$ e $22^{\circ} \mathrm{C}$. A precipitação é, em média, $1400 \mathrm{~m}$, distribuída não uniformemente ao alongo do ano, com os meses mais chuvosos em dezembro, janeiro, fevereiro e março, e os meses mais secos em junho, julho e agosto, quando são frequentes as inversões térmicas. A radiação solar pode exceder os $1000 \mathrm{~W} / \mathrm{m}^{2}$ em dias de céu claro no verão, quando também são frequentes as tempestades nos finais de tarde (Figura 17).
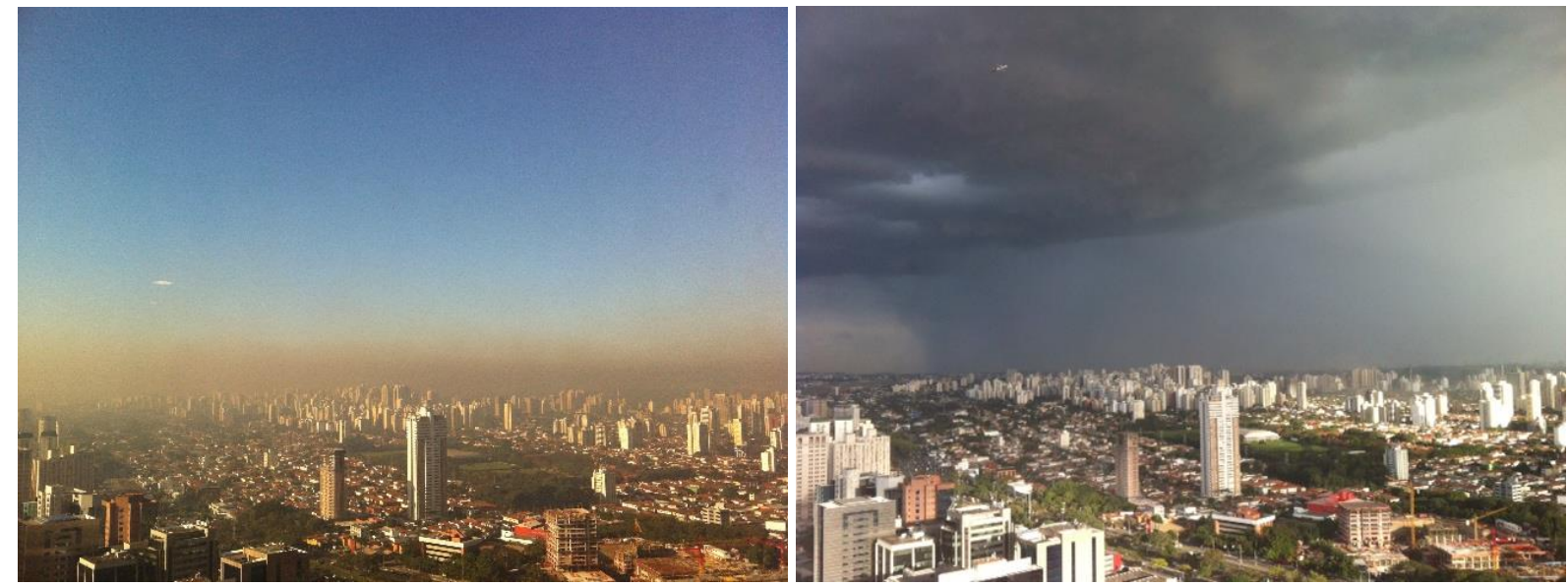

Figura 17 - Dois aspectos climáticos de São Paulo vistos do alto, a partir de um edifício comercial, em direção à zona sul da cidade; à esquerda, inversão térmica durante a estação seca no inverno, ao amanhecer, julho de 2012, e, à direita, uma tempestade se aproximando sobre a mesma área (Fotos: Júlio Calsinski, 2012).

Simulações sobre o efeito da urbanização em São Paulo mostram que a ilha de calor urbana faz com que haja uma propagação mais rápida da frente de brisa marítima até o centro da RMSP. Devido à 
forte convergência gerada pela ilha de calor urbana no centro da RMSP, a frente de brisa permanece estacionada nessa região por algumas horas, gerando correntes ascendentes mais fortes nessa região que ocasionam um maior transporte de umidade na vertical. Como consequência de um maior fluxo de calor sensível e um menor fluxo de calor latente sobre a área urbana, a razão de Bowen chega a ser cerca de 3,5 vezes maior do que seria caso essas regiões fossem cobertas por vegetação (FREITAS, 2003).

A presença das represas de Guarapiranga e Billings nas porções sul e sudoeste ocasiona a formação de brisas lacustres nessa região. Essas brisas causam uma alteração no campo de temperatura e umidade não somente das regiões próximas a elas, mas também em toda a RMSP, principalmente durante o dia. A presença dessas represas contribui para uma temperatura cerca de $1^{\circ} \mathrm{C}$ menor nas regiões próximas a elas e, nas regiões mais distantes dentro da RMSP, temperaturas entre $0,1^{\circ} \mathrm{e}$ $0,8^{\circ} \mathrm{C}$ menores no período da tarde. Durante a noite os efeitos são mais localizados na própria região das represas (FREITAS, 2003).

Sobre a ilha de calor urbana, em suas diversas manifestações, as divergências que têm sido encontradas em regiões tropicais já foram detectadas em algumas cidades brasileiras, incluindo São Paulo e Rio de Janeiro. Segundo Arnfield (2003), a ilha de calor urbana parece ser mais diversa do que se suspeitava inicialmente. Na superfície, a ilha de calor urbana é de fácil entendimento e visualização como resultante dos efeitos da urbanização. No entanto, a ilha de calor urbana é um fenômeno multifacetado cuja definição e bases físicas são bastante complexas. Um entendimento adequado dos diferentes tipos e suas definições, dinâmicas e processos físicos envolvidos é fundamental para a proposição de medidas de mitigação (ROTH, 2013). Além das diferenças do meio onde são estudadas (ar, superfície e subsuperfície), e do sistema de monitoramento empregado (ARNFIELD, 2003), crescem as evidências da defasagem de fase e de amplitudes da ilha de calor urbana em cidades tropicais, quando comparadas às latitudes médias e altas (CHOW; ROTH, 2006; MARQUES FILHO et al., 2009).

A ilha de calor em cidades tropicais e subtropicais é menos intensa do que em altas latitudes, e alguns estudos observacionais indicam que ela pode ser mais pronunciada durante o dia, divergindo da definição original de Oke (1973), e muito determinada pelo conteúdo de umidade da atmosfera e do solo em áreas rurais adjacentes (ROTH, 2007). Assim como em outros climas tropicais e subtropicais, Ferreira et al. (2012) identificaram a ilha de calor em São Paulo com um caráter diurno, com intensidade máxima à tarde (14h-16h LST) e um mínimo pela manhã (07h-08h LST) em quase todos os meses monitorados em 2004. A intensidade máxima variou de $2.6^{\circ} \mathrm{C}$ em julho (16h LST) a $5.5^{\circ} \mathrm{C}$ em setembro (15h LST).

Com relação ao clima futuro, para as mudanças de temperatura na RMSP, os modelos apontam que haverá um aumento do número de dias quentes, diminuição do número de dias frios, aumento do número de noites quentes e diminuição no número de noites frias, consistentes com um cenário de aquecimento global. As tendências positivas de aumento do número de noites quentes no Sudeste do Brasil, apresentadas em postos meteorológicos representativos da RMSP (Estação meteorológica IAG/USP na Água Funda) e de Campinas, variam de 5\% na década de 1950 até quase $35 \%$ no início do século XXI. A tendência de diminuição do número de dias frios apresentou frequência de $25-30 \%$ na década de 1970, chegando a até 5-10\% em 2001-2002 (MARENGO, 2007).

Essas tendências, entretanto, não se manifestarão de forma linear, sendo marcadas por oscilações térmicas e pluviométricas e pelo aumento da ocorrência de eventos meteorológicos e climáticos extremos e cuja previsibilidade ainda é muito reduzida. São previstos aumentos na frequência e na duração de períodos quentes e na duração de ondas de calor na RMSP, com uma forte variabilidade interanual (NOBRE, YOUNG, 2011).

As leituras dos dados medidos ao longo do tempo revelam as mudanças que estão ocorrendo no clima, em específico na cidade de São Paulo. Os dados médios de temperatura e umidade relativa registrados nas décadas de 1940, 1950, 1960, 1970, 1980, 1990 e 200 foram respectivamente: 
$17,7^{\circ} \mathrm{C} / 85,1 \%, \quad 18,0^{\circ} \mathrm{C} / 85,5 \%, \quad 18,3^{\circ} \mathrm{C} / 82,5 \%, \quad 18,7^{\circ} \mathrm{C} / 81,9 \%, \quad 19,0^{\circ} \mathrm{C} / 81,3 \%, \quad 19,4^{\circ} \mathrm{C} / 80,7 \%$, e $19,5^{\circ} \mathrm{C} / 80,0 \%$. Portanto (Tabelas 3 e 4), já ocorreu aumento de aproximadamente $2^{\circ} \mathrm{C}$ de temperatura do ar e redução nos valores de umidade relativa de aproximadamente $5 \%$ desde o início das medições meteorológicas na estação IAG/Água Funda, até o presente (ALVES, 2015; ALVES, DUARTE, GONÇALVES, 2015a; 2015b).

A comparação dos valores médios de temperaturas mensais ao longo dos anos revela a mudança climática já em curso na cidade de São Paulo com tendência de elevação nos valores médios de temperatura nas últimas décadas e, consequentemente, umidade relativa mais baixa (a umidade específica não registrou tendência significativa de alteração).

Sob o aspecto das temperaturas máximas e mínimas (absolutas e médias), observa-se que as alterações nas temperaturas máximas não são tão significativas quanto às das mínimas, estas estão mais altas no presente que no passado, assim, as amplitudes mensais (diferença entre máxima e mínima absolutas) e diferença entre os valores médios das temperaturas máximas e mínimas, apresenta números gradativamente menores, indicando um achatamento das temperaturas diárias e mensais, tendência que se mantém para os dados futuros, conforme simulação.

De acordo com o Instituto de Astronomia, Geofísica e Ciências Atmosféricas da Universidade de São Paulo, considerando os dados históricos da estação meteorológica IAG-USP, 67 WMO 83004, localizada na zona sul de São Paulo, no bairro da Água Funda, a temperatura média das máximas aumentou $1,8^{\circ} \mathrm{C}$ entre $1933-2014$, e a média das mínimas aumentou $2,2^{\circ} \mathrm{C}$ no mesmo período, desde que os registros se iniciaram, em 1933 (IAG/USP, 2015).

Todos os meses de 2014 apresentaram temperaturas médias mensais acima das médias históricas, destacando-se as altas temperaturas e a estiagem severa. Durante o verão, janeiro e fevereiro apresentaram temperaturas acima daquelas observadas em décadas e umidade relativa abaixo das historicamente registradas. Enquanto as médias históricas para esses meses eram, respectivamente, $21,6^{\circ} \mathrm{C}$ e $21,8^{\circ} \mathrm{C}$, os valore médios registrados em 2014 foram $24,2^{\circ} \mathrm{C}$ e $24,3^{\circ} \mathrm{C}$. Janeiro de 2014 foi $2.2^{\circ} \mathrm{C}$ mais quente do que o esperado, enquanto fevereiro foi $1.9^{\circ} \mathrm{C}$ mais quente do que a média histórica, ambos com temperatura máxima de $36,1^{\circ} \mathrm{C}$, as máximas já registradas desde que os registros se iniciaram em 1933 , superadas somente em janeiro de 2015 , com $36,2^{\circ} \mathrm{C}$. Considerandose a máxima absoluta já registrada, essa foi de $37,2^{\circ} \mathrm{C}$, em outubro de 2014 . Esse mesmo mês teve a máxima amplitude térmica já registrada, de $20,7^{\circ} \mathrm{C}$, em 12 de outubro, com mínima de $15,1^{\circ} \mathrm{C}$ e máxima de $35,8^{\circ} \mathrm{C}$. Ainda em 2014 outro recorde foi quebrado: foram 109 dias com temperaturas iguais ou maiores do que $30^{\circ} \mathrm{C}$, enquanto a média é de 47 dias. Enquanto janeiro e fevereiro são geralmente caraterizados por alta pluviosidade e umidade relativa de cerca de $83 \%$, os primeiros dois meses de 2014 apresentaram baixas taxas de precipitação valore menores de umidade relativa, 75\% e $73 \%$ respectivamente (IAG/USP, 2015).

Para a simulação de dados futuros produzidas por Llopart et al. (2014), cujo método foi descrito nos capítulos 5 e 7 , os cenários mantêm a mesma tendência que os dados medidos dos anos passados revelaram (Tabelas 5 e 6 ).

\footnotetext{
${ }^{67}$ Localizada no Parque Estadual das Fontes do Ipiranga (anteriormente Parque do Estado), bairro da Água Funda, São Paulo, latitude $23,6512^{\circ} \mathrm{S}$, longitude $46,6224^{\circ} \mathrm{W}$ altitude $799,2 \mathrm{~m}$. Disponível em: < http://www.estacao.iag.usp.br/Boletins/2014.pdf>. Acesso em 03/05/2015.
} 
Tabela 3 - Variação da temperatura média mensal na cidade de São Paulo ao longo dos anos. Dados de 1933 a 2014 medidos pela Estação Meteorológica do IAG-USP Parque de Ciência e Tecnologia da USP (ALVES, 2015; ALVES, DUARTE, GONÇALVES, 2015a; 2015b).

Temperaturas $\left({ }^{\circ} \mathrm{C}\right)$ : médias mensais

\begin{tabular}{l|l|l|l|l|l|l|l|l|l|l|l|l|} 
JAN & FEV & MAR & ABR & MAI & JUN & JUL & AGO & SET & OUT & NOV & DEZ & MÉDIA
\end{tabular}

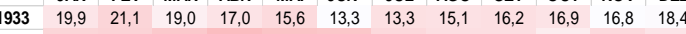
\begin{tabular}{l|llllllllllll|}
$\mathbf{1 9 3 4}$ & 20,6 & 21,1 & 20,3 & 18,7 & 16,5 & 15,6 & 13,7 & 15,2 & 16,2 & 16,3 & 18,8 & 19,5 \\
\hline $\mathbf{1 9 3 5}$ & 20,2 & 20,7 & 20,6 & 17,3 & 14,4 & 15,9 & 15,7 & 14,9 & 16,2 & 17,2 & 18,4 & 20,8 \\
\hline
\end{tabular} \begin{tabular}{lllllllllllll}
1935 & 20,2 & 20,7 & 20,6 & 17,3 & 14,4 & 15,9 & 15,7 & 14,9 & 16,2 & 17,2 & 18,4 & 20,8 \\
\hline 1936 & 21,4 & 19,7 & 19,5 & 18,5 & 18,8 & 17,0 & 14,9 & 14,0 & 15,4 & 17,6 & 18,0 & 19,9
\end{tabular} $\begin{array}{lllllllllllll}1936 & 21,4 & 19,7 & 19,5 & 18,5 & 18,8 & 17,0 & 14,9 & 14,0 & 15,4 & 17,6 & 18,0 & 19,9 \\ 1937 & 19,0 & 21,1 & 20,4 & 17,9 & 15,0 & 14,9 & 15,3 & 16,3 & 15,8 & 16,7 & 17,6 & 18,3\end{array}$ \begin{tabular}{l|lllllllllllllll}
1938 & 22,5 & 20,7 & 21,2 & 18,4 & 15,8 & 14,7 & 14,2 & 14,9 & 16,4 & 17,3 & 18,5 & 19,6
\end{tabular} $\begin{array}{llllllllllllll}1939 & 20,8 & 21,4 & 21,3 & 18,5 & 17,5 & 15,4 & 12,9 & 16,2 & 15,6 & 17,6 & 19,1 & 19,8 \\ 1940 & 21,4 & 19,8 & 2,9 & 20,1 & 17,8 & 15, & 16,4 & 16,4 & 16, & 17,3 & 18,3 & 22,6\end{array}$ $\begin{array}{llllllllllllll}1940 & 21,4 & 19,8 & 20,9 & 20,1 & 17,8 & 15,9 & 16,4 & 16,4 & 16,2 & 17,3 & 18,3 & 22,6\end{array}$ \begin{tabular}{llllllllllllll}
1941 & 21,8 & 22,0 & 19,9 & 20,8 & 17,4 & 14,5 & 14,0 & 17,0 & 13,8 & 16,7 & 18,6 & 19,7 \\
\hline
\end{tabular} $\begin{array}{llllllllllllll}1942 & 20,7 & 21,5 & 20,7 & 18,3 & 15,9 & 14,5 & 11,6 & 14,8 & 15,3 & 17,1 & 18,4 & 18,3 \\ 1943 & 19,8 & 20,3 & 20,3 & 163 & 16,5 & 15, & 14,0 & 13,4 & 15, & 17,1 & 18,3 & 18,4\end{array}$ \begin{tabular}{llllllllllllll}
1943 & 19,8 & 20,3 & 20,3 & 16,3 & 16,5 & 15,6 & 14,0 & 13,4 & 15,0 & 17,1 & 18,3 & 18,4 \\
\hline
\end{tabular} \begin{tabular}{llllllllllllll}
1944 & 21,2 & 20,2 & 20,7 & 17,0 & 15,3 & 15,0 & 12,9 & 15,9 & 17,1 & 19,7 & 17,6 & 19,2 \\
\hline & 20,2 & 21,5 & 19 & 18,0 & 14,5 & 13,4 & 14,4 & 17,1 & 157, & 17,7 & 18,3 & 18,6
\end{tabular} $\begin{array}{llllllllllllll}1945 & 20,2 & 21,5 & 19,8 & 18,0 & 14,5 & 13,4 & 14,4 & 17,1 & 15,7 & 17,7 & 18,3 & 18,6\end{array}$ $\begin{array}{lllllllllllll}1946 & 20,8 & 22,6 & 19,9 & 17,3 & 17,8 & 14,8 & 13,8 & 16,6 & 17,8 & 18,4 & 18,9 & 19,8 \\ 1947 & 21,2 & 22, & 19 & 18,0 & 17,8 & 16, & 13,4 & 14,8 & 16,1 & 15,2 & 16,9 & 18,6\end{array}$ $\begin{array}{lllllllllllllll}1948 & 22,0 & 21,4 & 19,0 & 18,4 & 16,3 & 15,2 & 16,2 & 14,1 & 16,7 & 16,7 & 18,7 & 19,4\end{array}$ $\begin{array}{lllllllllllll}1949 & 20,6 & 19,9 & 22,0 & 17,7 & 15,7 & 16,0 & 14,5 & 15,6 & 16,1 & 16,6 & 17,6 & 19,7\end{array}$ \begin{tabular}{llllllllllllll}
1950 & 20,5 & 20,8 & 20,6 & 18,8 & 17,5 & 16,1 & 14,8 & 17,0 & 17,1 & 16,9 & 17,8 & 20,0 \\
\hline 1951 & 20,3 & 20,8 & 19,8 & 15, & 15,7 & 14,4 & 13,1 & 13,9 & 16,3 & 17,5 & 19,0 & 18,5
\end{tabular} $\begin{array}{llllllllllllll}1951 & 20,3 & 20,8 & 19,8 & 15,9 & 15,7 & 14,4 & 13,1 & 13,9 & 16,3 & 17,5 & 19,0 & 18,5 \\ 1952 & 20,7 & 20,0 & 20,5 & 17,1 & 16,7 & 15, & 14,9 & 16,7 & 16,0 & 18,0 & 19,0 & 19,8\end{array}$ $\begin{array}{lllllllllllllll}1953 & 21,8 & 20,6 & 20,8 & 18,1 & 16,9 & 15,5 & 13,3 & 15,7 & 17,7 & 18,3 & 18,6 & 19,4\end{array}$ $\begin{array}{llllllllllllll}1954 & 22,1 & 21,6 & 20,8 & 18,2 & 16,6 & 16,3 & 15,6 & 16,4 & 17,7 & 17,8 & 18,6 & 19,6\end{array}$ $\begin{array}{lllllllllllll}1955 & 20,9 & 21,9 & 20,7 & 18,5 & 15,8 & 15,0 & 14,8 & 15,3 & 16,6 & 16,4 & 16,9 & 20,2 \\ 1956 & 23,4 & 21,2 & 20,2 & 18 & 15,0 & 13,4 & 13,9 & 13,7 & 17,7 & 17,1 & 10,8 & 19,1\end{array}$ $\begin{array}{llllllllllllll}1956 & 23,4 & 21,2 & 20,2 & 18,2 & 15,0 & 13,4 & 13,9 & 13,7 & 17,7 & 17,1 & 16,8 & 19,1 \\ 1957 & 21,1 & 20,3 & 20,3 & 18,1 & 16,0 & 15,0 & 14,4 & 15,8 & 15,8 & 19,1 & 18,7 & 20,7\end{array}$ $\begin{array}{llllllllllllll}1958 & 21,5 & 22,1 & 20,0 & 17,8 & 16,1 & 15,4 & 16,0 & 17,9 & 16,8 & 18,3 & 20,5 & 21,5\end{array}$ \begin{tabular}{lllllllllllllllll|}
1959 & 21,7 & 22,0 & 20,0 & 21,4 & 17,7 & 15,0 & 16,5 & 16,1 & 18,3 & 18,8 & 19,1 & 20,2
\end{tabular} \begin{tabular}{llllllllllllllll}
1960 & 20,1 & 20,3 & 20,1 & 18,4 & 14,8 & 15,0 & 15,1 & 17,0 & 17,2 & 19,7 & 19,2 & 20,5 \\
\hline
\end{tabular} $\begin{array}{llllllllllllll}1961 & 21,4 & 21,8 & 20,5 & 19,8 & 16,9 & 16,4 & 15,7 & 17,3 & 19,7 & 20,1 & 20,4 & 20,2\end{array}$ $\begin{array}{lllllllllll}20,7 & 18,2 & 15,4 & 13,6 & 13,2 & 15,2 & 17,1 & 16,7 & 18,6 & 19,4\end{array}$ $\begin{array}{llllllllllllll}1964 & 22,2 & 21,1 & 21,9 & 18,6 & 16,1 & 14,3 & 15,4 & 16,7 & 19,7 & 18,9 & 20,6 & 20,2\end{array}$ $\begin{array}{lllllllllllllll}1965 & 19,6 & 21,0 & 19,3 & 19,2 & 16,5 & 16,8 & 15,3 & 16,9 & 18,8 & 18,3 & 19,6 & 21,6\end{array}$ $\begin{array}{lllllllllllll}1966 & 22,0 & 23,0 & 20,9 & 19,0 & 17,0 & 16,6 & 16,5 & 15,6 & 16,0 & 18,1 & 18,8 & 20,8\end{array}$ $\begin{array}{lllllllllllllll}1967 & 20,7 & 21,6 & 20,6 & 18,9 & 18,0 & 16,1 & 15,6 & 17,9 & 17,7 & 20,2 & 18,8 & 18,8\end{array}$ $\begin{array}{llllllllllllll}1968 & 20,8 & 19,9 & 20,4 & 16,8 & 18,2 & 14,5 & 14,2 & 14,5 & 16,2 & 17,7 & 19,9 & 21,4\end{array}$ $\begin{array}{llllllllllllll}1969 & 22,4 & 22,2 & 21,4 & 18,3 & 17,1 & 16,2 & 15,3 & 16,6 & 17,9 & 16,4 & 19,7 & 18,9 \\ \mathbf{1 9 7 0} & 20,8 & 21,4 & 21,5 & 19,2 & 18,7 & 17,3 & 15,1 & 15,5 & 16,3 & 17,4 & 17,7 & 22,0\end{array}$ $\begin{array}{llllllllllllll}1971 & 22,9 & 22,3 & 21,8 & 18,5 & 16,3 & 14,9 & 15,0 & 16,4 & 16,9 & 17,1 & 17,8 & 20,3\end{array}$ $\begin{array}{llllllllllllll}1972 & 21,7 & 21,1 & 21,7 & 17,6 & 17,7 & 17,7 & 15,4 & 17,0 & 17,5 & 18,7 & 19,8 & 21,2 \\ \mathbf{1 9 7 3} & 22,9 & 23,2 & 20,6 & 21,8 & 17,1 & 17,4 & 16,4 & 15,2 & 16,3 & 17,5 & 17,9 & 20,9\end{array}$ \begin{tabular}{lllllllllllll}
1973 & 22,9 & 23,2 & 20,6 & 21,8 & 17,1 & 17,4 & 16,4 & 15,2 & 16,3 & 17,5 & 17,9 & 20,9 \\
\hline 1974 & 21,5 & 22,3 & 21,0 & 18,1 & 17,2 & 14,8 & 15,8 & 16,6 & 16,8 & 17,2 & 19,4 & 19,7
\end{tabular} $\begin{array}{lllllllllllll}1974 & 21,5 & 22,3 & 21,0 & 18,1 & 17,2 & 14,8 & 15,8 & 16,6 & 16,8 & 17,2 & 19,4 & 19,7 \\ 1975 & 21,0 & 22,1 & 21,6 & 18,1 & 16,2 & 15,5 & 13,7 & 18,4 & 17,6 & 18,0 & 19,5 & 21,2\end{array}$ $\begin{array}{llllllllllllllll}1976 & 22,3 & 20,7 & 20,8 & 18,9 & 16,5 & 15,3 & 14,8 & 15,8 & 16,1 & 17,4 & 19,5 & 21,1\end{array}$ $\begin{array}{llllllllllllll}1977 & 21,9 & 23,6 & 22,1 & 18,8 & 17,3 & 16,8 & 18,3 & 18,0 & 18,2 & 19,8 & 20,2 & 19,7\end{array}$ \begin{tabular}{lllllllllllll}
1978 & 22,2 & 21,9 & 21,7 & 18,1 & 15,8 & 15,2 & 16,5 & 15,5 & 17,1 & 19,2 & 19,8 & 20,7 \\
$\mathbf{1 9 7 9}$ & 19,2 & 21,6 & 19,9 & 18,5 & 17,3 & 14,9 & 14,6 & 17,3 & 16,7 & 19,8 & 19,2 & 21,3 \\
\hline
\end{tabular} \begin{tabular}{lllllllllllll}
1979 & 19,2 & 21,6 & 19,9 & 18,5 & 17,3 & 14,9 & 14,6 & 17,3 & 16,7 & 19,8 & 19,2 & 21,3 \\
\hline 1980 & 20,7 & 21,7 & 22,9 & 19,9 & 18,7 & 15,4 & 16,3 & 16,9 & 15,7 & 19,3 & 19,5 & 22,5
\end{tabular} \begin{tabular}{lllllllllllll}
1980 & 20,7 & 21,7 & 22,9 & 19,9 & 18,7 & 15,4 & 16,3 & 16,9 & 15,7 & 19,3 & 19,5 & 22,5 \\
\hline 1981 & 21,8 & 23,0 & 21,3 & 18,8 & 18,1 & 15,2 & 13,7 & 16,2 & 18,3 & 17,1 & 20,4 & 20,7 \\
\hline
\end{tabular} \begin{tabular}{lllllllllllll}
1981 & 21,8 & 23,0 & 21,3 & 18,8 & 18,1 & 15,2 & 13,7 & 16,2 & 18,3 & 17,1 & 20,4 & 20,7 \\
\hline 1982 & 19,8 & 2,5 & 20,4 & 17, & 16,3 & 17,7 & 16,5 & 17,4 & 17,4 & 18,9 & 21,3 & 20,2
\end{tabular} $\begin{array}{lllllllllllll}1982 & 19,8 & 22,5 & 20,4 & 17,9 & 16,3 & 17,7 & 16,5 & 17,4 & 17,4 & 18,9 & 21,3 & 20,2\end{array}$ $\begin{array}{lllllllllllll}1983 & 22,2 & 22,5 & 20,9 & 19,7 & 18,7 & 16,2 & 17,1 & 16,4 & 15,4 & 18,2 & 20,9 & 21,3 \\ 1 & 23,5 & 24,0 & 21,1 & 19,1 & 19,5 & 17,3 & 16, & 15,3 & 16,4 & 19,6 & 20,3 & 20,3\end{array}$ $\begin{array}{llllllllllllll}1984 & 23,5 & 24,0 & 21,1 & 19,1 & 19,5 & 17,3 & 16,6 & 15,3 & 16,4 & 19,6 & 20,3 & 20,3 \\ 1925 & 20,2 & 2,5 & 22,1 & 20,7 & 17,0 & 14,7 & 14,7 & 17,4 & 17,0 & 19,0 & 20,3 & 21,0\end{array}$ $\begin{array}{llllllllllllll}1985 & 20,2 & 22,5 & 22,1 & 20,7 & 17,0 & 14,7 & 14,7 & 17,4 & 17,0 & 19,0 & 20,3 & 21,0 \\ 1906 & 23,0 & 22,4 & 21,6 & 20,6 & 19,1 & 16,2 & 15,1 & 17,3 & 16,9 & 18,6 & 21,2 & 21,3\end{array}$ $\begin{array}{llllllllllllll}1986 & 23,0 & 22,4 & 21,6 & 20,6 & 19,1 & 16,2 & 15,1 & 17,3 & 16,9 & 18,6 & 21,2 & 21,3 \\ 1987 & 22,9 & 22, & 21,0 & 20,8 & 17,0 & 15,0 & 17,8 & 15,7 & 16,4 & 18,9 & 20,2 & 21,6\end{array}$ $\begin{array}{lllllllllllllll}1988 & 23,4 & 20,9 & 21,7 & 19,6 & 17,1 & 14,6 & 12,9 & 16,5 & 18,6 & 17,8 & 18,9 & 21,0\end{array}$ $\begin{array}{lllllllllllll}1989 & 21,9 & 22,5 & 21,6 & 20,6 & 16,8 & 15,8 & 14,2 & 16,1 & 17,0 & 16,8 & 19,2 & 20,4\end{array}$ $\begin{array}{llllllllllllll}1990 & 23,0 & 22,4 & 22,6 & 21,9 & 16,8 & 15,6 & 14,1 & 15,2 & 16,2 & 20,0 & 21,9 & 21,0\end{array}$ $\begin{array}{lllllllllllll}1991 & 21,2 & 21,3 & 20,7 & 19,5 & 17,9 & 16,9 & 15,7 & 16,7 & 16,4 & 19,2 & 20,6 & 22,3 \\ 1992 & 21,8 & 2,5 & 21,9 & 20, & 19,0 & 18,0 & 15,4 & 15,3 & 16,8 & 19,1 & 19,7 & 20,6\end{array}$ $\begin{array}{llllllllllllll}1992 & 21,8 & 22,5 & 21,9 & 20,2 & 19,0 & 18,0 & 15,4 & 15,3 & 16,8 & 19,1 & 19,7 & 20,6\end{array}$ $\begin{array}{lllllllllllll}1993 & 22,9 & 21,7 & 22,1 & 20,9 & 17,9 & 16,0 & 16,8 & 15,4 & 16,9 & 20,2 & 22,3 & 21,8 \\ 1994 & 21,6 & 24,0 & 21,2 & 20,0 & 19,0 & 15,9 & 16,5 & 16,2 & 18,8 & 20,3 & 20,9 & 22,7\end{array}$ $\begin{array}{llllllllllllll}1995 & 23,5 & 22,4 & 21,6 & 19,8 & 17,7 & 16,5 & 17,8 & 18,7 & 17,6 & 18,1 & 20,5 & 21,2\end{array}$ $\begin{array}{llllllllllllll}1996 & 23,2 & 22,6 & 21,7 & 20,3 & 16,8 & 16,0 & 13,9 & 15,5 & 16,8 & 19,2 & 19,7 & 22,1 \\ 1997 & 22,1 & 22,6 & 20,8 & 19,4 & 17, & 15,9 & 17,1 & 17,1 & 18,4 & 19,6 & 21,5 & 23,1\end{array}$ $\begin{array}{llllllllllllll}1998 & 23,9 & 23,6 & 22,5 & 20,6 & 17,1 & 15,6 & 16,0 & 18,4 & 18,1 & 18,2 & 19,2 & 22,0\end{array}$ \begin{tabular}{lllllllllllllllll}
1999 & 23,1 & 22,9 & 22,4 & 19,3 & 16,5 & 15,7 & 16,3 & 16,4 & 17,7 & 17,2 & 18,4 & 21,7 \\
\hline & 22,0 & 21,6 & 20,9 & 19,8 & 17,3 & 17,3 & 14,6 & 16,2 & 17,4 & 20,9 & 20,5 & 21,9
\end{tabular} $\begin{array}{lllllllllllll}2001 & 23,4 & 21,6 & 20,9 & 19,8 & 17,3 & 17,3 & 14,6 & 16,2 & 17,4 & 20,9 & 20,5 & 21,9\end{array}$ $\begin{array}{llllllllllllll}2001 & 23,4 & 23,6 & 22,7 & 21,8 & 17,5 & 16,9 & 16,5 & 17,8 & 17,7 & 19,3 & 20,8 & 21,3 \\ 2002 & 22,3 & 21,4 & 23,6 & 22 & 18,9 & 18 & 15,7 & 19, & 17,1 & 22,0 & 21,4 & 22,0\end{array}$ $\begin{array}{llllllllllllll}2002 & 22,3 & 21,4 & 23,6 & 22,2 & 18,9 & 18,6 & 15,7 & 19,2 & 17,1 & 22,0 & 21,4 & 22,6 \\ 2003 & 22,2 & 24,2 & 21,8 & 20,3 & 17,3 & 18,1 & 16,7 & 15,1 & 17,4 & 19,1 & 20,3 & 21,9\end{array}$ $\begin{array}{lllllllllllll}2004 & 22,2 & 24,2 & 21,8 & 20,3 & 17,3 & 18,1 & 16,7 & 15,1 & 17,4 & 19,1 & 20,3 & 21,9\end{array}$ $\begin{array}{lllllllllllll}2005 & 22,0 & 20,4 & 21,7 & 21,4 & 18,7 & 18,0 & 16,0 & 18,2 & 17,1 & 20,0 & 19,2 & 20,4\end{array}$ $\begin{array}{lllllllllllll}2005 & 22,0 & 21,4 & 21,7 & 21,4 & 18,7 & 18,0 & 16,0 & 18,2 & 17,1 & 20,0 & 19,6 & 20,4 \\ 2006 & 22,6 & 22,8 & 22,4 & 19,7 & 16,1 & 16, & 16,9 & 17,4 & 17,4 & 19,1 & 20,1 & 22,0\end{array}$ $\begin{array}{lllllllllllll}2007 & 22,6 & 2,8 & 23,0 & 21,2 & 16,9 & 17,3 & 15,3 & 17,0 & 19,1 & 20,1 & 19,8 & 21,7\end{array}$ $\begin{array}{lllllllllllll}2007 & 22,2 & 22,8 & 23,0 & 21,2 & 16,9 & 17,3 & 15,3 & 17,0 & 19,1 & 20,1 & 19,8 & 21,7\end{array}$ $\begin{array}{lllllllllllll}2000 & 21,1 & 22,1 & 21,5 & 20,2 & 16,8 & 16,4 & 16,1 & 17,6 & 17,0 & 19,8 & 19,6 & 20,3\end{array}$ $\begin{array}{llllllllllllll}2011 & 22,9 & 22,9 & 22,4 & 19,5 & 18,4 & 14,8 & 15,8 & 17,3 & 18,9 & 19,0 & 23,3 & 21,8\end{array}$ $\begin{array}{llllllllllllll}2010 & 22,9 & 23,8 & 22,2 & 19,7 & 17,8 & 15,6 & 17,4 & 16,0 & 18,5 & 17,7 & 20,1 & 22,0 \\ \mathbf{2 0 1 1} & 23,2 & 23,3 & 21,0 & 20,7 & 16,7 & 14,8 & 16,4 & 17,2 & 17,1 & 19,3 & 18,9 & 21,0\end{array}$ $\begin{array}{lllllllllllllll}2012 & 20,7 & 23,4 & 21,6 & 20,5 & 17,4 & 17,0 & 16,4 & 17,8 & 18,9 & 21,1 & 20,0 & 23,7\end{array}$ $\begin{array}{lllllllllllllll}2013 & 21,2 & 22,7 & 21,4 & 19,3 & 17,8 & 17,5 & 15,4 & 16,5 & 18,0 & 18,9 & 20,7 & 22,3\end{array}$ $\begin{array}{llllll}2014 & 24,2 & 24,3 & 22,3 & 20,0\end{array}$
Tabela 4 - Variação da umidade relativa média mensal na cidade de São Paulo ao longo dos anos. Dados de 1933 a 2014 medidos pela Estação Meteorológica do IAGUSP/Parque de Ciência e Tecnologia da USP (ALVES, 2015; ALVES, DUARTE, GONÇALVES, 2015a; 2015b).

Umidade relativa (\%): médias mensais 1933 JAN FEV MAR ABR MAI JUN JUL AGO SET OUT NOV DEZ MÉDIA

1934

1935

1936

\begin{tabular}{r|r}
1937 & 90.0 \\
1938 & 83,1
\end{tabular}

\begin{tabular}{l|lllllllllllll}
$\mathbf{1 9 3 9}$ & 87,1 & 84,3 & 86,7 & 88,8 & 88,2 & 86,8 & 84,2 & 84,4 & 86,2 & 88,7 & 87,2 & 87,0 \\
\hline 1940 & 87,8 & 87,4 & 83,8 & 85,3 & 75,8 & 85,4 & 80,3 & 85,2 & 87,0
\end{tabular} \begin{tabular}{llllllllllllll}
1940 & 83,9 & 88,0 & 86,1 & 85,1 & 84,3 & 83,2 & 77,2 & 77,8 & 80,1 & 85,2 & 87,1 & 81,9 \\
\hline
\end{tabular} \begin{tabular}{l|lll|l|l|l|l|l|l|l|l|l|}
$\mathbf{1 9 4 1}$ & 83,3 & 83,4 & 87,9 & 81,3 & 82,0 & 84,6 & 85,5 & 79,9 & 86,3 & 82,0 & 85,4 & 87,0 \\
$\mathbf{1 9 4 2}$ & 83,9 & 86,4 & 87,3 & 86,9 & 85,3 & 85,0 & 87,3 & 79,8 & 84,1 & 82,8 & 84,4 & 86,8 \\
\hline
\end{tabular} $\begin{array}{lllllllllllllll}\mathbf{1 9 4 2} & 83,9 & 86,4 & 87,3 & 86,9 & 85,3 & 85,0 & 87,3 & 79,8 & 84,1 & 82,8 & 84,4 & 86,8 \\ \mathbf{1 9 4 3} & 85,1 & 85,8 & 87,2 & 87,0 & 82,1 & 85,1 & 83,5 & 84,0 & 84,0 & 88,2 & 85,6 & 87,6\end{array}$ \begin{tabular}{l|l|l|l|l|l|l|l|l|l|l|l|l|l|l}
1944 & 81,7 & 88,5 & 86,2 & 87,5 & 86,8 & 80,7 & 83,9 & 76,3 & 79,8 & 82,0 & 87,0 & 84,7 \\
\hline
\end{tabular} 1945 1947

\begin{tabular}{|l|l|l|}
1948 \\
1949 \\
\hline 1950
\end{tabular}

1950

1951

1952

1953

1955

1956

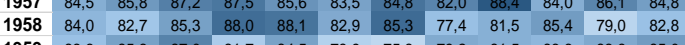
\begin{tabular}{lllllllllllllll}
1959 & 83,3 & 85,3 & 87,0 & 81,7 & 84,5 & 78,9 & 75,8 & 79,2 & 81,5 & 83,3 & 83,6 & 85,0 \\
\hline
\end{tabular} \begin{tabular}{l|l|l|l|l|l|l|l|l|l|l|l|l|}
1960 & 87,1 & 88,9 & 86,9 & 85,4 & 86,5 & 83,5 & 77,3 & 78,4 & 79,5 & 84,1 & 86,6 & 84,2 \\
\hline
\end{tabular} \begin{tabular}{lllllllllllllll}
1961 & 85,2 & 83,0 & 84,0 & 83,8 & 85,0 & 84,3 & 79,5 & 76,2 & 79,8 & 80,5 & 81,2 & 82,1 \\
1962 & 84,6 & 85,4 & 85,1 & 85,0 & 84,1 & 82,1 & 82,2 & 77,0 & 82,6 & 86,4 & 80,7 & 88,1 \\
\hline
\end{tabular} \begin{tabular}{lllllllllllllllll}
1963 & 82,6 & 85,4 & 85,1 & 85,0 & 84,1 & 82,1 & 82,2 & 77,0 & 82,6 & 86,4 & 80,7 & 88,1 \\
\hline 1964 & 82,3 & 82,8 & 81,1 & 79,9 & 79,6 & 75,0 & 71,0 & 70,1 & 83,9 & 81,2 & 79,5
\end{tabular} \begin{tabular}{l|llllllllllllll}
1963 & 82,0 & 83,3 & 82,8 & 81,1 & 79,9 & 79,6 & 75,0 & 71,0 & 70,1 & 83,9 & 81,2 & 79,5 \\
1964 & 82,7 & 86,5 & 79,8 & 86,1 & 85,5 & 84,5 & 85,1 & 81,4 & 78,6 & 87,2 & 82,1 & 86,1 \\
\hline 1965 & 86,7 & 85,5 & 84,1 & 84,4 & 84,7 & 6,2 & 82,5 & 74,1 & 80,0 & 83 & 85,1 & 85,
\end{tabular} \begin{tabular}{lllllllllllll}
$\mathbf{1 9 6 4}$ & 82,7 & 86,5 & 79,8 & 86,1 & 85,5 & 84,5 & 85,1 & 81,4 & 78,6 & 87,2 & 82,1 & 86,1 \\
\hline 1965 & 86,7 & 85,5 & 84,1 & 84,4 & 84,7 & 86,2 & 82,5 & 74,1 & 80,0 & 84,7 & 85,1 & 85,0
\end{tabular} \begin{tabular}{l|llllllllllll}
$\mathbf{1 9 6 5}$ & 86,7 & 85,5 & 84,1 & 84,4 & 84,7 & 86,2 & 82,5 & 74,1 & 80,0 & 84,7 & 85,1 & 85,0 \\
$\mathbf{1 9 6 6}$ & 83,1 & 80,9 & 81,9 & 84,7 & 84,2 & 76,3 & 76,5 & 79,9 & 80,8 & 83,7 & 85,4 & 85,7
\end{tabular} \begin{tabular}{l|lllllllllllllll}
19667 & 83,1 & 80,9 & 81,9 & 84,7 & 84,2 & 76,3 & 76,5 & 79,9 & 80,8 & 83,7 & 85,4 & 85,7 \\
\hline 196,7 & 87,0 & 85,1 & 80,7 & 82,0 & 80,0 & 74,3 & 80,3 & 80,0 & 82,7 & 85,3 \\
\hline
\end{tabular} \begin{tabular}{llllllllllllll}
1968 & 83,6 & 81,5 & 86,7 & 84,1 & 80,5 & 83,4 & 81,0 & 82,8 & 79,4 & 82,7 & 77,9 & 78,3 \\
\hline
\end{tabular} $\begin{array}{lllllllllllll}1969 & 80,5 & 83,7 & 83,4 & 84,9 & 81,1 & 80,7 & 80,1 & 78,7 & 82,4 & 87,3 & 85,9 & 82,4 \\ 1970 & 84,7 & 85,8 & 82,5 & 82,6 & 81,8 & 81,9 & 83,2 & 79,5 & 85,5 & 86,0 & 82,3 & 79,0\end{array}$ $\begin{array}{lllllllllllll}\mathbf{1 9 7 0} & 84,7 & 85,8 & 82,5 & 82,6 & 81,8 & 81,9 & 83,2 & 79,5 & 85,5 & 86,0 & 82,3 & 79,0 \\ \mathbf{1 9 7 1} & 76,2 & 81,5 & 84,1 & 85,9 & 84,9 & 85,5 & 81,2 & 81,2 & 80,9 & 83,9 & 83,3 & 84,4\end{array}$ $\begin{array}{llllllllllllll}\mathbf{1 9 7 1} & 76,2 & 81,5 & 84,1 & 85,9 & 84,9 & 85,5 & 81,2 & 81,2 & 80,9 & 83,9 & 83,3 & 84,4 \\ \mathbf{1 9 7 2} & 81,1 & 83,8 & 83,6 & 83,6 & 82,6 & 72,5 & 80,8 & 76,8 & 82,6 & 83,7 & 85,7 & 82,0\end{array}$ $\begin{array}{llllllllllllll}\mathbf{1 9 7 2} & 81,1 & 83,8 & 83,6 & 83,6 & 82,6 & 72,5 & 80,8 & 76,8 & 82,6 & 83,7 & 85,7 & 82,0 \\ \mathbf{1 9 7 3} & 81,6 & 81,8 & 85,6 & 85,2 & 84,5 & 80,1 & 81,8 & 84,9 & 85,9 & 83,7 & 83,2 & 83,8\end{array}$ $\begin{array}{lllllllllllll}\mathbf{1 9 7 3} & 81,6 & 81,8 & 85,6 & 85,2 & 84,5 & 80,1 & 81,8 & 84,9 & 85,9 & 83,7 & 83,2 & 83,8 \\ \mathbf{1 9 7 4} & 84,6 & 81,3 & 86,3 & 86,2 & 80,8 & 84,3 & 79,2 & 72,5 & 81,5 & 83,5 & 76,2 & 85,4\end{array}$ $\begin{array}{llllllllllllll}1974 & 84,6 & 81,3 & 86,3 & 86,2 & 80,8 & 84,3 & 79,2 & 72,5 & 81,5 & 83,5 & 76,2 & 85,4 \\ \mathbf{1 9 7 5} & 82,6 & 84,1 & 80,3 & 79,8 & 80,7 & 79,2 & 74,7 & 68,8 & 78,0 & 81,4 & 81,5 & 82,9\end{array}$

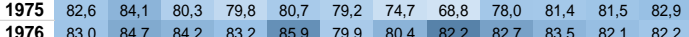
$\begin{array}{llllllllllllll}1976 & 83,0 & 84,7 & 84,2 & 83,2 & 85,9 & 79,9 & 80,4 & 82,2 & 82,7 & 83,5 & 82,1 & 82,2 \\ 1977 & 83,6 & 77,5 & 81,3 & 86,1 & 81,9 & 85,0 & 69,4 & 77,6 & 80,3 & 81,3 & 84,1 & 84,5\end{array}$ $\begin{array}{lllllllllllll}1977 & 83,6 & 77,5 & 81,3 & 86,1 & 81,9 & 85,0 & 69,4 & 77,6 & 80,3 & 81,3 & 84,1 & 84,5 \\ 1978 & 82,8 & 80,9 & 83,3 & 82,8 & 82,7 & 79,1 & 81,9 & 78,2 & 80,0 & 79,4 & 82,6 & 80,3\end{array}$ \begin{tabular}{lllllllllllllllll}
1979 & 82,8 & 83,4 & 83,6 & 82,8 & 82,5 & 81,3 & 77,8 & 79,5 & 80,7 & 81,3 & 81,3 & 83,5 \\
\hline
\end{tabular} \begin{tabular}{l|lll|l|llllllll}
1980 & 82,6 & 83,3 & 79,6 & 84,8 & 79,2 & 79,0 & 79,7 & 81,3 & 80,7 & 78,1 & 82,6 & 80,4
\end{tabular} $\begin{array}{lllllllllllllll}1981 & 84,4 & 79,1 & 82,8 & 81,8 & 83,1 & 78,9 & 77,6 & 78,1 & 72,1 & 84,8 & 84,3 & 79,9\end{array}$ \begin{tabular}{lllll|l|l|l|l|l|l|l|l|}
1982 & 84,6 & 79,0 & 87,2 & 84,5 & 81,2 & 82,3 & 79,2 & 79,8 & 77,8 & 82,1 & 82,7 & 86,5 \\
\hline 1983 & 83,6 & 82,4 & 83,8 & 86,5 & 85,5 & 85,5 & 75,8 & 74,5 & 889 & 84,8 & 77,3 & 828 \\
\hline
\end{tabular} \begin{tabular}{l|l|l|l|l|l|l|l|l|l|l|l|l|}
1983 & 83,6 & 82,4 & 83,8 & 86,5 & 85,5 & 85,5 & 75,8 & 74,5 & 88,9 & 84,8 & 77,3 & 82,8 \\
\hline 1984 & 77,0 & 77,5 & 83,1 & 84,7 & 80,9 & 77,8 & 76,7 & 81,4 & 76,6 & 77,6 & 80,5 & 84,1
\end{tabular} \begin{tabular}{l|llllllllllllllll}
1984 & 77,0 & 77,5 & 83,1 & 84,7 & 80,9 & 77,8 & 76,7 & 81,4 & 76,6 & 77,6 & 80,5 & 84,1 \\
\hline 1985 & 87,0 & 83,4 & 83,6 & 83,1 & 82,0 & 78,4 & 75, & 72,4 & 82, & 78,4 & 78,0 & 78,6
\end{tabular} \begin{tabular}{l|lllllllllllllllll}
1985 & 87,0 & 83,4 & 83,6 & 83,1 & 82,0 & 78,4 & 75,2 & 72,4 & 82,3 & 78,4 & 78,0 & 78,6
\end{tabular} \begin{tabular}{llllllllllllllll}
1986 & 78,8 & 83,2 & 84,0 & 82,2 & 82,4 & 79,0 & 81,0 & 79,5 & 79,6 & 77,7 & 76,9 & 85,2 \\
\hline 1987 & 81,3 & 80,8 & 81,8 & 83,2 & 86,0 & 82,5 & 74,0 & 74,7 & 83,3 & 82,4 & 80,0 & 80,9
\end{tabular} \begin{tabular}{l|llllllllllllllll}
1987 & 81,3 & 80,8 & 81,8 & 83,2 & 86,0 & 82,5 & 74,0 & 74,7 & 83,3 & 82,4 & 80,0 & 80,9
\end{tabular} \begin{tabular}{l|l|l|l|l|l|l|l|l|l|l|l|l|}
1988 & 81,2 & 88,0 & 81,5 & 86,8 & 87,4 & 81,4 & 81,5 & 72,9 & 73,8 & 83,8 & 81,4 & 83,2 \\
\hline
\end{tabular} \begin{tabular}{l|lllllllllllll}
1989 & 83,7 & 83,8 & 85,2 & 82,3 & 85,6 & 84,6 & 82,9 & 78,4 & 83,3 & 82,9 & 81,1 & 82,7
\end{tabular} \begin{tabular}{lllllllllllllll}
1990 & 80,9 & 80,1 & 82,3 & 80,5 & 81,4 & 80,3 & 86,4 & 80,7 & 79,3 & 80,4 & 80,9 & 80,3 \\
\hline
\end{tabular} \begin{tabular}{l|lll|l|l|l|l|l|l|lll}
1991 & 84,1 & 84,1 & 87,5 & 83,5 & 80,5 & 80,5 & 76,6 & 76,8 & 80,9 & 78,7 & 78,5 & 78,9
\end{tabular} \begin{tabular}{lllllllllllllll}
1992 & 81,6 & 77,0 & 82,0 & 79,5 & 82,1 & 79,0 & 82,3 & 83,8 & 86,0 & 83,5 & 83,8 & 80,0 \\
\hline 1993 & 79,1 & 8,9 & 82,7 & 8,6 & 80,9 & 8,8 & 76,8 & 75,8 & 85, & 77,6 & 72,8 & 79,4 \\
\hline
\end{tabular} $\begin{array}{lllllllllllllll}1993 & 79,1 & 82,9 & 82,7 & 82,6 & 80,9 & 80,8 & 76,8 & 75,8 & 85,6 & 77,5 & 72,8 & 79,4\end{array}$ $\begin{array}{llllllllllllllll}1995 & 81,2 & 85,4 & 81,4 & 81,2 & 84,3 & 79,3 & 76,7 & 72,0 & 78,5 & 83,2 & 78,2 & 80,6\end{array}$ \begin{tabular}{lllll|l|l|l|l|l|l|l|l|}
1996 & 80,5 & 83,6 & 86,5 & 81,7 & 84,2 & 80,7 & 81,4 & 78,6 & 83,2 & 80,9 & 81,0 & 81,9
\end{tabular} \begin{tabular}{l|lllllllllllllll}
1997 & 83,8 & 80,6 & 81,1 & 79,1 & 82,0 & 80,3 & 77,9 & 76,2 & 80,1 & 83,8 & 84,7 & 79,7
\end{tabular} \begin{tabular}{llllllll|lllllll}
1998 & 79,3 & 82,3 & 83,5 & 80,4 & 81,4 & 79,8 & 82,3 & 80,5 & 83,8 & 85,1 & 81,8 & 80,2
\end{tabular} $\begin{array}{lllllllllllll}1998 & 79,3 & 82,3 & 83,5 & 80,4 & 81,4 & 79,8 & 82,3 & 80,5 & 83,8 & 85,1 & 81,8 & 80,2 \\ 1999 & 83,6 & 82,5 & 79,4 & 79,3 & 77,9 & 84,1 & 81,4 & 74,0 & 76,2 & 82,8 & 77,9 & 77,3\end{array}$ \begin{tabular}{|l|l|l|l|l|l|l|l|l|l|l|l|l|}
2000 & 82,0 & 84,4 & 84,1 & 77,0 & 76,3 & 74,7 & 75,5 & 76,8 & 82,1 & 78,7 & 81,6 & 80,3 \\
\hline
\end{tabular} \begin{tabular}{llllllllllllllll}
2001 & 82,0 & 84,4 & 84,1 & 77,0 & 76,3 & 74,7 & 75,5 & 76,8 & 82,1 & 78,7 & 81,6 & 80,3 \\
\hline 20,6 & 80,3 & 76,8 & 82,1 & 81,1 & 78,6 & 76,4 & 80,9 & 77,8 & 80,8 & 81,3
\end{tabular} \begin{tabular}{llllllllllllllll|l}
2002 & 81,3 & 82,7 & 78,5 & 79,0 & 81,7 & 77,5 & 80,5 & 74,1 & 78,6 & 75,0 & 78,6 & 78,5
\end{tabular} $\begin{array}{llllllllllllllll}2003 & 83,4 & 77,1 & 81,6 & 80,8 & 76,9 & 79,0 & 74,3 & 77,5 & 78,2 & 79,9 & 79,4 & 80,6\end{array}$ $\begin{array}{llllllllllllll}2004 & 84,0 & 82,6 & 82,0 & 82,6 & 82,7 & 81,6 & 82,3 & 77,7 & 73,5 & 81,4 & 79,3 & 82,3\end{array}$ $\begin{array}{llllllllllllll}\mathbf{2 0 0 4} & 84,0 & 82,6 & 82,0 & 82,6 & 82,7 & 81,6 & 82,3 & 77,7 & 73,5 & 81,4 & 79,3 & 82,3 \\ \mathbf{2 0 0 5} & 84,6 & 79,8 & 82,6 & 81,4 & 79,5 & 79,9 & 79,0 & 73,1 & 85,0 & 84,8 & 81,3 & 80,7\end{array}$ $\begin{array}{lllllllllllllll}2006 & 79,8 & 80,6 & 82,1 & 80,5 & 81,4 & 79,8 & 76,5 & 73,4 & 76,6 & 83,0 & 81,2 & 82,2\end{array}$ $\begin{array}{lllllllllllll}2007 & 82,9 & 79,6 & 77,5 & 82,2 & 81,5 & 76,2 & 78,9 & 75,1 & 74,1 & 79,2 & 80,3 & 80,2\end{array}$ $\begin{array}{lllllllllllllll}2008 & 82,2 & 82,2 & 79,9 & 82,0 & 78,1 & 81,7 & 73,9 & 78,4 & 78,6 & 81,7 & 81,9 & 80,3\end{array}$ $\begin{array}{llllllllllllll}\mathbf{2 0 0 8} & 82,2 & 82,2 & 79,9 & 82,0 & 78,1 & 81,7 & 73,9 & 78,4 & 78,6 & 81,7 & 81,9 & 80,3 \\ \mathbf{2 0 0 9} & 82,2 & 82,2 & 81,7 & 82,6 & 80,7 & 81,2 & 86,6 & 76,7 & 83,5 & 86,1 & 79,9 & 84,3\end{array}$ $\begin{array}{llllllllllllll}\mathbf{2 0 0 9} & 82,2 & 82,2 & 81,7 & 82,6 & 80,7 & 81,2 & 86,6 & 76,7 & 83,5 & 86,1 & 79,9 & 84,3 \\ \mathbf{2 0 1 0} & 84,0 & 77,4 & 80,6 & 81,8 & 81,7 & 79,5 & 79,7 & 75,1 & 76,9 & 82,5 & 80,1 & 84,1\end{array}$ $\begin{array}{lllllllllllll}\mathbf{2 0 1 0} & 84,0 & 77,4 & 80,6 & 81,8 & 81,7 & 79,5 & 79,7 & 75,1 & 76,9 & 82,5 & 80,1 & 84,1 \\ \mathbf{2 0 1 1} & 83,4 & 80,7 & 86,9 & 81,7 & 82,7 & 81,1 & 79,3 & 77,3 & 76,7 & 80,0 & 79,3 & 78,5\end{array}$ $\begin{array}{lllllllllllll}\mathbf{2 0 1 1} & 83,4 & 80,7 & 86,9 & 81,7 & 82,7 & 81,1 & 79,3 & 77,3 & 76,7 & 80,0 & 79,3 & 78,5 \\ \mathbf{2 0 1 2} & 82,4 & 78,7 & 79,0 & 83,6 & 82,2 & 86,1 & 77,7 & 74,3 & 74,5 & 77,2 & 81,4 & 80,8\end{array}$ $\begin{array}{lllllllllllll}\mathbf{2 0 1 2} & 82,4 & 78,7 & 79,0 & 83,6 & 82,2 & 86,1 & 77,7 & 74,3 & 74,5 & 77,2 & 81,4 & 80,8 \\ \mathbf{2 0 1 3} & 84,7 & 80,5 & 82,6 & 81,9 & 81,7 & 84,8 & 81,9 & 74,3 & 76,4 & 80,1 & 79,7 & 78,3\end{array}$ $\begin{array}{lllll}2013 & 84,7 & 80,5 & 82,6 & 81,9 \\ 2014 & 74,9 & 72,8 & 80,9 & 82,0\end{array}$

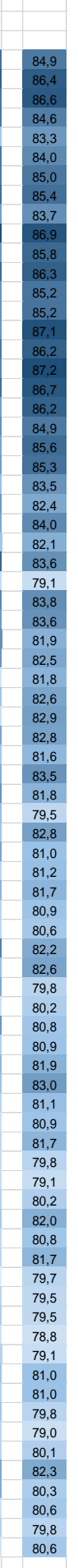


Tabela 5. Variação das temperaturas médias mensais nos cenários simulados pelo IAG-USP (ALVES, 2015; ALVES, DUARTE, GONÇALVES, 2015a; 2015b).

\begin{tabular}{|c|c|c|c|c|c|c|c|c|c|c|c|c|}
\hline & JAN & FEV & MAR & ABR & MAI & JUN & JUL & AGO & SET & OUT & NOV & DEZ \\
\hline Presente & 21,2 & 20,9 & 19,9 & 18,1 & 16,3 & 14,8 & 13,7 & 14,3 & 16,1 & 17,8 & 18,6 & 19,8 \\
\hline Futuro Próximo & 21,8 & 21,9 & 20,8 & 19,0 & 17,3 & 15,5 & 14,8 & 15,4 & 17,5 & 19,0 & 19,4 & 20,5 \\
\hline Futuro Mé & 22,8 & 22,7 & 21,9 & 20,2 & 18,4 & 16,8 & 15,9 & 16,8 & 19,4 & 20,3 & 21,2 & 21, \\
\hline turo Distante & 24,4 & 23,6 & 22,8 & 21,1 & 19,7 & 18,0 & 16,6 & 18,3 & 20,5 & 22,4 & 22,3 & \\
\hline
\end{tabular}

Tabela 6. Variação da umidade relativa mensal nos cenários simulados pelo IAG-USP (ALVES, 2015; ALVES, DUARTE, GONÇALVES, 2015a, 2015b).

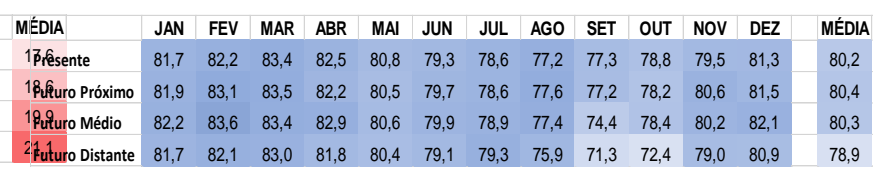

\subsection{Distribuição da vegetação urbana}

Com relação à infraestrutura verde em São Paulo, os serviços ambientais que a vegetação urbana proporciona, como mitigação do aquecimento urbano, manejo da água, estabilidade do solo e biodiversidade, foram desconsideradas na cidade e a distribuição da vegetação é, com certeza, muito desigual. A distribuição espacial e a qualidade ambiental dos parques refletem as desigualdades encontradas nos aspectos econômicos e sociais. Alguns bairros são caraterizados por maior quantidade de vegetação, em parques e arborização de vias, enquanto outros, mesmo na cidade formal, especialmente no centro e na zona leste da cidade são a vegetação é praticamente inexistente (Figura 18).
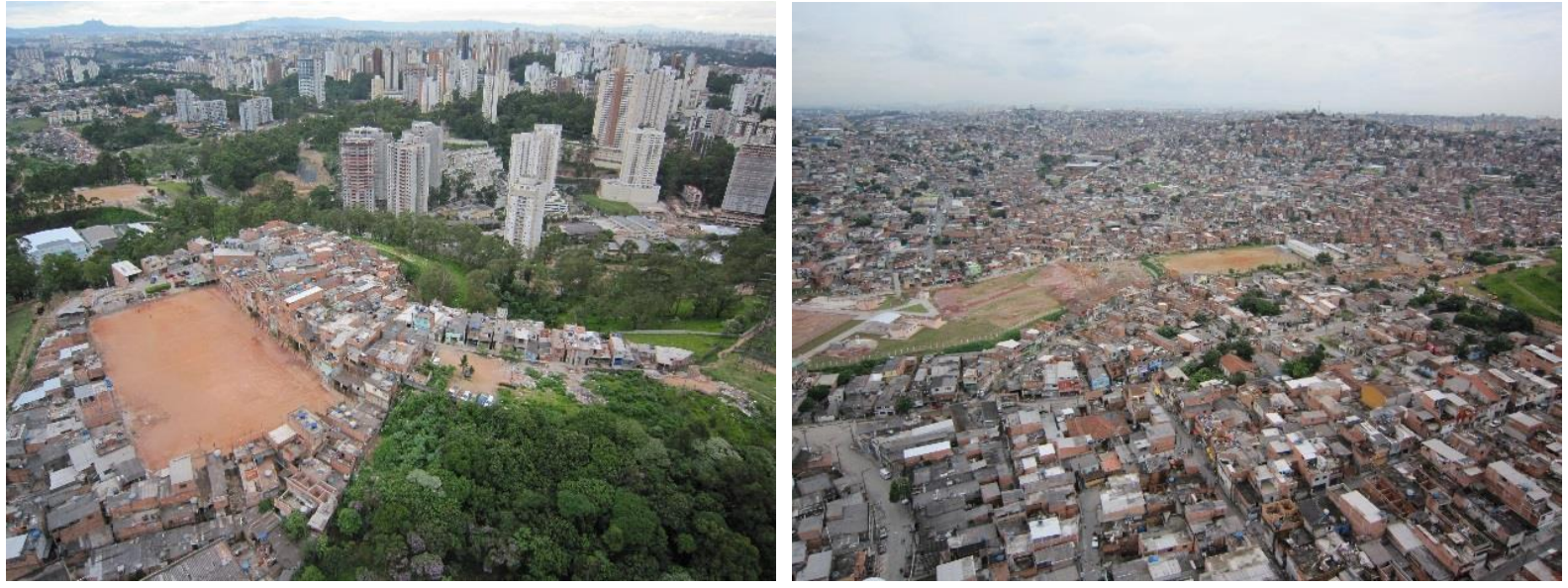

Figura 18 - São Paulo vista do alto: à esquerda, contrastes entre a cidade formal e informal e a infraestrutura verde existente, no distrito da Vila Andrade, e, à direita, a periferia árida, de baixa densidade construída e praticamente sem vegetação, na Cidade Ademar, zona sul de São Paulo (fotos aéreas: Luciana S. Ferreira, 2010)

Ainda que, segundo dados da administração municipal, a área verde média por habitante seja de $12.5 \mathrm{~m}^{2}$, muitas subprefeituras têm quase zero de vegetação (Figura 19). A média de área verde por subprefeitura é $9.28 \%$, também com grandes desigualdades (Figura 20).

Um estudo recente de Ferreira $(2012 ; 2015)$ mostrou que, apesar da falta de dados sistemáticos sobre a evolução da cobertura verde em São Paulo, pode-se deduzir uma diminuição da floresta urbana nas últimas décadas. Desde 1971, ocupações legais e ilegais removeram 31\% da vegetação nativa existente, destruindo morros, ocupando áreas de várzea com habitações informais e avenidas, ocupando as margens das represas, degradando também a qualidade da água. $O$ estudo analisou os processos de aprovação para a remoção de vegetação e os métodos de compensação ambiental em vigor na cidade de São Paulo, mostrando os custos e benefícios da floresta urbana não são considerados em todos os seus aspectos. Devido ao fato da Secretaria Municipal do Verde e do Meio Ambiente permitir a conversão das árvores a serem plantadas em serviços como compensação da perda das árvores, é clara a urgência em se estabelecer melhores parâmetros para esta conversão. 


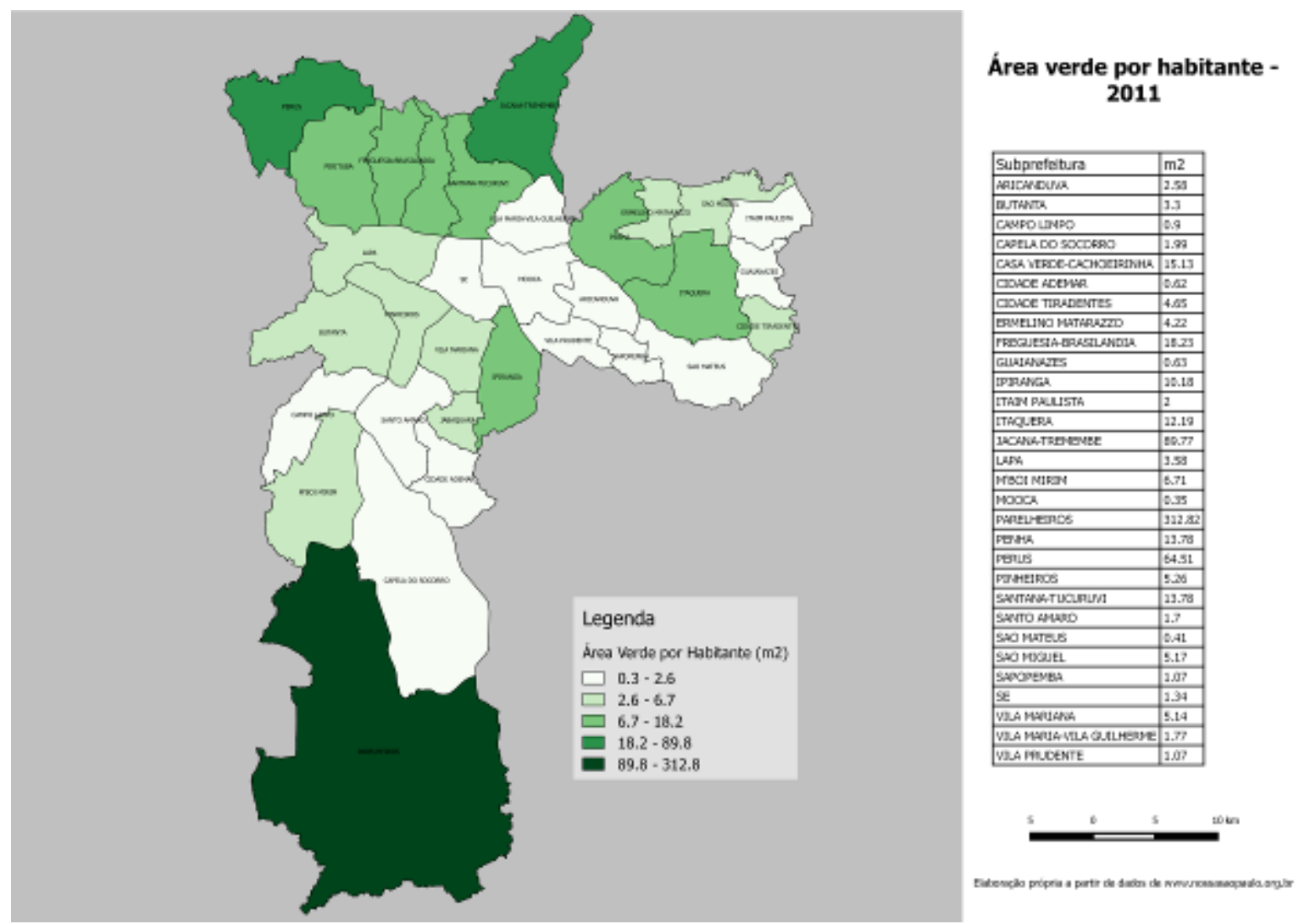

Figura 19 - Porcentagem de área verde por habitante na cidade de São Paulo, 2011. Fonte: dados disponíveis em www.nossasaopaulo.org.br, acesso junho de 2015, sobre base do Mapa Digital da Cidade (CESAD-FAU/USP e L. Ferreira).

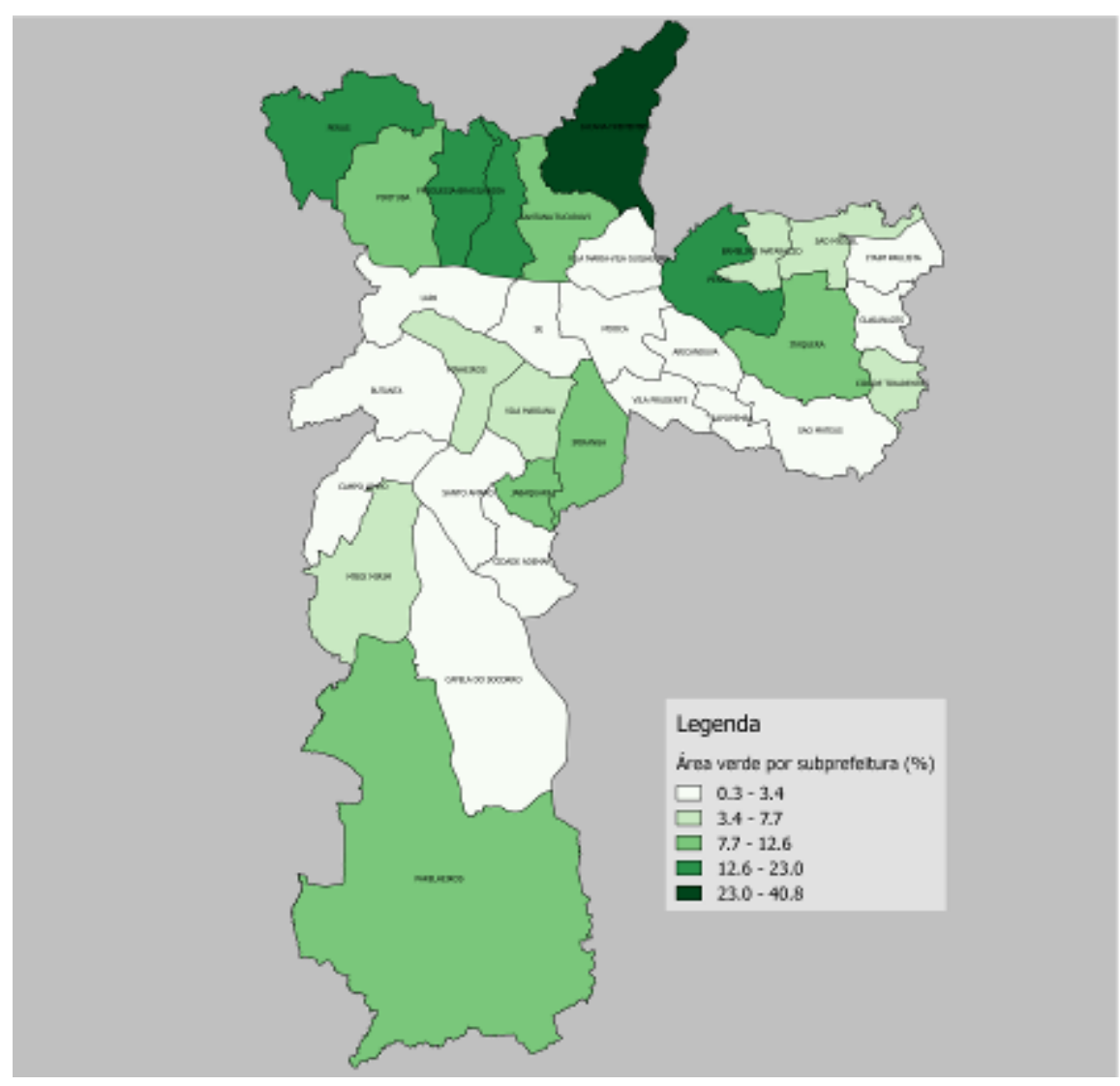
Porcentagem de áreas verdes em
relação à área da subprefeitura 2011

\begin{tabular}{|c|c|}
\hline Fine & Wo de ives Vende \\
\hline Afichoura, & 3.1 \\
\hline EITANA & 2.53 \\
\hline CANPO UNRO & 1.52 \\
\hline CAPELACO SOCOMNO & a.9 \\
\hline 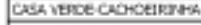 & אבד17 \\
\hline COACE ACENAR & 0.54 \\
\hline COOACE TPRDENTES & 6.5 \\
\hline ERNEUWA MUARWTDO & 5.54 \\
\hline 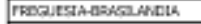 & 22.03 \\
\hline GLUNOWNS & $0,9 \pi$ \\
\hline IPHAWGa & 12.6 \\
\hline ITAM PAUUSTA & 3,43 \\
\hline ITHQUERA & 11.58 \\
\hline 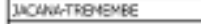 & 60,28 \\
\hline UPA & 272 \\
\hline HRCI NIFOM & 6.69 \\
\hline $1000 \mathrm{an}$ & 0.34 \\
\hline porteveres & 12.33 \\
\hline FER & 15,60 \\
\hline FEUS & 17.03 \\
\hline 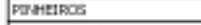 & $a n$ \\
\hline 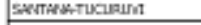 & 10.13 \\
\hline SETTO AUASO & 1.06 \\
\hline Swo Munus & 0.78 \\
\hline SNO HOXIII & 7.74 \\
\hline
\end{tabular}

Figura 20 - Porcentagem de área verde por subprefeitura na cidade de São Paulo, 2011. Fonte: dados disponíveis em www.nossasaopaulo.org.br, acesso junho de 2015, sobre base do Mapa Digital da Cidade (CESAD-FAU/USP e L. Ferreira). 
Considerando-se os esforços em muitas cidades do mundo em encontrar métodos para valorar adequadamente bens e serviços, não é aceitável considerar que o valor de uma árvore seja principalmente o custo do plantio. $O$ aumento de restrições para a remoção de árvores e o aumento do valor da compensação ambiental, desconectado de outras medidas, não garante a preservação da vegetação, especialmente em áreas-foco para o mercado imobiliário de alta renda. Comparando-se a perda de vegetação detectadas por imagens de satélite com o número de solicitações para cortes legais de arvores submetidos à administração municipal, verifica-se que não há correspondência especial entre as duas. Não há monitoramento em tempo real com imagens de satélite na 4a maior cidade do mundo, ao mesmo tempo em que o sensoriamento remoto é aplicado com sucesso no monitoramento do desflorestamento na Amazônia (FERREIRA, 2015).

Em São Paulo, existe uma coincidência espacial entre as áreas de expansão urbana e as áreas ambientalmente frágeis, com os mais preservados fragmentos florestais e reservatórios de água. $\mathrm{A}$ falta de controle governamental sobre o território, especialmente nas franjas urbanas, coloca essas áreas em risco permanente. Por todas essas razões, é urgente o desenvolvimento de novos programas e medidas de preservação que encorajem a manutenção e o aumento da cobertura vegetal. Entre outras limitações está o fato de não haver espaço físico suficiente para replantar as árvores ao final da construção, especialmente em empreendimentos privados. Isso sugere a necessidade de um plano alternativo para guiar a remoção de arvores, a compensação ambiental e o replantio das mesmas, baseado nos custos e benefícios ambientais da vegetação (FERREIRA, 2015), trabalho este em desenvolvimento no mesmo grupo. ${ }^{68} \mathrm{~A}$ questão da falta de espaço para o replantio e a compatibilidade da vegetação com o adensamento urbano também continua em investigação. ${ }^{69}$

\footnotetext{
68 Com o Doutoramento em curso da Arq. MSc. Luciana Schwandner Ferreira, sob a orientação da Prof. Dra. Denise Duarte.

69 Com o Pós-doutoramento em curso da Arq. Dra. Paula Shinzato, com bolsa PNPD Capes de novembro de 2014 a maio de 2015, e, a partir de junho de 2015, com bolsa Fapesp, sob supervisão da Prof. Dra. Denise Duarte.
} 


\section{O que aprendemos com as medições microclimáticas e de vegetação, e com as simulações numéricas}

\subsection{Medições microclimáticas e de vegetação}

Ao longo desta trajetória, muito se apreendeu com as medições de campo, fundamentais para a indução dos fenômenos, para leituras comparativas entre diferentes padrões de ocupação urbana ou para a calibração dos modelos computacionais, como abordado no capitulo 5 . As medições microclimáticas em parques urbanos e seus arredores foram conduzidas pelo laboratório para diversos estudos, em diferentes momentos, de início com equipamentos portáteis bastante simples.

Incialmente medições foram feitas na Av. Paulista, em transectos ao longo do canteiro central, começando na altura da Rua Augusta e passando pelo Parque Trianon, com uma equipe de seis alunos, no verão e no inverno, com uma estação automática bastante simples, de uso quase doméstico, e outros instrumentos portáteis do laboratório. $O$ trabalho foi motivado por uma pesquisa de iniciação científica (SOUZA, DUARTE, 2003; SOUZA, DUARTE, 2004), quando a equipe pode perceber, principalmente, a necessidade de uma melhor proteção dos sensores contra radiação direta e difusa, e outras dificuldades na realização de transectos, tais como o tempo insuficiente para a estabilização dos equipamentos, que indicavam uma temperatura um pouco mais baixa e uma umidade um pouco mais elevada um quarteirão depois do parque.

Posteriormente foi feita uma medição na Barra Funda, incluindo o Memorial da América Latina, o Parque da Água Branca (DUARTE, GONÇALVES, 2006; DUARTE, GONÇALVES, MONTEIRO, 2007a; DUARTE, GONÇALVES, MONTEIRO, 2007b), com vários pontos fixos e transectos, sendo necessário gerenciar de uma equipe bem maior, de cerca de dezoito pessoas ao longo de um dia, envolvendo os alunos da disciplina de pós-graduação AUT 5823 - Conforto Ambiental Urbano e outros integrantes de graduação e pós-graduação do laboratório, vinculados aos estudos de conforto térmico e conforto acústico no meio urbano. Foram utilizadas duas estações automáticas bastante simples e instrumentos portáteis do laboratório. Nesse segundo trabalho ficaram claras as limitações dos equipamentos disponíveis, novamente a importância do abrigo adequado para proteção contra radiação solar direta e difusa nos termo-higrômetros, o tempo necessário para a estabilização dos termômetros de globo, e mais uma vez as demais dificuldades a serem superadas com medidas em transectos.

Medições também foram feitas no Parque da Luz, em São Paulo, e outras áreas próximas, em dois períodos distintos, em 2006 e 2007, com uma equipe de cerca de doze pessoas, no início da formação do grupo dos verdinhos no laboratório, ${ }^{70}$ envolvendo também orientandos de graduação e pós-graduação de outros professores do grupo, estudando as condições ambientais nos canyons urbanos. Nessa oportunidade foram registrados os seguintes parâmetros: temperatura do ar, umidade do ar, direção e velocidade dos ventos, temperatura de globo e fator de visão do céu, para se investigar a diminuição da temperatura do ar, o aumento da umidade do ar, a diminuição da temperatura média radiante e o efeito da distribuição espacial da vegetação em diferentes configurações. Foram utilizadas uma estação automática ELLE, as duas estações automáticas já empregadas nos trabalhos anteriores e instrumentos portáteis do laboratório.

Na primeira medição foram monitorados o parque, um canyon urbano e uma praça pavimentada, e a temperatura do ar no parque foi até $2^{\circ} \mathrm{C}$ mais baixa do que nas demais áreas. Na segunda medição foram monitorados novamente o parque e dois pontos próximos, do outro lado da via, já sem vegetação, e houve uma redução de até $1.5^{\circ} \mathrm{C}$ na temperatura do ar no parque, se comparadas aos outros dois pontos. Ao longo do dia, os resultados indicaram que no parque houve um aumento mais lento da temperatura do ar, e a umidade específica apresentou um incremento de $1 \mathrm{~g} / \mathrm{m}^{3}$ no parque

\footnotetext{
70 Na época Erik Johansson (Pos-doc), Jörg Spangenberg (DO), Paula Shinzato (ME) e Lara Del Bosco (IC).
} 
em relação à praça e ao canyon. Esses resultados ocorrem em consequência do efeito do sombreamento das copas, do processo evapotranspiração da vegetação e da disponibilidade de água do solo, além das interações com a atmosfera. Os resultados mostraram a influência da vegetação na diminuição da temperatura superficial em cerca de $23^{\circ} \mathrm{C}$, medidos sob a copa das árvores, em relação a uma área descoberta com superfície em asfalto. Isso acontece pelo efeito do sombreamento das árvores com copa densa que evitam a chegada da radiação direta no solo. No entanto, verificou-se que os efeitos microclimáticos da vegetação são bastante localizados na altura do pedestre; o efeito das árvores é sentido abaixo das copas e, sua influência não vai muito além dos limites das áreas verdes, fora do efeito do sombreamento e da cobertura do solo natural (SPANGENBERG; JOHANSSON; SHINZATO; DUARTE, 2007; JOHANSSON, 2008; SPANGENBERG et. al, 2008; SHINZATO, 2009).

Partindo-se dessa base de dados medidos e dando início aos primeiros estudos com simulações da área real e simulações paramétricas no modelo ENVI-met, verificou-se que: 1) o efeito da vegetação é local e não ocorre uma influência significativa muito além dos limites das áreas verdes; nas simulações, sob baixa velocidade do ar, a influência da vegetação termina na borda do parque; 2) a redução na temperatura do ar não ocorre principalmente devido à diferença na distribuição espacial da vegetação (parque linear, grande massas de vegetação, pequenos agrupamentos espaçados, etc.), mas principalmente pela densidade foliar que contribui nos processos de evapotranspiração e sombreamento. Assim, quanto maior a área de exposição das folhas, ou seja, maior o índice de área foliar - IAF, maior o efeito. Percebeu-se que a densidade e a distribuição das folhas afetam a interceptação da radiação solar incidente abaixo do dossel, determinando a qualidade do sombreamento e sua influência na temperatura do ar e das superfícies. Desde então, ficou claro que - IAF era um importante parâmetro biofísico que não poderia ser ignorado nas medições e na parametrização dos modelos preditivos envolvendo a interação solo, vegetação, ambiente construído e atmosfera, sendo a densidade da copa um dos principais fatores para a qualidade do sombreamento (SHINZATO, DUARTE, 2011a; SHINZATO, DUARTE, 2011b; SHINZATO, DUARTE, 2012).

Nessa época, em busca de estudos mais aprofundados sobre os parâmetros da vegetação que interferem nos fenômenos de sombreamento e evapotranspiração, deu-se início ao contato com o Prof. Dr. Demostenes Ferreira da Silva Filho, coordenador do Laboratório de Silvicultura Urbana da ESALQ/USP, em Piracicaba - SP. Pouco tempo depois, a primeira experiência de medição do IAF pelo grupo dos verdinhos aconteceu em conjunto com o grupo da ESALQ, no Parque do Ibirapuera, em São Paulo (SHINZATO, DUARTE, 2012), ainda adotando o método de fotos planas de Peper e McPherson (1998), mais tarde substituído por outros métodos hoje adotados. A experiência foi importante porque deu a primeira ordem de grandeza do IAF de árvores locais, a princípio mais baixos dos que os comumente encontrados na literatura. Com a equipe da ESALQ o grupo veio a conhecer também o analisador de dossel, depois utilizado em trabalhos do grupo.

Mais recentemente novas medições de campo foram realizadas no Parque Tenente Siqueira Santos (Trianon), na Av. Paulista, em São Paulo, em três períodos distintos. A primeira medição aconteceu com alunos da disciplina de pós-graduação AUT 5823 - Conforto Ambiental Urbano, improvisando abrigos para os dataloggers Hobo Onset de uso interno para registro de temperatura e umidade do ar, e compondo a instalação com outros equipamentos portáteis do laboratório. Nessa ocasião foram testados abrigos de madeira, mas que se mostraram inadequados para esta finalidade, além de pesados e volumosos para o transporte e pouco práticos no trabalho de campo.

Mais duas campanhas de medições foram feitas no mesmo local, ${ }^{71}$ um pouco melhor equipados, agora já com duas estações automáticas Campbell, sendo a primeira delas durante três dias

\footnotetext{
${ }^{71}$ As medições microclimáticas e de vegetação foram realizadas originalmente para o trabalho de Shinzato (2014), e para as iniciações científicas de Fernanda de Camargo Barros, Denise Cordeiro Moreira, Érica Osako e Bárbara Ferronato.
} 
consecutivos em setembro de 2012, sob uma ocorrência não usual de dias frios para essa época do ano, mas mesmo assim confirmando a influência da densidade foliar na redução da temperatura do ar e da temperatura de superfície abaixo do dossel.

Nesse meio tempo, outro método para a quantificação do IAF também foi explorado, o de fotos hemisféricas, desta vez com o apoio do Prof. Dr. Humberto Ribeiro da Rocha, IAG/USP, coordenador do Laboratório de Clima e Biosfera do IAG/USP e equipe.

Com a intenção de aplicar os dois métodos para determinação do IAF em paralelo, previamente às medições microclimáticas propriamente ditas, os valores de IAF foram medidos no parque Trianon com o uso de duas técnicas de medição indireta: com o analisador de dossel e por meio da análise de fotos hemisféricas.

Pré-testes de sensibilidade dos equipamentos foram realizados no entorno da FAU-USP e os dois métodos indiretos não destrutivos foram aplicados no parque Trianon em agosto e setembro de 2012 para se estimar o índice de área foliar médio para a copa das arvores, utilizando-se o LAI-2000 Plant Canopy Analyzer ${ }^{72}$ e as fotos hemisféricas com uma câmera digital Nikon COOLPIX 4500 e lente grande angular Nikon 8mm FC-E8. As imagens digitais são pós-processadas no software Can-eye ${ }^{73}$, após a calibração da câmera e da lente, para se definir o centro ótico da mesma, seguindo os procedimentos indicados pelo modelo (SHINZATO et al., 2013a; SHINZATO et al., 2013b; SHINZATO, 2014; SHINZATO, YOSHIDA, DUARTE, 2015).

Para tanto, uma malha de $20 \mathrm{~m} \times 20 \mathrm{~m}$ foi estabelecida, definindo-se 22 pontos de medição, sendo uma área próxima à entrada principal do parque, e outra mais ao fundo, com vegetação mais densa. Nessa ocasião, a parte central do parque apresentou um valor médio de IAF $=3$, enquanto a entrada principal tem uma distribuição de árvores mais espaçada e árvores pouco densas com IAF = 1,5, em média.

Medições locais do índice de área foliar foram fundamentais para informar posteriormente os parâmetros de vegetação adotados na simulação com o ENVI-met. Antes das medições, adotavam-se os índices encontrados na literatura, com vegetação e condições climáticas diferentes e, nem sempre, baseados em medições. Em muitos trabalhos fica claro que os autores partem de bases preexistentes sem validação local, adotando valores, na maioria das vezes, superestimados, como fizemos anteriormente (SHINZATO, 2003; SHINZATO, DUARTE, 2011), o que não acontece mais nos trabalhos do grupo, pela possibilidade e pelo domínio da técnica de medição do IAF.

Comparações entre as medições pelos dois métodos mostram os valores médios de LAI variando entre 2,14 (fotos hemisféricas) e 2,52 (analisador de dossel), e a escolha do sistema precisa considerar as condições locais (Figura 21). No caso do Parque Trianon, com um arranjo razoavelmente denso de arvores, com poucos pontos de céu desobstruído, a técnica de fotos hemisféricas se mostrou mais adequada, se comparada à medida com o analisador de dossel. Outra vantagem das fotos hemisféricas é o registro visual do dossel, com sua densidade e distribuição foliar, que podem ser interessantes para estudos sazonais comparativos, ou para se avaliar diferentes espécies e pontos de maturação das árvores, etc. ${ }^{74}$

\footnotetext{
72 Gentilmente cedido pelo Prof. Dr. Demostenes Ferreira da Silva Filho, coordenador do Laboratório de Silvicultura Urbana da ESALQ/USP, em Piracicaba - SP. Atualmente este modelo já não está mais disponível no mercado, tendo sido substituído pelo LAl-2200C em diferentes versões. Disponível em http://www.licor.com/env/products/leaf_area/LAl-2200C/, acesso em 04/06/2015.

73 Desenvolvido pelo INRA - National Institute of Agronomical Research (2003), disponível em < http://www6.paca.inra.fr/can-eye >. Acesso em fevereiro de 2014.

${ }^{74} \mathrm{Em}$ outra medição mais recente, realizada no mês de novembro de 2014, com uma nova câmera e lente grande angular, abrangendo os mesmos 22 pontos medidos em duas áreas de estudo no Parque Trianon, os estudos avançaram para a distinção entre o IAF efetivo e IAF verdadeiro. Os resultados apresentaram valores médios de IAF efetivo (effective LAI) de 2,0 e valores médios de IAF verdadeiro (true LAI) de 3,7, uma diferença de $54 \%$, sendo que o que define a opção pelo uso do IAF efetivo ou verdadeiro é a sua aplicação. O IAF verdadeiro expressa melhor o potencial das atividades fisiológicas,
} 


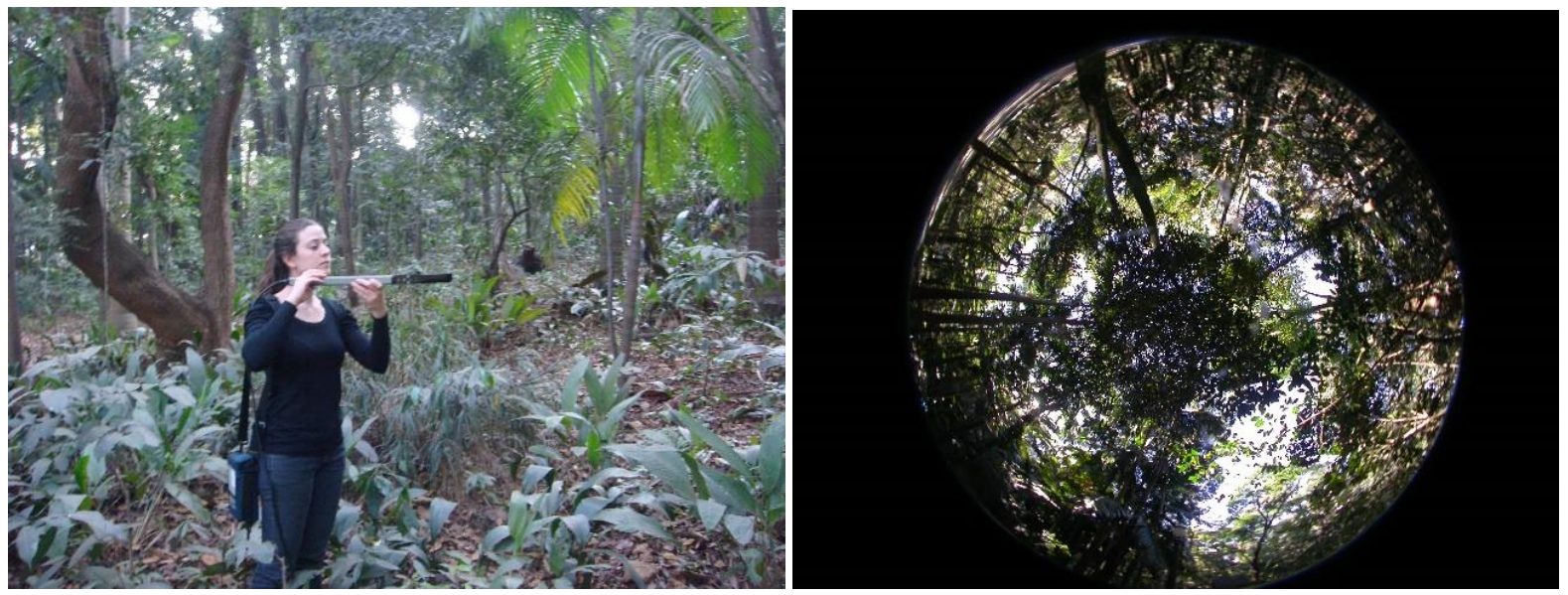

Figura 21 - Medições do IAF com o analisador de dossel e com fotos hemisféricas no Parque Trianon, em setembro de 2012. (Fotos: Paula Shinzato)

A medição microclimática no Parque Trianon também foi feita em dois pontos, um localizado na entrada principal, em frente à Av. Paulista e outro na parte central, próximo à área do playground. Nessa medição, a estação no centro do parque registrou temperaturas cerca de $1^{\circ} \mathrm{C}$ mais baixas em relação à estação da entrada, principalmente nos picos da temperatura máxima às $14 \mathrm{~h}$, e mínima, às $5 \mathrm{~h}$. Na área de maior densidade foliar houve um aumento de até $0,5 \mathrm{~g} / \mathrm{kg}$ na umidade específica e diminuição de $5^{\circ} \mathrm{C}$ na temperatura de globo entre $10 \mathrm{~h}$ e $19 \mathrm{~h}$. $\mathrm{O}$ conjunto dos dados mostra o impacto da vegetação no microclima devido aos efeitos de sombreamento e evapotranspiração, principalmente. Pela primeira vez foram utilizadas no grupo imagens termográficas (Figuras 22 a 24) com uma câmera FLIR i40, verificando-se a temperatura superficial de superfícies naturais e construídas, em diferentes horários.

A terceira medição realizada no Trianon aconteceu de 13 a 16 de novembro de 2013, em dias de calor. Foram usadas novamente as duas estações Campbell aproximadamente nos mesmos pontos e a câmera termográfica, bem como foi realizada nova medição do índice de área foliar, nos mesmos 22 pontos da vez anterior (Figuras 25 e 26), desta vez apenas com as fotos hemisféricas, por indisponibilidade de uso do analisador de dossel.

Os resultados mostraram que, apesar da proximidade dos dados coletados nas duas estações, a temperatura do ar no ponto 2 foi ligeiramente mais baixa, devido à densidade mais alta do dossel arbóreo, com LAI 3 e solo natural, comparado com o ponto 1 , de LAI 1,5 e mais próximo a um piso impermeável para passagem de pedestres. Ainda assim, as diferenças de temperatura do ar dentro do parque alcançaram $1.9^{\circ} \mathrm{C}$ em 15 de novembro, às $13 \mathrm{~h}$ (Figura 27).

Foram usadas duas estações fixas de referência, do Aeroporto de Congonhas e do IAG/Água Funda, localizada dentro um parque muito maior, mas com a estação sobre grama, sem sombreamento de árvores ou edifícios, seguindo o padrão das estações WMO, e, portanto, com uma perda muito maior de radiação de onda longa no período noturno, se comparada ao Parque Trianon. Nesse período a temperatura do ar mais alta, de $31,5^{\circ} \mathrm{C}$ ocorreu no Aeroporto de Congonhas, às $15 \mathrm{~h}$.

como a taxa fotossíntese de fotossíntese e de evapotranspiração pelas folhas, e o IAF efetivo descreve com mais precisão a interceptação da radiação pela distribuição das folhas e o regime radiativo dentro e abaixo da copa. Estes resultados serão publicados em: SHINZATO, Paula, YOSHIDA, Daniel, DUARTE, Duarte. O impacto da vegetação nos microclimas urbanos: estimativa do IAF pelo método de fotos hemisféricas. Artigo aceito para o ENCAC 2015. 

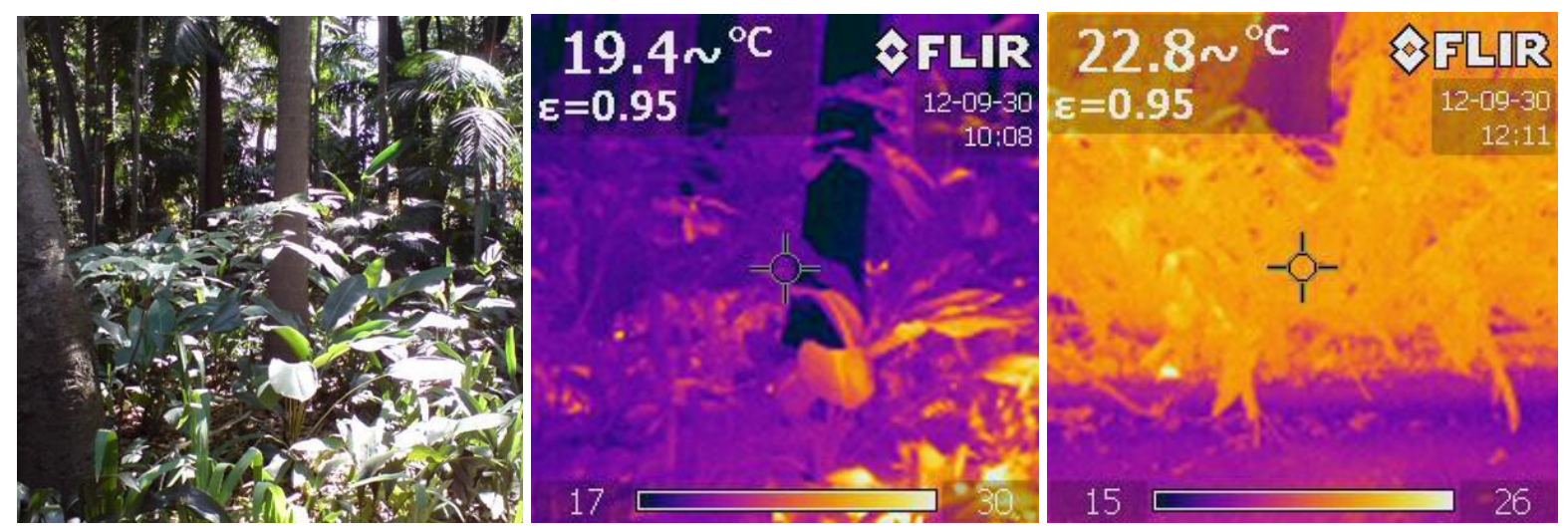

Figura 22 - Temperaturas superficiais medidas na vegetação parcialmente sombreada dentro do Parque Trianon (30/09/12, às 10:08h e às 12:11h). Fotos: B. Ferronato.
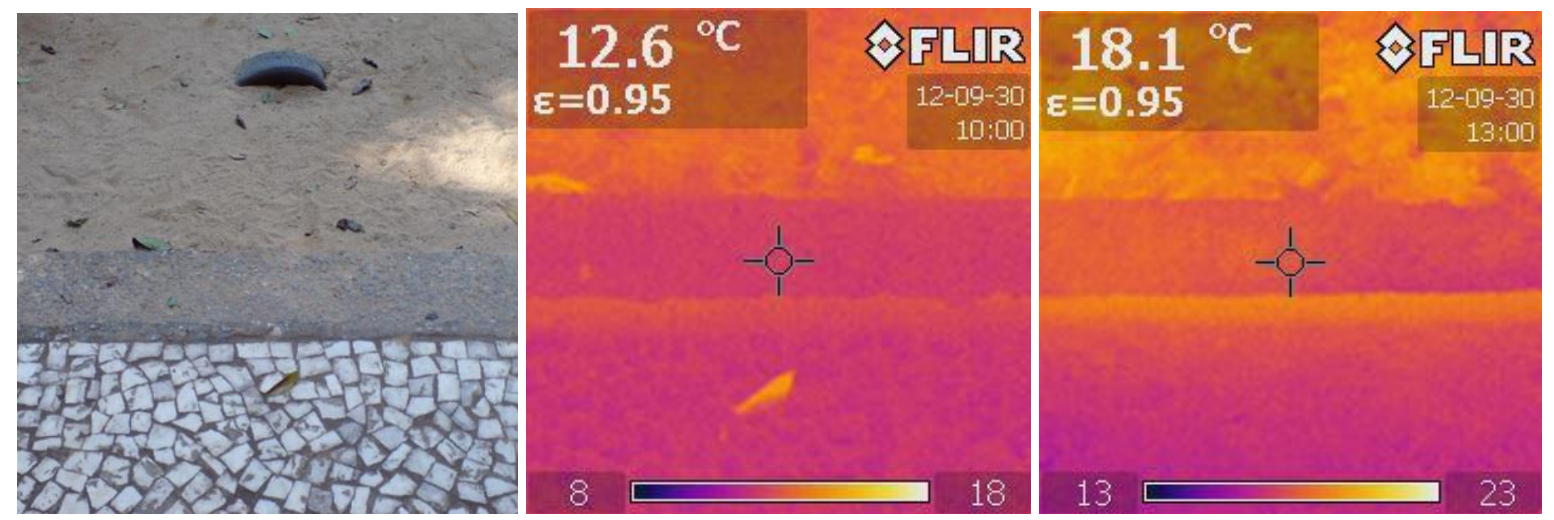

Figura 23- Temperaturas superficiais medidas sobre piso pavimentado à sombra dentro do Parque Trianon (30/09/12, às 10:00h e às 13:00h). Fotos: B. Ferronato.
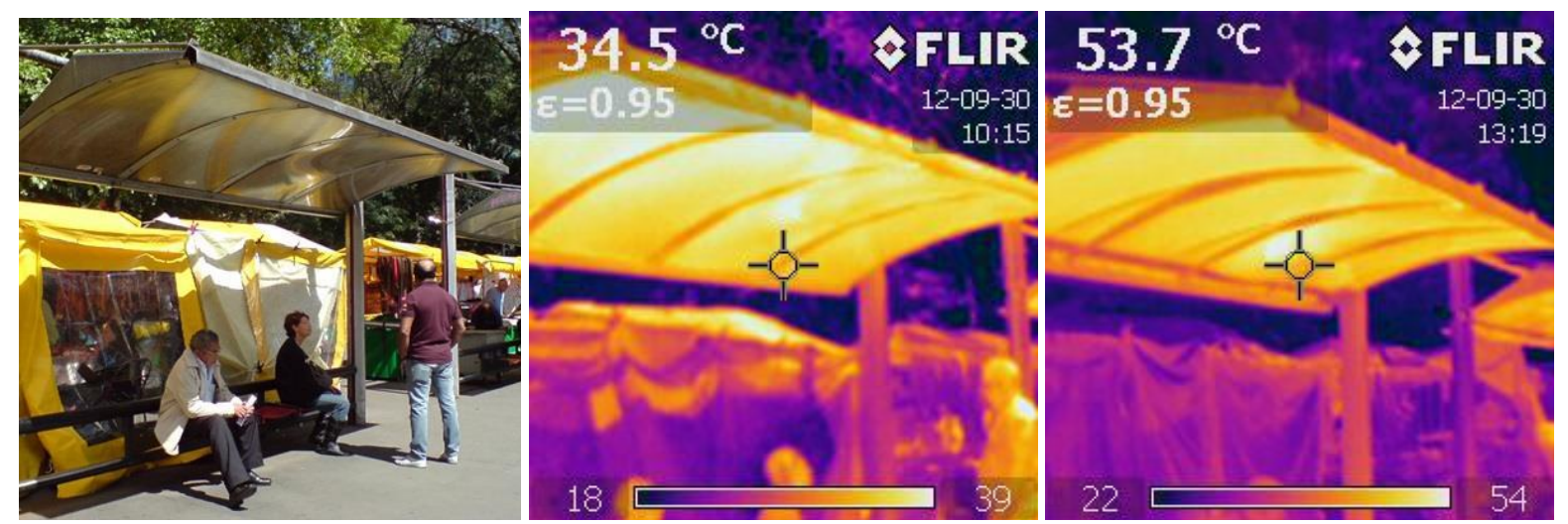

Figura 24 - Temperaturas superficiais medidas na face interna do ponto de ônibus, em frente ao Parque Trianon (30/09/12, às $10: 15 \mathrm{~h}$ e às $13: 19 \mathrm{~h})$. Fotos: B. Ferronato. 


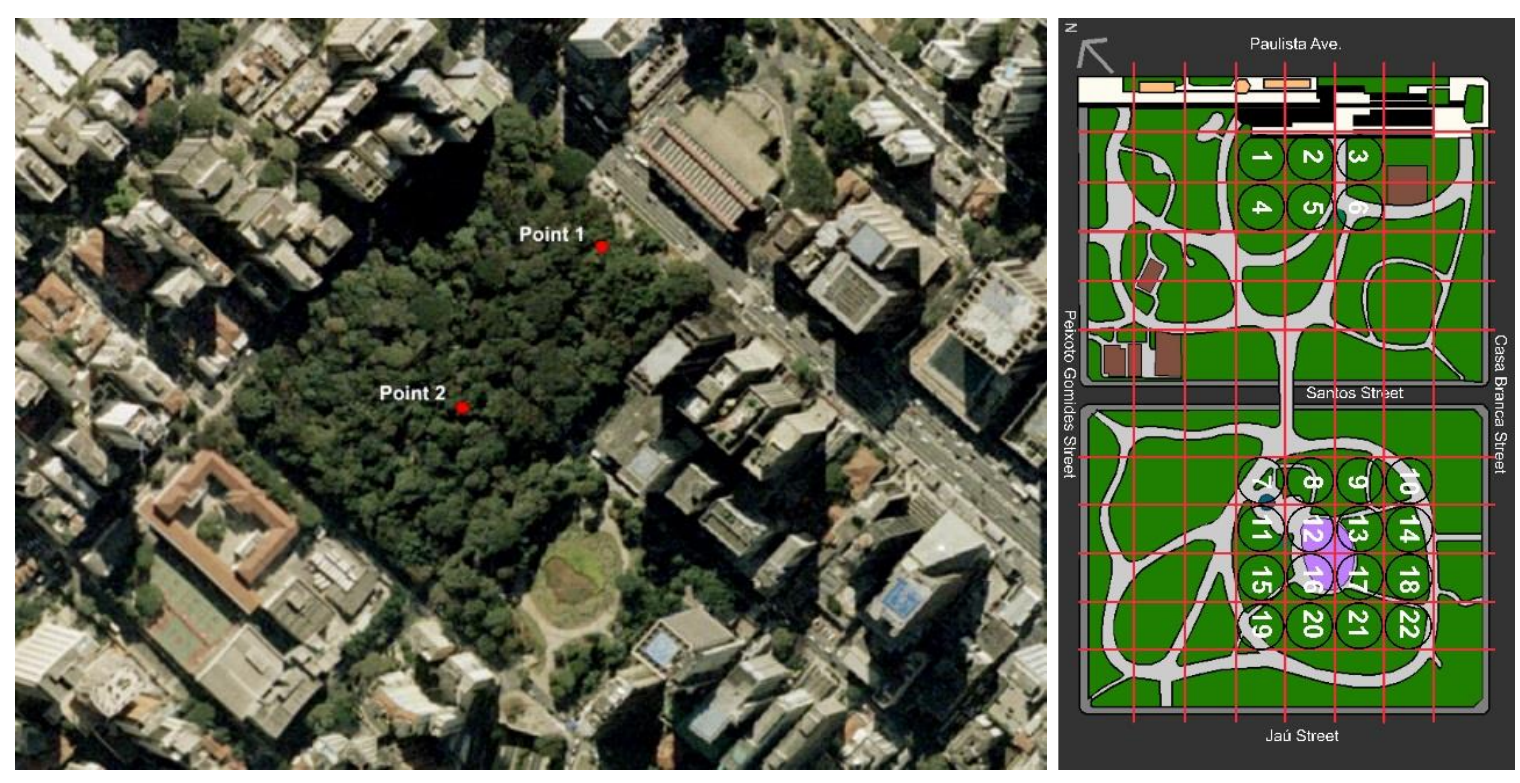

Figura 25 - À esquerda, Parque Trianon na Av. Paulista com os dois pontos de medição microclimática onde foram locadas as estações e, à direita, a malha de 22 pontos de medição do IAF. (Fonte: ortophoto digital 1:5000 - Emplasa 2007. Disponível em: http://www.cesadweb.fau.usp.br, acesso em 18/06/2014. Desenhos Paula Shinzato)
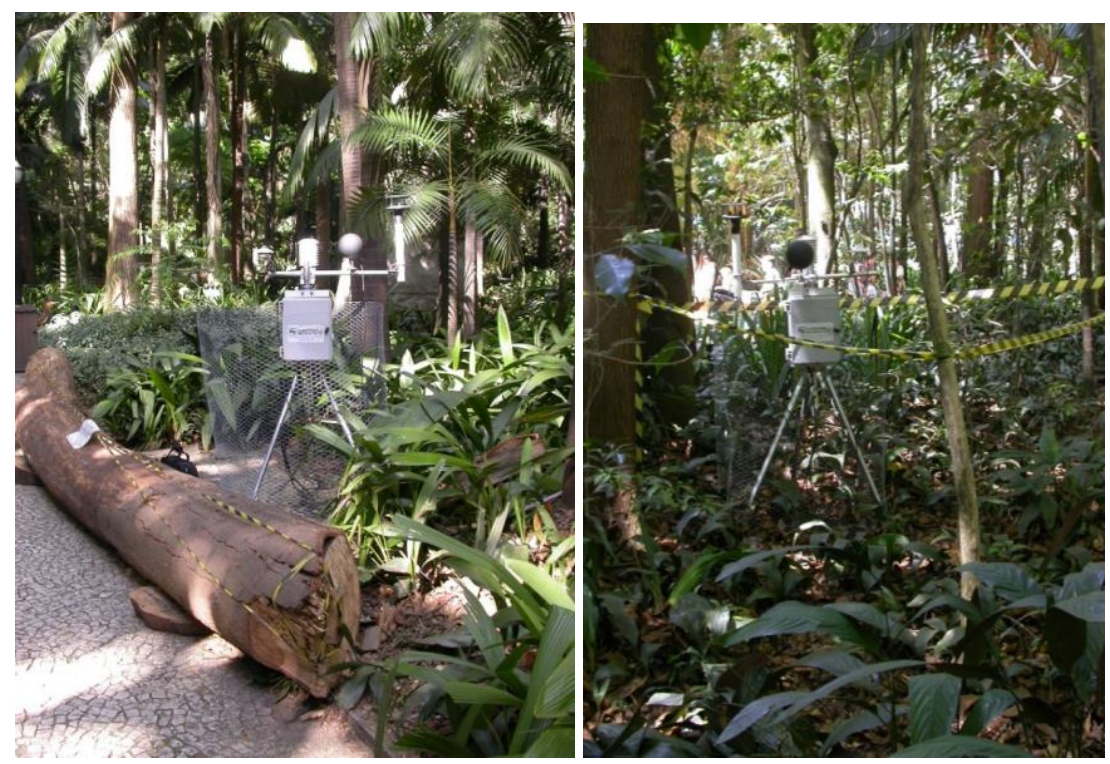

Figura 26 - Estações meteorológicas nos pontos 1 e 2 no Parque Trianon, a 1,5m do solo, em novembro de 2013 (Fotos: Paula Shinzato)

Quando comparado aos parques, o aeroporto de Congonhas é, em geral, mais quente durante o dia e mais frio durante a noite, devido ao céu desobstruído, sem sombreamento, com maior perda de radiação de onda longa no período noturno. Por outro lado, nos dois parques, especialmente no Trianon, com as duas estações meteorológicas locadas abaixo do dossel arbóreo, as temperaturas do ar são um pouco mais altas à noite, conforme esperado para um espaço semi-confinado e com pouca ou quase nenhuma visão de céu, ainda que verde.

A comparação dos valores de umidade específica, calculadas a partir dos dados medidos segundo Bolton (1980) mostra as diferenças entre o conteúdo real de umidade entre os pontos, contrastando o ambiente mais seco do aeroporto de Congonhas com os locais mais úmidos nos parques, principalmente devido ao solo natural gramado e ao sombreamento do dossel arbóreo denso. De forma geral, ambos os pontos 1 e 2 no Parque Trianon apresentaram umidade específica intermediária entre o IAG/Água Funda e o aeroporto de Congonhas (Figura 28). 


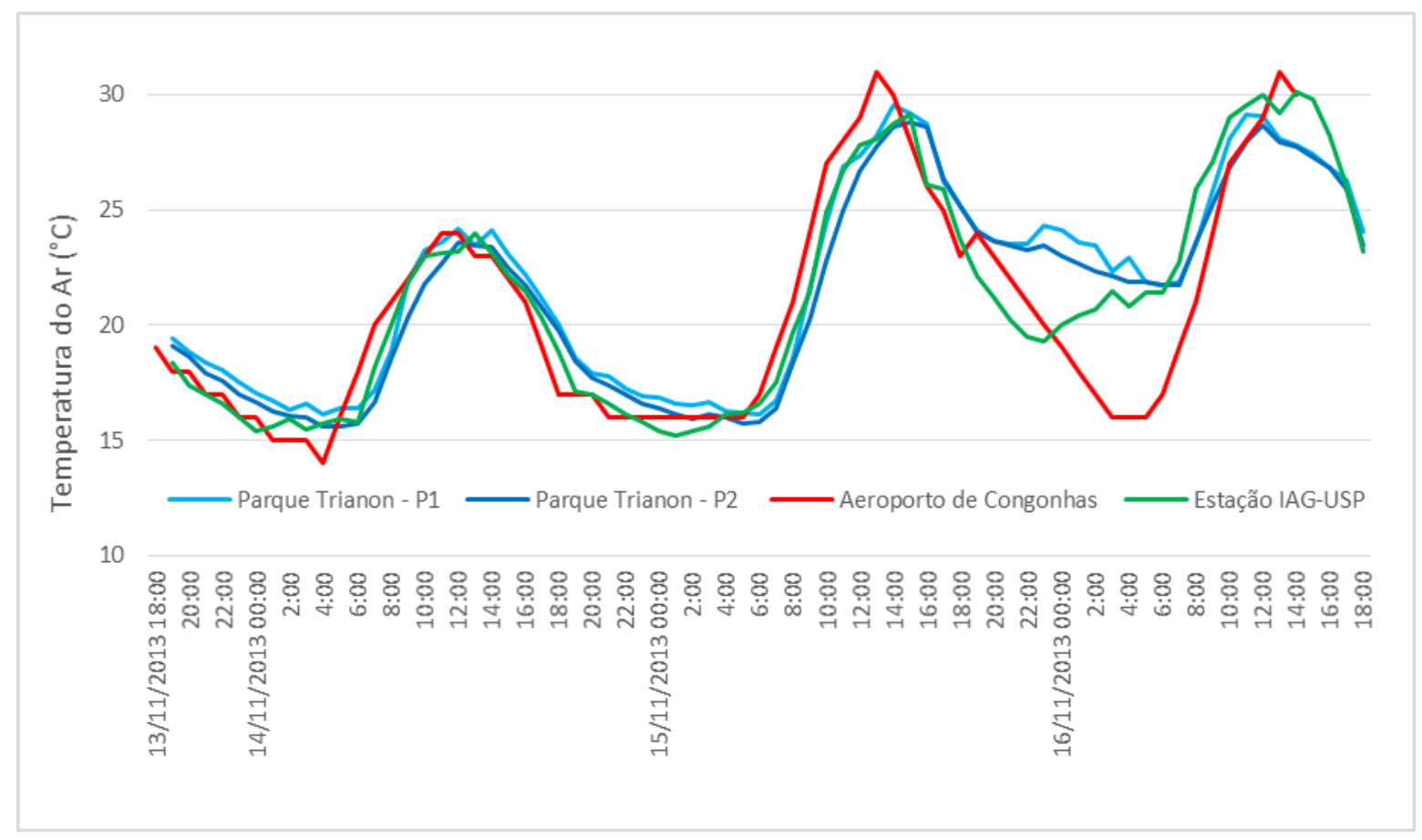

Figura 27 - Temperatura do $\operatorname{ar}\left({ }^{\circ} \mathrm{C}\right)$ registrada no Trianon (pontos 1 e 2), no Aeroporto de Congonhas (WMO 83780) e no IAG/USP - Água Funda (WMO 83004), em novembro de 2013 LST - Local Standard Time (DUARTE, 2015).

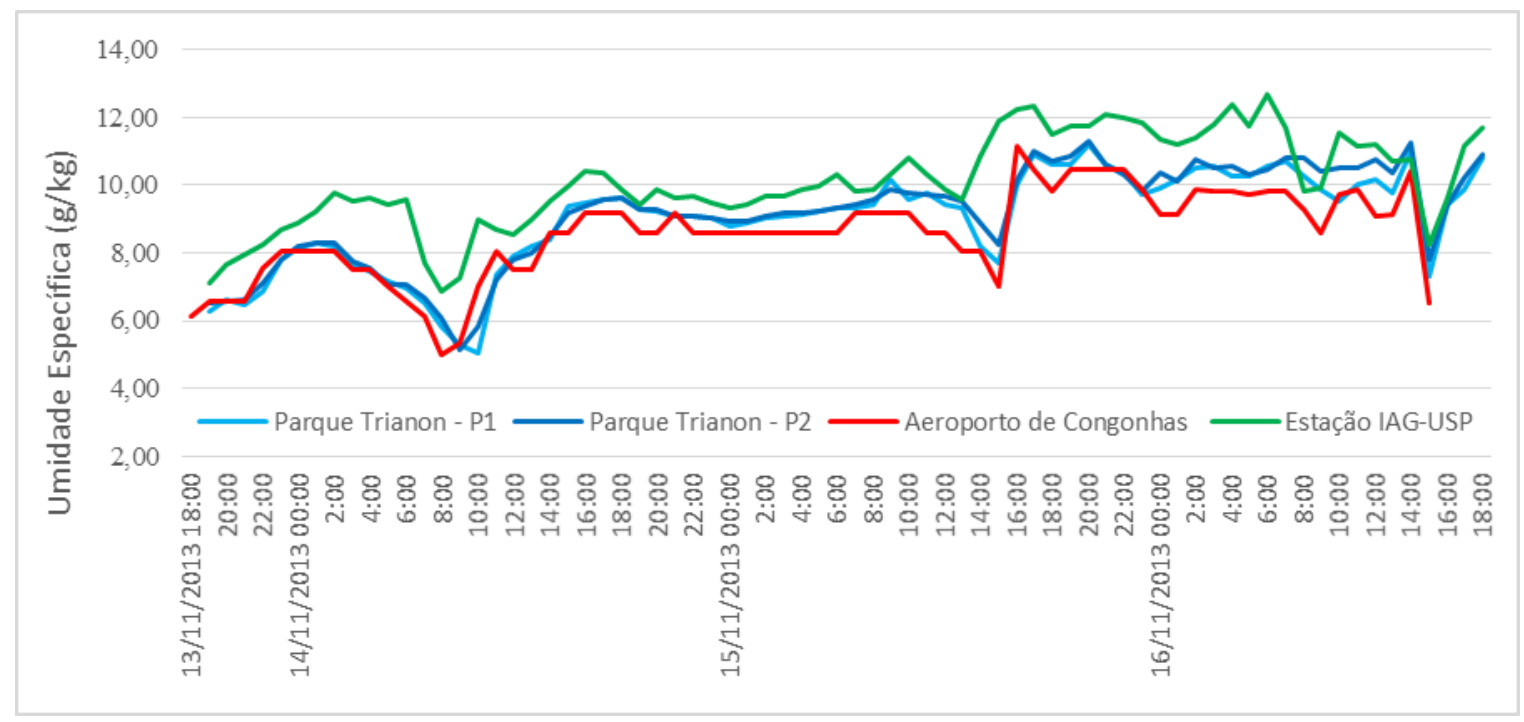

Figura 28 - Umidade específica calculada (g/Kg) com base nos dados registrados no Trianon (pontos 1 e 2), no Aeroporto de Congonhas (WMO 83780) e no IAG/USP - Água Funda (WMO 83004), em novembro de 2013 LST - Local Standard Time (DUARTE, 2015).

Os dados microclimáticos medidos, além da temperatura de solo e de vegetação (IAF) foram então utilizados para a calibração do modelo, neste caso, o ENVI-met 3.1 para as condições locais, além dos valores de umidade de solo e umidade especifica a $2500 \mathrm{~m}$, ambos explicados em detalhes mais à frente. Depois disso, simulações paramétricas foram realizadas para se testar a sensibilidade do modelo à tipologia da copa, velocidade do vento, umidade do solo e extensão dos efeitos microclimáticos para além do parque.

Os resultados da simulação sob copa densa (forma elíptica com LAI=5) mostraram uma redução média de $1^{\circ} \mathrm{C}$ na temperatura do ar e $19^{\circ} \mathrm{C}$ na temperatura de superfície do solo, comparadas às condições fora do parque. A evapotranspiração mais alta e a temperatura de superfície 
significativamente mais baixa sob o dossel levam à uma diminuição dramática na temperatura média radiante. Este é o parâmetro mais afetado pelo sombreamento, seja por árvores ou edifícios. A redução na temperatura média radiante pelo sombreamento resulta da menor quantidade de radiação de onda curta direta, difusa e refletida, vindas do sol, e consequentemente das temperaturas de superfície mais baixas que, por sua vez, emitindo menos radiação de onda longa a partir das superfícies urbanas, afetando positivamente os índices de conforto térmico para as condições climáticas tropicais e subtropicais (SHINZATO, 2014).

Ambos os índices adotados, PET - Physiological Equivalent Temperature (HÖPPE, 1999) e TEP Temperatura Equivalente Percebida (MONTEIRO, ALUCCI, 2011), índice empírico desenvolvido para as condições locais, são significativamente influenciados pela temperatura média radiante. O Parque Trianon apresenta uma redução de $3^{\circ} \mathrm{C}$ (ponto 1) a $5^{\circ} \mathrm{C}$ (ponto 2) no índice adaptativo TEP quando comparado às condições externas ao parque. Além dos limites do parque, o modelo indica algum efeito no nível do pedestre até $5 \mathrm{~m}$ na direção do vento, para uma velocidade de $1 \mathrm{~m} / \mathrm{s}$, com $40 \%$ de umidade do solo na camada superior, de 0-20cm (SHINZATO, 2014).

O trabalho continua no grupo com o estudo de propriedades especificas da vegetação, tais como:

- aprimoramento das medições de índice de área foliar pelo método de fotos hemisféricas, com uma nova câmera digital e lente grande angular, ${ }^{75}$ que foram também calibradas para esta pesquisa com o uso do modelo Can-Eye; desta vez a calibração foi um pouco mais simples devido à experiência com uma câmera anterior e por recursos da própria câmera. Medições foram feitas no Parque Trianon, em novembro de 2014, e no Parque Villa-Lobos, em maio de 2015. Neste último trabalho o grupo explorou os recursos do Can-Eye para distinção entre IAF verdadeiro (True LAI) e IAF efetivo (Effective LAI), e diferenças significativas foram encontradas entre essas duas métricas, de mais de $50 \%$ entre os valores, explicando as discrepâncias entre valores encontrados na literatura e as primeiras medições locais, o que nos leva à revisão da métrica a ser adotada para os próximos trabalhos (SHINZATO; YOSHIDA, DUARTE, 2015). ${ }^{76}$

- a medida de emissividade de superfícies verdes para uma leitura mais precisa de temperatura superficial por sensoriamento remoto, seja por câmera termovisora portátil, no nível do solo, ou câmera acoplada em aviões, ou mesmo por satélite. Essa medida foi possível com o uso de um emissômetro, neste caso de bancada e campo, previamente ao uso de uma câmera termográfica. ${ }^{77} \mathrm{~A}$ transparência parcial das folhas dificulta e, na maioria das vezes, inviabiliza a medição de emissividade; grosso modo, é uma dificuldade que também acontece nas leituras de emissividade em materiais transparentes ou translúcidos, já encontrada e outros trabalhos do grupo na tentativa de leitura em fachadas de edifícios principalmente. Estão sendo testadas formas de se contornar essa dificuldade de leitura pela transparência das folhas, sobrepondo-se várias camadas de folhas sobre o leitor, por dobra mesmo, já que a amostra é pequena. Essas leituras de emissividade e temperatura de superfície têm diversas aplicações nas pesquisas do grupo, incluindo a calibração de dados de saída do ENVI-met, e o acoplamento entre leituras por sensoriamento remoto de solo e satélite, sejam para vegetação ou elementos inertes.

\footnotetext{
75 Bolsista AT-NM Daniel Yoshida, na cota do auxílio-pesquisa CNPq, coordenado pela Prof. Denise Duarte. Câmera e lente adquiridas com recursos de Reserva Técnica Fapesp da então doutoranda Paula Shinzato.

${ }^{76}$ SHINZATO, Paula; YOSHIDA, Daniel; DUARTE, Denise. O impacto da vegetação nos microclimas urbanos: estimativa do índice de área foliar - IAF pelo método de fotos hemisféricas. Artigo aceito para o ENCAC 2015.

77 Bolsista IC Stefani Sayuri Seki, na cota do auxílio-pesquisa CNPq, coordenado pela Prof. Denise Duarte. Câmera termográfica FLIR i7 adquirida com recursos de auxilio-pesquisa CNPq, do Prof. Dr. Leonardo Monteiro; emissômetro AE1/RDI-12v Device and Services Company e câmera termográfica FLIR T640, estes dois últimos adquiridos pelo IAG, com recursos do projeto temático Fapesp processo 2010/10189-5, do qual o LABAUT também participa.
} 


\subsection{Simulações numéricas com o ENVI-met: simulação de áreas de estudo reais, calibração entre dados medidos e simulados e simulações paramétricas}

Para a melhoria da qualidade das simulações numéricas, foi fundamental o entendimento da interação solo/vegetação/atmosfera sobre as condições microclimáticas, incluindo dados do subsolo e dados da atmosfera a $2500 \mathrm{~m}$ acima do nível do mar, além dos demais dados de superfície, relativos ao ambiente construído, imprescindíveis ao correto funcionamento do modelo micrometeorológico. Também foi necessária a quantificação de dados locais de vegetação, com medição em campo do índice de área foliar. ${ }^{78}$

Para que se possa calibrar o modelo para as condições locais, considera-se de fundamental importância a realização de medições microclimáticas nas áreas de estudo por um período mais longo, de alguns dias pelo menos, mas idealmente por semanas ou meses, o que permite ao usuário janelar o período mais estável para a calibração da simulação.

Pela oportunidade de estágio de uma das alunas do grupo junto ao Environmental Modelling Group (Geoinformatik/EMG) do Geographisches Institut, da Johannes Gutenberg Universität Mainz, na Alemanha, com o Prof. Michael Bruse, autor do modelo, e sua equipe, no período de abril a julho de 2013, foi possível ter acesso ao ENVI-met V4 preview desde então (GUSSON, 2014), ainda em fase de testes, sendo que essa versão se tornou pública em 31 de outubro de 2014, como ENVI-met V4 Preview I. Esta foi substituída em fevereiro de 2015, ainda como versão preview e com alguns problemas operacionais que já foram detectados, inclusive por este grupo, e informados aos autores.

As versões mais recentes permitem simular cenários climáticos mais detalhados e condizentes com as medições de campo (JANSSON, 2006). No ENVI-met V4 Preview I o recurso simple forcing permite uma melhor calibração entre dados medidos e simulados, pois é possível se definir a variação diurna das variáveis temperatura e umidade relativa do ar, em base horária (HUTTNER et al. 2009), antes das simulações paramétricas de diferentes cenários. Desde esta versão, o modelo dos edifícios também foi atualizado para levar em conta a inércia térmica de paredes e coberturas (YANG, 2013).

Foram então realizadas novas rodadas de simulações com finalidade de se avaliar os efeitos do resfriamento provocado pela vegetação, especialmente durante o dia, na cidade adensada, para contrabalançar os possíveis fenômenos de aquecimento urbano resultantes de um aumento da densidade construída em São Paulo.

Nas cidades adensadas, o efeito microclimático mais importante da vegetação é prevenir o aquecimento dos canyons urbanos, diminuindo a absorção da radiação solar pelo sombreamento, e pelos efeitos da evapotranspiração. Foram então realizados estudos paramétricos explorando-se diferentes cenários de quadras urbanas adensadas com diferentes distribuições de vegetação, buscando-se melhorias microclimáticas no nível do pedestre, a 1,5m do solo, usando o modelo ENVImet V4 Preview I, previamente calibrado com medições microclimáticas de campo em uma área densamente construída em São Paulo, e tendo em mãos dados locais de vegetação.

Visando beneficiar as atividades urbanas no espaço público, a temperatura do ar, da superfície e a temperatura média radiante foram comparadas entre diferentes estratégias de distribuição da vegetação arbórea, mantendo-se constante a área construída, aumentando-se a altura dos edifícios quando necessário, para a redistribuição da mesma nos diferentes cenários. Com base nos resultados, os dois índices de conforto externo adotados anteriormente foram aplicados, TEP e PET, para se quantificar a influência da vegetação nas condições de conforto do pedestre.

\footnotetext{
78 Para a superação dessas etapas contamos com a colaboração do Prof. Humberto Ribeiro da Rocha (IAG/USP), Prof. Dra. Eleonora Assis (UFMG) e Prof. Dr. Demóstenes Ferreira da Silva Filho (ESALO/USP).
} 


\subsubsection{Medições de campo em alta densidade construída, visando à calibração do modelo}

Para os estudos envolvendo o adensamento construído, e visando à posterior calibração do modelo para a realização das simulações paramétricas, medições microclimáticas foram realizadas entre os dias 4 de março e 29 abril de 2013 no distrito da Bela Vista, região central de São Paulo, próximo à Av. Paulista, a fim de se registrar os dados de temperatura e umidade relativa do ar, radiação solar global, temperatura do solo, direção e velocidade do vento, com o objetivo de calibrar previamente o modelo ENVI-met V4 Preview 1 antes das simulações paramétricas. ${ }^{79}$

A figura 29 mostra a área de nove quadras definida na Bela Vista e, na parte central, onde fica a quadra mais densa, foi posicionada a estação meteorológica no piso térreo de um edifício residencial. Buscando-se evitar obstruções para a circulação dos moradores e pensando também na proteção do equipamento, a administração do edifício permitiu a colocação da estação num espaço coberto por grama e sob uma pérgola leve de madeira.
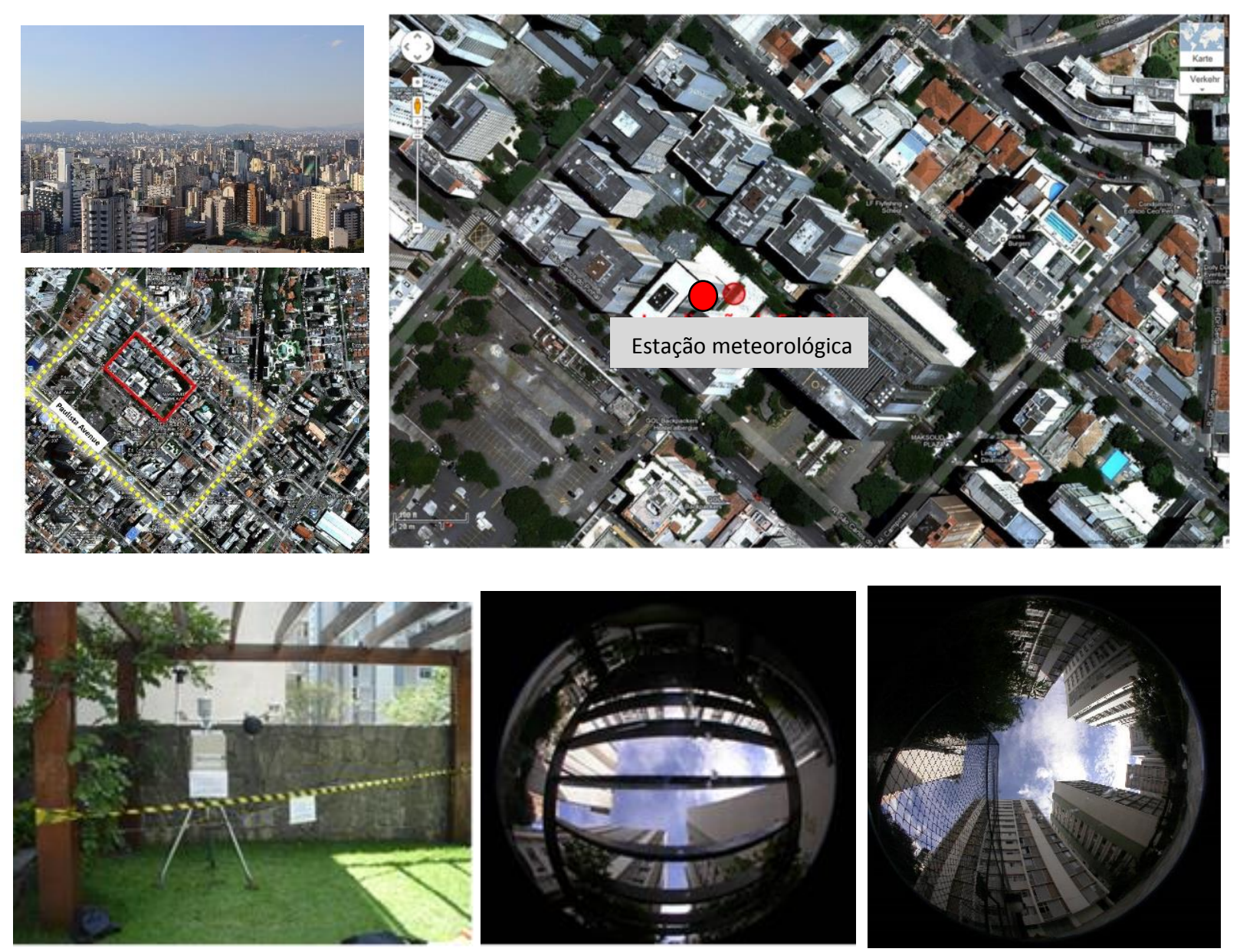

Figura 29 - No alto, à esquerda, vista aérea do distrito da Bela Vista com as nove quadras e a indicação (em vermelho) da quadra mais adensada ao centro; no alto, à direita, localização do ponto de medição na quadra mais densa; abaixo, da esquerda para a direita, estação meteorológica e imagens hemisféricas sob a pérgola de madeira e a poucos metros de distância da mesma (GUSSON, 2014).

\footnotetext{
${ }^{79}$ As medições microclimáticas foram realizadas originalmente para o trabalho de GUSSON (2014), e as simulações para este trabalho contaram com a colaboração de Paula Shinzato e Carolina Gusson, pos-doc e doutoranda, respectivamente.
} 
O impacto da pérgola, neste caso em particular, não foi tão relevante, considerando-se que a estrutura ainda permitiu uma boa visão do céu, quase sem a presença de vegetação, o que, dessa forma, não causaria o aprisionamento do calor durante a noite. Como a visão do céu já é bastante obstruída pelos edifícios altos do entorno, como mostra a Figura 26, a incidência de radiação solar global no sensor não foi afetada, uma vez que os valores medidos e simulados da radiação global foram similares, conforme mostra a Figura 31.

O dia de início para as simulações durante o processo de calibração foi definido com base em dados pluviométricos, registrados em duas estações meteorológicas fixas: uma na zona norte e outra na zona sul da cidade, para o mesmo período das medições na Bela Vista. As estações de referência indicaram que o maior período com condições climáticas estáveis (baixa velocidade do vento e sem chuva) estava entre os dias 25 e 28 de abril de 2013. Assim, a simulação teve início no dia 25 de abril e os dados de entrada são apresentados na Tabela 7.

A temperatura para a camada superior do solo foi medida no local utilizando-se o sensor Campbell 107 e a umidade do solo foi estimada a partir dos resultados do modelo simple Biosphere - SIB2 ${ }^{80}$. A umidade específica a $2500 \mathrm{~m}$ acima do nível do mar foi obtida a partir dos dados de sondagem do Aeroporto Campo de Marte (cerca de 3,3 km ao norte da área de estudo), disponível para Oh UTC e $12 \mathrm{~h} \mathrm{UTC}, 21 \mathrm{~h}$ e $9 \mathrm{~h}$ em horário local (LST - local standard time), respectivamente. Por isso, de acordo com a disponibilidade de dados para umidade específica a $2500 \mathrm{~m}$ e com o objetivo de minimizar os erros de convergência relacionados à radiação de onda curta nas primeiras horas da simulação, ficou definido que a simulação começaria no período noturno, às $21 \mathrm{~h} \mathrm{LST}$.

Recomenda-se desconsiderar as primeiras $24 \mathrm{~h}$ de simulação, adotando-se o segundo dia para a análise dos resultados. No terceiro dia, o modelo tende a se aquecer e gerar dados menos confiáveis (GOLDBERG et al., 2014). Portanto, para essa fase de simulação da área real de estudo, o tempo total de simulação foi de $72 \mathrm{~h}$, sendo que os dados do segundo dia foram utilizados para calibrar o modelo. O resultado da simulação ficou próximo aos dados medidos em campo quando se observa a sobreposição das curvas com dados de temperatura do ar e radiação solar global (Figuras 30 e 31), e os resultados foram considerados satisfatórios para a próxima fase das simulações paramétricas.

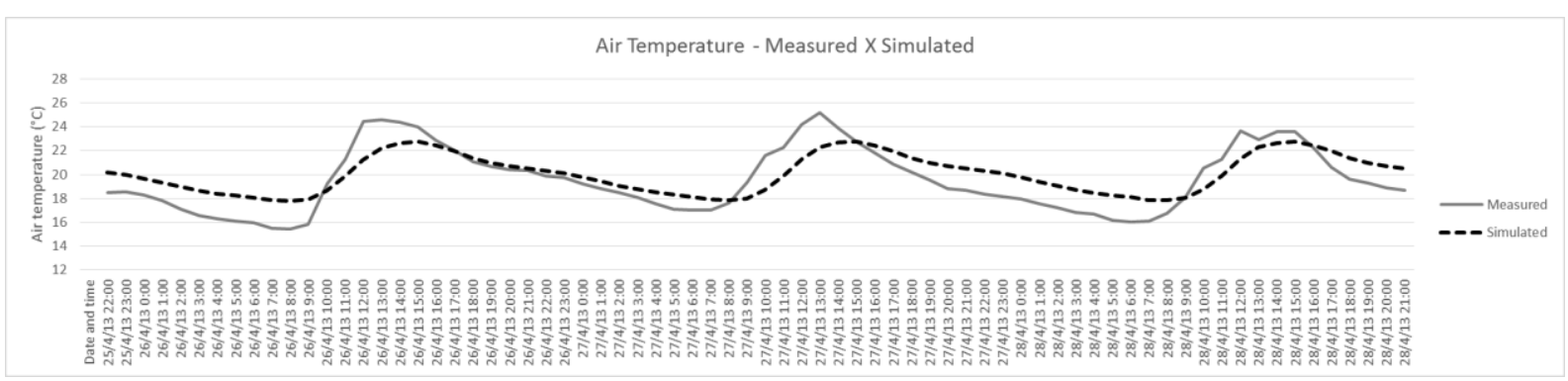

Figura 30 - Comparação dos dados medidos e simulados para temperatura do ar na Bela Vista.

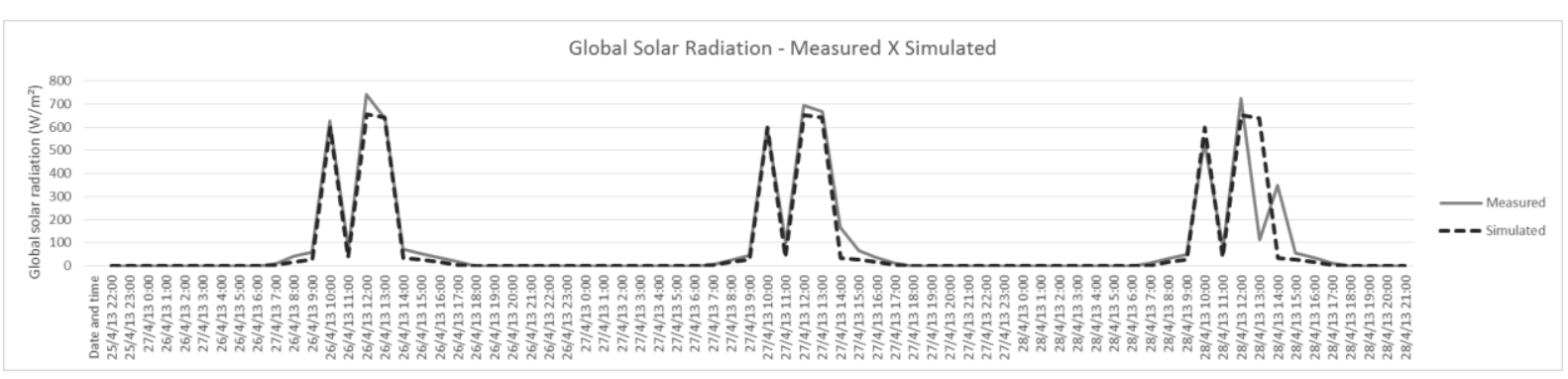

Figura 31 - Comparação dos dados medidos e simulados para radiação solar global na Bela Vista.

\footnotetext{
${ }^{80}$ Com a colaboração do Prof. Dr. Humberto Ribeiro da Rocha, IAG/USP.
} 


\subsubsection{Simulações paraméticas no ENVI-met V4 Preview I no cenário climático atual}

Após a fase de calibração, um cenário base (cenário a) foi criado para os estudos paramétricos e o domínio da área de entrada foi composto por nove blocos com $100 \mathrm{~m} \times 100 \mathrm{~m}$ (1ha ou $10.000 \mathrm{~m}^{2}$ ) cada, que pode ser considerado o tamanho médio de uma quadra no centro São Paulo. Em cada bloco foram incluídas nove torres com $45 \mathrm{~m}$ de altura (grosso modo, 15 andares, também uma altura média para o distrito da Bela Vista), tendo cada edifício uma planta quadrada, com dimensões de $20 \mathrm{~m} \times 20 \mathrm{~m}$, resultando em um coeficiente de aproveitamento de 5,4. O edifício torre foi adotado considerando-se 4 unidades habitacionais com $58 \mathrm{~m}^{2}$ cada, por andar, podendo a quadra abrigar uma densidade populacional volta de 1764 hab/ha, considerando-se 3,5 pessoas/apartamento, em média.

Três outros cenários foram propostos com diferentes distribuições da vegetação, mas mantendo-se a mesma densidade construída: um parque de 1 ha com árvores ocupando toda quadra central (cenário b); a mesma área verde distribuída em pequenos parques (pocket parks) no miolo das quadras (cenário c); e, mais uma vez, a mesma área verde distribuída em árvores nas calçadas ao longo de todo o perímetro de cada quadra (cenário d). Foi adotado o solo franco-argilo-arenoso (sandy-clayloam) e a velocidade do vento foi mantida constante em $0,5 \mathrm{~m} / \mathrm{s}$ em todos os cenários, com o objetivo de minimizar os efeitos de convecção e para enfatizar o efeito da vegetação e da densidade construída. Para as vias, foi especificado asfalto com propriedades térmicas obtidas dos estudos de Hellmann (2008), para as condições brasileiras. Nos cenários b e c os edifícios tiveram um acréscimo de altura, para se manter a mesma densidade construída, com a inclusão dos parques. No cenário d manteve-se a mesma altura, pois as árvores foram incluídas nas calçadas (Figura 32), sem necessidade de alteração nas torres.

No ENVI-met V4 Preview 1, além do banco de dados 1D das plantas, que segue a mesma estrutura do banco de dados de plantas da versão anterior V3.1 Beta 5, um novo banco de dados 3D foi recentemente implementado, com uma forma mais sofisticada para se criar outros tipos de vegetação. Nesta última versão, permite ao usuário editar e criar novas plantas através do módulo Albero, que é um aplicativo existente dentro do modelo ENVI-met V4 para se definir a geometria das plantas em 3D. O Albero está sendo explorado para pesquisas futuras e, neste estudo, para todos os cenários, foram adotadas árvores densas com $\mathrm{IAF}=4,6 \mathrm{~m}^{2} / \mathrm{m}^{2}$, a partir da base de dados disponíveis 1D. ${ }^{81}$
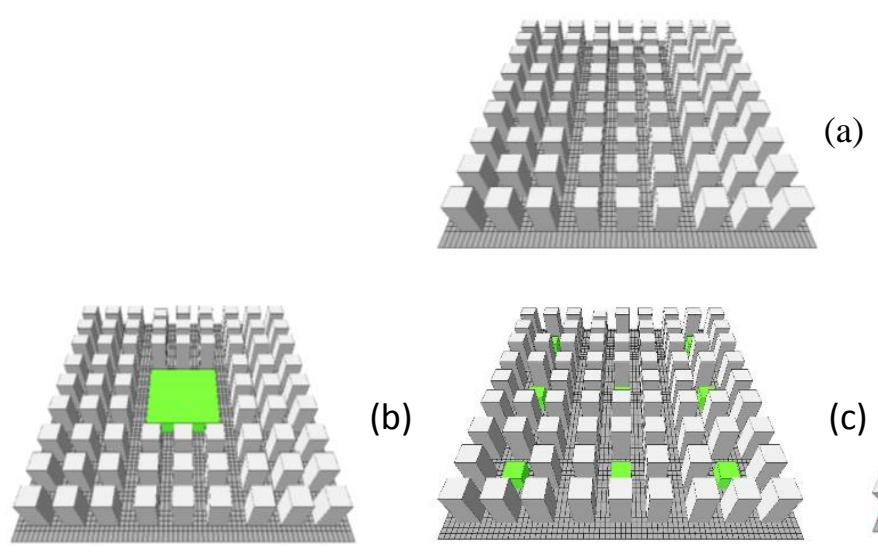

(b)

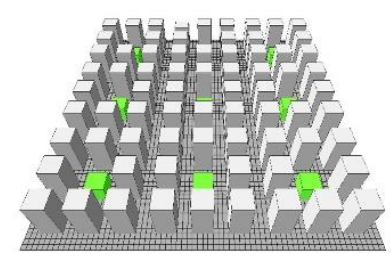

(a)

(c)

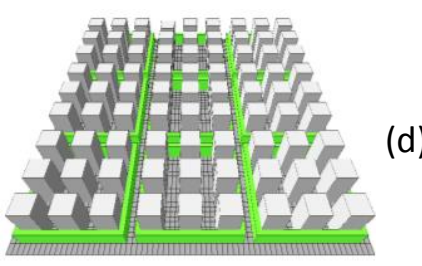

Figura 32 - Os quatro cenários gerados no modelo ENVI-met V.4 Preview 1: (a) cenário base (base case), apenas com torres, (b) Torres + parque central, (c) + torres + pocket parks, (d) torres + árvores nas vias.

\footnotetext{
81 O IAF 4,6 m2/m2 é valor mais baixo disponível no banco 1D, ainda assim mais alto do que os valores encontrados nas medições de campo em São Paulo, a priori. A técnica de medição está sendo revista no grupo, assim como as distinções entre IAF verdadeiro e IAF efetivo, encontradas na literatura. Os primeiros resultados foram submetidos sob a forma de artigo e aceitos para o ENCAC 2015 (SHINZATO, Paula; YOSHIDA, Daniel; DUARTE, Denise. O impacto da vegetação nos microclimas urbanos: estimativa do índice de área foliar - IAF pelo método de fotos hemisféricas (Artigo aceito para o ENCAC 2015).
} 
Dois dias representativos foram escolhidos para simular os quatro cenários: abril de 2013, que coincide com o período medido, durante o outono, caracterizado por temperaturas amenas e taxas de umidade mais baixas; e fevereiro de 2014, representando um verão extremo e quente, caracterizado por uma onda de calor, com temperaturas mais elevadas e taxas de umidade mais baixas já registradas em décadas, conforme apresentado no capítulo 6. Os dados de entrada são apresentados na Tabela 7. Em todos os estudos paramétricos, o tempo total de simulação foi de $48 \mathrm{~h}$, sendo que o segundo dia foi utilizado para a análise dos resultados.

Tabela 7 - Dados de entrada utilizados nos quatro cenários simulados pelo ENVI-met V4 Preview 1.

\begin{tabular}{|l|l|l|}
\hline Data de início da simulação & 25.04 .2013 & 06.02 .2014 \\
\hline Velocidade dos ventos a $10 \mathrm{~m}$ do solo $[\mathrm{m} / \mathrm{s}]$ & 0.5 & 0.5 \\
\hline Direção dos ventos $\left(0^{\circ} \mathrm{N} / 90^{\circ} \mathrm{L} / 180^{\circ} \mathrm{S} / 270^{\circ} \mathrm{O}\right)$ & 135 & 112.5 \\
\hline Umidade específica a $2500 \mathrm{~m}[\mathrm{~g}$ de água/ $\mathrm{kg}$ de ar] & 7 & 7 \\
\hline Umidade do solo - camada superior $(0-20 \mathrm{~cm})[\%]$ & 50 & 50 \\
\hline Umidade do solo - camada intermediária $(20-50 \mathrm{~cm})[\%]$ & 60 & 60 \\
\hline Umidade do solo - camada inferior $(50-200 \mathrm{~cm})[\%]$ & 70 & 70 \\
\hline Fator de ajuste da radiação solar & 1.05 & 1.4 \\
\hline Cobertura de nuvens baixas [octas] & 1 & 0 \\
\hline Cobertura de nuvens médias [octas] & 1 & 0.4 \\
\hline Cobertura de nuvens altas [octas] & 0 & \\
\hline
\end{tabular}

A fim de se extrair os dados das simulações geradas pelo ENVI-met Preview 1, foi adotado o aplicativo Leonardo 2014 Beta para gerar mapas gráficos 2D dos resultados, e também para calcular os valores médios das variáveis microclimáticas, como temperatura do ar, temperatura radiante média, umidade relativa do ar, umidade específica e velocidade do vento.

A Figura 30 mostra a quadra central em destaque, onde se espera encontrar dados mais precisos do que nas áreas periféricas da grade do modelo, por questões ligadas aos efeitos de borda. Ao invés de se extrair os resultados para pontos receptores em lugares específicos, que podem variar bastante dependendo das condições de exposição dos mesmos ao sol ou à sombra, em determinadas horas do dia ou períodos do ano, optou-se por extrair os valores médios para cada variável de interesse na quadra central, utilizando-se a ferramenta Map Script do aplicativo Leonardo, sendo estas: temperatura do ar, temperatura radiante média e temperatura de superfície.
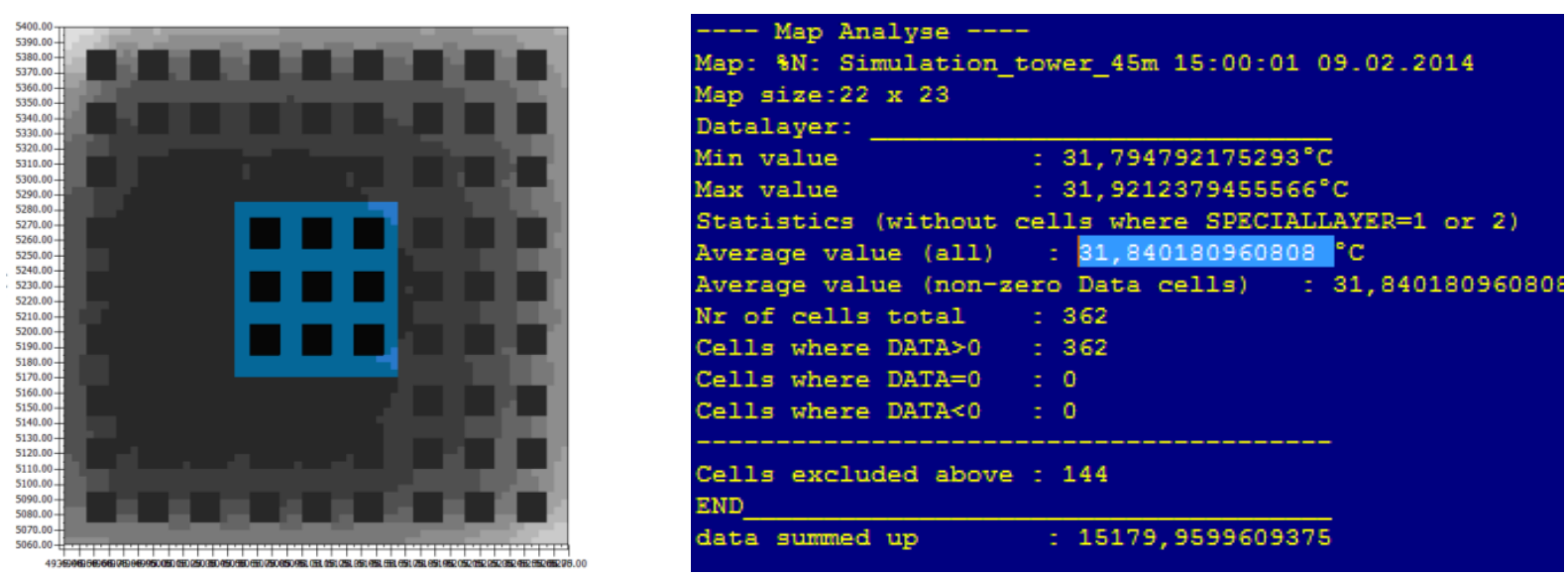

Figura 33 - À esquerda, quadra central considerada para a análise dos dados médios; à direita, resultados médios obtidos por meio da ferramenta Map Script do aplicativo Leonardo 2014 Beta.

Para padronizar e facilitar a leitura das imagens de simulação, abrangendo uma faixa relativamente extensa de temperaturas do ar, das mínimas até as máximas diárias, em diferentes períodos do ano, 
no cenário climático atual e futuro, um padrão de cores foi proposto para este trabalho (Figura 34), a cada $2^{\circ} \mathrm{C}$, com escala a cada $0,2^{\circ} \mathrm{C}$ em cada cor, variando de $16^{\circ} \mathrm{C}$ a $36^{\circ} \mathrm{C}$. Para temperatura de superfície e temperatura radiante média foi usada uma paleta à parte, em função dos valores extrapolarem muito o padrão adotado para a temperatura do ar.

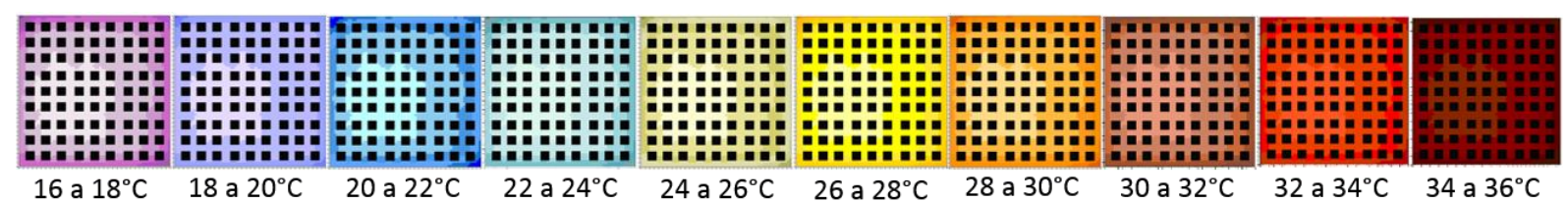

Figura 34 - Padrão de cores para as temperaturas do ar nas imagens de simulação (Elaboração: Carolina Gusson).

Todas as simulações foram geradas em LST. A Tabela 8 mostra os resultados para a temperatura do ar simulada para as $6 \mathrm{~h}$, horário em que a temperatura mínima foi registada, comparando-se o cenário somente com torres e os cenários com vegetação (IAF $=4,6 \mathrm{~m}^{2} / \mathrm{m}^{2}$ ) em abril de 2013 e fevereiro de 2014. Foram também comparados os resultados às $15 \mathrm{~h}$ (Tabela 9), horário que corresponde à temperatura do ar mais alta nas medições de campo e nos resultados simulados (Figura 31).

\subsubsection{Resultados das Simulações}

De acordo com as Tabelas 8 e 9, o cenário base apresentou uma temperatura média do ar de $17,5^{\circ} \mathrm{C}$ às $6 \mathrm{~h}$ e $23,2^{\circ} \mathrm{C}$ às $15 \mathrm{~h}$, em abril de 2013. Em fevereiro de 2014, a temperatura do ar média foi de $24,8^{\circ} \mathrm{C}$ e $31,8^{\circ} \mathrm{C}$ às $6 \mathrm{~h}$ e $15 \mathrm{~h}$, respectivamente. Nos meses simulados, a temperatura do ar no cenário base foi sempre maior do que os cenários com vegetação (Figura 34).

O efeito do resfriamento pela vegetação depende da configuração urbana, da temperatura e da umidade do solo, do índice de área foliar e da distribuição da vegetação. Em abril às $15 \mathrm{~h}$, a redução da temperatura média do ar na quadra central variou de $0,3^{\circ} \mathrm{C}$, comparando-se os cenários a (caso base) e c (pocket parks) até o máximo de $0,5^{\circ} \mathrm{C}$, dentro e no entorno do parque, comparando-se os cenários a (caso base) e d (árvores nas vias). No que se refere à distribuição, o efeito de oásis é mais pronunciado e homogêneo no cenário d (árvores nas vias) do que em b (parque central) e c (pocket parks).

Em fevereiro de 2014, às $15 \mathrm{~h}$, o efeito do resfriamento pela vegetação é um pouco mais acentuado, indicando diferenças na temperatura do ar de até $0,6^{\circ} \mathrm{C}$ ao se comparar com os cenários a (caso base) e d (árvores nas vias), e cerca de $0,4^{\circ} \mathrm{C}$ comparando-se os cenários a (caso base) e $\mathrm{c}$ (pocket parks).

Em abril, às $6 \mathrm{~h}$, comparando-se a temperatura média do ar na quadra central do cenário a (caso base) e $b$ (parque central) e $d$ (árvores nas vias), foram obtidas reduções de $0,5^{\circ} \mathrm{C}$ e $1,1^{\circ} \mathrm{C}$, respectivamente. A mesma comparação realizada para fevereiro 2014 mostrou diferenças de $1,3^{\circ} \mathrm{C}$ e $1,5^{\circ} \mathrm{C}$, mais significativas para o verão, sob a onda de calor. Os resultados obtidos para às $15 \mathrm{~h}$ apresentaram diferenças similares entre os cenários para a temperatura do ar (Figura 35). 
Tabela 8 - Resultados para a temperatura do ar às $6 \mathrm{~h}$.

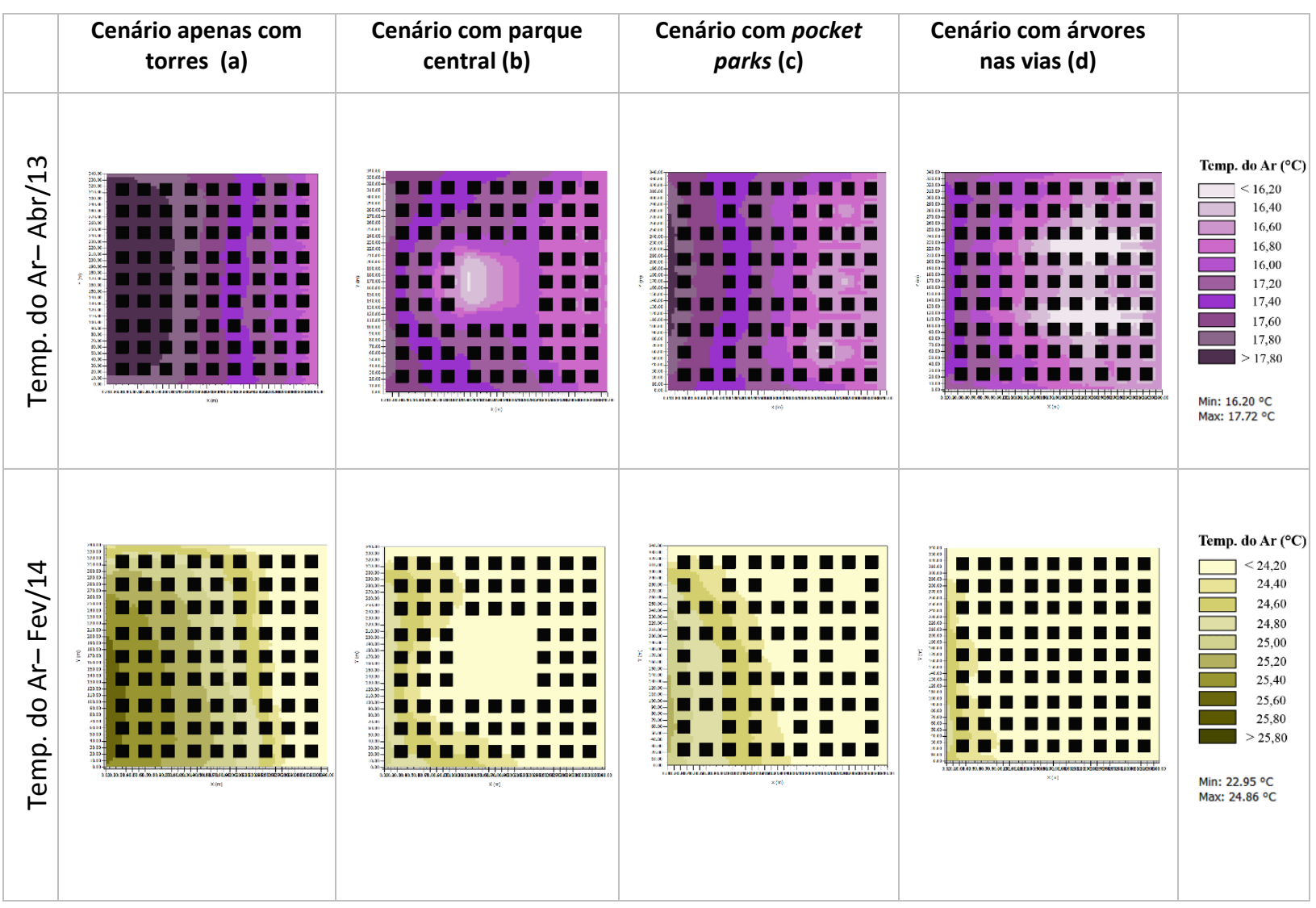

Tabela 9 - Resultados para temperatura do ar às $15 \mathrm{~h}$.

\begin{tabular}{|c|c|c|c|c|c|}
\hline & $\begin{array}{c}\text { Cenário apenas com } \\
\text { torres (a) }\end{array}$ & $\begin{array}{c}\text { Cenário com parque } \\
\text { central (b) }\end{array}$ & $\begin{array}{c}\text { Cenário com pocket } \\
\text { parks (c) }\end{array}$ & $\begin{array}{c}\text { Cenário com árvores } \\
\text { nas vias (d) }\end{array}$ & \\
\hline $\begin{array}{l}m \\
\text { In } \\
\frac{1}{1} \\
\frac{1}{4} \\
\frac{1}{4} \\
0 \\
\frac{0}{0} \\
\frac{0}{E} \\
\frac{8}{0}\end{array}$ & 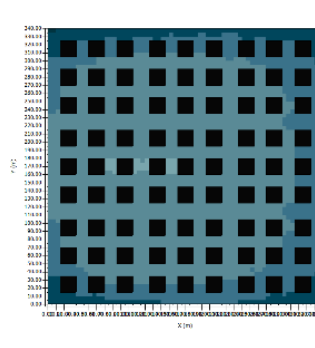 & 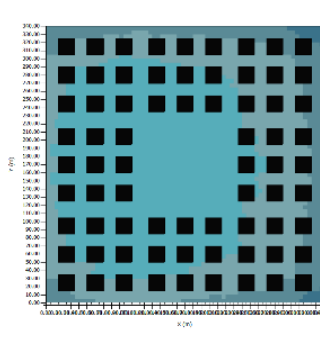 & 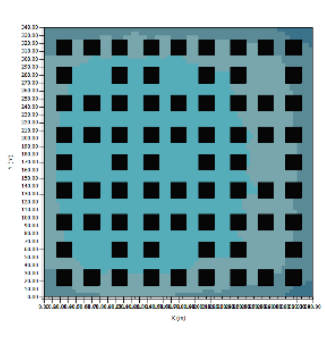 & 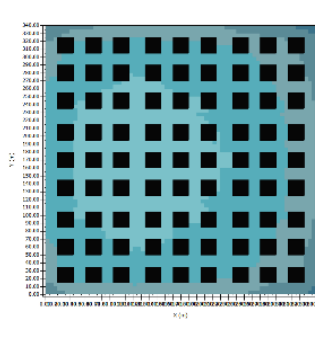 & 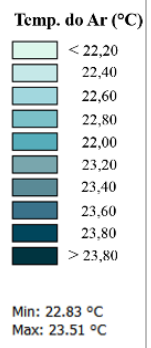 \\
\hline 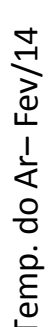 & 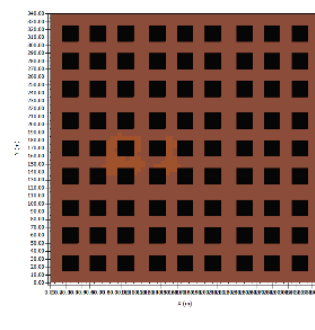 & 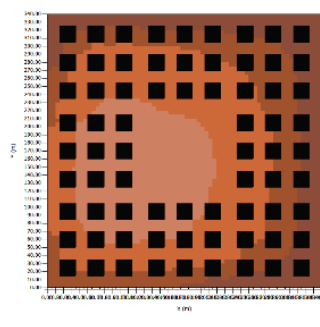 & 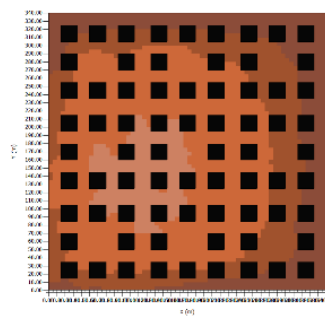 & 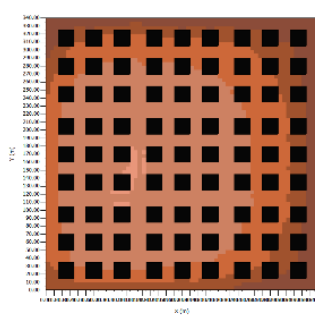 & 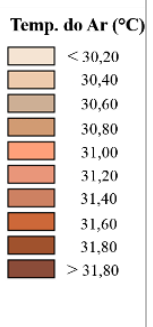 \\
\hline
\end{tabular}




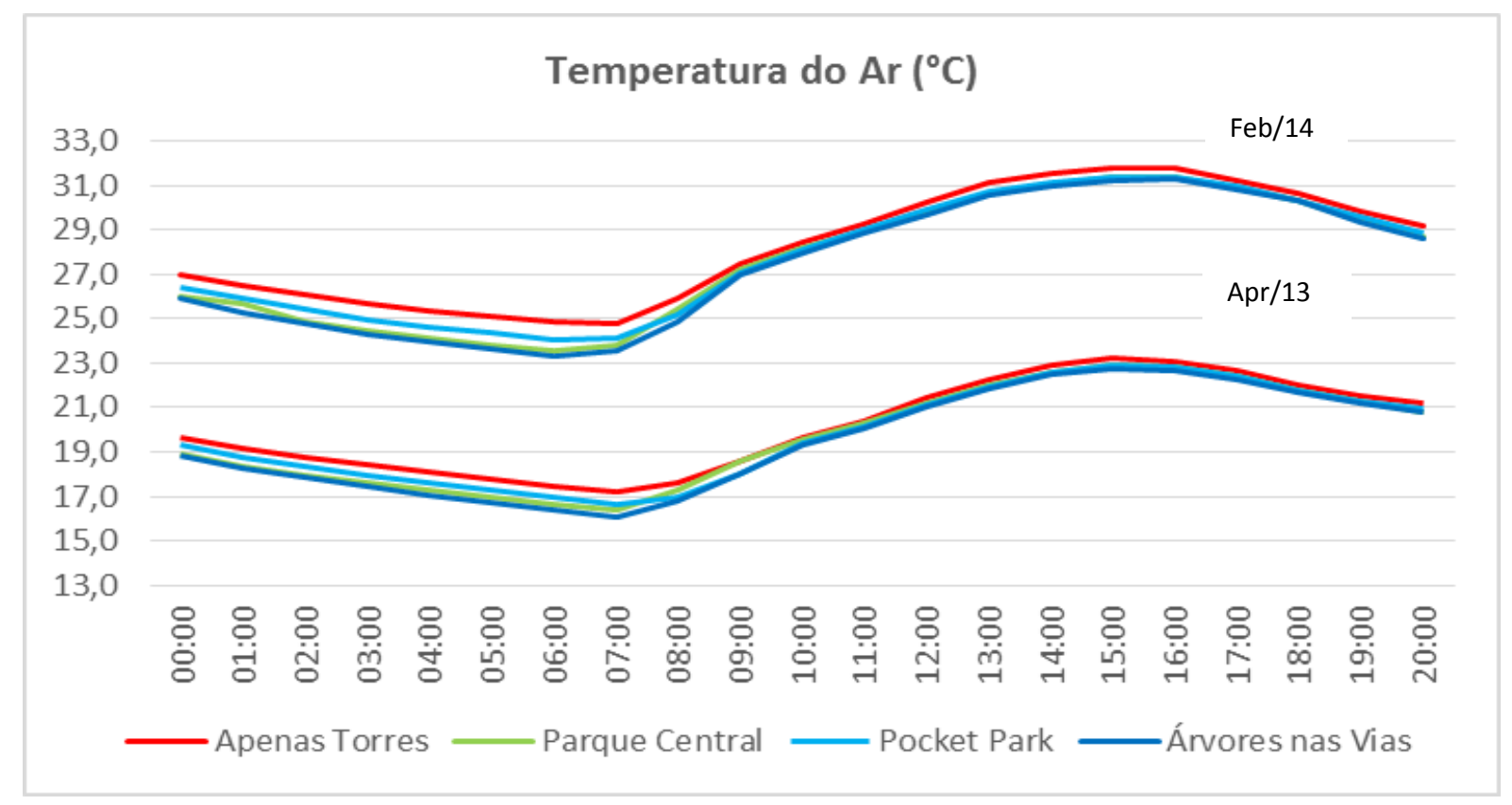

Figura 35 - Resultados para temperatura média do ar na quadra central dos quatro cenários para abril de 2013 e fevereiro de 2014.

O fato de que as árvores apresentam um efeito limitado (por volta de $1^{\circ} \mathrm{C}$ ) na temperatura do ar é condizente com os resultados obtidos em medições de campo (SHASHUA-BAR; HOFFMAN, 2004; WONG; CHEN, 2009; BOWLER et al., 2010) e nas simulações feitas pelo ENVI-met (BRUSE; FLEER, 1998; ALI-TOUDERT; MAYER, 2007; HUTTNER, 2012). Porém, diferentemente de resultados anteriores obtidos com o ENVI-met 3.1 Beta 5 (SHINZATO; DUARTE, 2012), neste estudo, o efeito parque no entorno avança cerca de uma quadra além dos limites das copas das árvores a sotavento (cenário b na Tabela 9), efeito este que continua sendo investigado no grupo.

A temperatura radiante média (TRM) é um parâmetro diretamente influenciado pelo sombreamento das árvores e edifícios. A redução da TRM por meio do sombreamento ocorre com a diminuição na radiação incidente de onda curta direta, difusa e refletida do sol, reduzindo as temperaturas de superfície e, consequentemente, é menor a emissão da radiação de ondas longa pelas superfícies urbanas. A Tabela 10 mostra como a TRM varia no nível do pedestre (1,5 $\mathrm{m}$ acima do solo) para os quatro cenários às $15 \mathrm{~h}$.

Durante as horas em que a rua recebe radiação solar direta, os efeitos do sombreamento mútuo dos edifícios e da vegetação contrastam com o aquecimento das superfícies nas ruas e os espaços não sombreados entre os edifícios, mostrando uma diferença média da TRM, na quadra central, de até $19,5^{\circ} \mathrm{C}$, comparando-se os cenários a (base case) e d (árvores nas vias), no mês de abril de 2013 , às 13h. No cenário c (pocket parks), a TRM é menor ao longo das ruas sombreadas, embora dentro da quadra do cenário $b$ (parque central) tenham sido obtidos os melhores resultados, configurando um efeito de oásis (ERELL et al., 2010).

Em fevereiro de 2014, o desenho é quase o mesmo, mas com TRM mais elevadas nos três cenários, sendo que a temperatura média radiante no cenário $\mathrm{b}$ (parque central) é aproximadamente $18,4^{\circ} \mathrm{C}$ menor que o cenário a (base case) às $13 \mathrm{~h}$. No cenário d (árvores nas vias) os benefícios de sombreamento das árvores são evidentes na TRM ao longo das ruas, abaixo das copas, mas o efeito não avança para as outras quadras (Tabela 10). A figura 36 apresenta os valores para a TRM no nível do pedestre (1,5 m acima do solo) em abril de 2013 e fevereiro 2014. 
Tabela 10 - Resultados para TRM às $15 \mathrm{~h}$.

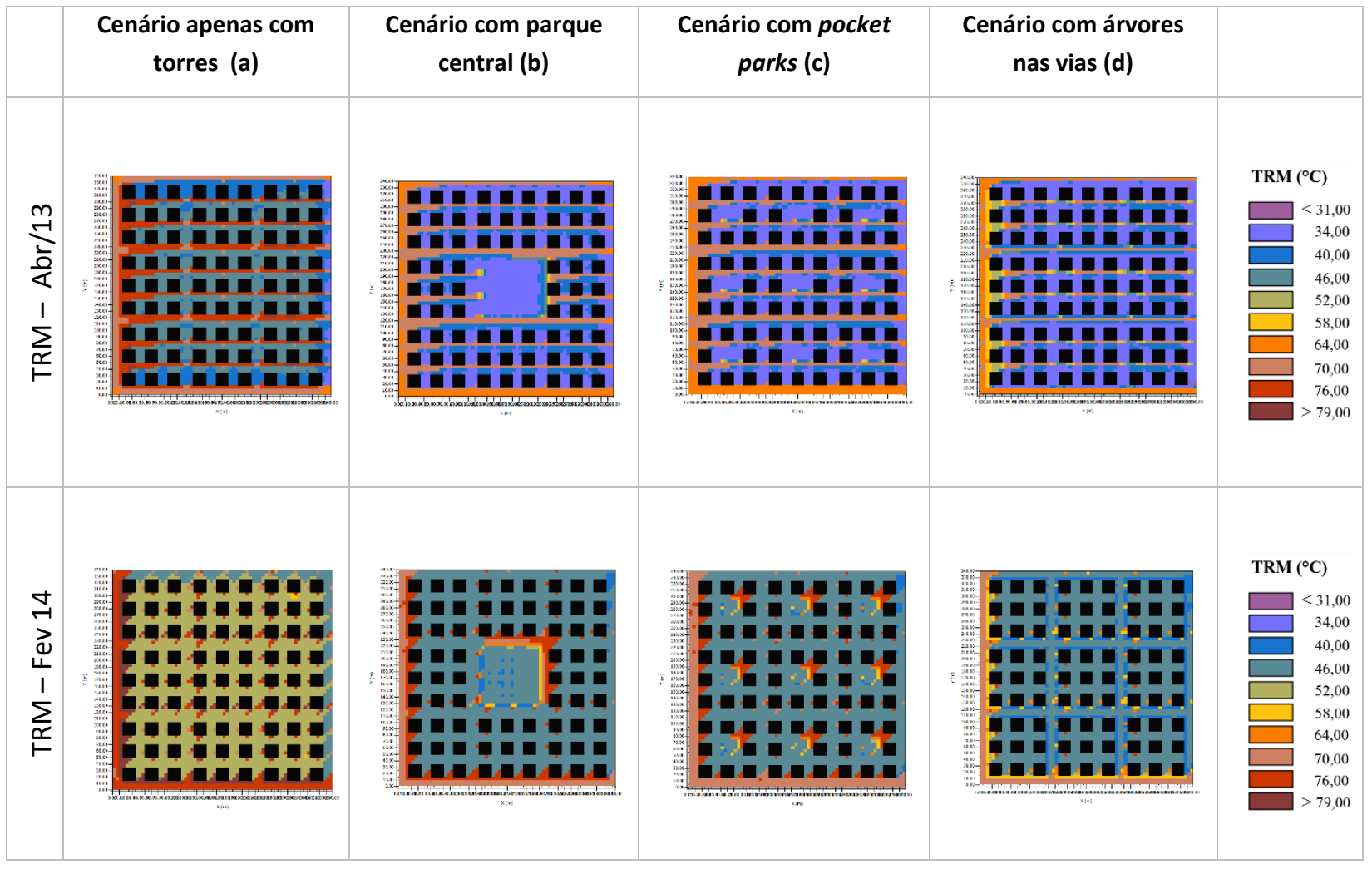
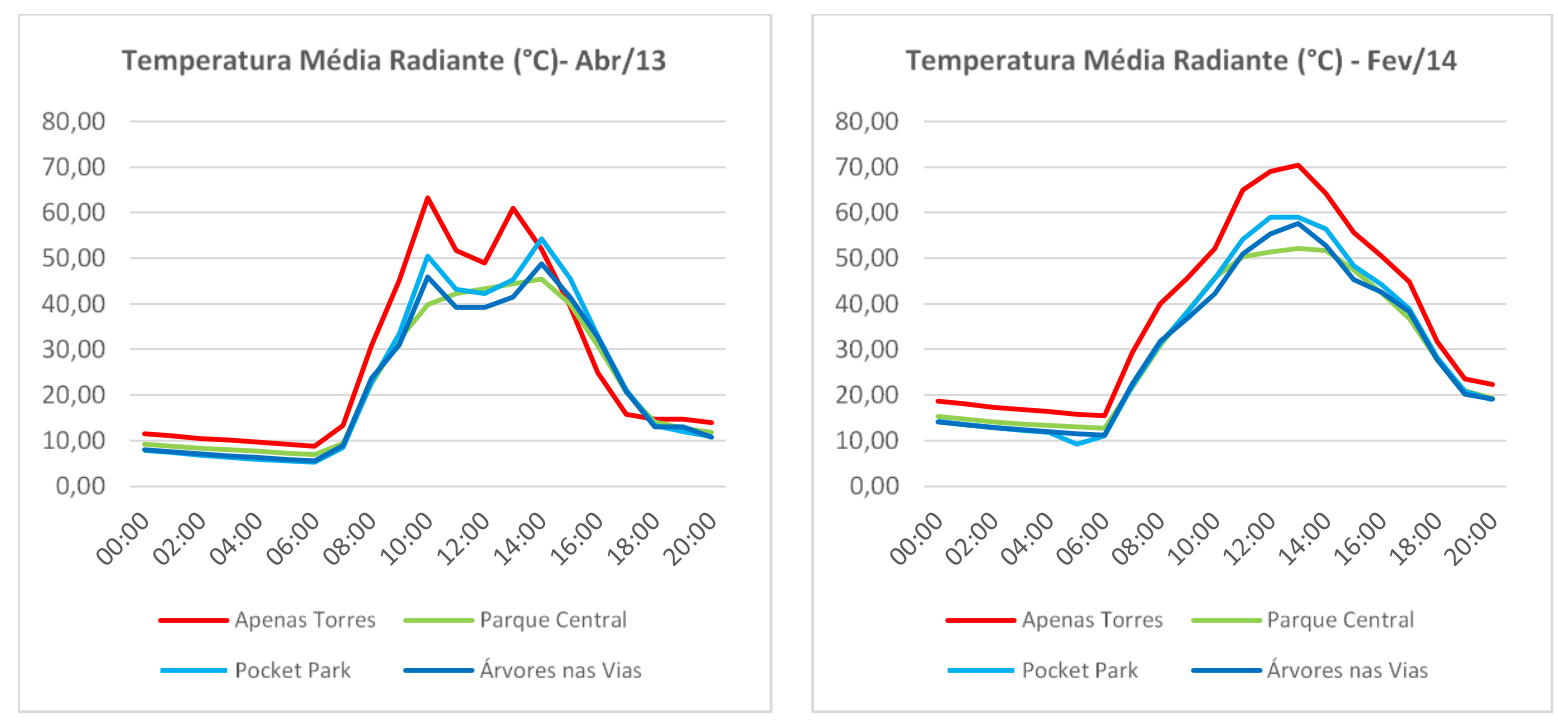

Figura 36 - Resultados para TRM no nível do pedestre (1,5m acima do solo), em valores médios da quadra central, em abril de 2013 e fevereiro de 2014.

A Tabela 11 mostra a temperatura da superfície do asfalto das vias para os três cenários com vegetação. Durante o período em que a rua recebe radiação solar direta, os três casos com vegetação (b, c, e d) mostram que as árvores têm um impacto significativo sobre a temperatura da superfície do solo, e que a presença de vegetação pode reduzir a temperatura superficial em até $13^{\circ} \mathrm{C}$ em abril de 2014 e até $16^{\circ} \mathrm{C}$ em fevereiro de 2014. 
Tabela 11 - Resultados para a temperatura de superfície às $15 \mathrm{~h}$.

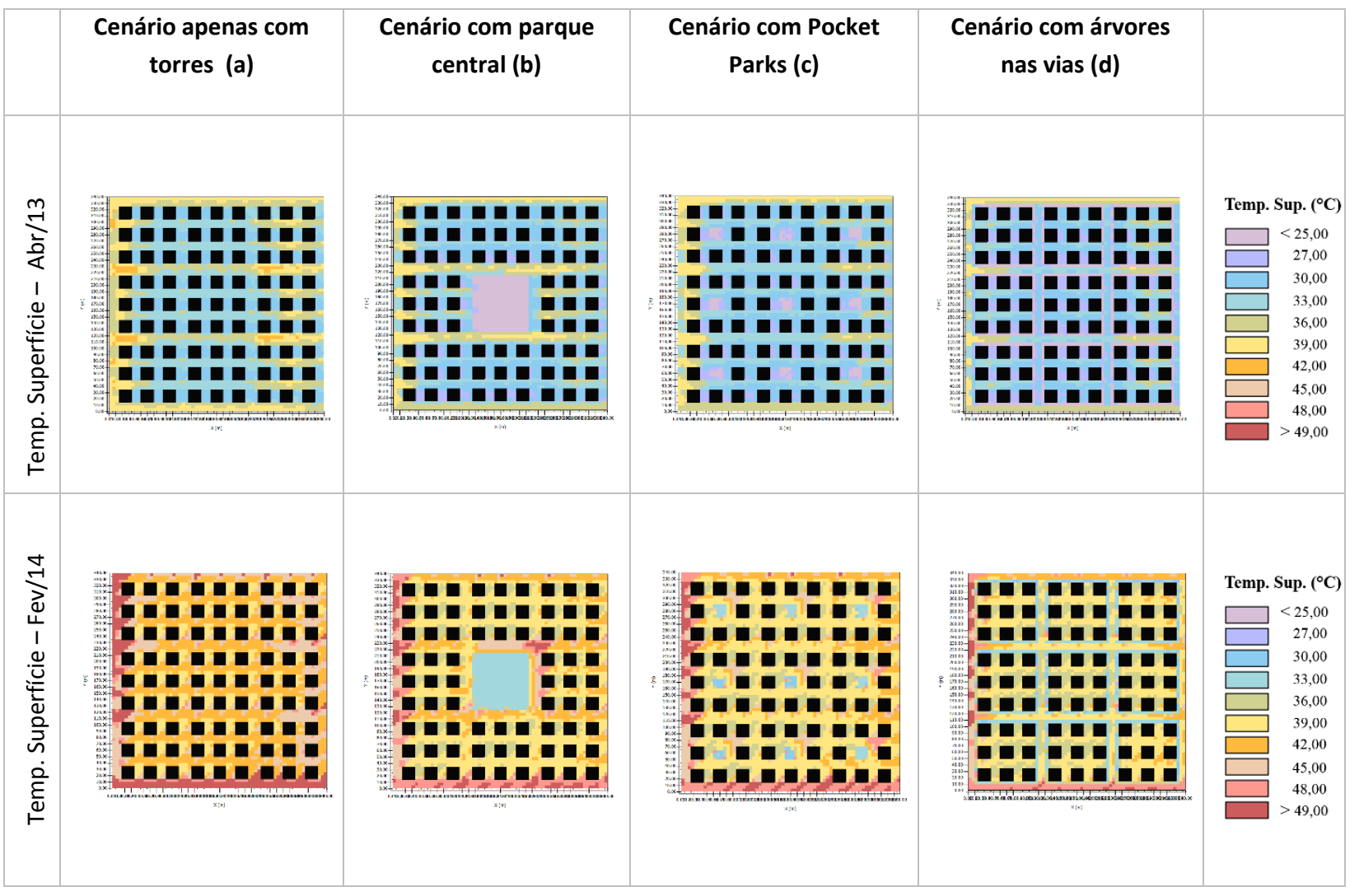

Com base nos resultados obtidos, dois índices de conforto térmico foram aplicados. O primeiro é a Physiological Equivalent Temperature - PET, que é um índice derivado do balanço de energia do corpo humano (HÖPPE, 1999), e a segunda é a Temperatura Equivalente Percebida - TEP (MONTEIRO; ALUCCI, 2011), um índice empírico e desenvolvido para as condições locais em São Paulo, o que permite uma previsão mais adequada do conforto térmico em espaços abertos para climas subtropicais.

Os dois índices foram calculados com base em valores médios simulados para a quadra central nos quatro cenários, considerando-se os dois períodos, abril de 2013 e fevereiro de 2014. Um valor inicial de $0,5 \mathrm{~m} / \mathrm{s}$ foi definido nos dados de entrada do ENVI-met, mas a variação na velocidade do vento, durante o dia, foi obtida a partir do cálculo da velocidade média na quadra central do domínio, também considerada para os cálculos do PET e TEP.

Ambos os índices são bastante influenciados pela TRM, sendo que os valores mais altos foram obtidos entre $9 \mathrm{~h}$ e $14 \mathrm{~h}$ para abril de 2013 e entre $9 \mathrm{~h}$ e $16 \mathrm{~h}$, para fevereiro de 2014 . Quando comparados com o cenário base, os resultados foram mais expressivos nos meses de abril e fevereiro para o cenário $b$ (parque central) às $13 \mathrm{~h}$, com uma diferença no TEP por volta de $10^{\circ} \mathrm{C}$ e uma diferença de cerca de $13,4^{\circ} \mathrm{C}$ para o PET; as menores diferenças ocorreram para abril e fevereiro no cenário c (pocket parks) às $13 \mathrm{~h}$, sendo as diferenças para o TEP de $6,0^{\circ} \mathrm{C}$ e o PET de $7,7^{\circ} \mathrm{C}$, ainda assim bastante significativas para o conforto humano. As Figuras 37 e 38 apresentam os valores de TEP e PET no nível do pedestre (1,5 m acima do solo) em abril de 2013 e fevereiro de 2014. 

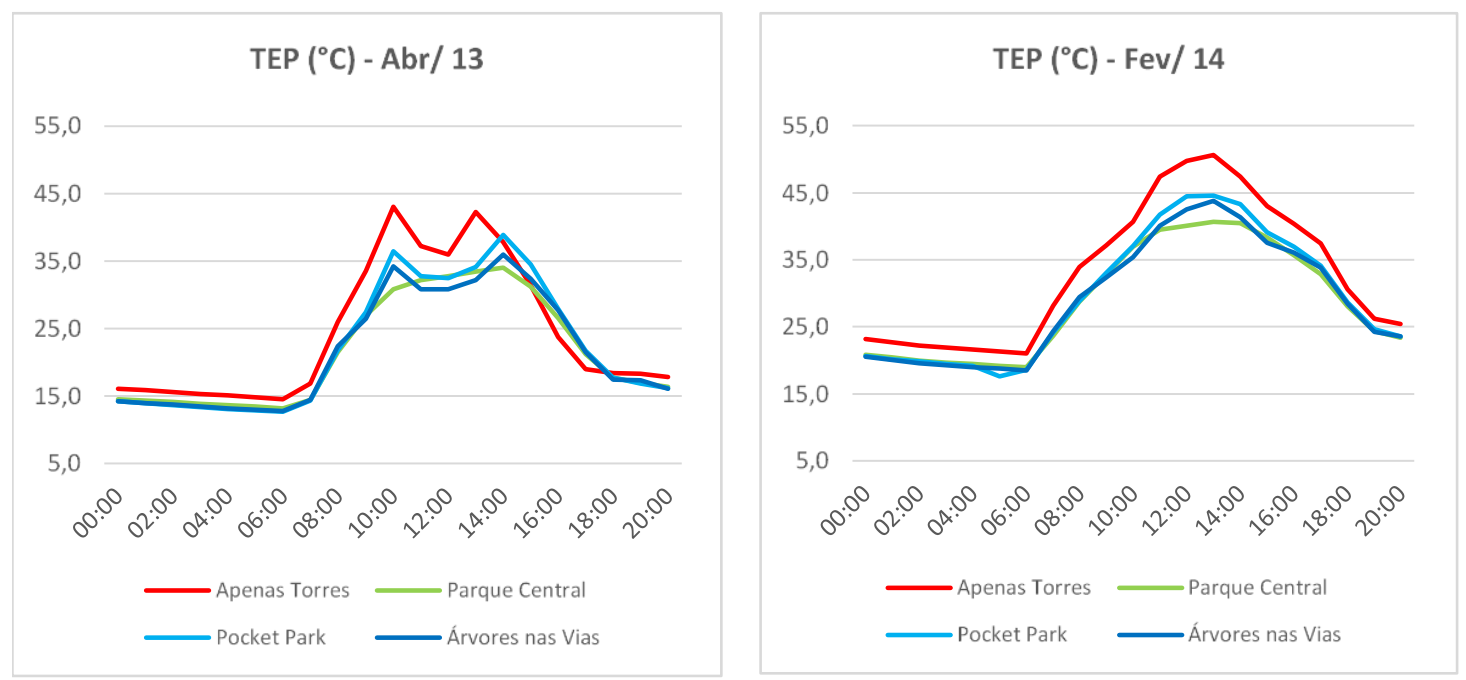

Figura 37 - Resultados do TEP para abril de 2013 e fevereiro de 2014.
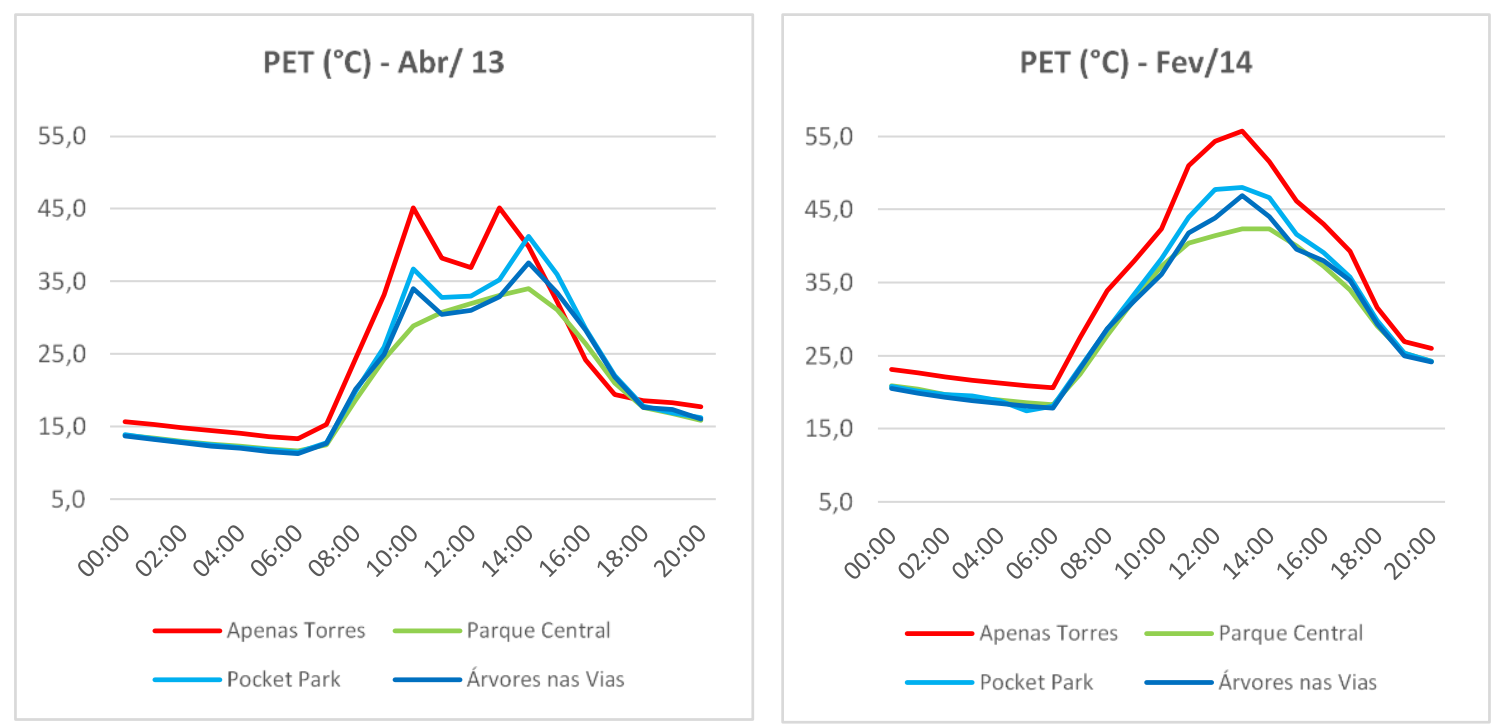

Figura 38 - Resultados do PET para abril de 2013 e fevereiro de 2014.

\subsubsection{Considerações sobre os resultados das simulações}

Durante o outono, em abril de 2013, ocorre um período com temperaturas amenas em São Paulo, em que a diferença máxima da temperatura do ar foi de até $0,5^{\circ} \mathrm{C}$, comparando o cenário base com o cenário d (árvores nas vias). Em fevereiro de 2014, durante o verão extremo, as diferenças na temperatura do ar tornam-se mais significativas e o efeito da vegetação foi um pouco mais acentuado, mostrando diferenças máximas na temperatura do ar de até $0,6^{\circ} \mathrm{C}$, comparando o cenário a (base case) e d (árvores nas vias). Nesse sentido, a configuração espacial do cenário d, com árvores densas ao longo da calçada, apresentou os menores valores para a temperatura do ar e uma distribuição mais homogênea do efeito de resfriamento pela vegetação, em comparação com o parque central e os pocket parks. Apesar das pequenas diferenças na temperatura do ar entre os três cenários, a redução na TRM gera uma melhora sensível nos níveis de conforto térmico de acordo com os dois índices aplicados, especialmente para o cenário b (parque central), às $13 \mathrm{~h}$, com uma diferença no TEP por volta de $10^{\circ} \mathrm{C}$ e, no PET, de cerca de $13,4^{\circ} \mathrm{C}$, caracterizando o que Erell et al. (2010) chamou de park cooling island - $\mathrm{PCl}$, um efeito de oásis entre as torres, mesmo em um contexto de alta densidade. 


\subsubsection{Simulações paramétricas no ENVI-met V4 Preview I nos cenários climáticos futuros}

Conforme apresentado no capítulo 5, de material e método, de acordo com o banco climático de temperatura e umidade do ar simulado por Llopart et al. (2014) para os períodos futuro próximo (2015 a 2044), futuro intermediário (2045 a 2074) e futuro distante (2076 a 2096), o dia 27 de janeiro apresentou as médias mais elevadas para temperatura do ar, do total de 365 dias do ano simulados para cada período, conforme mostra a Tabela 12.

Tabela 12 - Projeção futura dos dados médios de temperatura e umidade relativa do ar, para o dia 27 de janeiro, correspondentes a cada período: futuro próximo (2015 a 2044), futuro intermediário (2045 a 2074 ) e futuro distante (2076 a 2096).

\begin{tabular}{|c|c|c|c|c|c|c|}
\hline \multirow[b]{3}{*}{ HORA } & \multicolumn{6}{|c|}{ MAIORES MÉDIAS } \\
\hline & \multicolumn{2}{|c|}{ Futuro próximo } & \multicolumn{2}{|c|}{ Futuro Intermediário } & \multicolumn{2}{|c|}{ Futuro Distante } \\
\hline & Temperatura & UR & Temperatura & UR & Temperatura & UR \\
\hline 1 & 24,74 & 77 & 26,53 & 76 & 27,67 & 77 \\
\hline 2 & 24,72 & 78 & 26,59 & 76 & 27,68 & 77 \\
\hline 3 & 25,40 & 70 & 27,35 & 68 & 28,39 & 68 \\
\hline 4 & 24,68 & 73 & 26,68 & 71 & 27,67 & 72 \\
\hline 5 & 24,66 & 73 & 26,71 & 71 & 27,65 & 72 \\
\hline 6 & 23,95 & 80 & 26,04 & 78 & 26,93 & 79 \\
\hline 7 & 25,65 & 68 & 27,71 & 66 & 28,60 & 67 \\
\hline 8 & 26,65 & 63 & 28,68 & 62 & 29,57 & 63 \\
\hline 9 & 28,26 & 57 & 30,25 & 56 & 31,14 & 58 \\
\hline 10 & 30,65 & 47 & 32,58 & 47 & 33,53 & 48 \\
\hline 11 & 31,64 & 48 & 33,51 & 47 & 34,53 & 48 \\
\hline 12 & 32,43 & 43 & 34,24 & 42 & 35,33 & 43 \\
\hline 13 & 32,49 & 43 & 34,36 & 42 & 35,42 & 43 \\
\hline 14 & 33,37 & 39 & 35,28 & 38 & 36,33 & 39 \\
\hline 15 & 33,13 & 41 & 35,10 & 39 & 36,12 & 40 \\
\hline 16 & 32,27 & 44 & 34,26 & 41 & 35,25 & 42 \\
\hline 17 & 32,30 & 44 & 34,33 & 41 & 35,28 & 42 \\
\hline 18 & 30,74 & 45 & 32,80 & 42 & 33,71 & 43 \\
\hline 19 & 29,46 & 55 & 31,46 & 52 & 32,35 & 52 \\
\hline 20 & 27,57 & 56 & 29,51 & 54 & 30,38 & 54 \\
\hline 21 & 27,69 & 64 & 29,58 & 63 & 30,42 & 61 \\
\hline 22 & 26,35 & 67 & 28,20 & 66 & 29,01 & 65 \\
\hline 23 & 25,11 & 69 & 26,91 & 69 & 27,69 & 68 \\
\hline 24 & 23,77 & 73 & 25,53 & 72 & 26,28 & 72 \\
\hline MEDLA & 28,24 & & 30,17 & & 31,12 & \\
\hline
\end{tabular}

Buscaram-se referências para o uso do ENVI-met em condições semelhantes e foram encontradas algumas aplicações para dados medidos durante a onda de calor de 2003 na Europa, tais como o estudo de Huttner, Bruse e Dostal (2008), e Huttner, Bruse, Dostal, Katzchner (2009), mas nenhum com dados projetados para o futuro.

As projeções de dados futuros foram utilizadas na configuração do módulo simple forcing do ENVImet V4 Preview I, permitindo definir previamente a variação diurna de temperatura e umidade do ar, ajudando na calibração dos dados de entrada no modelo.

O processo de calibração nessa fase seguiu o mesmo procedimento feito nas simulações anteriores, mantendo-se, inclusive, parte dos dados já definidos na simulação para fevereiro de 2013 como a velocidade e direção dos ventos $\left(0,5 \mathrm{~m} / \mathrm{s} ; 112,5^{\circ}\right)$, temperatura superficial do solo pela medição do sensor em campo na Bela Vista $\left(18,76^{\circ} \mathrm{C}\right)$ e umidade do solo para as três camadas $(50 \%, 60 \%, 70 \%)$. 
As alterações foram feitas no ajuste da radiação, na cobertura de nuvens, na data de início das simulações e na umidade específica a $2500 \mathrm{~m}$ acima do nível do mar. Da mesma forma que nas simulações com dados medidos, o ajuste da radiação foi feito no módulo Radition Preview da versão 3.1 Beta 5 do ENVI-met, ${ }^{82}$ quando foram ajustados os dados da radiação máxima global e difusa, de acordo com os dados obtidos da estação da Água Funda do IAG-USP. ${ }^{83} \mathrm{~A}$ radiação média global e radiação média difusa para o mês de janeiro de 2014 foram de $850 \mathrm{~W} / \mathrm{m}^{2}$ e $272 \mathrm{~W} / \mathrm{m}^{2}$, respectivamente. Assim, o valor para o adjustment factor para radiação foi de 1,0.

Os dados de nebulosidade também foram importantes para o ajuste da radiação no modelo; a estação IAG-USP/Água Funda registrou apenas cobertura por nuvens baixas para o dia 27 de janeiro de 2014, com 3 octas para nuvens baixas, não considerando cobertura para nuvens médias e altas. A umidade específica a $2500 \mathrm{~m}$ o para o dia 26 de janeiro às $21 \mathrm{~h}$ LST foi de $9 \mathrm{~g}$ de água/ $\mathrm{kg}$ de ar. ${ }^{84}$

A simulação teve início no dia 27 de janeiro de cada período, sendo os anos de 2015, 2045 e 2076 definidos para representar os períodos futuro próximo, futuro intermediário e futuro distante, respectivamente. As simulações foram iniciadas às $21 \mathrm{~h}$ LST, a fim de minimizar os erros de convergência relacionados à radiação de onda curta nas primeiras horas da simulação.

Após a fase de calibração e dos resultados obtidos anteriormente para abril de 2013 e fevereiro de 2014, três cenários foram definidos para esta rodada de simulações: um cenário base apenas com edifícios (2a), um parque com árvores densas ocupando toda a quadra central (2b), e um parque central com arborização em todas as calçadas (2c).

A modelagem do caso base e parque central seguem os mesmos parâmetros do estudo paramétrico anterior, com o domínio da área de entrada formado por nove quadras com $100 \mathrm{~m} \times 100 \mathrm{~m}$ (1ha ou $10.000 \mathrm{~m}^{2}$ ) cada, sendo que nas quadras sem vegetação, foram propostas as mesmas nove torres de base $20 \mathrm{~m} \times 20 \mathrm{~m}$ e $45 \mathrm{~m}$ de altura, com piso impermeável cimentado; na quadra com vegetação, foram colocadas árvores densas com o mesmo IAF $=4,6 \mathrm{~m}^{2} / \mathrm{m}^{2}$ e solo franco-argilo-arenoso (sandyclay-loam). As vias foram revestidas com um asfalto modificado, a partir de dados obtidos em Hellmann (2008), para as condições brasileiras.

Partindo-se dos resultados da etapa de simulação anterior, para esta segunda rodada inclui-se o cenário com o parque central, que demostrou ser o mais favorável dentre os testados anteriormente, quando comparado com o cenário base, com uma diferença no TEP por volta de $10^{\circ} \mathrm{C}$ e uma diferença de no PET de cerca de $13,4^{\circ} \mathrm{C}$, às $13 \mathrm{~h}$, para abril de 2013 e fevereiro de 2014 . Para esta segunda rodada um novo cenário então foi proposto, considerando-se o parque central acrescido de árvores nas vias, explorando uma maior conexão da infraestrutura verde na área urbana. Este cenário teve a intenção de avaliar os efeitos microclimáticos para a inserção da vegetação de forma mais incisiva em um cenário adensado com edifícios altos, com um incremento de $20 \%$ da vegetação do cenário b (parque central) para o c (parque central + árvores nas vias).

Os dados de entrada são apresentados na Tabela 13. Em todos os estudos paramétricos, o tempo total de simulação foi de $48 \mathrm{~h}$, sendo que o segundo dia foi utilizado para a análise dos resultados.

\footnotetext{
82 Como já informado anteriormente, o modelo ENVI-met V4 Preview 1 não apresenta o módulo Radiation Preview, para ajuste da radiação global e difusa, com os mesmos recursos que eram visíveis na versão 3.1 Beta 5, por isso a necessidade de se voltar à versão anterior para esta etapa.
${ }^{83}$ A estação do IAG-USP só disponibiliza dados diários totais da radiação e o modelo ENVI-met necessita de dados horários para o input da radiação. A conversão da radiação total diária para dados horários foi feita pelo Prof. Dr. Maurício Roriz, in memoriam, que muito colaborou para o trabalho de ALVES (2015).

84 Dados de sondagens realizadas no Aeroporto Campo de Marte em São Paulo, disponíveis em: <http://weather.uwyo.edu/upperair/sounding.html>. Acesso em: abril de 2015. A forma de utilização dessa variável também está sendo revista no grupo, após informação verbal da Prof. Dra. Eleonora Assis, em fevereiro de 2014. 


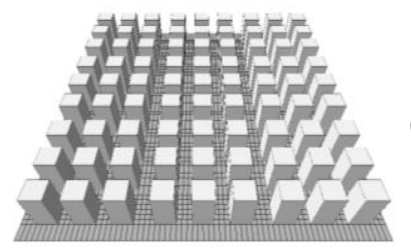

(a)

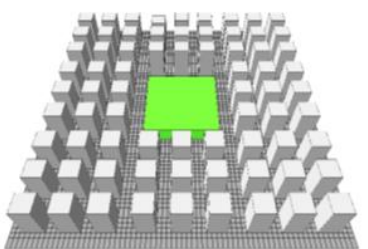

(b)

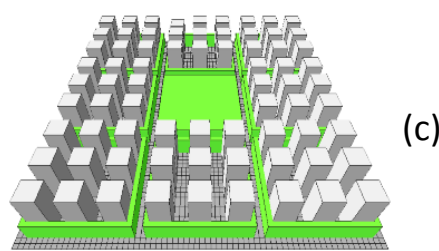

Figura 39 - Os três cenários gerados no modelo ENVI-met V.4 Preview 1 para a simulação com dados futuros: (a) cenário base (caso base, apenas com torres, (b) torres + parque central, (c) parque central + árvores nas vias.

Tabela 13 - Dados de entrada utilizados para a simulação com dados futuros nos três cenários urbanos simulados pelo ENVImet V4 Preview I

\begin{tabular}{|l|l|}
\hline Velocidade dos ventos a 10m do solo [m/s] & 0.5 \\
\hline Direção dos ventos (0:N/ 90:L/ 180:S/ 270:O) & 112.5 \\
\hline Umidade específica a 2500m [g de água/ kg de ar] & 9 \\
\hline Umidade do solo - camada superior $(0-20 \mathrm{~cm})[\%]$ & 50 \\
\hline Umidade do solo - camada intermediária $(20-50 \mathrm{~cm})[\%]$ & 60 \\
\hline Umidade do solo - camada inferior $(50-200 \mathrm{~cm})[\%]$ & 70 \\
\hline Fator de ajuste da radiação solar & 1 \\
\hline Cobertura de nuvens baixas [octas] & 3 \\
\hline Cobertura de nuvens médias [octas] & 0 \\
\hline Cobertura de nuvens altas [octas] & 0 \\
\hline
\end{tabular}

\subsubsection{Resultados das simulações}

Os dados foram extraídos da mesma forma que no estudo paramétrico anterior, por meio do cálculo dos valores médios das variáveis microclimáticas, utilizando a ferramenta Map Script do aplicativo Leonardo Beta.

A Tabela 14 mostra os resultados para a temperatura do ar simulada para as $6 \mathrm{~h}$, horário em que a temperatura mínima foi registada, comparando-se o cenário base, somente com torres, com os dois cenários com vegetação $(\mathrm{IAF}=4,6)$ para os períodos futuro próximo, intermediário e distante. Foram também comparados os resultados às $15 \mathrm{~h}$ (Tabela 15), horário que corresponde à temperatura do ar mais alta nos resultados simulados (Figura 40). Da mesma forma que na rodada anterior, todas as simulações foram geradas em local standard time - LST.

De acordo com as Tabelas 14 e 15, o cenário base apresentou uma temperatura média do ar na quadra central de $26^{\circ} \mathrm{C}$ às $6 \mathrm{~h}$ e $31,4^{\circ} \mathrm{C}$ às $15 \mathrm{~h}$, para o futuro próximo. Para o futuro intermediário, a temperatura do ar média na quadra central foi de $28^{\circ} \mathrm{C}$ e $33,3^{\circ} \mathrm{C}$, às $6 \mathrm{~h}$ e $15 \mathrm{~h}$, respectivamente, e no futuro distante, de $28,8^{\circ} \mathrm{C}$ e $34,2^{\circ} \mathrm{C}$, às $6 \mathrm{~h}$ e $15 \mathrm{~h}$, respectivamente.

Tabela 14 - Resultados para a a temperatura do ar às 6h, no future próximo, intermediário e distante.

\begin{tabular}{|c|c|c|c|c|}
\hline & $\begin{array}{c}\text { Cenário base, apenas com } \\
\text { torres (a) }\end{array}$ & $\begin{array}{l}\text { Cenário com parque central } \\
\text { (b) }\end{array}$ & $\begin{array}{c}\text { Cenário com parque central e } \\
\text { árvores nas vias (c) }\end{array}$ & \\
\hline 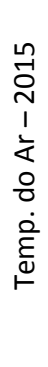 & 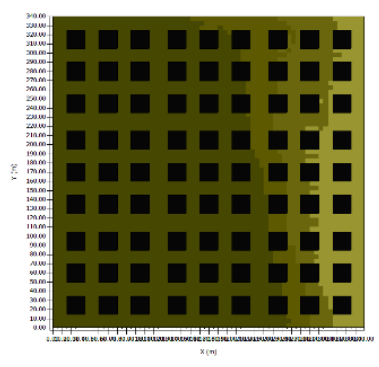 & 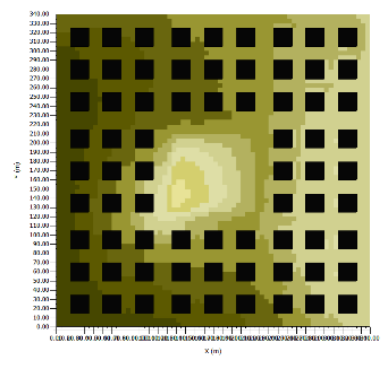 & 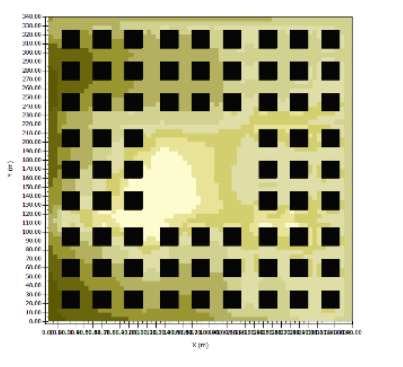 & 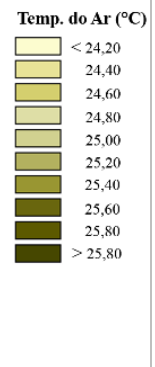 \\
\hline
\end{tabular}




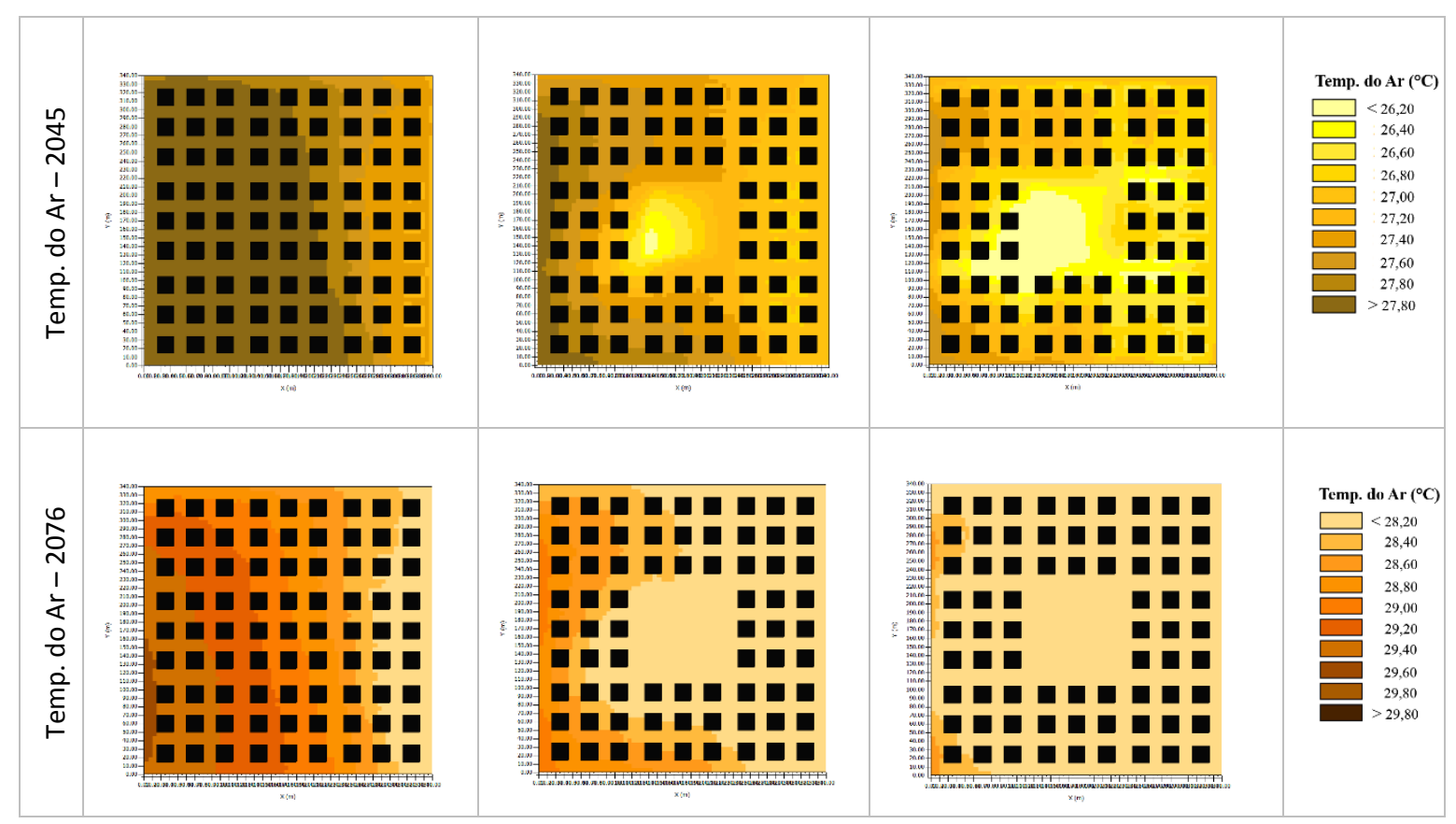

Tabela 15 - Resultados para temperatura do ar às 15h, no future próximo, intermediário e distante.

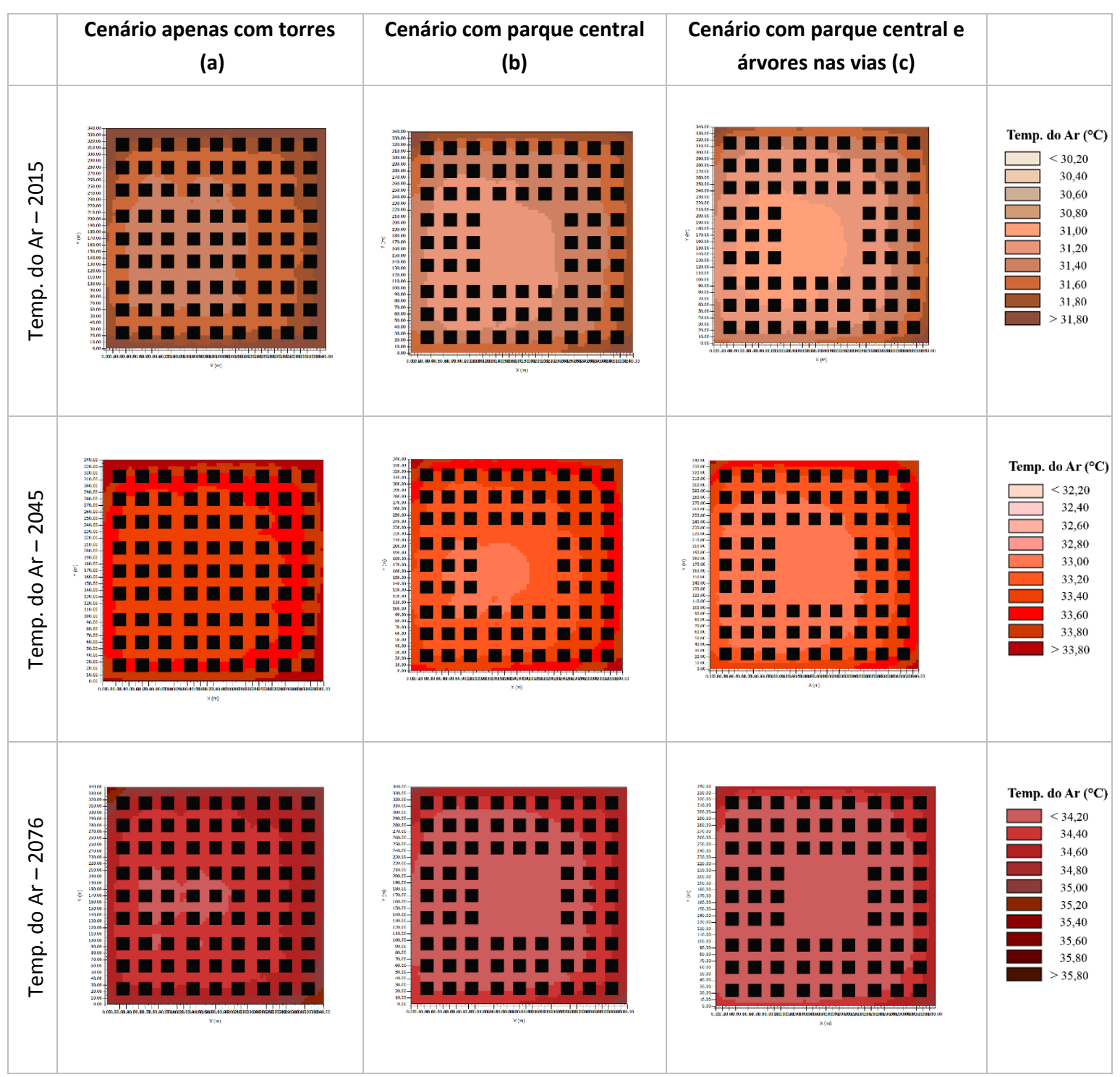


Nos períodos simulados, a temperatura do ar no cenário base manteve-se sempre maior do que os cenários com vegetação (Figura 40), sendo que as maiores diferenças ocorreram às 6 h, ou seja, nas temperaturas mínimas. No futuro próximo, às $6 \mathrm{~h}$, comparando-se a quadra central do cenário a (caso base) com b (parque central) e d (parque central + árvores nas vias), foram obtidas reduções na temperatura média do ar de $1,1^{\circ} \mathrm{C}$ e $1,7^{\circ} \mathrm{C}$, respectivamente. A mesma comparação realizada para futuro intermediário mostrou diferenças de $1,2^{\circ} \mathrm{C}$ e $1,7^{\circ} \mathrm{C}$ e, para o futuro distante, as diferenças foram de $1,2^{\circ} \mathrm{C}$ e $1,8^{\circ} \mathrm{C}$.

Os resultados obtidos para às $15 \mathrm{~h}$, quando a temperatura do ar é máxima, apresentaram diferenças ou pouco menores entre os cenários do mesmo período, em relação às obtidas para as 6h, para a temperatura do ar (Figura 40). No futuro próximo e futuro distante, às $15 \mathrm{~h}$, a redução da temperatura média do ar na quadra central foi de $0,2^{\circ} \mathrm{C}$, comparando-se o cenário a (caso base) com b (parque central) e de $0,4^{\circ} \mathrm{C}$, dentro e no entorno imediato do parque, comparando-se o cenário a (caso base) e c (parque central + árvores nas vias). A mesma comparação realizada para futuro intermediário mostrou diferenças de $0,2^{\circ} \mathrm{C}$ e $0,6^{\circ} \mathrm{C}$.

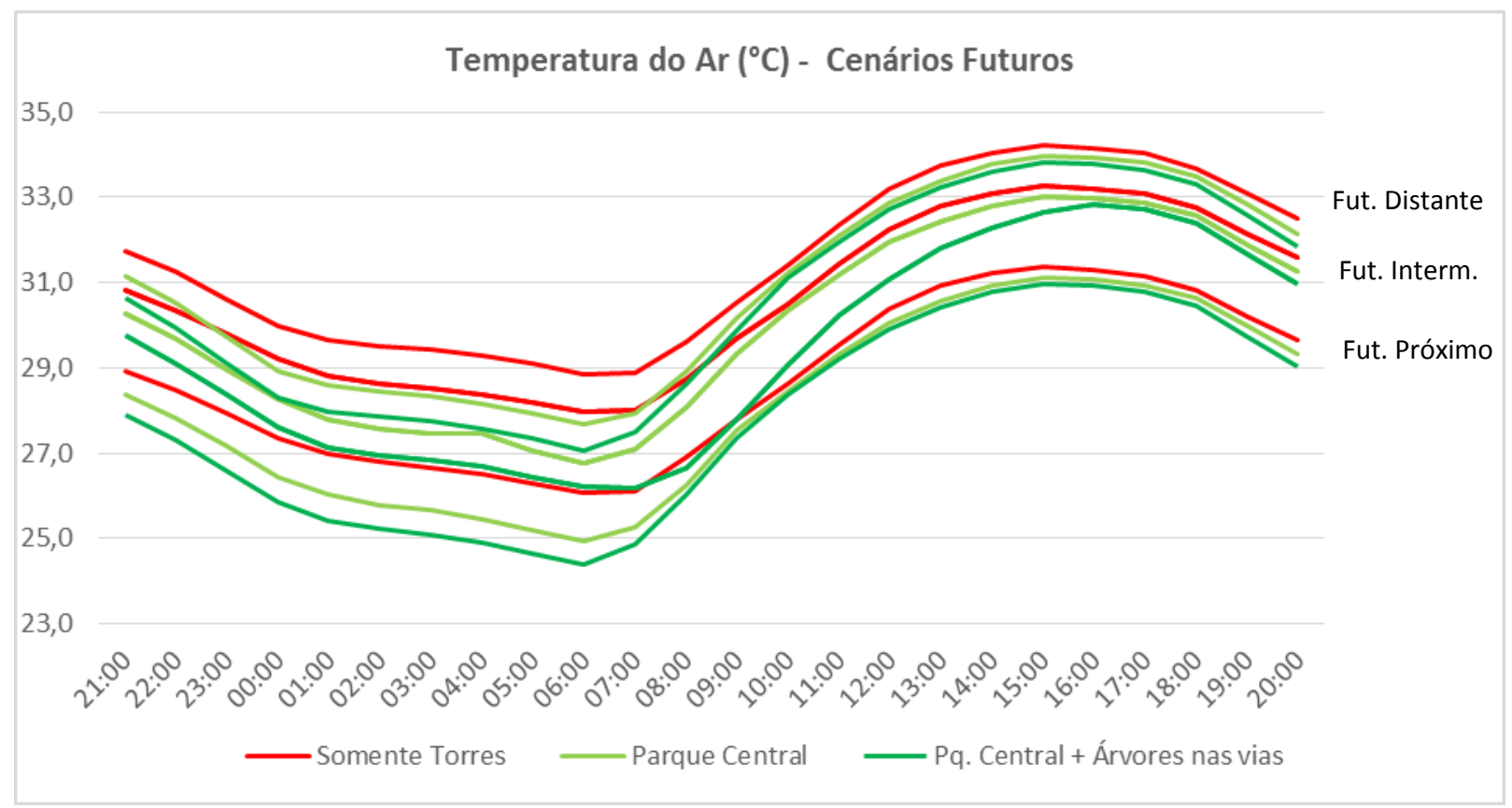

Figura 40 - Resultados para temperatura média do ar na quadra central dos três cenários (a, b e c), no futuro próximo, intermediário e distante.

\subsubsection{Considerações sobre os resultados das simulações}

Comparando-se os resultados de temperatura do ar obtidos nos cenários futuros, observa-se o aumento da mesma ao longo de cada período simulado, especialmente nas temperaturas mínimas.

Em todos os períodos simulados a diferença máxima da temperatura do ar ocorreu às $6 \mathrm{~h}$, sendo que no futuro próximo foi de até $1,7^{\circ} \mathrm{C}$, comparando-se o cenário base com o cenário $\mathrm{c}$ (parque central + árvores nas vias). No futuro intermediário, a diferença máxima também foi de $1,7^{\circ} \mathrm{C}$; e no futuro distante, foi de $1,8^{\circ} \mathrm{C}$.

Em relação à configuração espacial do cenário c, conforme esperado, foram obtidos os menores valores para a temperatura do ar e uma distribuição mais homogênea do efeito de resfriamento pela vegetação, em comparação com parque central apenas. Na análise da temperatura do ar na quadra central, com o aumento de $20 \%$ da vegetação (parque central + árvores nas vias) em relação ao 
cenário b (parque central), por causa das árvores a mais locadas nas vias, houve uma redução de até $0,2^{\circ} \mathrm{C}$ no pico da temperatura do ar dentro do parque, às $15 \mathrm{~h}$, comparando-se o cenário c em relação ao cenário $\mathrm{b}$, para o futuro distante.

Este é um estudo em andamento e alguns resultados para temperatura radiante média mostraramse inconclusivos até o fechamento deste trabalho, optando-se, portanto, por não apresenta-los aqui, bem como as aplicações detalhadas dos índices de conforto decorrentes deles, dentre outras variáveis. As simulações de TRM estão sendo revistas, inclusive de forma comparativa com outros modelos (CHEN; LIN; MATZARAKIS, 2014) e, nas próximas etapas do estudo, serão detalhados os índices PET e TEP para todos os cenários testados.

Em função dos resultados preliminares obtidos para a TRM, para o futuro intermediário (2045 a 2074) os dois índices foram calculados com base em valores médios simulados para a quadra central, em todos os cenários. Um valor inicial de $0,5 \mathrm{~m} / \mathrm{s}$ foi definido nos dados de entrada do ENVI-met, mas a variação na velocidade do vento, ao longo do dia, foi obtida a partir do cálculo da velocidade média na quadra central do domínio, também considerada para os cálculos do PET e TEP. Os resultados apresentaram uma diferença máxima às $12 \mathrm{~h}$ para o TEP de $5^{\circ} \mathrm{C}$ e $7^{\circ} \mathrm{C}$, e para o $P E T$ de $6^{\circ} \mathrm{C}$ e $8,5^{\circ} \mathrm{C}$, no nível do pedestre, comparando-se os cenários b (parque central) e $\mathrm{c}$ (parque central com árvores nas vias) com o cenário a (caso base, somente torres), respectivamente.

As tendências de aquecimento urbano e aumento dos casos de ondas de calor não serão resolvidos com a presença da vegetação nas cidades. Porém, a estratégia de manter uma vegetação arbórea com uma massa vegetal significativa conectada entre pequenos parques urbanos, com arborização nas vias, para uma melhor distribuição, formando uma rede de infraestrutura verde e densa na cidade, pode contribuir, no mínimo, para a adaptação da população aos eventos extremos, provocando um efeito oásis (park cool island - PCl) durante as ondas de calor, e também, indiretamente, para a mitigação dos fenômenos de aquecimento urbano, por diminuir as temperaturas de superfície e o armazenamento de calor no tecido urbano. 


\section{Infraestrutura verde: iniciativas locais e aplicações em políticas públicas}

À primeira vista, edifícios e vegetação competem por espaço nas áreas urbanas, mas mesmo em áreas de baixa densidade, muitas vezes não há vegetação alguma, dependendo do padrão de ocupação do solo. Assumindo que o adensamento é inevitável e desejável do ponto de vista da sustentabilidade urbana, é preciso discutir como incluir a infraestrutura verde em áreas adensadas e desenvolver propostas de projetos urbanos (Figura 41) ${ }^{85}$ para contrabalançar a densidade construída em diferentes escalas urbanas, com diferentes contextos climáticos, incluindo na discussão as mudanças climáticas em curso e as previsões futuras.

Neste capítulo são exemplificadas algumas experiências na implementação de espaços de amenidade climática em diferentes cidades, no espaço público e no espaço privado, e também no espaço privado de acesso e uso público. Muitas dessas iniciativas incluem explicitamente a vegetação, e ao final, são tratados alguns planos municipais para ocorrências de calor extremo, quando é ressaltado o papel do planejamento e do desenho urbano na criação de espaços apropriados a essas ações.

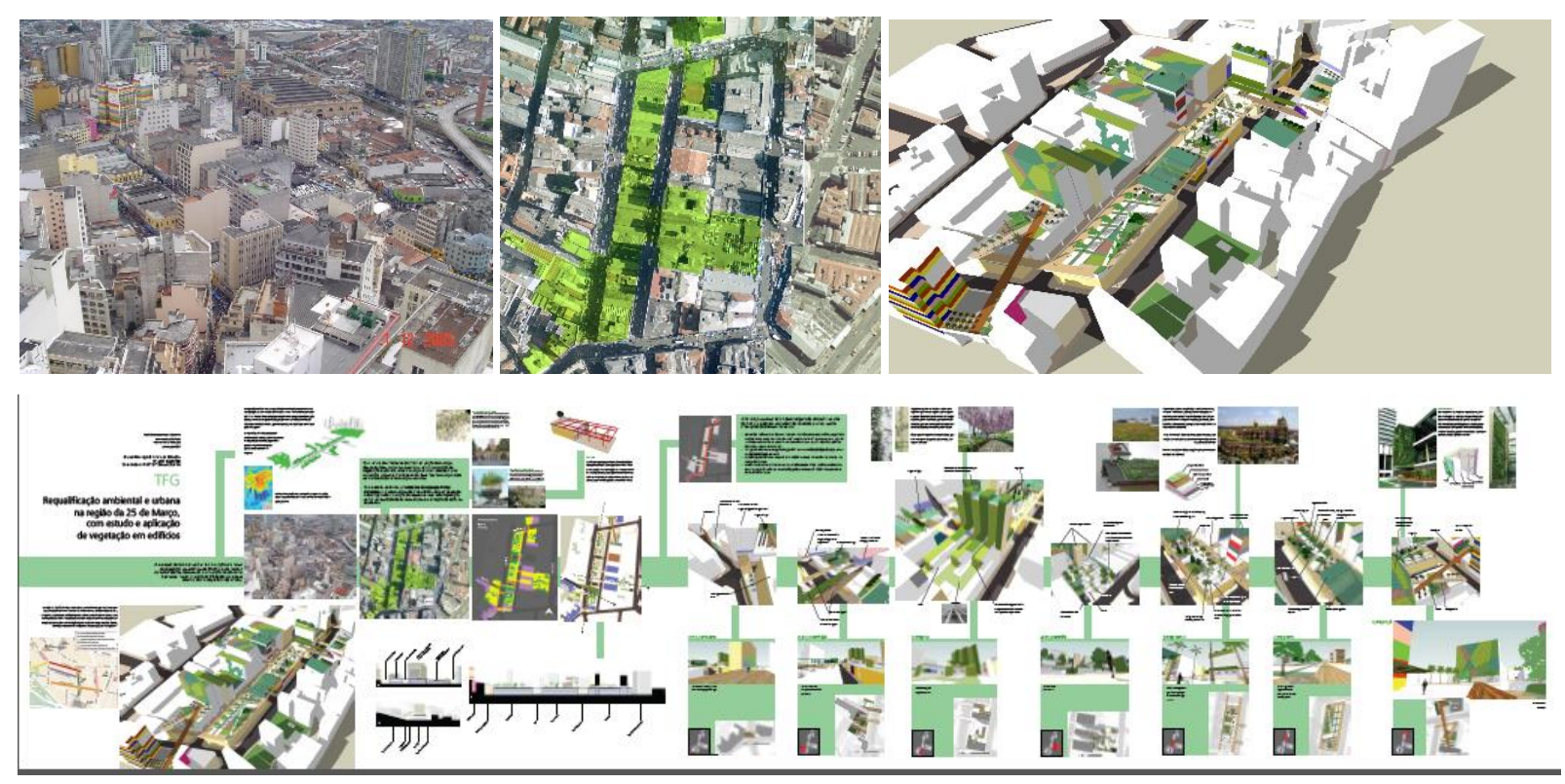

Figura 41 - Proposta de projeto urbano incluindo a infraestrutura verde na Rua 25 de Março e entono, a rua de comércio popular mais movimentada de São Paulo, adensada e árida, sem qualquer amenidade climática. Fonte: Requalificação ambiental e urbana na região da Rua 25 de Março, através da aplicação de vegetação em edifícios. Trabalho Final de Graduação de Bruno Henrique Emmanuel Mendes, FAUUSP, 2007. Orientadora. Prof. Dra Denise Duarte.

\subsection{Para o espaço público}

Uma cidade mais verde e o uso da vegetação como uma das estratégias de adaptação aos efeitos de aquecimento urbano, dentre outros serviços ambientais, são possíveis, desde pequenos agrupamentos de arvores até as intervenções em grande escala, incentivados pela legislação municipal e por iniciativas da sociedade civil.

Essas iniciativas estão surgindo espontaneamente também na cidade de São Paulo, ainda que em pequena escala e em vários locais, por iniciativas da população na cidade formal ou informal, como exemplo o caso da favela de Paraisópolis, apresentado no capítulo 4. Movimentos recentes estão acontecendo em outras partes da cidade, por iniciativa da sociedade civil organizada pela ocupação

\footnotetext{
$85 \quad$ Disponível em: <http://www.fau.usp.br/disciplinas/tfg/tfg_online/tr/072/a018.html> e $<$ http://www.fau.usp.br/pesquisa/laboratorios/labaut/trabalhos_recentes/bruno_mendes.pdf $>$. Acesso em 23 de julho de 2015.
} 
de espaços públicos com qualidade, como pode ser visto no Largo da Batata, no Parque Augusta e no Minhocão. Recentemente, uma dessas inciativas se concretizou no Largo da Batata, em Pinheiros (Figuras 42 e 43), que abriga, dentre outros, uma estação de metrô, um bibicletário e um terminal de ônibus urbanos. Em janeiro de 2015 , a população desafiou a prefeitura e, após uma negativa à solicitação de plantio de arvores, plantou sem apoio e nem mesmo autorização da prefeitura, ${ }^{86}$ para amenizar o deserto do ponto de vista microclimático. A resposta da Prefeitura foi que o consórcio que ganhou a licitação para as obras é que era responsável pelo plantio e que este já havia sido executado. Porém, as mudas plantadas não se desenvolveram, algumas morreram, outras foram plantadas sobre a laje de concreto da estação subterrânea do metrô, com uma chance praticamente nula de maturação. No Largo são várias as iniciativas populares, inclusive os improvisos para se criar algum tipo de sombreamento para a proteção de vendedores ambulantes e demais usuários no terminal de ônibus.
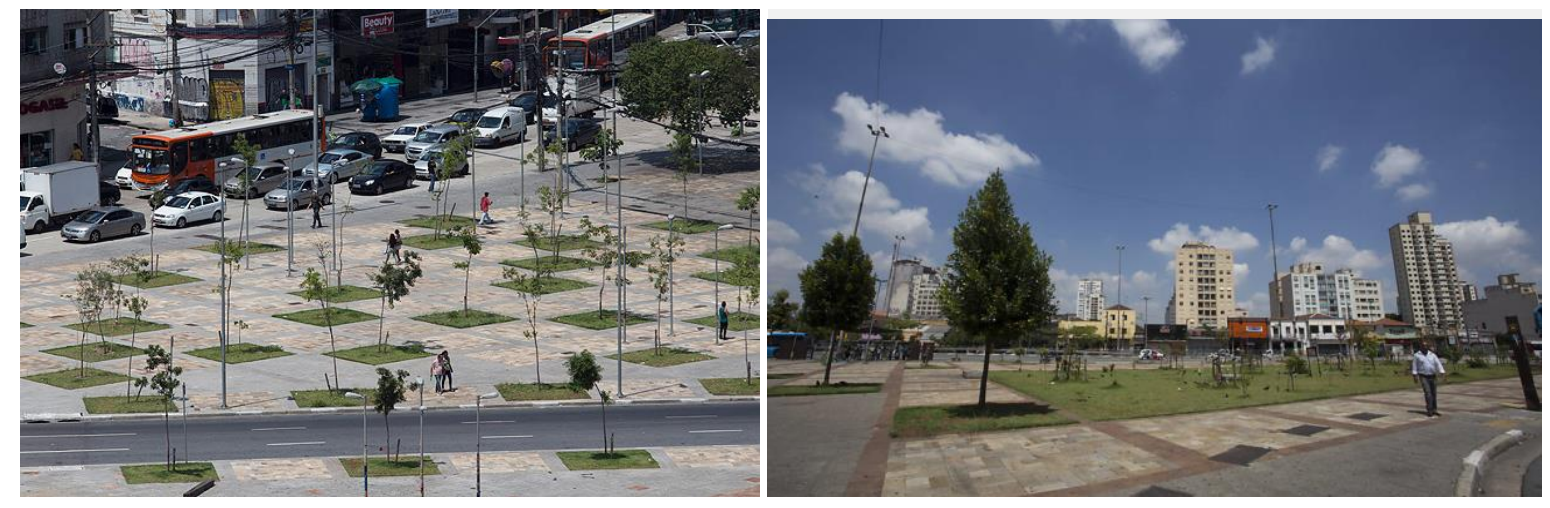

Figura 42 - Vistas do Largo da Batata, em Pinheiros, São Paulo. Disponível em:

http://www1.folha.uol.com.br/cotidiano/2015/01/1576528-grupo-desafia-prefeitura-e-planta-32-arvores-no-largo-dabatata-em-sp.shtml. Acesso em: 24 de julho de 2015.
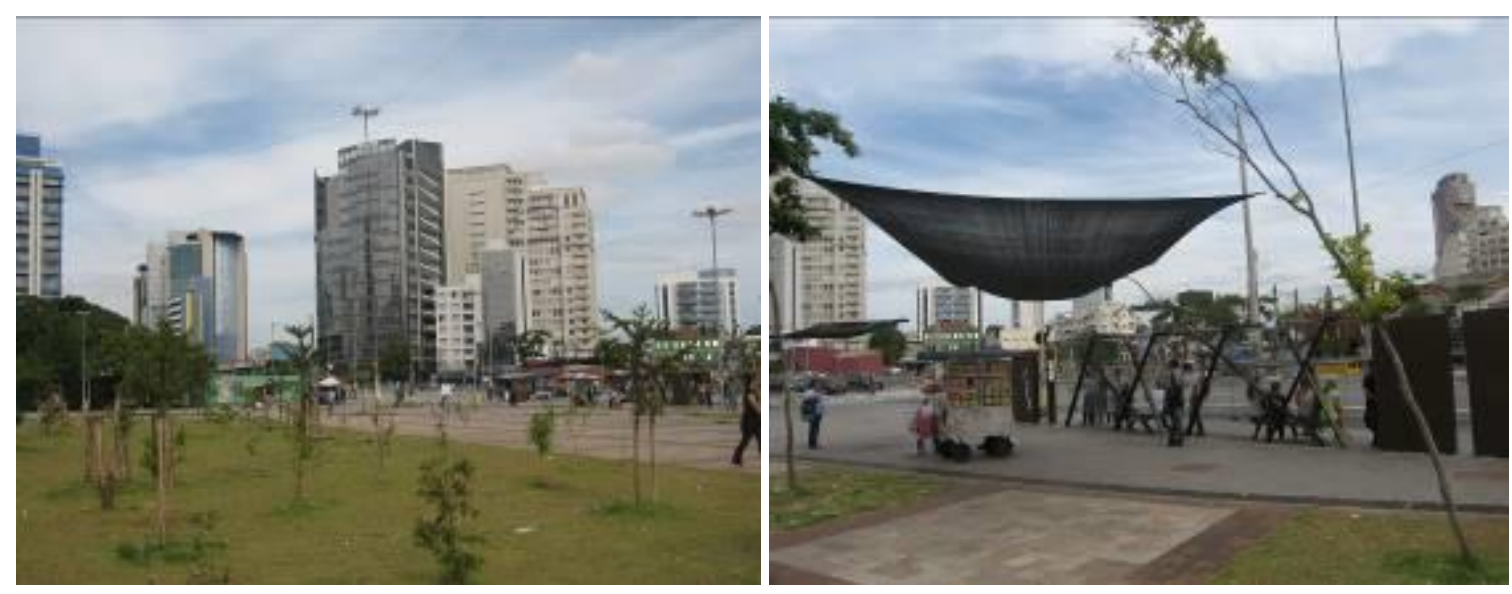

Figura 43 - Largo da Batata, quase um deserto do ponto de vista microclimático, que abriga, dentre outros usos, um terminal de transporte público no distrito de Pinheiros, em São Paulo. Uma organização da sociedade civil se mobilizou para o plantio de árvores e usuários estão improvisando algum sombreamento nos pontos de maior permanência (fotos: Denise Duarte, maio de 2015)

Em várias cidades no mundo, os parklets ganham cada vez mais espaço e significado, como expressões temporárias de apropriação de espaços urbanos, na maioria das vezes ligados à

86 Disponível em: <http://www1.folha.uol.com.br/cotidiano/2015/01/1576528-grupo-desafia-prefeitura-e-planta-32arvores-no-largo-da-batata-em-sp.shtml>. Acesso em: 23 de julho de 2015. Folha de São Paulo, 17 de janeiro de 2015. 
infraestrutura verde (Figuras 44 e 45). Em São Paulo, grupos de discussão estão surgindo para discutir as possibilidades de se otimizar os parklets como espaços de amenidade climática, com a intensificação da vegetação nesses locais, superando as restrições de espaço para o plantio (informação verbal). ${ }^{87}$
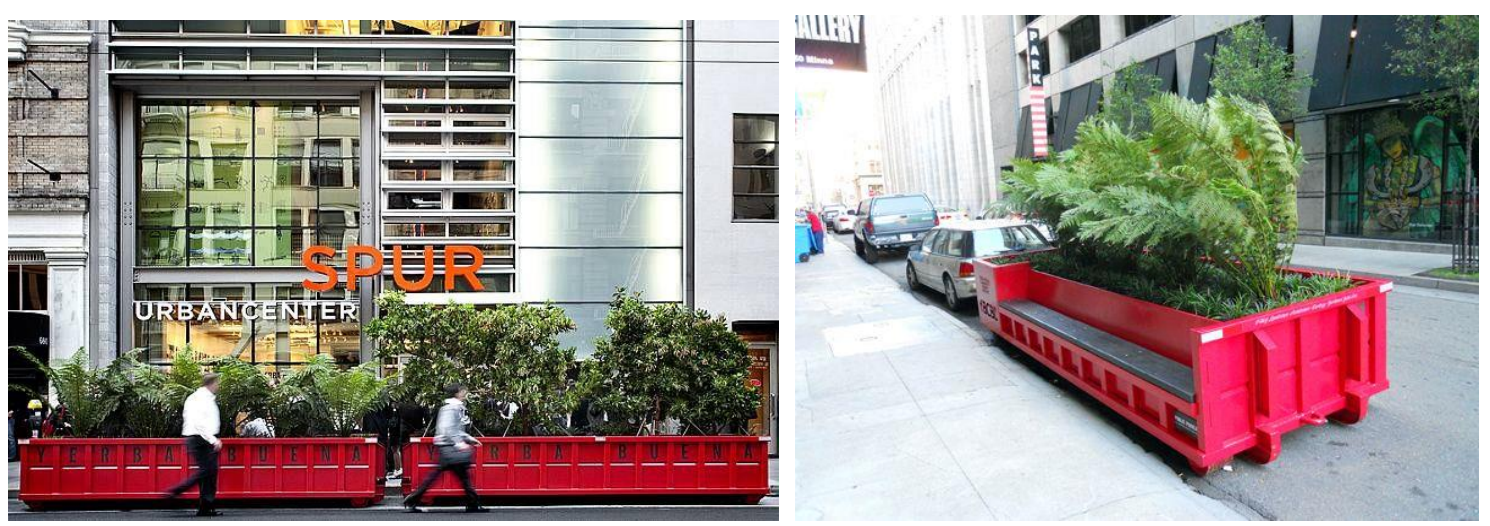

Figura 44 - Parklets em São Francisco, Califórnia. Disponíveis em: < http://www.cmgsite.com/projects/parkmobiles/> e < http://www.livesoma.com/wp-content/uploads/2011/10/Minna-St-Parklet-3.jpg>. Acesso em 24 de julho de 2015.
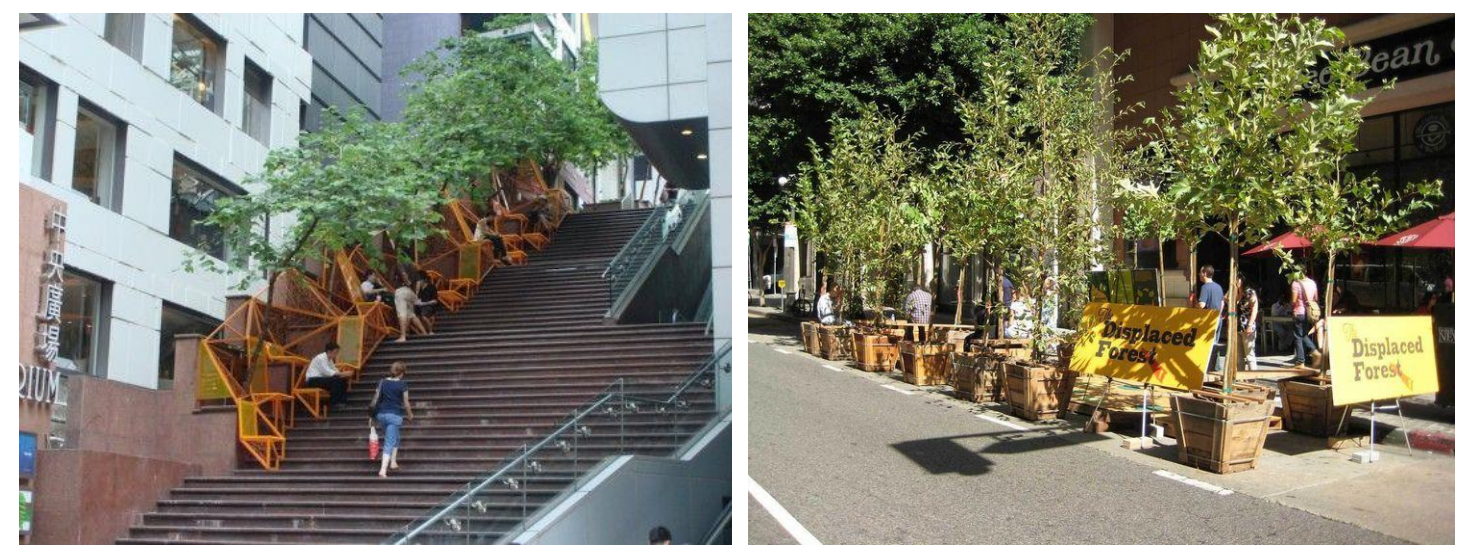

Figura 45 - Parklets em Hong Kong e Los Angeles, Califórnia. Disponíveis em: < http://inhabitat.com/the-cascade-projecttransforms-disused-staircase-into-inspiring-urban-space-for-hong-kong-residents/> e

<http://la.curbed.com/archives/2012/09/visiting 4 of parking days temporary parklets across la.php >. Acesso em 24 de julho de 2015.

Desde abril de 2014, a PMSP regulamentou a instalação e o uso de parklets, como uma extensão temporária de calçadas (Figuras 46 e 47), pioneira na América Latina. O parklet é definido pela PMSP como "uma ampliação do passeio público, realizada por meio da implantação de plataforma sobre a área antes ocupada pelo leito carroçável da via pública, equipada com bancos, floreiras, mesas e cadeiras, guarda-sóis, aparelhos de exercícios físicos, paraciclos ou outros elementos de mobiliário, com função de recreação ou de manifestações artísticas. [...] O parklet, assim como os elementos neles instalados, serão plenamente acessíveis ao público, vedada, em qualquer hipótese, a utilização exclusiva por seu mantenedor." ${ }^{88} \mathrm{~A}$ instalação dos parklets poderá ser de iniciativa da administração pública ou de qualquer munícipe (pessoa física ou jurídica). Os custos financeiros referentes à instalação, manutenção e remoção do parklet são de responsabilidade exclusiva do mantenedor.

\footnotetext{
${ }^{87}$ Luciana Schwander Ferreira, em 23 de julho de 2015.

88 Disponível em: < http://gestaourbana.prefeitura.sp.gov.br/parklets/>. Acesso em: 4 de maio de 2015.
} 


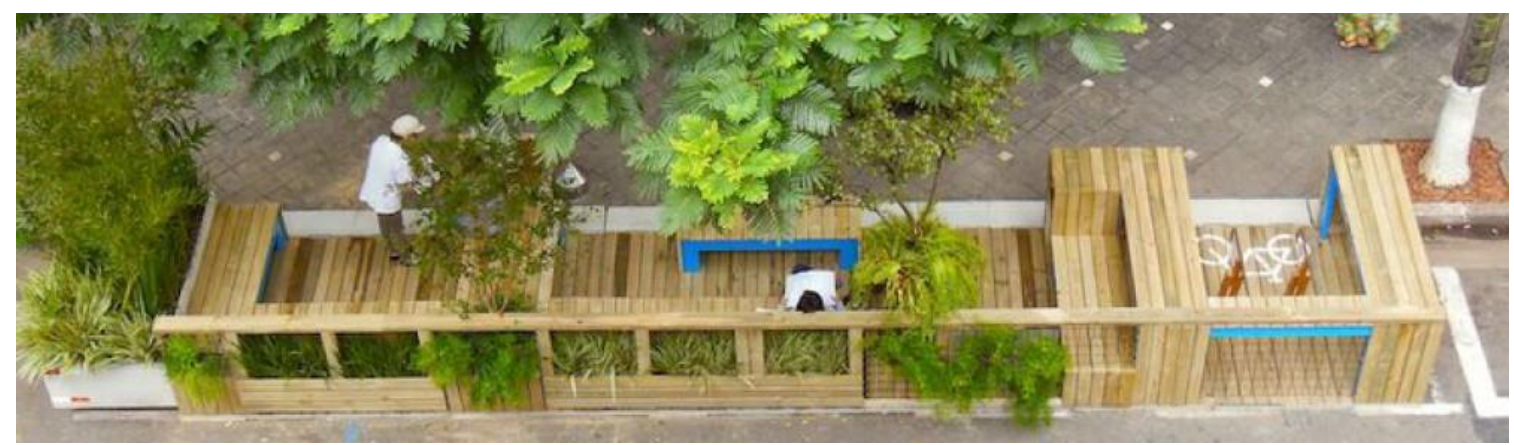

Figura 46 - Parklet permanente da Rua João Manoel, próximo à Av. Paulista, São Paulo. Disponível em: https://institutomobilidadeverde.wordpress.com/. Acesso em: 24 de julho de 2015.
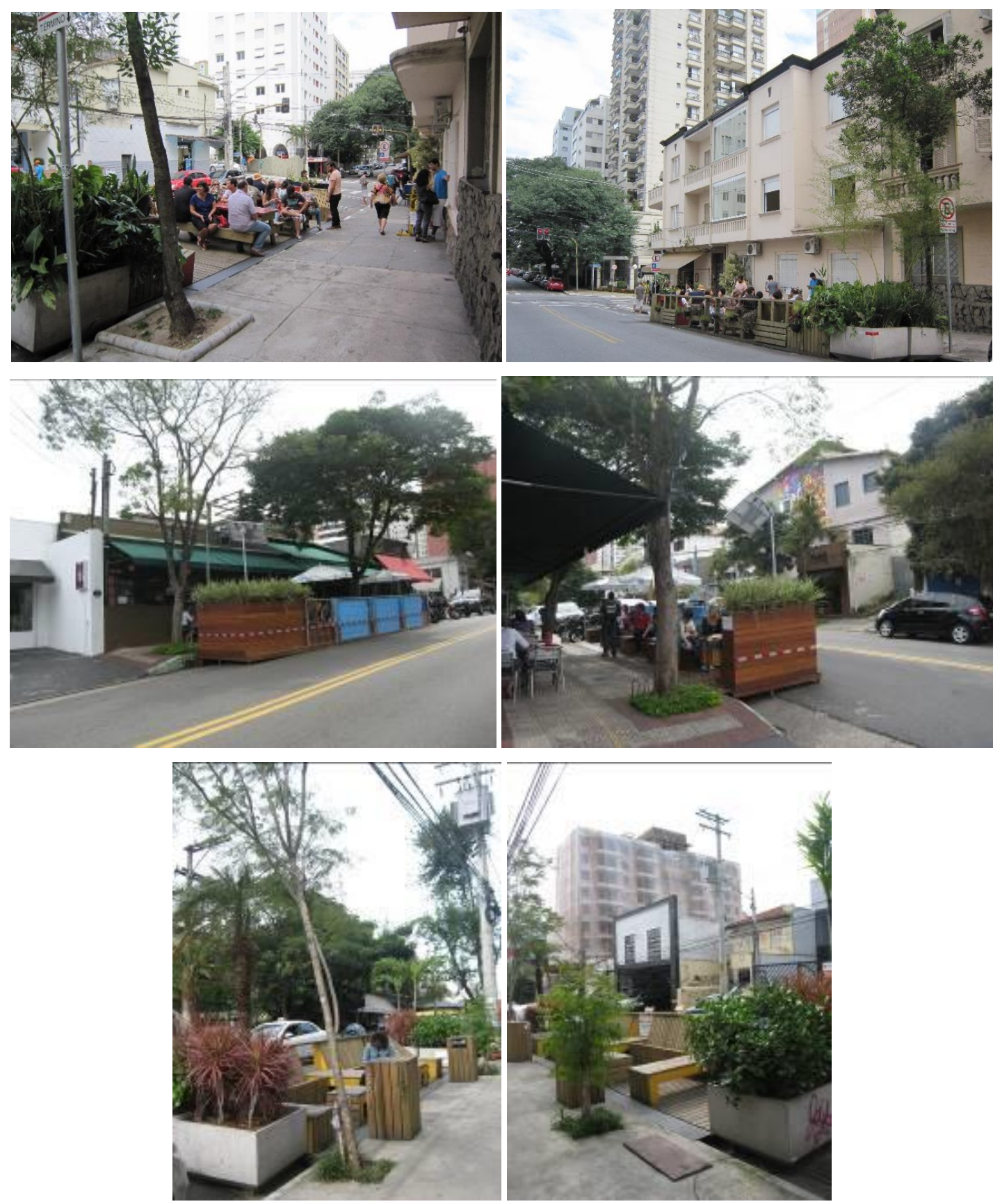

Figura 47 - Parkets em São Paulo, de cima para baixo, nas ruas Oscar Porto, Harmonia e Fidalga (Fotos: Luciana Ferreira (Oscar Porto), Denise Duarte (Harmonia e Fidalga), em maio de 2015). 


\subsection{Para o espaço privado de acesso público}

Uma iniciativa que vem ganhando força em várias cidades é a rede de espaços de propriedade privada, mas de acesso e uso público, com regulamentação de horários de funcionamento, na maioria das vezes incluindo vegetação e, em vários casos, especialmente em Nova lorque, arte urbana.

Um dos exemplos são os Privetely Owned Public Open Spaces - POPOS, ${ }^{89}$ nas áreas centrais de São Francisco, Califórnia, espalhados pela cidade, principalmente nos distritos comerciais, e que foram sendo apropriados pela população para as atividades cotidianas, como almoçar e fazer pequenas pausas ao longo do dia. Os POPOS são espaços disponibilizados e mantidos pela iniciativa privada, mas acessíveis ao uso público, com o objetivo de disponibilizar espaços abertos de qualidade em quantidade e variedade suficientes para atender às necessidades dos trabalhadores, moradores e visitantes. O San Francisco Planning + Urban Research Association - SPUR mapeou 68 POPOS na cidade; desse total, que inclui parques, terraços, átrios e pequenos espaços (snippets), 45 foram criados entre 1959 e 1985. Os outros 23 foram criados na implementação do Downtown Plan em 1985. Antes de 1985, alguns empreendimentos disponibilizavam os POPOS em três circunstâncias: voluntariamente, em troca de um bônus para maior densidade, ou mesmo como condição para aprovação. A partir do Downtown Plan, 1985, um novo conjunto de regulamentações urbanas passou orientar o crescimento da cidade e incluiu diretrizes para a criação de mais espaços abertos de acesso público nas áreas centrais da cidade.
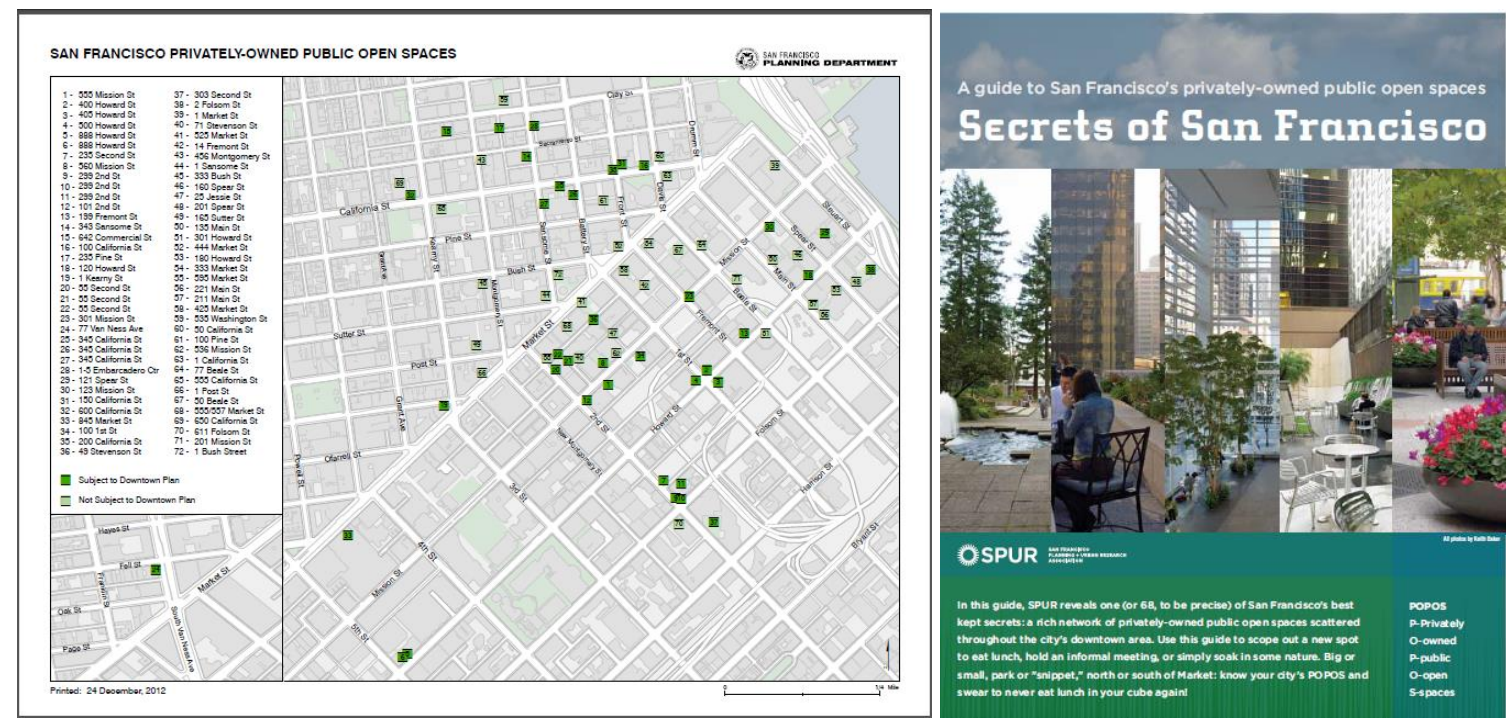

Figura 48 - Mapa dos POPOS em São Francisco e guia dos POPOS na cidade (Disponível em: < http://www.sfplanning.org/ftp/files/gis/POPOS/SF POPOS.pdf>. Acesso em 25 de julho de 2015).

Em Nova lorque, uma iniciativa semelhante chamada Privately Owned Public Spaces - POPS, ${ }^{90}$ foi colocada em prática, em troca de potencial construtivo. São regulamentados para os distritos de alta densidade comerciais ou residenciais com a intenção de prover um espaço aberto com vegetação como amenidade na cidade. Desde 1961 o zoneamento permitiu a inclusão de diferentes tipos de POPS, incluindo praças, arcadas, praças em empreendimentos residenciais, extensões de calçada, espaços cobertos para pedestres em arcadas, espaços semienterrados, etc. Em 2007, o New York City Council revisou a regulamentação para os POPS, com adendos em 2009.

89 Disponível em: <https://www.spur.org/sites/default/files/migrated/anchors/popos-guide.pdf> e $<$ http://www.sf-
planning.org/index.aspx?page=3339>. Acesso em 26 de julho de 2015 .

90 Disponível em: <http://www.nyc.gov/html/dcp/html/pops/pops.shtml $>$ e $<$ http://www.nyc.gov/html/dcp/pdf/pops/pops_map.pdf>. Acesso em 26 de julho de 2015. 


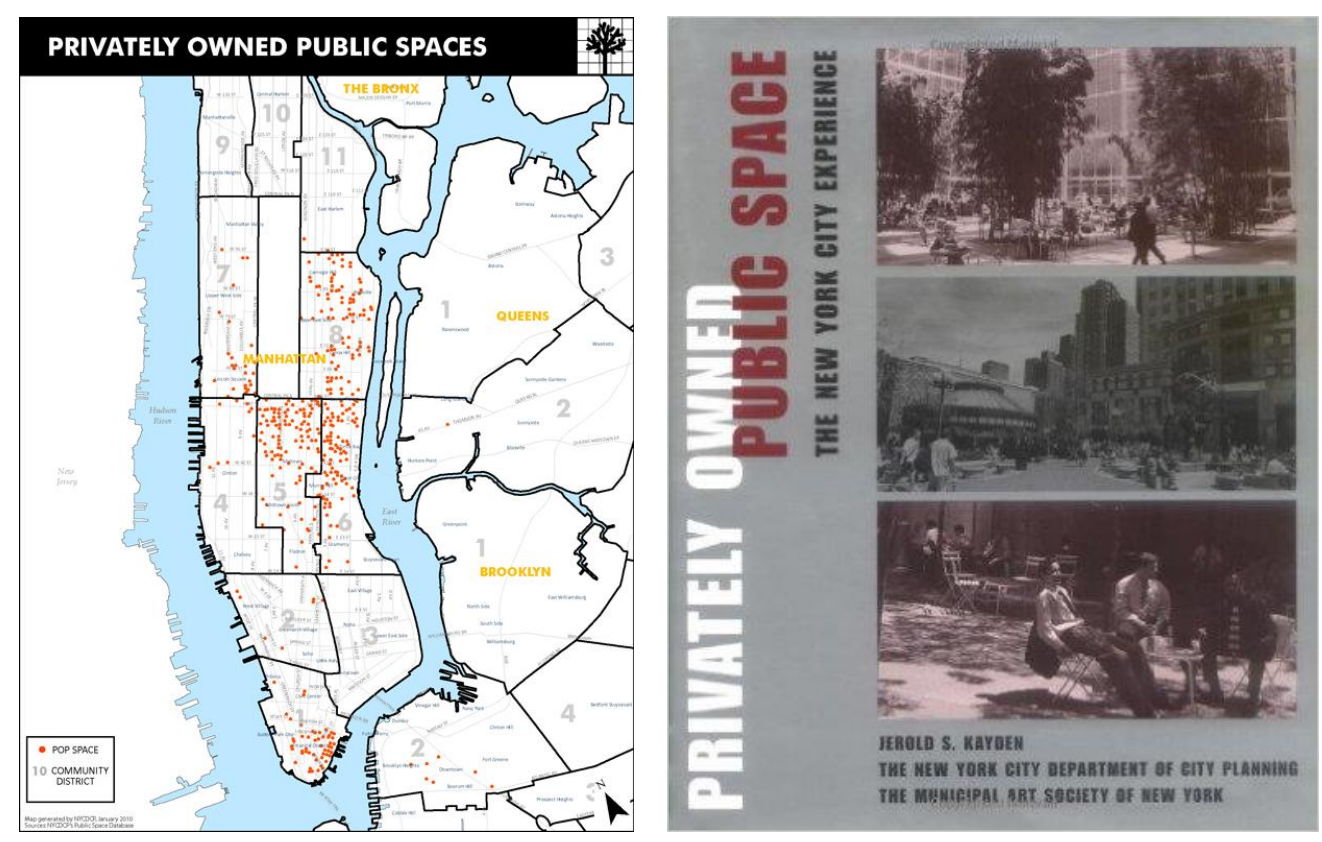

Figura 49 - Mapa dos POPS em Nova lorque e publicação das experiências locais. Disponível em: < http://www.nyc.gov/html/dcp/html/pops/pops inventory.shtml>. Acesso em 26 de julho de 2015.

\subsection{Para o espaço privado}

Políticas para incentivar ou exigir a inclusão de alguma forma de infraestrutura verde nos lotes privados têm sido estabelecidas em diversas partes do mundo, como o Green Plot Ratio (GnPR) em Cingapura (ONG, 2002; 2012; 2015), o Biotope Area Factor (BAF) adotado em Berlim desde $1997^{91}$ e outras cidades na Alemanha, e suas variações para o Seattle Green Factor (SGF) ${ }^{92}$ em Seattle, EUA, e o Green Space Factor (GSF), ${ }^{93}$ adotado em algumas áreas em Malmo e Lund, na Suécia. Uma revisão crítica detalhada sobre alguns desses índices, com suas métricas e processos de implementação, bem como suas aplicações em diferentes contextos é apresentada em Keeley (2011), que aponta a falta de base científica para o seu estabelecimento. Na maioria dos casos, os projetos são aprovados antes que a vegetação cresça, portanto, os índices pontuam o potencial futuro da vegetação proposta, quando entram em questão as falhas de monitoramento e fiscalização ao longo do tempo. Outro ponto levantado por Keeley é que os índices não podem incentivar a ocupação nas áreas menos densas e muitas vezes mais afastadas, quando a exigência do índice é menor; essa é uma das questões que se coloca para o caso de São Paulo também, como discutido mais à frente.

Neste trabalho, aborda-se com maiores detalhes o GnPR que, dentre os encontrados na literatura e em aplicação em diferentes cidades do mundo, parece ser o mais bem fundamentado. O GnPR foi introduzido como conceito em 2002, e a ideia era propor uma métrica para a quantidade de vegetação em um determinado lote, dada a dificuldade em se comunicar o valor da vegetação à prática profissional em arquitetura. $O$ valor da vegetação é, de certa forma, ligado à densidade foliar, e o GPR é, essencialmente, o IAF médio para um dado lote.

\footnotetext{
91 Disponível em:

<http://www.stadtentwicklung.berlin.de/umwelt/landschaftsplanung/bff/download/Auszug_BFF_Gutachten_1990_eng.pd f>. Acesso em 20 de julho de 2015.

92 Disponível em: < http://www.seattle.gov/dpd/cityplanning/completeprojectslist/greenfactor/documents/>. Acesso em: 20 de julho de 2015.

93 Disponível em: <http://malmo.se/English/Sustainable-City-Development/Bo01---Western-Harbour/Green-City.html>. Acesso em 20 de julho de 2015.
} 
Uma lista de 300 espécies mais comuns em Cingapura foi gerada pelo National Parks Board; dois métodos foram usados para medir o IAF, um indireto, com o analisador de dossel para árvores e arbustos, e outo direto, por amostragem parcial das folhas, quantificadas por um medidor de área foliar portátil, aplicado em palmeiras, forrações e turfa. Baseados nesses dados da vegetação local e, por simplificação, foram sugeridos os valores IAF = 1 para grama, IAF = 3 para arbustos e IAF $=6$ para árvores ${ }^{94}$ Testes estatísticos mostraram que o IAF é independente do diâmetro do tronco, medido a $1 \mathrm{~m}$ do solo. Dessa forma, um único valor de IAF para cada classe de densidade de copa foi adotado. O GnPR é, na prática, "the area-weightted average leaf area index of a site, to also account for unequal amount of area occupied by different plants as one would typically expect in a landscape" (TAN, SIA, 2010), ou seja, o GnPR resulta do IAF de cada espécie multiplicado pela projeção da copa.

Um dos diferenciais do GnPR é que ele é tridimensional, ou seja, de certa forma, o IAF mede o volume da vegetação, e não é apenas um índice unidimensional, como por exemplo, o número de indivíduos, ou bidimensional, como uma cobertura vegetal ou projeção da área arborizada, como sugerido por outros índices, como o SGF ou BAF. Também é a única métrica que considera o IAF. Conceitualmente o GnPR é similar ao coeficiente de aproveitamento (CA), o que facilita o seu entendimento e a sua aplicação entre arquitetos e urbanistas, só que, ao invés de metrificar a densidade construída, estipula a quantidade mínima de densidade de vegetação (green density) que deve ser prevista em projeto para cada lote (TAN, SIA, 2010).

De início, o GnPR foi incorporado ao one-north Project, do Jurong Town Corpration (JTC) em Cingapura, quando os projetos foram solicitados a informar o GnPR como parte da proposta. Quando - GreenMark foi lançado pelo Building Control Authority, em 2005, o GnPR foi incluído como parte do incentivo para promover a inclusão da vegetação nos projetos. Os valores para IAF 1,3 e 6 originalmente propostos foram mantidos.

Uma outra vantagem do GnPR é que ele discrimina categorias de vegetação, e não espécies, e prioriza vegetação de porte arbóreo e, na sequência, arbustiva, sobre forrações (ONG; HO; HO, 2012), o que é vantajoso do ponto de vista microclimático e, consequentemente, do conforto em espaços abertos.

Os próprios autores também tecem considerações sobre as limitações do GnPR e seu significado para aplicações urbanas. O valor do IAF também varia ao longo das estações do ano e em função de uma série de variáveis; há dificuldades de monitoramento e fiscalização também. Outro fator é que, diante das muitas variáveis envolvidas, os próprios autores lembram que um IAF mais alto não significa necessariamente um valor ecológico maior, levando-se em conta o leque de serviços ecossistêmicos providos pela vegetação (ONG; HO; HO, 2012).

Uma variação chamada Green Index foi então proposta para incluir uma ponderação que valorasse também as espécies locais e a vegetação arbórea, pelas vantagens do sombreamento e, eventualmente, outros benefícios ecossistêmicos da vegetação (ONG; HO; HO, 2012).

Recentemente foram realizados dois workshops em Melbourne, Austrália, onde o autor do GnPR está vinculado atualmente, para se discutir um maior engajamento do setor privado com relação à vegetação urbana. Foram discutidas as lacunas de pesquisa e as políticas públicas, e os participantes identificaram como uma dessas lacunas o papel da vegetação na mudança climática, como parte das estratégias para mitigação e adaptação, ${ }^{95}$ parte do escopo deste trabalho.

Em São Paulo, a quota ambiental, atualmente em discussão, propõe uma ferramenta para ser aplicada durante o licenciamento sobre o solo privado, incluído na política de uso do solo. A quota

\footnotetext{
94 Para cada local, os valores de referência poderiam seriam diferentes, conforme o clima e as as espécies locais.

95 ONG, Boon Lay, HES, Dominique, AYE, Lu, FRYD, Ole, TUAN, Duc-Ngo. Towards greater private sector uptake on urban greenery in Melbourne. Disponível na página do autor em: <https://www.mendeley.com/profiles/boon-ong/>. Acesso em 20 de julho de 2015.
} 
parte do princípio que o zoneamento pode contribuir estabelecendo regras de parcelamento, uso e ocupação do solo que levem em conta a melhoria da qualidade ambiental. Dentro desse contexto a quota ambiental estabelece um conjunto de regras de ocupação que fazem com que cada lote na cidade contribua com a melhoria da qualidade ambiental, sendo que tais regras passam a incidir quando se pretender uma nova edificação ou a reforma de um edifício existente. Dessa forma, a quota teria efeito sobre o mundo licenciável, nos lotes privados, e ficaria restrita à cidade formal.

Segundo a PMSP," 96 "na concepção da quota ambiental se optou por adotar parâmetros relacionados à drenagem, microclima e biodiversidade, com intuito de promover melhoria da drenagem e redução das ilhas de calor com atenção à biodiversidade, ainda que tais parâmetros não abranjam a totalidade dos problemas ambientais existentes na cidade. Esta opção se deve a possibilidade de utilização de parâmetros de uso mais consagrados em outras cidades do mundo, onde a eficácia de sua adoção se encontra melhor descrita. "

Ainda segundo a PMSP, a proposta do instrumento é que cada lote/empreendimento deve atingir uma pontuação mínima que está relacionada à drenagem e microclima/biodiversidade. A pontuação mínima varia conforme a localização na cidade (perímetros de qualificação ambiental) e conforme a dimensão do lote (quanto maior o terreno, maior a pontuação). A pontuação mínima tem como objetivo exigir uma maior qualificação ambiental nas áreas mais críticas, bem como manter a qualificação de áreas que apresentem uma boa qualificação ambiental, além de levar em consideração a Macroárea de localização e seu potencial de transformação da ocupação urbana existente. Uma vez identificada a pontuação mínima a ser atingida, os parâmetros a serem aplicados para obtenção de pontos podem ser combinados de forma cumulativa (vários num mesmo lote) ou alternativa (escolha de um ou outro parâmetro), a partir de opções pré-estabelecidas. E cada parâmetro tem um desempenho em relação à melhoria da drenagem e à atenuação do microclima. Por exemplo, árvores pontuam mais do que pisos semipermeáveis; vegetação arbustiva pontua mais do que fachada verde, e assim por diante. Comparativamente ao que é exigido hoje na Lei 13.885/04 (taxa de permeabilidade mínima), a quota ambiental não exige necessariamente mais área de terreno para a obtenção da pontuação mínima, mas induz a qualificação dessa área, por exemplo, por meio do plantio de árvores, de vegetação arbustiva, de cobertura verde, de piso semipermeável, de piscininhas, etc.

Durante a fase de elaboração da proposta, em outubro de 2014, foi realizada uma Oficina Técnica Discutindo a Proposta da Quota Ambiental, na Secretaria Municipal de Desenvolvimento Urbano SMDU, para a qual foram convidados outros representantes do poder público, pesquisadores ligados à academia, incluindo a autora deste trabalho, representantes de entidades não governamentais ligadas às questões que envolvem a vegetação e especialistas de diversas áreas vinculadas ao tema.

Durante a oficina, uma série questões foram levantadas pelos participantes, incluindo a autora deste trabalho, tais como consorciar a quota ambiental com outros assuntos do PDE, devendo a quota estar vinculada à densidade construída, principalmente, para se manter uma maior coerência com o plano recém-aprovado. $O$ argumento microclimático utilizado também é parcial, pois foi tratado com base em uma leitura de temperatura aparente de superfície, registrada para uma data e horário específicos, sem um diagnóstico mais detalhado. Ao final, o mapa com a definição das macroáreas foi calibrado 'politicamente', com a intenção de atenuar a exigência nas áreas mais pobres. Porém, na maioria dos casos, essas são as áreas mais vulneráveis, com pouca ou nenhuma amenidade urbana e climática, onde o poder público, por sua vez, deveria ser mais exigido, pela maior vulnerabilidade a alagamentos, sobreaquecimento, aridez, etc.

Por parte dos participantes mais ligados à biodiversidade, foi lembrado que vegetação arbórea e biodiversidade não são sinônimos; pela proposta apresentada, um projeto poderia até ser bem

\footnotetext{
${ }_{96}$ Disponível em: <http://gestaourbana.prefeitura.sp.gov.br/cota-ambiental-2/>. Acesso em: 24 junho de 2015.
} 
pontuado mas prejudicar a biodiversidade, o que também foi apontado na proposta inicial do GnPR, por exemplo, e há uma tentativa de ponderação na proposta atual (ONG; HO; HO, 2012).

Outro ponto sugerido foi considerar a massa vegetal de alguma forma, já que pelo diâmetro à altura do peito - DAP, uma palmeira quase sem folhas pode ter um DAP enorme, mas baixa densidade foliar, e poucos benefícios do ponto vista microclimático. Também foi proposto distinguir as árvores existentes das propostas.

Uma crítica importante foi que arquitetos paisagistas não foram envolvidos para desenvolver as propostas possíveis de desenho, principalmente para os casos mais críticos, como terrenos pequenos, terrenos inclinados, etc., onde a aplicação da proposta torna-se praticamente inviável.

E não menos importante para a eficácia da medida, assim como em muitas outras cidades, já apontadas anteriormente, São Paulo teria as mesmas dificuldades de fiscalização e de acompanhamento desses casos ao longo do tempo.

Esta agenda ambiental da PMSP poderia também considerar o IPTU Verde - Imposto Predial e Territorial Urbano, em vigor em algumas cidades brasileiras, vinculando a manutenção de vegetação e/ou outros elementos para retenção de água da chuva, por exemplo, a descontos no IPTU. Poderia incluir questões de governança e outros critérios para compensação ambiental, já que com a legislação atual tudo se corta e se compensa (FERREIRA, 2015) e, muito importante, as relações entre infraestrutura verde e adensamento populacional e construído, que é ainda é pouco discutido localmente, tendo em vista que o adensamento deveria ser obrigatoriamente seguido por maior controle da qualidade ambiental urbana, com a exigência de contrapartidas. Todas estas questões demandam disponibilidade de dados oficiais, mapeamento de vegetação atualizado, monitoramento permanente dos microclimas urbanos e da vegetação, inventário da vegetação existente e suas relações com os serviços ecossistêmicos, etc. A implementação desses recursos viabilizaria melhor apoio à pesquisa e discussões de políticas públicas para se diminuir o déficit de infraestrutura verde nas áreas urbanas.

\subsection{Infraestrutura verde como parte da estratégia de adaptação aos fenômenos de aquecimento urbano}

As alterações climáticas têm implicações para o planejamento da cidade e para o desenho urbano, da escala do edifício até a escala da cidade. Portanto, políticas para mitigar os fenômenos de aquecimento urbano também devem ser consideradas nas legislações pertinentes, incluindo o entendimento de ambas as escalas.

Há estudos recentes identificando as escalas de abordagem para a inclusão de diferentes medidas na legislação, e colocando propostas para estruturar as interações entre elas. Esse é um trabalho necessariamente interdisciplinar que inclui a climatologia urbana, o planejamento e desenho urbanos, bem como o entendimento da legislação ambiental e urbana. Lambert-Habib et al. (2013) fazem um levantamento da legislação nas cidades francesas, e apontam novos caminhos, principalmente visando à introdução de espaços de amenidade climática com vegetação e água (oases of freshness) nas áreas urbanas.

Vários trabalhos recentes abordam pontos críticos, relacionando principalmente stress térmico e saúde, mas também uma série de questões ligadas à infraestrutura urbana, que podem levar ao colapso, em um efeito cascata, o sistema de abastecimento de energia e água e de transporte. 0 abastecimento de energia está longe de ser resiliente aos efeitos climáticos extremos, incluindo o aumento de demanda para os sistemas de ar-condicionado, e dele dependem quase todos os serviços de infraestrutura urbana, como abastecimento de água e transporte. Nesse sentido estão sendo feitos o monitoramento e a modelagem do impacto do calor extremo sobre as redes de infraestrutura urbana (STONE, 2012; CHAPMAN et al. 2013). 
Em um documento divulgado em tom de alerta, lançado conjuntamente por duas importâncias agências das Nações Unidas, a WMO e WHO, sobre planos de ação para as ondas de calor, podem ser encontradas várias considerações para as áreas de arquitetura e urbanismo, várias delas abordadas ao longo deste trabalho, tais como:

During periods of hot weather, nocturnal temperatures in urban areas may rise several degrees above their rural counterparts because of the UHI effect. As a result, urban inhabitants will not benefit from the relief that night-time normally offers.

The principal causes of UHI are the storage by day of solar energy in the urban fabric and release of this energy into the atmosphere at night and the fact that evaporation from urban surfaces as a cooling process is very limited. Given this, strategies for tackling the root causes of $\mathrm{UHI}$ - and thus stressful night-time temperatures - need to focus on controlling the absorption and release/escape of heat from the urban fabric and tipping the balance between the apportionment of available natural energy between heating and cooling of the urban atmosphere. Policies designed to reduce $\mathrm{UHI}$ may need to balance the requirement to manage heat at the building, neighbourhood and city scales, taking into account the nature of building development (new versus existing) and being aware of what is achievable in reality. Climate change has implications for the planning and design of current and future urban spaces from the local to city scale. Urban designers and planners need to acknowledge this and, in so doing, base design criteria on data that describe the current and projected future climate.

Urban designers and planners need to acknowledge this and, in so doing, base design criteria on data that describe the current and projected future climate. Because anthropogenic heat, for example from air-conditioners, could become an important future source of extra heat in the atmosphere for some major urban areas, strategies focused on managing heat emissions and the location of heat ejection to the atmosphere from infrastructure will become an important issue for planners.

In developing UHI mitigation strategies and applying the philosophy of climate-sensitive urban design, it must be borne in mind that UHI is a cityscale phenomenon and the outcome of the combination of a vast range of urban microclimates. As the built components of the urban system occur at different scales (individual building to industrial park to major industrial zone, etc.), any physical alteration of these will have climate impacts at different scales. Consequently, the link between UHI management policy and urban-climate scale needs to be acknowledged [...]. Perhaps focusing on the ways in which climate at the individual-building to neighbourhood scale can be managed will eventually have a cumulative effect at the larger city scale. While the choice of strategies for local climate modification through invoking a range of building-design and urban planning strategies is considerable [...], the degree of benefit (the intensity of cooling and improvements to human thermal comfort) depends on a multitude of factors [...]

WHO also extends its advice to urban designers and town planners in an attempt to raise awareness that long-term intervention strategies to do with the nature of the built environment can also assist with managing the heat-health problem. (UN, 2015) 
Planos de ação para ocorrências de ondas de calor estão sendo colocados em prática em muitos lugares do mundo, principalmente nos países mais desenvolvidos de clima temperado e frio. $\mathrm{Na}$ Europa, a Inglaterra tem um heatwave plan, e estabelece um link entre políticas públicas e escalas climáticas urbanas adotadas em Londres, assim como a França, que perdeu milhares de vidas na onda de calor de 2003, e vem enfrentando um verão escaldante para os padrões locais, agora em 2015, quando Paris colocou à disposição dos cidadãos os edifícios públicos com ar-condicionado. Cidades canadenses também estão se mobilizando, como Toronto e Manitoba, ajustando outros planos municipais para incluir as ações necessárias para adaptação às ondas de calor. Várias cidades americanas, incluindo Filadélfia, Chicago, Nova lorque e Portland, já implementaram seus planos de ação. Também há iniciativas em países de clima quente, como em Victoria, na Austrália (UN, 2015).

Filadélfia foi a primeira cidade americana a introduzir um sistema de alerta relacionando calor excessivo e saúde (Philadelphia Hot Weather-Health Watch Warning System - PWWS) como parte do Excessive Heat Plan em 1997. Nesse sistema, equipes municipais trabalham em conjunto com o National Weather Service - NWS para se determinar quando uma onda de calor é iminente, incluindo o acesso a um mapa interativo, disponível na internet, chamado Stay Cool Interactive Map, ${ }^{97}$ elaborado para ajudar a população, no caso americano, principalmente aqueles que não tem acesso ao ar-condicionado, a identificar locais mais amenos (cool locations) para se refugiar temporariamente e se recuperar do stress térmico (UN, 2015).

As pessoas são orientadas a procurar edifícios públicos, escolas, bibliotecas, shopping centers, abrigos para idosos e outros espaços condicionados artificialmente, além de piscinas públicas e spraygrounds. Alguns locais chamados cooling centers são abertos à população sempre que há o alerta de uma onda de calor, e o plano inclui também o transporte das pessoas até esses locais. Há também pessoas da comunidade para checar as condições de vizinhos idosos, para fazer visitas domiciliares, e um serviço telefônico no qual enfermeiros dão assistência a pessoas com problemas de saúde relacionados ao calor excessivo. Com o sucesso dessa experiência, sistemas análogos estão sendo propostos para cerca de 50 a 60 cidades americanas, com população superior a 500 mil habitantes e que dispõem de um serviço meteorológico, e os sistemas já foram implantados em Portland e Chicago (UN, 2015).

Muitas das recomendações encontradas nos planos para adaptação às ondas de calor recomendam que as pessoas busquem espaços condicionados artificialmente para se recuperar do calor extremo, ainda que por algumas horas.

Stay indoors and, if at all possible, stay in an air-conditioned place. If your home does not have air conditioning, go to the shopping mall or public library - even a few hours spent in an air-conditioned place can help your body stay cooler when you go back into the heat. Call your local health department to see if there are any heat-relief shelters in your area (UN, 2015)

Muitas das referências encontradas para prevenção de doenças e mortes relacionadas ao calor excessivo são propostas pela perspectiva de países desenvolvidos, em climas temperados e frios. A população em países tropicais e subtropicais são mais aclimatadas em função da vestimenta, dos edifícios naturalmente ventilados e hábitos culturais, mas esses usos e costumes também vem mudando, aumentando a vulnerabilidade às ondas de calor em regiões antes consideradas mais tolerantes aos rigores do clima. Milhares de pessoas já morreram no verão de 2015 na Índia e no Paquistão, com temperaturas muito acima da capacidade de adaptação do corpo humano, e com cortes no fornecimento de energia e água, durante a onda de calor considerada a pior da história.

Rosenthal, Kinney e Metzger (2014) e Rosenthal (2014) apresentam um estudo para a cidade de Nova lorque, com análises espaciais e estatísticas, abrangendo características demográficas, sociais,

\footnotetext{
97 Disponível em: http://oem.readyphiladelphia.org/StayCoolMap. Acesso em 24 de julho de 2015.
} 
da saúde pública, do ambiente construído e biofísico, de forma conjunta na escala dos bairros. Fazendo associações entre lugares que já apresentaram altas taxas de mortalidade em função do calor extremo e as caraterísticas do seu ambiente construído, como a parcela de vegetação, foi possível identificar as populações mais vulneráveis e apontar medidas de prevenção. $O$ estudo mostra que faz muita diferença na adaptação se o usuário tem a oportunidade ou não de modificar comportamentos e rotina para se adaptar melhor às temperaturas extremas, o que nos leva a pensar na criação de espaços de amenidade climática nos bairros, distribuídos pela cidade, incluindo parques, praças, ruas e demais espaços públicos, abertos ou semiconfinados, conectados entre si, formando uma rede de infraestrutura urbana, apoiando as estratégias de mobilidade, e incluindo a vegetação.

No Brasil, edifícios com ar-condicionado não são acessíveis a todos no setor residencial, e a maioria dos nossos edifícios públicos (bibliotecas, escolas, centros comunitários) também não têm arcondicionado. Ainda que se disponha de condicionamento artificial em alguns desses locais, em caso de racionamento do uso da energia e até mesmo interrupção do fornecimento, com vários precedentes no país e por diversas razões, inclusive por sobrecarga pela intensificação do uso de arcondicionado, é preciso traçar um plano de ação que inclua principalmente os espaços público ou pelo menos de acesso público, que não podem ser relegados.

É preciso preparar as nossas cidades, os edifícios públicos e privados para as mudanças que já estão em curso, considerando os critérios ambientais que deveriam estar na base da tomada de decisões. Mais ainda, é preciso preparar os espaços públicos e privados de acesso e uso público, acessíveis a qualquer cidadão, que independam de condicionamento artificial, pois o Brasil não tem edifícios públicos condicionados para atender a essa demanda, e nem sequer segurança energética para sustentar tal medida, pelo menos não nas contingências atuais do setor hídrico e energético, em situações de ondas de calor, quando o consumo de energia aumenta significativamente.

Para o caso de São Paulo, esboça-se aqui uma proposta incluindo espaços de amenidade climática que precisam aumentar em quantidade e qualidade e ser melhor distribuídos pela cidade, aproveitando os edifícios de uso público e espaços abertos de amenidade climática ou que poderiam vir a ser, desde que incrementados com estratégias de sombreamento e evaporação, que podem ser providos pela infraestrutura verde, acrescidas dos seus muitos outros serviços ecossistêmicos.

Na cidade de São Paulo, vários espaços públicos ou de uso público já oferecem oportunidades de adaptação, mas são nitidamente insuficientes frente ao tamanho da cidade. Algumas reservas ecológicas são significativas, mas de difícil acesso à população. Há também outros espaços potenciais de uso como refúgios de amenidade climática (cooling places), públicos ou privados que poderiam vir a ser de acesso e uso público, como os POPOS e POPS já apresentados anteriormente, desde que recebessem intervenções incluindo vegetação e água, incluindo ou não outras estruturas leves para sombreamento.

Dentre os edifícios de uso público que já possuem intrinsecamente essas condições como cooling places, podem ser incluídos o vão livre do Museu de Arte de São Paulo - MASP, pelo sombreamento e ventilação, o Centro Cultural São Paulo - CCSP, com boa parte do edifício semienterrado e um enorme cobertura verde, várias bibliotecas públicas como, por exemplo, a Mário de Andrade, na República, e a Alceu Amoroso Lima, em Pinheiros, pela efeito de inércia térmica dos edifícios, os próprios edifícios da FAUUSP e da FFLCH-USP, na Cidade Universitária, etc.

Nessa rede poderiam ser incluídos espaços de uso público como as instalações do Serviço Social do Comércio - SESC e Centros Educacionais Unificados - CEU. A esses importantes pontos da rede podem ser conectados, com a infraestrutura verde apoiando as ações de mobilidade, os parques municipais e estaduais, pode ser ampliada a rede de parklets e os poucos pocket parks existentes na cidade, podem ser propostas iniciativas na legislação municipal nos moldes do POPOS e POPS, para engajar os empreendimentos privados, aproveitando esses espaços para a inclusão de vegetação e água e incluindo outras intervenções leves para o sombreamento, quando necessário (Figura 50). 


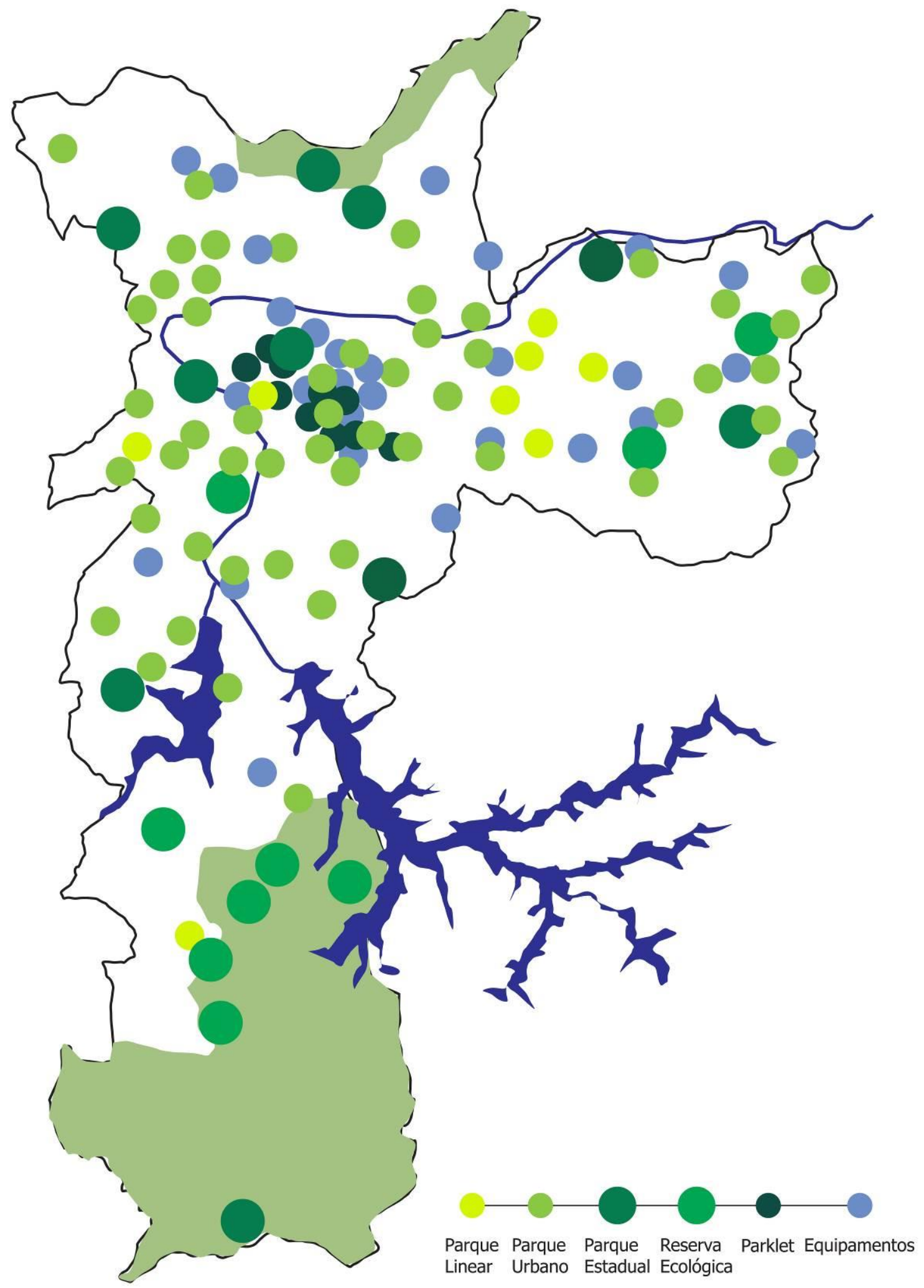

Figura 50 - Proposta esquemática de uma rede de espaços de amenidade climática (cooling places) para a cidade de São Paulo (Elaboração: Eduardo Pizarro) 


\section{Interações com outras áreas e atividades de pesquisa alimentando as aplicações didáticas nos currículos de graduação e pós-graduação}

Para que propostas como as apresentadas anteriormente aconteçam, o trabalho interdisciplinar deve se iniciar na formação dos profissionais envolvidos. Nos últimos anos, as atividades de ensino e pesquisa no grupo foram indubitavelmente aprimoradas com uma série de parcerias interdisciplinares. ${ }^{98}$ As experiências prévias e em curso envolvendo arquitetura e urbanismo com outras áreas do conhecimento como meteorologia, geografia, medicina, engenharia civil, engenharia de transportes e engenharia florestal, melhorou e muito o entendimento dos fenômenos, a qualidade das medições de campo para o levantamento de condições microclimáticas urbanas, as simulações computacionais em microescala, com as interações absolutamente necessárias entre solo, ambiente construído, vegetação, atmosfera, realimentando as atividades de ensino e pesquisa em arquitetura e urbanismo.

Com as interações interdisciplinares em pesquisa, nos últimos anos alguns avanços foram possíveis:

- a quantificação do impacto das mudanças climáticas previstas e em curso no desempenho térmico e conforto em edifícios (Alves, 2015; Alves, Duarte, Gonçalves, 2015a; 2015b; 2015c), tornando os bancos climáticos futuros compatíveis com os modelos de simulação de desempenho térmico e energético em edifícios (Building Energy Simulation models - BES), em parceria com a meteorologia;

- o levantamento local das variáveis da vegetação necessárias à modelagem micrometeorológica, testando dois métodos em paralelo (fotos hemisféricas pós-processadas e analisador de dossel), contando com a colaboração da meteorologia e da engenharia florestal, respectivamente;

- a especificação das caraterísticas de solo e propriedades dos pavimentos necessária à modelagem micrometeorológica, com a colaboração da meteorologia e da engenharia de transportes;

- o entendimento das interações entre solo, vegetação e atmosfera, e não só o papel da vegetação em si, com as colaborações da meteorologia e da engenharia florestal.

Também foram aprimoradas as medições em campo de variáveis microclimáticas e outras envolvidas indiretamente no processo, visando a um melhor entendimento dos fenômenos e também à calibração dos modelos para a realidade de condições climáticas subtropicais, antes de se levar adiante estudos paramétricos ou estudos preditivos para áreas reais da cidade, a fim de se estudar estratégias de alterações na ocupação do solo (land-based mitigation strategies) para o aquecimento urbano, por exemplo.

No laboratório os sensores foram sendo melhorados, os protocolos de medições foram sendo estabelecidos, apesar das poucas referências existentes para estudos urbanos na escala do pedestre. Os muitos trabalhos de campo realizados envolviam quase sempre, alunos de graduação e de pósgraduação em conjunto, mantendo a individualidade de cada trabalho, mas, ao mesmo tempo, com os alunos colaborando entre si, para um trabalho maior em conjunto. Assim foram sendo formados vários alunos de iniciação científica que depois vieram a desenvolver mestrados e doutorados no grupo.

Como muito lembrado por Monteiro et al. (2015), só há como desenvolver a pesquisa em clima urbano em laboratórios, com equipes interdisciplinares capacitadas para tal. E assim, a pesquisa

\footnotetext{
98 Em uma declaração recente sobre a interdisciplinaridade nas ciências ambientais, o Prof. Dr. Paulo Artaxo do IF/USP diz que "é preciso olhar a ciência ambiental não com olhos direcionados a disciplinas específicas, pois a natureza não distingue a física, a química ou a biologia." Entrevista do Prof. Dr. Paulo Artaxo, IF/USP, ao CNPq, em 08 de junho de 2015.
} 
segue alimentando o ensino de graduação e pós-graduação e, paulatinamente, as políticas públicas e a prática de planejamento e desenho urbano, com a formação de profissionais capacitados e instrumentados para tal.

\subsection{Ensino na pós-graduação}

Há doze anos, em 2003, uma nova disciplina de pós-graduação foi proposta no Programam de PósGraduação em Arquitetura e Urbanismo na FAUUSP, no tema do conforto térmico urbano. A disciplina foi inicialmente denominada AUT 5823 - Conforto Ambiental Urbano, com nome alterado posteriormente para AUT 5823 - Conforto Ambiental em Espaços Urbanos Abertos, na área de concentração em Tecnologia da Arquitetura.

Para atender o escopo pretendido, era necessário incluir tópicos em clima urbano, escalas climáticas, acesso ao sol e ventilação em áreas urbanas, abordar o papel da geometria, das superfícies e da vegetação, para um entendimento abrangente dos fenômenos e das variáveis relacionadas aos índices de conforto térmico em espaços abertos, sejam elas físicas ou subjetivas.

Ao longo de oito oferecimentos, o curso recebeu alunos das mais variadas formações, além da FAUUSP, de outros programas de pós-graduação da USP em Meteorologia do IAG, Geografia da FFLCH, Engenharia Civil da Escola Politécnica, Saúde Pública da FSP e Engenharia Florestal da ESALq. São arquitetos e urbanistas, meteorologistas, geógrafos, engenheiros civis e florestais, além de uma médica da saúde pública e uma gerontóloga interessados na relação entre conforto e saúde, especialmente para os idosos, fisiologicamente mais vulneráveis às alterações climáticas. Entre os alunos estão professores, profissionais do mercado e do setor público, vinculados às administrações municipais, como da Secretaria do Verde e do Meio Ambiente, por exemplo.

A diversidade de formações criou oportunidades para tratar esses temas de forma interdisciplinar, avançando em tópicos até então nebulosos para a arquitetura e o urbanismo. Também foi muito proveitosa a oportunidade de melhorar protocolos de medições microclimáticas com a ajuda dos meteorologistas, de medições das variáveis da vegetação com os engenheiros florestais, e assim por diante. Nos últimos anos, houve melhorias nos sensores do laboratório, em qualidade e número, e eventualmente alunos de pós-graduação trazem também instrumentos de suas instituições de origem para incrementar as medidas, comparar resultados entre instrumentos diferentes, e mesmo para aprimorar o seu próprio treinamento na operação dos sensores.

Os incrementos teóricos e práticos foram sendo incorporados ano a ano, e hoje o curso se desenvolve como uma referência na área. Os objetivos do curso são: 1) caracterizar as condições de conforto ambiental urbano, 2) desenvolver a leitura e a representação dos fenômenos ambientais urbanos, 3) abordar as relações entre os fenômenos ambientais urbanos e os padrões de ocupação do solo, o projeto dos espaços abertos e o desenho dos edifícios, e 4) definir a instrumentação e os procedimentos para trabalhos de campo, bem como para a análise dos resultados e o tratamento dos dados.

O programa contempla: índices de conforto térmico em espaços abertos, acesso ao sol em áreas urbanas, ventilação urbana, acústica urbana, efeitos da geometria, das superfícies e da vegetação no ambiente urbano, balanço de energia, escalas climáticas, teorias sobre clima urbano, além da parte prática, que ocupa cerca de um terço do curso versando sobre técnicas de pesquisa em clima urbano: medidas fixas, transectos, instrumentação, procedimentos de medição, tratamento dos dados; treinamento em aula de bancada e planejamento do trabalho de campo propriamente dito.

Os métodos incluem aulas expositivas, seminários de leitura, treinamento em laboratório, medições de campo, análise e tratamento dos dados. O contato com os instrumentos de medição se inicia ainda durante as aulas teóricas, para os alunos irem ganhando familiaridade com as variáveis em questão e suas formas de registro, para posterior treinamento na aula de bancada, nas primeiras medições no entorno da FAUUSP, antes de planejar e ir a campo de fato. Ressalta-se aqui a 
importância didática das medições, seguindo protocolos estabelecidos, as condições para exposição os instrumentos, todas estas etapas prévias e indispensáveis à calibração dos modelos para as condições ambientais locais.

Nos últimos anos os trabalhos de campo foram feitos dentro e fora da Cidade Universitária, na Praça do Relógio, no Parque Villa-Lobos, nas ruas de São Paulo, avaliando o conforto (ou desconforto) do pedestre nos pontos de ônibus, os antigos e os de vidro, implantados nos últimos anos, dentre outros estudos.

Como resultado, a disciplina vem formando profissionais para carreiras acadêmicas e para a prática profissional, que atuam em escritórios, organizações não governamentais ou órgãos públicos, ligados às questões ambientais urbanas.

\subsection{Ensino na graduação}

Há anos, a participação de um número significativo de alunos de Iniciação Científica nas pesquisas do grupo, trabalhando sempre em conjunto com a pós-graduação, aproxima os alunos de graduação das pesquisas em curso. São bolsistas de iniciação científica Fapesp, PIBIC e PIBITI CNPq, Santander, RUSP, FUPAM, além de cotas de iniciação científica e apoio técnico vinculadas aos projetos dos docentes no CNPq e na Fapesp. São importantes também as vagas de estágios FAUUSP vinculadas à implementação e ao desenvolvimento de novos projetos para a escola.

Além dos bolsistas e estagiários, é desejável estender essa interação implementando mais disciplinas optativas, de caráter experimental, principalmente, para aproximar a pesquisa da graduação. Dessa forma, as inovações na pesquisa são objeto das disciplinas de pós e optativas de graduação e, paulatinamente, são incorporadas às obrigatórias.

Na FAUUSP há uma demanda clara por interação das disciplinas de conforto ambiental com temas do desenho urbano e do desenho da paisagem. Algumas interações já acontecem espontaneamente, por iniciativa dos alunos ou professores, em colaborações pontuais nas disciplinas de graduação. Em pesquisa, foram muitos os alunos de IC no laboratório envolvidos com o tema, junto com os alunos de pós-graduação, trabalhando em projetos maiores, estruturados para tal pelos professores do grupo.

Buscando-se criar um espaço na grade curricular para fomentar ainda mais essas interações, a disciplina optativa de graduação AUT 225 - Conforto Ambiental em Espaços Urbanos Abertos foi aprovada em 2014 para oferecimento em 2015/2.

Atualmente são poucas as optativas do grupo oferecidas com regularidade (AUT 217 - Ergonomia Aplicada ao Planejamento e Projeto do Mobiliário Urbano, AUT 215 - Ergonomia Aplicada ao Projeto e Dimensionamento dos Espaços da Habitação, AUT 213 - O Projeto de lluminação no exercício da Arquitetura e AUT 221 - Arquitetura, Ambiente e Desenvolvimento Sustentável); o plano é ampliar a oferta com outras disciplinas abordando tópicos avançados de conforto térmico em edificações e em espaços abertos, como a AUT 225 - Conforto Ambiental em Espaços Urbanos Abertos. Esta última apresenta caráter teórico-prático, com trabalho laboratorial e de campo, que vem atender a uma demanda dos alunos de graduação e dos professores de outras áreas pelo tema. Até então esse conteúdo era oferecido somente na pós-graduação, mas alguns alunos de iniciação científica já acompanharam a disciplina como ouvintes, participando das aulas de bancada, dos trabalhos de campo, e interagindo com os alunos da pós-graduação.

Uma proposição para uma outra disciplina optativa é explorar o processo de desenvolvimento de formas para edifícios e cidades, utilizando-se de modelagens computacionais de construção de forma com critérios ambientais, que poderia ser oferecida em conjunto por professores do Grupo de Disciplinas de Conforto Ambiental e de Metodologia, do Departamento de Tecnologia da Arquitetura. 
A ideia é colocar em prática um escopo que reúna questões advindas do planejamento urbano, do desenho urbano e do paisagismo, enriquecidas com as abordagens técnica e de percepção do conforto ambiental.

No futuro próximo, pode se pensar em outras disciplinas obrigatórias e optativas interdepartamentais entre planejamento e tecnologia, paisagismo e tecnologia, incluindo teoria, medições de campo e desenho urbano e da paisagem em ateliê, com abordagens tratadas por alguns autores como Brown (2010), Brown e Gillespie (1995) e Emmanuel (2005).

\subsection{O papel dos laboratórios no ensino de graduação e pós-graduação}

Um ponto importante dessa abordagem é o uso da experimentação e demais atividades de laboratório como parte essencial das atividades didáticas. Para o domínio dessas habilidades, os equipamentos para simulação em conforto ambiental são instrumentos didáticos imprescindíveis para os alunos de Arquitetura e Urbanismo, pois possibilitam a visualização e a compreensão mais imediata dos fenômenos de insolação, iluminação e ventilação na fase de projeto, não só na escala urbana, mas também no projeto de edifícios, possibilitando uma melhor avaliação de cada opção estudada. A possibilidade da experimentação é parte integrante do processo de ensino/aprendizagem, tanto nas disciplinas obrigatórias do conforto ambiental como nas optativas de caráter ainda mais experimental, e esses instrumentos são fundamentais para que se possa incorporar a valorização da descoberta, da tentativa e do erro nos processos educativos, usando uma linguagem que é inerente à prática profissional do Arquiteto e Urbanista.

É com base nesse trabalho experimental de apoio, caracterizado não só pela prática, mas principalmente pela pesquisa projetual em ambas as escalas, da cidade e do edifício, que se estabelece o desenvolvimento e a avaliação do projeto do ambiente construído, no qual se fundamenta a constituição de laboratórios de conforto ambiental ${ }^{99}$ nas escolas de Arquitetura e Urbanismo.

Dentro desses princípios, o LABAUT - Laboratório de Conforto Ambiental e Eficiência Energética atua, desde a sua implementação, em 2002, nas atividades de ensino alimentadas pela pesquisa, com incentivo e apoio ao desenvolvimento de pesquisa voltada para o aperfeiçoamento da graduação, numa constante transferência do avanço científico e tecnológico para os cursos de graduação. Isso se traduz nas aulas práticas nas disciplinas obrigatórias e optativas, no apoio laboratorial aos Trabalhos Finais de Graduação, aos trabalhos para concursos de arquitetura e nas inúmeras iniciações científicas já desenvolvidas no laboratório em mais de 13 anos de atuação ininterrupta. 0 trabalho colaborativo entre alunos de graduação e pós-graduação nos mesmos projetos de pesquisa, financiados pela Fapesp, Capes e CNPq, fazem com que os alunos desenvolvam diferentes competências e habilidades, principalmente a análise crítica e o trabalho em equipe; esses trabalhos resultam sistematicamente em participações dos alunos de IC no SIICUSP, com algumas menções e

\footnotetext{
${ }^{99}$ Os laboratórios de conforto ambiental foram considerados obrigatórios nas escolas de Arquitetura e Urbanismo pela Portaria MEC 1770/94, pelos Perfis da Área e Padrões de Qualidade e tiveram sua configuração mínima recomendada pela CEAU/MEC 1996 - Comissão de Especialistas de Ensino de Arquitetura e Urbanismo. Pela portaria, as então chamadas matérias profissionais do curso de Arquitetura e Urbanismo incluíam o Conforto Ambiental com a exigência de espaços e equipamentos especializados. Essas disciplinas tinham como exigência, para sua oferta, a utilização de laboratórios e equipamentos correspondentes, e não deveriam ter seus conteúdos ministrados sem que se propiciassem práticas experimentais aos estudantes, incluindo a experimentação em modelos físicos.
}

Posteriormente, nas Resoluções CNE/CES no6, 2006 e CNE/CES no 2, 2010 (em vigor), que instituíram as Diretrizes Curriculares Nacionais do curso de graduação em Arquitetura e Urbanismo, o Núcleo de Conhecimentos Profissionais continuou contemplando o Conforto Ambiental e as competências e habilidades exigidas da formação profissional incluíram o entendimento das condições climáticas, acústicas, luminosas e energéticas e o domínio das técnicas apropriadas a elas associadas. 
premiações, em apresentações e publicações dos trabalhos em eventos científicos na área de conforto ambiental, como o ENCAC - Encontro Nacional e Latino-Americano de Conforto no Ambiente Construído e o PLEA Conference - Passive and Low Energy Architecture, em menções e premiações de trabalho em concursos de projetos de arquitetura, como na Bienal de Arquitetura Bioclimática José Miguel Aroztegui, premiações de TFGs em concursos nacionais e internacionais.

Nos últimos 10 anos a FAUUSP teve um heliodon em arco, um céu artificial caixa de espelhos de pequenas dimensões e um túnel de vento de camada limite atmosférica projetados e construídos na FAUUSP, por alunos de iniciação científica, em trabalhos conjuntos do LABAUT e do LAME Laboratório de Modelos e Ensaios para uso dos alunos da graduação, principalmente.

No final de 2012/início de 2013, com a conquista de uma vaga de técnico em eletrônica, que vinha sendo solicitada pelo grupo há mais de 15 anos, foi possível iniciar uma nova fase de aulas práticas e dar novo impulso ao suporte laboratorial a outras atividades ligadas à graduação. $O$ laboratório foi reorganizado, os instrumentos agora têm manutenção preventiva e corretiva, o controle de empréstimos de equipamentos ficou mais eficiente, a qualidade e a quantidade de trabalhos práticos aumentou significativamente, melhorando e muito o apoio laboratorial às atividades didáticas. A FAU tem cerca de 1300 alunos de graduação, sendo cerca de 160/180 alunos matriculados por disciplina obrigatória, a cada semestre, incluindo intercambistas e alunos do programa de dupla formação POLI/FAU, além de turmas menores nas optativas. Para atender minimamente a essa demanda, os equipamentos básicos para as aulas práticas de graduação incluem 15 kits contendo termohigrômetro, luxímetro, decibelímetro, anemômetro, contador e bússola, além de outros mais sofisticados em menor quantidade.

Esses fatores em conjunto criaram um ambiente propício à renovação de conteúdos, incluindo aulas teóricas e, principalmente, práticas, para o ensino de graduação. Para tanto, a reposição de professores aposentados do grupo que começou a acontecer precisa ter continuidade, pois o grupo ainda está desfalcado em algumas áreas essenciais das disciplinas obrigatórias de graduação, como acústica e iluminação, além de temas de ponta para a pesquisa, como a integração entre sistemas ativos e passivos para condicionamento ambiental com os edifícios operando em modo misto, iluminação por sistemas óticos, paisagem sonora, psicologia ambiental, etc.

\subsection{Expectativas para os próximos 10 anos}

A grade de disciplinas obrigatórias de conforto ambiental é periodicamente revista, com a última atualização implementada em 2014, mas precisam ser criadas e implementadas novas disciplinas optativas. Também é urgente a reposição de professores aposentados no grupo, comprometidos com as propostas em curso.

Todas as disciplinas do grupo podem ter em seus programas aulas práticas com ensaios em modelos físicos, com uso de instrumentação e de softwares de simulação computacional. Além dessas, as demais disciplinas da FAU podem solicitar apoio laboratorial dentro dos seus programas.

As aulas práticas precisam ser feitas com equipamentos atualizados, calibrados e em número suficiente para a quantidade de alunos de graduação, cerca de 1.300 atualmente.

Nos últimos anos foi possível a reorganização do parque de equipamentos, o estabelecimento de uma rotina de trabalho essencial de manutenção preventiva e corretiva, o controle de empréstimos em função das atividades programadas das disciplinas e a retomada das aulas práticas e do suporte laboratorial às outras atividades ligadas à graduação, como ICs, TFGs, trabalhos para concursos, etc.

Porém, as aulas práticas de graduação ainda vêm sendo feitas com equipamentos antigos, alguns deles obsoletos e em número insuficiente para a quantidade de alunos da FAUUSP. Alguns equipamentos quebrados foram recuperados, mas muitos deles estão danificados sem possibilidade de conserto, sem peças de reposição; muitas vezes os fabricantes não têm assistência técnica no Brasil, o que torna o seu uso inviável, por dano ou obsolescência. 
O grupo preza muito o parque de instrumentos que herdou das gerações anteriores desde o Prof. Cintra do Prado; a infraestrutura laboratorial foi sendo construída ao longo dos 50 anos do departamento, e mesmo antes disso, com os primeiros professores de conforto ambiental que vieram da Escola Politécnica (DUARTE, GONÇALVES, 2014), ${ }^{100}$ mas o parque de equipamentos precisa de atualizações e acréscimos constantes, que acompanhem as inovações tecnológicas e as novas demandas de ensino e pesquisa nos cursos de Arquitetura e Urbanismo e Design.

Pensando num panorama para 10 anos, é necessário melhorar a infraestrutura de apoio didático do laboratório para incrementar a instrumentação e a experimentação com modelos físicos para uso no heliodon, no túnel de vento, no céu real e céu artificial, com softwares didáticos e equipamentos de medição de variáveis ambientais, com os alunos aplicando em projeto de forma sistemática.

Estão em andamento adaptações de espaço físico na FAUUSP para que se possa prover um espaço adequado os instrumentos para simulação em modelos físicos construídos há anos, com muito trabalho, envolvendo alunos de iniciação científica, e que até hoje não funcionam plenamente por falta de condições para operação, como o túnel de vento e o heliodon. Até hoje não temos um céu artificial hemisférico, que agregaria muito ao ensino de iluminação natural e insolação.

Para atender a demanda com a quantidade de alunos de graduação da FAUUSP, poderíamos ter um espaço de experimentação em cada estúdio, além dos laboratórios existentes no LAME. Cada ateliê poderia ter um espaço para testes com modelos em um heliodon e um túnel de vento simplificado, de pequenas dimensões, ainda que em 2D, como a mesa d'água, por exemplo, para estudos qualitativos preliminares de insolação e ventilação, para que os alunos pudessem trabalhar em paralelo com experimentação e simulação computacional. Com a participação dos monitores já envolvidos nas disciplinas de graduação, esses espaços de experimentação poderiam ser muito mais aproveitados, com os alunos aplicando essas ferramentas em projeto rotineiramente, nas disciplinas de projeto.

É notório o interesse crescente dos alunos, que colocam em prática aplicações em planejamento, desenho urbano e paisagismo, principalmente nas variáveis que podem ser interpretadas e quantificadas graficamente. A câmera termográfica é disputada entre os alunos, a lente grande angular também, o luminancímetro que ainda não conseguimos adquirir, mas que pontualmente tomamos emprestado de outro laboratório do IEE/USP, faz muita falta.

Para arquitetos e planejadores, imagens e observações visuais ajudam muito, por exemplo: 1) combinando medidas de emissividade com imagens termográficas para ler as temperaturas superficiais na escala do edifício e da cidade, ou 2) usando imagens termográficas para levantar índice de área foliar ou fator de visão de céu. Novas técnicas como essas são necessárias, incluindo mapeamentos, imagens, fotografias e outras interfaces gráficas. Pretende-se investir, nos próximos projetos, em equipamentos de qualidade com interface visual, incluindo câmeras termográficas com mais recursos, luminancímetro para uso interno e externo e câmera acústica para registro e análise de ruído com visualização da distribuição espacial do som em tempo real.

Por outro lado, para arquitetos e planejadores, um conhecimento básico de climatologia é essencial. Os modelos microclimáticos de simulação são complexos, trabalham com variáveis que não são familiares aos arquitetos e planejadores, demandam tempo e capacidade computacional. Os alunos que se envolvem no tema acabam por aprender porque não há outra forma de se fazer estudos preditivos de caráter quantitativo. Os modelos físicos em heliodon ou túnel de vento são utilíssimos, mas não respondem a todas as questões envolvidas no conforto ambiental urbano. Para os demais alunos, que tem este tema como parte do todo, mas não como algo central na pesquisa, o trabalho

\footnotetext{
100 Para uma breve descrição da trajetória do GD de conforto ambiental da FAUUSP, ver: DUARTE, Denise; GONÇALVES, Joana Carla Soares. Da física aplicada à qualidade ambiental: a trajetória do Grupo de Conforto Ambiental e Eficiência Energética e perspectivas futuras. In: Rosaria Ono, Vera Maria Pallamin. (Org.). AUT 50 Anos 1964-2014 Uma reflexão sobre o passado e o presente para uma visão do futuro. São Paulo: FAUUSP, 2014 (no prelo).
} 
de medições no real ajuda muito no entendimento dos fenômenos, e o trabalho em equipe com outros alunos, mais afins à simulação, torna-se mais produtivo, como vem acontecendo na disciplina da pós-graduação.

Até o momento, diferenças de escala entre arquitetura e urbanismo e áreas afins, como a meteorologia, são um obstáculo ainda a ser superado, especialmente com relação aos dados observacionais e modelagem; o chamado downscalling dos estudos de clima urbano para se entender o que acontece numa quadra, praça ou edifício ainda está sendo construído. 


\section{Considerações finais e conclusões}

Tendo em mente a interdependência o entre edifício e o ambiente urbano e as relações necessárias e desejadas entre o espaço interior e o exterior, a concepção do ambiente construído climaticamente responsável passa necessariamente:

- pelo entendimento dos fenômenos envolvidos na questão ambiental urbana em seus diferentes aspectos (climático, acústico, visual, qualidade do ar, mobilidade, etc.) (BROWN; GILLESPIE, 1995; EMMANUEL, 2005; WONG, CHEN, 2009);

- pela descrição adequada da cidade em modelos numéricos, para que se possa fazer estudos preditivos de diferentes cenários (ROBINSON, 2012);

- pelo acoplamento entre as diferentes escalas climáticas envolvendo a meteorologia e a geografia, com suas distintas contribuições (ROBINSON, 2012);

- pelo acoplamento entre os modelos microclimáticos e os Building Energy Simulation models em edifícios (ALLEGRINI, et al., 2012);

- pela integração dos índices de conforto térmico, visual, acústico, de qualidade do ar, de mobilidade, etc. para que os resultados possam ser referenciados em indicadores de qualidade para auxílio à tomada de decisão em planejamento;

- pela proposição de parâmetros passíveis de controle pelas legislações urbanas (geometria no desenho urbano e nos edifícios, revestimentos urbanos e dos edifícios, desempenho térmico, acústico e luminoso de materiais e componentes construtivos, impacto da vegetação, etc.) (ASSIS, 1995; ONG, 2002; DUARTE et al., 2004);

- pela integração de resultados sobre demanda de energia nas edificações associada à mudança climática, com avaliação de desempenho térmico de edifícios nos cenários climáticos atuais e futuros, que atendam as condições de conforto térmico diante das mudanças climáticas previstas.

A arquitetura e o urbanismo têm um papel importante a desempenhar nas estratégias de adaptação aos fenômenos climáticos urbanos, e essas ações são praticamente inexploradas do ponto de vista do planejamento, do desenho urbano e mesmo do projeto de edifícios.

No âmbito do setor público, os estudos de desempenho ambiental do ambiente construído, em especial aqueles relacionados aos microclimas urbanos e o consequente impacto na qualidade ambiental de espaços externos e desempenho de edifícios, têm o potencial de informar políticas públicas.

O novo plano diretor de São Paulo, em vigor desde 31 de julho de 2014, determina regras para o crescimento da cidade nos próximos 16 anos. Um dos objetivos é colocar moradia e trabalho mais próximos, enfrentando desigualdades sociais e territoriais. Para se atingir estes objetivos, várias estratégias foram definidas, tais como o enfretamento de áreas subutilizadas para habitação social, melhorar a mobilidade urbana, incentivar o crescimento próximo aos eixos de transporte, aumentar a participação popular nas decisões sobre o futuro da idade e incorporar a agenda ambiental. 0 plano e as revisões em curso da lei de uso, parcelamento e ocupação do solo, a lei de zoneamento e o código de edificações, incluindo a quota ambiental, criam uma oportunidade para governo e sociedade proporem novas formas de incorporação da infraestrutura verde nas regulações municipais.

A contribuição do grupo parte dos princípios que uma determinada meta de adensamento populacional está atrelada a diferentes possibilidades de forma urbana e que essas, por sua vez, exercem impactos distintos sobre a qualidade ambiental do espaço urbano. Ou seja, o grupo apoia a 
estratégia pública de reforçar o adensamento urbano ao longo dos principais eixos de transporte público da cidade, mas pergunta: com que forma urbana e quais tipologias arquitetônicas e quais os impactos ambientais de cada uma dessas escolhas?

Ao longo de 2013 e 2014, nas discussões para a revisão do PDE o grupo contribuiu alertando o poder público sobre os temas fundamentais do desempenho ambiental da forma urbana, sendo esses: conforto térmico do pedestre, acesso ao sol para edifícios e espaços abertos, conforto acústico nos edifícios e nos espaços abertos, mobilidade do pedestre, ventilação urbana para a dispersão de poluentes e o potencial de captação da energia solar para o consumo dos edifícios. Seguramente, o sucesso das metas estabelecidas pelo plano depende também das estratégias de implementação e da sua continuidade.

No final de 2014, nas discussões sobre a quota ambiental, novamente foram colocadas considerações para se atrelar a densidade construída pretendida pelo plano à infraestrutura verde, e sobre a necessidade de se especificar a massa vegetal a ser exigida de fato, tendo em vista os benefícios microclimáticos e demais serviços ecossistêmicos envolvidos. Os profissionais ligados à biodiversidade e ao desenho da paisagem também alertaram para outras questões.

Após os desdobramentos do trabalho de Ferreira (2012; 2015), que demostrou que a compensação ambiental vigente na cidade de São Paulo não funciona, audiências públicas sobre a compensação foram realizadas ${ }^{101}$ e uma Comissão Parlamentar de Inquérito - CPI da compensação já foi proposta por vereadores de São Paulo.

Ao mesmo tempo, a PMSP regulamenta a construção de equipamentos públicos nas áreas da Zona Especial de Preservação Ambiental - ZEPAM, sem sequer a obrigatoriedade da compensação ambiental direta, como reflorestamento em outra área com o mesmo tamanho, colocando em risco a vegetação de porte já existente nos parques e praças da cidade. A liberação para a construção de equipamento social em áreas verdes já estava prevista no Plano Diretor de 2014 e foi regulamentada pelo decreto no 55.955, de 26 de fevereiro de 2015. A Lei de Uso e Ocupação do Solo apenas define as contrapartidas no caso dessas ocupações. ${ }^{102}$

No momento do fechamento deste trabalho, aguarda-se o acontecimento da Conferência das Partes - COP21 ( $21^{\text {st }}$ Session of the Conference of the Parties), que será realizada em Paris, em novembro de 2015, com o tema For a Universal Climate Agreement. O objetivo da COP21 inclui metas de adaptação que sejam adotadas por todos os países do mundo, desenvolvidos e em desenvolvimento.

Ao mesmo tempo, o ano de 2015 caminha para quebrar o recorde entre os mais quentes já registrados no mundo. $\mathrm{O}$ primeiro semestre teve temperatura $0,85^{\circ} \mathrm{C}$ acima da média, ultrapassando o recorde de 2010, e foi o mais quente desde 1880 . A maior parte do planeta coberta por terra foi muito mais quente do que a média. Essas regiões incluem praticamente toda a Eurásia, América do Sul, África e o oeste da América do Norte. Toda a Austrália foi mais quente do que a média. Junho foi o terceiro mês este ano a quebrar os seus recordes, depois de março e maio. Os outros meses não ficam muito atrás: janeiro e fevereiro foram cada um o segundo mais quente, e abril foi o quarto mais quente. ${ }^{103}$

No Brasil, entre os anos de 1991 e 2012, mais de metade da população teve sua vida afetada por eventos climáticos extremos. Secas, enchentes e deslizamentos de terra atingiram 127 milhões de pessoas. $O$ número de registros cresceu $40 \%$ na década passada em comparação à anterior, segundo

\footnotetext{
101 Disponível em: <http://www.camara.sp.gov.br/blog/compensacao-ambiental-nao-funciona-diz-especialista/>. Acesso em: 26 de julho de 2015.

102 Disponível em: <http://www.oeco.org.br/salada-verde/29167-prefeitura-de-sao-paulo-abre-brecha-para-obras-publicasdesmatarem>. Acesso em: 26 de julho de 2015.
}

103 Disponível em: <https://www.wmo.int/media/content/january-june-2015-hottest-record-noaa>. Acesso em: 26 de julho de 2015. 
- Atlas Brasileiro dos Desastres Naturais. Tragédias recentes incluem a de Santa Catarina, em 2008, e a da serra fluminense, em 2011. Neste ano, um quinto dos municípios do país entrou em situação de emergência ou de calamidade pública. ${ }^{104}$

Em 26 de junho último, o Observatório do Clima - OC ${ }^{105}$ lançou uma proposta demostrando como o Brasil pode chegar a 2030 limitando suas emissões de gases de efeito-estufa - GEE a 1 bilhão de toneladas de gás carbônico equivalente, portanto, bastante totalmente focado nas estratégias de mitigação. O documento está sendo chamado de INDC (Contribuições Nacionalmente Determinadas Pretendidas, tradução livre de Intended Nationally Determined Contributions) da sociedade civil. As INDCs são metas que todos os países deverão apresentar até $1^{\circ}$ de outubro deste ano para que um acordo seja assinado na COP21. Para que o Brasil faça a sua parte na limitação do aquecimento global em $2^{\circ} \mathrm{C}$ e no corte de 1 trilhão de toneladas de carbono até 2100 , o Observatório do Clima diz que será preciso zerar o desmatamento, não só o ilegal, como prometeu a presidente há poucas semanas, limitar as emissões por uso de energia a cerca de 617 milhões de toneladas de $\mathrm{CO}_{2}$ e as do setor agropecuário a 280 milhões de toneladas de $\mathrm{CO}_{2}$. Manter esse limite pressupõe uma ação em políticas públicas sem paralelo no país desde a era Vargas. Isso inclui recuperar milhões de hectares em pastagens degradadas, ter $60 \%$ dos carros flex rodando com álcool em 2030 e congelar a expansão das termelétricas a óleo e a carvão. E todas as tecnologias consideradas estão disponíveis no país. Não entraram nessa conta os benefícios colaterais de tal ação: cidades mais habitáveis e menos vulneráveis, população mais saudável, um país mais verde, com maior biodiversidade e acesso aos serviços ecossistêmicos, como água potável. A proposta do Observatório do Clima para a INDC do Brasil inclui também a definição de um Plano Nacional de Adaptação às Mudanças do Clima, que deveria ser concluído até 2016, incluindo, dentre outros, o planejamento de expansão de infraestrutura urbana e os programas de habitação para população de baixa renda.

Segundo o $\mathrm{OC}^{106}$ o Brasil é um dos dez maiores emissores de $\mathrm{CO}_{2}$ do planeta. Devido às emissões do desmatamento descontrolado da última metade do século $X X$, também pode ser considerado um dos cinco países que mais contribuíram para o aumento verificado hoje na temperatura global.

Segundo opiniões de especialistas divulgadas recentemente, ${ }^{107}$ os compromissos que foram apresentados pelo Brasil até o momento, a caminho da COP21, não sinalizam um esforço de descarbonização. A proposta mais enfatizada é zerar o desmatamento 'ilegal' até 2030, ou seja, a promessa é levar mais 15 anos para se cumprir a lei vigente no país.

Nesse cenário, pouco ou nada se fala sobre a escala das cidades, sobre as esferas municipais, onde muitas das ações necessárias precisam ser concretizadas. Como as metas nacionais, sejam quais forem, vão se refletir nas esferas municipais? Segundo o IBGE (2015) o mais alto escalão da urbanização brasileira é representado por 26 grandes concentrações urbanas, formadas, em sua maioria, por arranjos populacionais com população acima de 750 mil habitantes. Das grandes concentrações urbanas, 12 são aglomerações de caráter metropolitano, destacando-se aquelas com população superior a 2, 5 milhões de habitantes: São Paulo, Rio de Janeiro, Belo Horizonte, Recife, Porto Alegre, Salvador, Brasília, Fortaleza e Curitiba. Se o Brasil é predominantemente urbano, qual o papel das cidades nas estratégias de mitigação e adaptação?

\footnotetext{
104 Disponível em: <http://www1.folha.uol.com.br/fsp/opiniao/225166-a-parte-que-nos-cabe.shtml>. Acesso em: 26 de julho de 2015.

105 Disponível em: < http://www.oc.org.br/>. Acesso em: 26 de julho de 2015.

106 Disponível em: http://www.observatoriodoclima.eco.br/wp-content/uploads/2015/06/notatecnica_oc.pdf. Acesso em: 26 de julho de 2015.

107 Disponível em: <http://www1.folha.uol.com.br/fsp/opiniao/225166-a-parte-que-nos-cabe.shtml> e <http://www.observatoriodoclima.eco.br/proposta-do-brasil-em-paris-vai-ser-ruim/>. Acesso em: 26 de julho de 2015.
} 
Em encontro recente, realizado em 20 de julho de 2015, a convite do Papa Francisco, poucas semanas depois da divulgação da encíclica Laudato Si, sobre o cuidado da casa comum, ${ }^{108}$ sessenta prefeitos de todo o mundo, incluindo alguns do Brasil, estiveram reunidos no workshop Escravidão Moderna e Mudanças Climáticas: o Compromisso das Cidades. Da declaração dos prefeitos brasileiros consta o reconhecimento da responsabilidade dos governos locais, o pedido de transferência de recursos e tecnologias dos países desenvolvidos aos países em desenvolvimento diretamente às cidades, e a reivindicação pelo reconhecimento pelas Nações Unidas "dos governos locais como atores fundamentais na promoção da sustentabilidade global e do desenvolvimento humano." 109

Sendo assim, nas esferas municipais, que a meta de zerar a perda de cobertura florestal (legal e ilegal, e dentro de um prazo mais curto do que o anunciado pelo governo brasileiro), se estenda aos ambientes urbanos, minimamente com a revisão dos mecanismos de compensação ambiental que já se sabe que não funcionam a contento e que estão sendo questionados. Que a infraestrutura verde (e azul) seja tratada de fato como uma rede, tão importante quanto o abastecimento de água e energia, esgotamento sanitário e transporte, tendo em vista os benefícios microclimáticos que podem ser incluídos no plano de adaptação aos fenômenos de aquecimento urbano, atuais e futuros, bem como os demais serviços ecossistêmicos prestados.

Neste verão de 2015, pessoas continuam morrendo na Índia e no Paquistão como consequência do calor extremo e da falta de infraestrutura adequada para o enfrentamento dessas questões. A Europa atravessa um verão escaldante, agora um pouco mais preparada do que estava em 2003, tendo em vista os planos de adaptação implementados.

As mudanças climáticas previstas já estão em curso, e tudo indica que há uma antecipação dos cenários em cerca de 20 anos, segundo Carlos Nobre. A aglomeração urbana de São Paulo amplifica esses fenômenos e pode servir de alerta para o país. Lester Brown, em entrevista recente na semana do meio ambiente, ${ }^{110}$ diz que a estiagem dos últimos anos em São Paulo é um sinal evidente das alterações climáticas em curso.

A infraestrutura urbana precisa ser planejada, projetada e implementada para lidar com extremos cada vez mais frequentes, para muitos especialistas, o chamado novo normal (the new normal). Para tanto, há a necessidade de se formar equipes interdisciplinares que incluem profissionais arquitetos e urbanistas capacitados para o entendimento desses fenômenos e capazes de planejar e projetar as estratégias necessárias de adaptação e mitigação, na escala da cidade e do edifício.

As tendências de aquecimento urbano e aumento dos casos de ondas de calor não serão resolvidos com a presença da vegetação nas cidades. Segundo Stone (2012), nenhum destes cenários irá reverter as tendências de aquecimento a longo prazo, mas a combinação dessas estratégias pode diminuir o ritmo de aquecimento nos próximos anos e moderar os eventos de clima extremo.

Nos cenários climáticos atuais, simulados para abril de 2013 e fevereiro de 2014, os resultados microclimáticos do parque central em meio ao entorno adensado, com torres de cerca de 15

108 Disponível em: <http://www.connect4climate.org/images/uploads/papa-francesco_20150524_enciclica-laudatoPortugues.pdf>. Acesso em: 26 de julho de 2015.

109 Disponível em: http://www.observatoriodoclima.eco.br/prefeitos-pedem-recursos-para-combater-mudancasclimaticas/>. Acesso em: 26 de julho de 2015.

110 Lester Brown, em entrevista a Lucas Mendes, Globonews Milênio, em 1 de junho de 2015. Quando perguntando sobre a seca na California e depois em São Paulo, Lester Brown responde que "o desmatamento no litoral do Atlântico vai exacerbar isso, já está contribuindo, porque reduz a capacidade de reciclar a chuva no interior. Se há árvores lá, quando chove, um quarto da água escorre e três quartos são reciclados para o interior. Mas, se não há árvores, três quartos escorrem imediatamente e muito menos água vai para o interior, então eu diria que São Paulo é uma das primeiras provas do efeito das mudanças climáticas. Acho que a maioria das pessoas ainda não percebe isso, e também não posso garantir, mas me parece que uma das manifestações da mudança climática é o que está acontecendo em São Paulo." 
pavimentos, demonstraram uma redução do desconforto às $13 \mathrm{~h}$ da ordem de $10^{\circ} \mathrm{C}$ para o TEP e de $13,4^{\circ} \mathrm{C}$ para o $\mathrm{PET}$, quando comparado com o cenário base, com apenas torres.

Nos cenários futuros, com o aumento expressivo da temperatura do ar, o parque central foi novamente testado, além de um cenário com o parque conectado à arborização das vias, com um incremento de cerca de $20 \%$ na vegetação, mas com o mesmo índice de área foliar dos casos anteriores. Para o futuro intermediário (2045 a 2074), os resultados preliminares apresentaram uma diferença às $12 \mathrm{~h}$ para o TEP de $5^{\circ} \mathrm{C}$ e $7^{\circ} \mathrm{C}$, e para o PET de $6^{\circ} \mathrm{C}$ e $8,5^{\circ} \mathrm{C}$, no nível do pedestre, comparando-se os cenários b (parque central) e c (parque central com árvores nas vias), com o cenário a (caso base, somente torres), respectivamente, o que é bastante significativo para conforto humano.

A estratégia de manter uma vegetação arbórea com uma massa vegetal significativa conectada entre pequenos parques urbanos, com arborização nas vias, para uma melhor distribuição, formando uma rede de infraestrutura verde e densa na cidade, pode contribuir diretamente, no mínimo, para a adaptação da população aos eventos extremos, criando oportunidades de adaptação, provocando um efeito oásis (park cool island - $P C l$ ) durante as ondas de calor; e também, indiretamente, para a mitigação dos fenômenos de aquecimento urbano, por diminuir as temperaturas de superfície pelo sombreamento, por aumentar as perdas de calor por evaporação e, consequentemente, diminuir o armazenamento de calor no tecido urbano. 


\section{Bibliografia consultada e referenciada}

1. AKBARI, H. et al.. Cooling our communities. Environmental Protection Agency, 1992.

2. AKBARI, H., KURN, D., BRETZ, S. HANFORD, J.. Peak Power and Cooling Energy Savings of Shade Trees. Energy and Buildings, v. 25, p.139-148, 1997.

3. AKBARI, H.; POMERANTZ, M; TAHA, H.. Cool surface energy use and shade trees to reduce energy use and improve air quality in urban areas. Solar Energy, v.70, n.3, p. 295-310, 2001.

4. ALI-TOUDERT, F., MAYER, H.. 2007. Thermal comfort in an east-west oriented street canyon in Freiburg (Germany) under hot summer conditions. Theoretical and Applied Climatology, 87(14), 223-237.

5. ALI-TOUDERT, F.; MAYER, H. Effects of asymmetry, galleries, overhanging façades and vegetation on thermal comfort in urban street canyons. Solar Energy, Tampa, vol. 81, p. 742754, 2007.

6. ALLEGRINI, Jonas, DORER, Viktor; CARMELIET, Jan. Influence of the urban microclimate in street canyons on the energy demand for space cooling and heating of buildings. Energy and Buildings, v.55, p. 823-832, 2012.

7. ALVES, Carolina A.; Duarte, Denise Helena Silva; GONÇALVES, Fabio L. T.; TATEOKA, Suzana. Thermal comfort in residential buildings for the elderly under climate changes context. In: PLEA 2014 - Passive and Low Energy Architecture, 2014, Ahmedabad. Proceedings... Sustainable Habitat for Developing Societies. Ahmedabad: CEPT University, 2014.

8. ALVES, Carolina A.; DUARTE, Denise; GONÇALVES, Fabio L. T. Residential Buildings Thermal Performance and Comfort for the Elderly under Climate Changes Context in the city of São Paulo, Brazil. Energy and Buildings, 2015a (in press).

9. ALVES, Carolina A.; DUARTE, Denise; GONÇALVES, Fabio L. T.. Resiliência das edificações às mudanças climáticas na região metropolitana de São Paulo. Parte 1: revisão crítica e contextualização. Artigo submetido ao ENCAC 2015 (em análise, 2015b).

10. ALVES, Carolina A.; DUARTE, Denise; GONÇALVES, Fabio L. T.. Resiliência das edificações às mudanças climáticas na região metropolitana de São Paulo. Parte2: estudo de caso desempenho térmico de edifícios residenciais de idosos. Artigo submetido ao ENCAC 2015 (em análise, 2015c).

11. ALVES, Carolina A.; DUARTE, Denise; GONÇALVES, Fabio L. T.; TATEOKA, Suzana. Thermal performance and comfort in traditional residential buildings for the elderly under climate changes context. In: Third International Conference on Countermeasures to Urban Heat Island, 2014, Venice. Proceedings.... Venice, 2014. p. 476-487.

12. ALVES, Carolina Abrahão. Resiliência das Edificações às Mudanças Climáticas na Região Metropolitana de São Paulo. Estudo de caso: desempenho térmico de edifícios residenciais para idosos. 2015. Dissertação (Mestrado em Arquitetura e Urbanismo) - Universidade de São Paulo.

13. ARAGÃO, L. E.; SHIMABUKURO, Y.E.; SANTO, F. D. B.; WILLIAMS, M. Landscape patterns ad spatial variability of leaf area index in eastern Amazonia. Forest Ecology and Management. 211, 2005, 240-253.

14. ARNFIELD, John. Two decades of urban climate research: a review of turbulence, exchanges of energy and water, and the urban heat island. International Journal of Climatology, 23: 1-26 (2003). 
15. ASSIS, E. S.. Abordagem do Clima Urbano e Aplicações no Planejamento: Reflexões sobre uma trajetória. In: VIII Encontro Nacional sobre Conforto no Ambiente Construído, 2005, Maceió. Anais... Maceió: ENCAC-ELACAC, 2005.

16. ASSIS, E. S.. Aplicações da climatologia urbana no planejamento da cidade: revisão dos estudos brasileiros. RUA. Revista de Arquitetura e Urbanismo, v. 9, p. 20-25, 2007.

17. ASSIS, E. S.. Bases para a determinação dos recuos e volumetria dos edifícios, considerando a insolação e iluminação natural, na revisão da lei de uso e ocupação do solo de Belo Horizonte, MG. In: III Encontro Nacional de Conforto no Ambiente Construído, 1995, Gramado. Anais... Gramado: ANTAC, 1995. p. 511-516.

18. ASSIS, E. S.. Bases teóricas para a aplicação da climatologia ao planejamento urbano. In: IV Encontro Nacional de Conforto no Ambiente Construído, 1997, Salvador. Anais... Salvador: FAUUUFBA/LACAM-ANTAC, 1997. v. 1. p. 134-139.

19. ASSIS, E. S.. Editorial. Fórum Patrimônio: Ambiente Construído e Patrimônio Sustentável (UFMG. Online), v. 3, p. 189, 2009.

20. ASSIS, E. S.. Impacto da forma urbana na mudança climática: método para previsão do comportamento térmico e melhoria do desempenho do ambiente urbano. São Paulo, 2000. Tese (Doutorado em Arquitetura) Faculdade de Arquitetura e Urbanismo, Universidade de São Paulo, 2000.

21. ASSIS, E. S.. Mecanismos de desenho urbano apropriados à atenuação da ilha de calor: análise de desempenho de áreas verdes urbanas em clima tropical. Belo Horizonte: 1990 (Dissertação) Mestrado em Arquitetura e Urbanismo.

22. ASSIS, E. S.. Planejamento urbano e clima: um enfoque disciplinar no curso de especialização em urbanismo da Escola de Arquitetura da Universidade Federal de Minas Gerais. In: IV Encontro Nacional de Conforto no Ambiente Construído, 1997, Fortaleza. Anais...Fortaleza: ANTAC, 1997.

23. ASSIS, E. S.. Urban climate applications on city planning: reviewing the Brazilian studies. In: $6^{\text {th }}$ International Conference on Urban Climate, 2006, Göteborg. Proceedings... Göteborg University, 2006. v. 1. p. 663-666.

24. BARBIRATO, Gianna Melo. Análise do ambiente térmico urbano e aplicação de modelo de balanço de energia. São Carlos, 1998. 173p. Tese (Doutorado) - Escola de Engenharia de São Carlos, Universidade de São Paulo.

25. BARCLAY, H. J.; TROFYMOW, J. A.; LEACH, R. I. Assessing bias from boles in calculating leaf area index in immature Douglas-fir with the LI-COR canopy analyzer. Agricultural and Forest Meteorology. 100, 2000, 255-260.

26. BENEDICT, Mark A.; McMAHON, Edward T.. Green Infrastructure: Smart Conservation for the 21st Century. The Conservation Fund. [s.d].

27. BITAN, Arieh. The high climatic quality city of the future. Atmospheric Environment, v.26B, n. 3, 313 329, 1992.

28. BITTENCOURT, Leonardo Salazar et al. A influência da relação entre taxa de ocupação $\times$ no de pavimentos no potencial de ventilação natural dos ambientes internos e externos. In: IV ENCAC - Encontro Nacional de Conforto no Ambiente Construído, 1997, Salvador. Anais... Salvador, FAUUUFBA/LACAM-ANTAC, 1997, p. 102-106. 
29. BOLTON, David. The computation of equivalent potential temperature. Monthy Weather Review, American Meteorological Society, v.108, 1046-1053, July 1980.

30. BONAN, Gordon. Ecological Climatology. Concepts and Applications. 2 ed. Cambridge: Cambridge University Press, 2010.

31. BOSSELMANN, Peter. Urban Transformation. Understanding city design and form. Washington: Island Press, 2008.

32. BOWLER, D. et al. Urban greening to cool towns and cities: A systematic review of the empirical evidence. Landscape and Urban Planning, 97, 147-155, 2010.

33. BRANDÃO, Rafael Silva. Acesso ao sol e à luz natural: Avaliação do impacto de novas edificações no desempenho térmico, luminoso e energético no seu entorno. 2004. Dissertação (Mestrado em Arquitetura) Faculdade de Arquitetura e Urbanismo, Universidade de São Paulo, 2004.

34. BRANDÃO, Rafael Silva. As interações espaciais urbanas e o clima. São Paulo, 2009. Tese (Doutorado em Arquitetura e Urbanismo - Faculdade de Arquitetura e Urbanismo, Universidade de São Paulo, 2009.

35. BRASIL. Ministério de Minas e Energia (MME). Balanço energético nacional 2014: ano base 2013. Rio de Janeiro: Empresa de Pesquisa Energética, EPE, 2013.

36. BREDA, N.J. Ground-based measurements of leaf area index: a review of methods, instruments and current controversies. Journal of Experimental Botany, 54, 2403-2417, 2003.

37. BROWN R. D.. Design with Microclimate. Washington/Covelo/London: Island Press, 2010.

38. BROWN, R. D..; GILLESPIE, T. J.. Microclimatic Landscape Design: creating thermal comfort and energy efficiency. New York: John Wiley \& Sons, 1995.

39. BRUSE M. Modeling and Strategies for improved urban climates. In: International Conference on Urban Climatology and International Congress of Biometeorology. Proceedings... Sydney, 1999.

40. BRUSE M., SKINNER C. J. Rooftop Greening and Local Climate: A Case Study in Melborne. In: Biometeorology and Urban Climatology at the Turn of the Millennium, WMO, 21-25, 1999.

41. BRUSE, M. Simulating human thermal comfort and resulting usage patterns of urban open spaces with a Multi-Agent System. In: Wittkopf, St. Tan, B. K. (eds.). PLEA 2007. The 24th International Conference on Passive and Low Energy Architecture. Proceedings... p.699-706.

42. BRUSE, M. Simulating the Effects of Urban Environmental on Microclimate with a ThreeDimensional Numerical Model. In: Climate and Environmental Change. Conference Meeting of the Commission on Climatology, Évora, 1998. Proceedings... Évora, 1998.

43. BRUSE, M., FLEER, H. 1998. Simulating surface-plant-air interactions inside urban environments with a three-dimensional numerical model. Environmental Software and Modelling, v.13, 373384.

44. BRUSE, Michael. ENVI-met website. Retrieved on April 5, 2012 from: http://www.envimet.com/

45. BURDETT, R. (ed.), SUDJIC, D. (ed). Living in the endless city: The Urban Age Project. The London School of Economics and Deutsche Bank's Alfred Herrhausen Society, Phaidon, London, 2011.

46. CA V.T., ASAEDA T, ABU E.M. Reduction in air conditioning energy caused by a nearby park. Energy and Buildings, 1998, 29, 83-92. 
47. $C A B E, 2010$. Community green: using local spaces to tackle inequality and improve health. London: Commission for Architecture and Built Environment. Disponível em: http://webarchive.nationalarchives.gov.uk/20110118095356/http://www.cabe.org.uk/files/com munity-green.pdf. Acesso em agosto de 2014.

48. CATALANO, M. New York City Microclimate Policy. Applying Green Infrastructure to Mitigate Environmental Health Impacts caused by the Urban Heat Island Effect and Heat Waves. A Platform for Climate Change Resiliency in New York City. Disponível em: https://www.pratt.edu/tiny mce/plugins/imagemanager/files/MCatalano.pdf. Acesso em: 23 de julho de 2015.

49. CBCS, PNUMA, MMA. Aspectos da Construção Sustentável no Brasil e Promoção de Políticas Públicas Subsídios para a Promoção da Construção Civil Sustentável. Conselho Brasileiro para a Construção Sustentável, Programa das Nações Unidas para o Meio Ambiente, Ministério do Meio Ambiente, [s.I.], 2014.

50. CHANDLER, T. J.. Urban climatology and its relevance to urban design. Geneva, 1976. WMO Technical Note 149.

51. CHANDLER, Tony. The Climate of London. Random House, 1965. Disponível em:< http://www.urban-climate.org/resources/classic-texts/. Acesso em: 21 de julho de 2015.

52. CHANG K. F; CHOU P.C.. Measuring the influence of the greening design of the building environment on the urban real estate market in Taiwan. Building and Environment, 45, 10, 2057-2067, 2010

53. CHAPMAN, Lee, AZEVEDO, Juliana Antunes, PRIETO-LOPEZ, Tatiana. Urban heat \& critical infrastructure networks: A viewpoint. Urban Climate, 3, 7-12, 2013.

54. CHATZIDIMITRIOU, A.; CHRISSOMALLIDOU, N.; YANNAS, S. Microclimate modifications of an urban street in northern Greece. In: PLEA 2005 - Passive and Low Energy Architecture, 2005, Beirut. Proceedings ... Beirut: PLEA International, 2005, p. 689-694.

55. CHEN, J. M., BLACK, T. A. Foliage area and architecture of clumped plant canopies from sunfleck size distributions. Agricultural and Forest Meteorology, 60, 249-266, 1992.

56. CHEN, M. J.; GOVIND, A.; SONNENTAG, O.; ZHANG, Y.; BARR, A.; AMIRO. B. Leaf area index measurements at Fluxnet-Canada forest sites. Agricultural and Forest Meteorology, 140, 257$268,2006$.

57. CHEN, Yu, WONG, Nyuk Hien. Thermal benefits of city parks. Energy and Buildings, 38, 2006, 105-120.

58. CHEN, Yung-Chang; LIN, Tzu-Ping; MATZARAKIS, Andreas. Comparison of mean radiant temperature from field experiment and modelling: a case study in Freiburg, Germany. Theoretical and Applied Climatology, 118, 535-551, 2014.

59. CHENG, Vicky et al. Urban Form, Density and Solar Potential. In: PLEA2006. The $23^{\text {rd }}$ Conference on Passive and Low Energy Architecture. Proceedings... Geneva, Switzerland, 2006.

60. CHENG, Vicky. Human Perception of Urban Density. PhD Thesis, Department of Architecture, University of Cambridge, 2010.

61. CHOW, Winston; ROTH, Matthias. Temporal dynamics of the urban heat island of Singapore. International Journal of Climatology, 26, 2243-2260, 2006.

62. City of Boston. A Climate of Progress. City of Boston Climate Action Plan Update 2011. April, 2011. Disponível em: 
<http://www.cityofboston.gov/images documents/A\%20Climate\%20of\%20Progress\%20\%20CAP\%20Update\%202011 tcm3-25020.pdf>. Acesso em: 23 de julho de 2015.

63. City of New York. PlanNYC. A greener, greater New York. April, 2011. Disponível em: <http://www.nyc.gov/html/planyc/downloads/pdf/publications/planyc 2011 planyc full repor t.pdf>. Acesso em: 23 de julho de 2015.

64. City of Stuttgart. Climate change - challenge facing urban climatology. Office of Urban Planning and the Environment, Environmental Protection Office, Section of Urban Climatology in association with the Communication Department, 2010.

65. DAVIES, M. et al. Strategies for the modification of the urban climate and the consequent impact on building energy use. Energy Policy, 36 (2008) 4548-4551.

66. DAVIS, Mike. Planeta Favela. São Paulo: Boitempo, 2007.

67. DEARDORFF, J.W. Efficient Prediction of Ground Surface Temperature and Moisture with a Inclusion of a Layer of Vegetation. Journal of Geophysical Research, Colorado, 83, 1978.

68. DEMAREZ, V.; DUTHOIT, S.; BERET, F.; WEISS, M.; DEDIEU, G. Estimation of leaf area and clumping indexes of crops with hemispherical photographs. Agricultural and Forest Meteorology. 148, 2008, 644-655.

69. DIMOUDI, Argiro; NIKOLOPOULOU, Marialena. Vegetation in the Urban Environment: Microclimatic Analysis and Benefits. Energy and Buildings, v.35, n.1, p. 69-76, 2003.

70. DUARTE, Denise, BRANDÃO, Rafael, PRATA, Alessandra. Environmental Criteria Incorporation in a Brazilian Building Code. In: PLEA 2004. The 21th Conference on Passive and Low Energy Architecture. Proceedings... Eindhoven, 2004.

71. DUARTE, Denise. A inclusão de questões relacionadas aos microclimas urbanos nas regulamentações municipais no Brasil. In: Sinopses, Especial Tecnologia, São Paulo, FAUUSP, out. 2001, p.24-34.

72. DUARTE, Denise. Densidade e qualidade ambiental: o inevitável, o desejável e o possível. In: GALICIA, Sérgio, FREIXANET, Victor. Hábitat Sustentable. Mexico D.F.: UAM Azcapotzalco, 2012, p.85-99.

73. DUARTE, Denise. Estado da arte em clima urbano e planejamento. In: NUTAU/FAUUSP, Anais... São Paulo, 2002.

74. DUARTE, Denise. O Clima Urbano e o Ambiente Construído. In: Gonçalves, Joana Carla Soares; Bode, Klaus. (Org.). Edifício ambiental. São Paulo: Oficina de Textos, 2015a, p. 155-179.

75. DUARTE, Denise. Padrões de Ocupação do Solo e Microclimas Urbanos na Região de Clima Tropical Continental. Tese (Doutorado em Arquitetura e Urbanismo). São Paulo: FAUUSP, 2000. Faculdade de Arquitetura e Urbanismo, Universidade de São Paulo.

76. Duarte, Denise. Variáveis urbanísticas e microclimas urbanos - modelo empírico e proposta de um indicador. Fórum Patrimônio: Ambiente Construído e Patrimônio Sustentável (UFMG. Online). Clima Urbano e Planejamento das Cidades, vol. 4, n. 2 (2009). Disponível em: $<$ http://www.forumpatrimonio.com.br/>. Acesso em: agosto, 2011.

77. DUARTE, Denise. Vegetation and climate-sensitive public places. In: EMMANUEL, Rohinton. (Org.). Urban climate challenges in the Tropics: rethinking planning and design opportunities. Glasgow: Imperial College Press, 2015b (in press).

78. DUARTE, Denise; GONÇALVES, Joana Carla Soares. Da física aplicada à qualidade ambiental: a trajetória do Grupo de Conforto Ambiental e Eficiência Energética e perspectivas futuras. In: 
Rosaria Ono, Vera Maria Pallamin. (Org.). AUT 50 Anos 1964-2014 Uma reflexão sobre o passado e o presente para uma visão do futuro. São Paulo: FAUUSP, 2014 (no prelo).

79. DUARTE, Denise; GONÇALVES, Joana Carla Soares. Environment and Urbanization: Microclimatic Variations in a Brownfield Site in Sao Paulo, Brazil. In: $23^{\text {rd }}$ International Conference PLEA 2006 Passive and Low Energy Architecture, 2006, Geneve. Proceedings... Clever Design, Affordable Comfort. A Challenge for Low Energy Architecture and Urban Planning. Fribourg: Université de Genève, 2006. v. 2. p. 497-503.

80. DUARTE, Denise; GONÇALVES, Joana Carla Soares; MONTEIRO, Leonardo Marques. Urban design and thermal comfort: assessments of urban spaces in Barra Funda, a brownfield site in Sao Paulo, by means of site measurements and predictive simulations. In: Seventh Conference on Coastal Atmospheric and Oceanic Prediction and Processes joint with the Seventh Symposium on the Urban Environment, 2007, San Diego. Proceedings... , San Diego, 2007.

81. DUARTE, Denise; GONÇALVES, Joana Carla Soares; MONTEIRO, Leonardo Marques. Desenho urbano e conforto térmico: avaliação dos espaços abertos da Barra Funda, em São Paulo, por meio de levantamentos de campo e simulação preditiva. In: ENCAC / ELACAC 2007 - IX Encontro nacional e V Encontro latino-Americano de Conforto no Ambiente Construído, 2007, Ouro Preto. Anais... , 2007.

82. DUARTE, Denise; SERRA, Geraldo Gomes. Padrões de Ocupação do Solo e Microclimas Urbanos na Região de Clima Tropical Continental. Pós. Revista do Programa de Pós Graduação em Arquitetura e Urbanismo da FAU/USP, São Paulo, v. n.9, n.junho, p. 88-107, 2001.

83. DUARTE, Denise; SERRA, Geraldo Gomes. Padrões de ocupação do solo e microclimas urbanos. Téchne. Revista de Tecnologia da Construção, São Paulo, v. 64, p. 46-49, 2002

84. DUARTE, Denise; SERRA, Geraldo. G. Padrões de ocupação do solo e microclimas urbanos na região de clima tropical continental brasileira. Correlações e proposta de um indicador. Ambiente Construído, Porto Alegre, v. 3, n. n.2, p. 7-20, 2003.

85. DUARTE, Denise; SHINZATO, Paula; GUSSON, Carolina dos Santos; ALVES, Carolina A. The impact of vegetation on urban microclimates to counterbalance built density in a subtropical changing climate. In: PLEA 2014 - Passive and Low Energy Architecture, 2014, Ahmedabad. Proceedings... Sustainable Habitat for Developing Societies. Ahmedabad: CEPT University, 2014.

86. DUARTE, Denise; SHINZATO, Paula; GUSSON, Carolina dos Santos; ALVES, Carolina A.. The impact of vegetation on urban microclimate to counteract the increase in built density in a tropical changing climate. In: Third International Conference on Countermeasures to Urban Heat Island, 2014, Venice. Proceedings... Venice, 2014. p. 668-679.

87. DUARTE, Denise; SHINZATO, Paula; GUSSON, Carolina; ALVES, Carolina A. The Impact of Vegetation on Urban Microclimate to Counterbalance Built Density in a Subtropical Changing Climate. Urban Climate, 2015 (em análise, após revisões).

88. ECHENIQUE, Marcial. Models: a discussion. In: Martin, Leslie; March, Lionel. Urban space and structures. Cambridge University Press, 2010.

89. EDWARDS, Brian, HYETT, Paul (colab.) Rough Guide to Sustainability. London: RIBA, 2002.

90. EMMANUEL, M. Rohinton. A hypothetical "shadow umbrella" for thermal comfort enhancement in the equatorial urban outdoors. Architectural Science Review, 36(4): 25-36, December 1993.

91. EMMANUEL, M. Rohinton. An Urban Approach to Climate-Sensitive Design. Strategies for the Tropics. New York: Spon Press, 2005. 
92. EnergyPlus Engineering Reference, 2014. Disponível em: < http://apps1.eere.energy.gov/buildings/energyplus/pdfs/engineeringreference.pdf>. Acesso em: 23 de julho de 2015.

93. ENVI-met 4.0. In: The seventh International Conference on Urban Climate (ICUC-7), 29 June - 3 July 2009, Yokohama, Japan. 2009. Proceedings... Disponível em: <http://www.ide.titech.ac.jp/ icuc7/extended_abstracts/pdf/382880-2-090514010851002.pdf>. Acesso em: julho de 2013.

94. ERELL, E.; PEARLMUTTER, D.; WILLIAMSON, T.. Urban Microclimate: Designing the Spaces between Buildings. London: Earthscan, 2010.

95. FANGER, P. O. Thermal comfort: analysis and application in environment engineering. New York: McGraw Hill, 1972.

96. FAO. Food and Agriculture Organization of the United Nations. Trees Connecting People: In Action Together. FAO collaborative meeting on urban \& peri-urban forestry. Proceedings... diurnal and seasonal variations. Bogotá, Colombia, 2008.

97. FERREIRA, João Sette Whitacker (coord.). Produzir casas ou construir cidades? Desafios para um novo Brasil urbano. Parâmetros de qualidade para a implementação de projetos habitacionais e urbanos. São Paulo: LABHAB; FUPAM, 2012.

98. FERREIRA, Luciana S. Manejo da vegetação na cidade de São Paulo: supressão e compensação. O caso do Distrito da Vila Andrade. Dissertação (Mestrado) - Faculdade de Arquitetura e Urbanismo, Universidade de São Paulo, 2012.

99. FERREIRA, Luciana S. Vegetation Management in São Paulo, Brazil: Clearing of Urban Vegetation and Environmental Compensation. In: Johnston, M., Percival, G. eds. (2015) Trees, People and the Built Environment II. Institute of Chartered Foresters: Edinburgh, 2015.

100. FRANCISCO, Rúbia C. A. Clima urbano: um estudo aplicado a Belo Horizonte, MG. Belo Horizonte: EA UFMG, 2012. 122 p. Dissertação (Mestrado) - Escola de Arquitetura, Universidade Federal de Minas Gerais, Belo horizonte, 2012.

101. FREITAS, E. D. Circulações locais em São Paulo e sua influência sobre a dispersão de poluentes. Tese (Doutorado em Meteorologia). São Paulo, IAG-USP, 2003. Instituto de Astronomia, Geofísica e Ciências Atmosféricas. Universidade de São Paulo.

102. FREITAS, E. D.; SILVA DIAS, P. L. Alguns efeitos de áreas urbanas na geração de uma ilha de calor. Revista Brasileira de Meteorologia, 20 (3), 355-366, 2005.

103. FREITAS, E.D.; SILVA DIAS, P.L; ROZOFF, C.M; COTTON, W.R. Interactions of an urban heat island and sea-breeze circulations during winter over the metropolitan area of São Paulo, Brazil. Boundary-Layer Meteorology, v.122, p. 43-65, 2007.

104. FROTA, Anésia Barros. Clima Local e Micro-Clima na Cidade Universitária. Dissertação (Mestrado em Arquitetura e Urbanismo). Faculdade de Arquitetura e Urbanismo. Universidade de São Paulo, 1983.

105. FUTCHER, Julie; MILLS, Gerald. No building is an 'energy' island: the cautionary tale of the Fryscaper. Urban Climate News, n.49, Sept. 2013, p.15-17. Disponível em: <www.urbanclimate.org>. Acesso em: 13/11/2013.

106. GEIGER, Rudolf. Manual de Microclimatologia. O clima da camada de ar junto ao solo. Lisboa: Fundação Calouste Gulbenkian, 1980.

107. GIRADET, Herbert. Creating Sustainable Cities. Schumacher Briefings n.2. Bristol: Green Books, 2003. 
108. GIRIDHARAN, R. et al. Lowering the outdoor temperature in high-rise high-density residential developments of coastal Hong Kong: The vegetation influence. Building and Environment, 43, 2008, p.1583-1595.

109. GIVONI B. Impact of Planted Areas on Urban Environmental Quality - A review. Atmospheric Environment. v.25, n. 3, 1991, p. 289-299.

110. GIVONI, Baruch. Climate considerations in building and urban design. New York: J. Wiley \& Sons, 1998.

111. GIVONI, Baruch. Man, Climate and Architecture. Applied Science, 1969.

112. GIVONI, Baruch. Urban Design in Different Climates. Geneva: World Meteorological Organization - WMO/TD No. 346, 1989.

113. GOLDBERG, Valeri; KURBJUHN, Cornelia; BERNHOFER, Christian. How relevant is urban planning for the thermal comfort of pedestrians? Numerical case studies in two districts of the City of Dresden (Saxony/Germany). Meteorologische Zeitschrift, v.22, n. 6, 739-751, January, 2014.

114. GONÇALVES, Joana et al. Adensamento urbano e desempenho ambiental no centro da cidade de São Paulo. In: XI Encontro Nacional e VII Encontro Latino-Americano de Conforto no Ambiente Construído, 2011, Búzios. Anais... Búzios, FAUUFRJ, 2011.

115. GONÇALVES, Joana. Sustentabilidade urbana. AU, São Paulo, n.212, 2011.

116. GONSAMO, A., PELLIKKA, P. The computation of foliage clumping index using hemispherical photography. Agricultural and Forest Meteorology, 149, 1781-1787, 2009.

117. GOWER, S. Direct and Indirect Estimation of Leaf Area Index, $\mathrm{f}_{A P A R}$, and Net Primary Production of Terrestrial Ecosystems. Remote Sensing of Environment. 70, 29-51, 1999.

118. GRIMMOND, S. et al. Initial results from Phase 2 of the international urban energy balance model comparison. International Journal of Climatology, 31, p.244-272, 2011.

119. GRIMMOND, S. et al. The international urban energy balance models comparison project: first results from phase 1. Journal of Applied Meteorology and Climatology, 49, p.1268-1292, 2010.

120. GROAT, Linda; WANG, David. Architectural Research Methods. 2ed. New Jersey: John Wiley \& Sons, 2013.

121. GUAN, Lisa. Energy use, indoor temperature and possible adaptation strategies for airconditioned office buildings in face of global warming. In: Building and Environment, v. 55, p. 819, 2012.

122. GUSSON, Carolina dos Santos. Efeito da densidade construída sobre o microclima urbano: construção de diferentes cenários possíveis e seus efeitos no balanço de energia de áreas urbanas. São Paulo, 2014. Dissertação (Mestrado em Arquitetura e Urbanismo) - Faculdade de Arquitetura e Urbanismo, Universidade de São Paulo.

123. GUSSON, Carolina dos Santos; MADEIRA, Ângela Helena Yamaguishi; DUARTE, Denise. São Paulo: a dense city? In: SASBE 2012 4th CIB International Conference on Smart and Sustainable Built Environments, 2012, São Paulo. Proceedings... Emerging Economies. Campinas: FUNCAMP, 2012. v. 1. p. 1-8.

124. HAMADA S., OHTA, T. Seasonal variations in the cooling effect of urban green areas on surrounding urban areas, Urban Forestry \& Urban Greening, 9, 1, p.15-24, 2010.

125. HEBBERT, Michael; JANKOVIC, Vladimir, WEBB, Brian (ed.). City Weathers. Meteorology and urban design 1950-2010. Proceedings... Manchester, 2011. 
126. HEBBERT, Michael. Climatology for city planning in historical perspective. Urban Climate, 10, p.204-215, 2014.

127. HEBBERT, Michael; JANKOVIC, Vladimir. Cities and Climate Change: The Precedents and Why They Matter. Urban Studies, 50 (7), p.1332-1347, 2013.

128. HEBBERT, Michael; MacKILLOP, Fionn. Urban Climatology Applied to Urban Planning: A postwar Knowledge Circulation Failure. International Journal of Urban and Regional Research, v.37, p.1542-1558, September 2013.

129. HEBBERT, Michael; WEBB, Brian. Towards a Liveable Urban Climate: Lessons from Stuttgart. ISOCARP, Review 07. Liveable Cities: Urbanising World, p.120-137, 2011.

130. HEISLER, G.M. Effects of individual trees on the solar radiation climate of small buildings. Urban Ecol. 9, 337-359, 1986.

131. HELLMANN, L. Determinação de propriedades térmicas de materiais de pavimentação. 2008, 97p. Dissertação (Mestrado) - Programa de Pós-Graduação em Matemática do Departamento de Física, Estatística e Matemática (DeFEM) e Departamento de Tecnologia (DeTEC), Universidade Regional do Noroeste do Estado do Rio Grande do Sul - UNIJUI, 2008.

132. HONG KONG (Special Administrative Region). Hong Kong Figures. Hong Kong Census and Statistics Department, 2012. Disponível em: www.censtatd.gov.hk. Acesso em janeiro de 2012.

133. HONJO T., TAKAKURA T. Simulation of thermal effects of urban green areas on their surrounding areas. Energy and Buildings, 15-16, p. 443-6, 1990/91.

134. HÖPPE, P. The physiological equivalent temperature - a universal index for the biometeorological assessment of the thermal environment. International Journal of Biometeorology, 43, 71-75, 1999.

135. HÖPPE, Peter. A universal index for the assessment of the thermal environmental - the physiolocal equivalent temperature PET. In: de Dear et al. Biometeorology and Urban Climatology at the turn of the millenium. Selected papers from the Conference ICB - ICUC' 99. WCASP-50, WMO/TD No 1026.

136. HOWARD, Luke. The Climate of London. Volume 1 (1833). Republicado pelo IAUC. Disponível em:< http://www.urban-climate.org/resources/classic-texts/. Acesso em: 21 de julho de 2015.

137. HUTTNER, Sebastian. Further development and application of the 3D microclimate simulation ENVI-met. PhD Thesis. Mainz University, Germany, 2012.

138. HUTTNER, S.; BRUSE, M.; DOSTAL, P. Using ENVI-met to simulate the impact of global warming on the microclimate in central European cities. Berichte des Meteorologischen Instituts der Albert-Ludwigs-Universität Freiburg Nr. 18 (2008). Proceedings... Helmut Mayer and Andreas Matzarakis (eds.): 5th Japanese-German Meeting on Urban Climatology, October 2008, pp. 307312.

139. HUTTNER, S.; BRUSE, M.; DOSTAL, P.; KATZSCHNER, L.. Strategies for mitigating thermal heat stress in central European cities: the project KLIMES. In: The Seventh International Conference on Urban Climate, 2009, Yokohama, Japan. Proceedings... Yokohama, Japan.

140. IAG/USP. Boletim Climatológico Anual da Estação Meteorológica do IAG/USP. Seção Técnica de Serviços Meteorológicos. Instituto de Astronomia, Geofísica e Ciências Atmosféricas da Universidade de São Paulo, v. 17, 2014, São Paulo: IAG/USP, 2015.

141. IBGE. Instituto Brasileiro de Geografia e Estatística. Arranjos Populacionais e Concentrações Urbanas do Brasil. 2015.20 Disponível <http://www.ibge.gov.br/apps/arranjos populacionais/2015/>. Acesso em 26 de julho de 2015. 
142. IBGE. Instituto Brasileiro de Geografia e Estatística. Censo 2010. Disponível em: <http://www.censo2010.ibge.gov.br>. Acesso em: 02 ago. 2011.

143. IEA. INTERNATIONAL ENERGY AGENCY. Capturing the multiple benefits of energy efficiency. IEA/OECD: Paris, 2013.

144. IPCC. INTERGOVENMENTAL PANEL ON CLIMATE CHANGE (IPCC). Climate change 2007: synthesis report. Contribution of working groups I, II and III to the fourth assessment report of the intergovernmental panel on climate change. Pachauri, RK, Reisinger, A. (ed.). Core writing team. Geneva: IPCC; 2007.

145. IPCC. INTERGOVENMENTAL PANEL ON CLIMATE CHANGE (IPCC). Climate Change 2013: The Physical Science Basis. IPCC Working Group I Contribution to AR5. 2013.

146. IPCC. INTERGOVENMENTAL PANEL ON CLIMATE CHANGE (IPCC). Climate Change 2014: Impacts, Adaptation, and Vulnerability. IPCC Working Group II Contribution to AR5. 2014a.

147. IPCC. INTERGOVENMENTAL PANEL ON CLIMATE CHANGE (IPCC). Climate Change 2014: Mitigation of Climate Change. IPCC Working Group III Contribution to AR5. 2014b.

148. JACOBS, C.M.J. Direct Impact of Atmospheric CO2 Enrichment on Regional Transpiration. Wageningen. Ph.D. Thesis. Agricultural University, Netherlands, 1994.

149. JANSSON, Christer. Urban microclimate and surface hydrometeorological processes. PhD Thesis. Stockholm: KTH, 2006.

150. JAUREGUI, Ernesto. Influence of a Large Urban Park on Temperature and Convective Precipitation in a Tropical City. Energy and Buildings, $15-16$, p.457-463, 1990/91.

151.JENDRITZKY, G. ; NÜBLER, W. A Model Analysing the Urban Thermal Environment in Physiologically Significant Terms. Archives for meteorology, geophysics, and bioclimatology. Ser. B, 29, 313-326, 1981.

152. JOHANSSON, E. et al. Scale-integrated atmospheric simulations to assess thermal comfort in different urban tissues in the warm humid summer of São Paulo, Brazil. Urban Climate, 6, 2014, 24-43, 2013.

153. JOHANSSON, Erik. Urban design and outdoor thermal comfort in warm climates - studies in Fez and Colombo, 2006. Thesis (PhD in architecture), Housing Development \& Management, Lund University, Lund, Sweden, 2006.

154. JOHANSSON, Erik. Urban microclimate and outdoor thermal comfort in São Paulo. Final Report. Housing Development \& Management, Lund University, Sweden, May 2008. Post-doctoral project funded by the Swedish International Development Cooperation Agency (Sida). Laboratory of Environment and Energy Studies (LABAUT), Faculty of Architecture and Urbanism (FAU), University of São Paulo (USP), Brazil.

155. JONCKHEERE, I. G. C., MUYS, B., COPPIN, P. R. Derivative Analysis for In Situ High Dynamic Range Hemispherical Photography and Its Application in Forest Stands. IEEE Geoscience and Remote Sensing Letter, 2, 296-300, 2005b.

156. JONCKHEERE, I., NACKERTS, K., MUYS, B., COPPIN, P. Assessment of automatic gap fraction estimation of forests from digital hemispherical photography. Agricultural Forest Meteorology, 132, 96-114, 2005.

157. JONCKHEERE, I. et al. Review of methods for in situ leaf area index determination Part I. Theories, sensors and hemispherical photography. Agricultural and Forest Meteorology, 121: 19-35, 2004. 
158. JONES, Hamlyn G. Plants and Microclimate. A quantitative approach to Environment and Plant Physiology. 3ed. Cambridge: Cambridge University Press, 2014.

159. JONES, Hamlyn G.; VAUGHAN, Robin A. Remote sensing of vegetation. Principles, techniques and applications. New York: Oxford University Press, 2010.

160. JUSUF, S. K., WONG, N. H. Development of empirical models for an estate level air temperature prediction in Singapore. In: Second International Conference on Countermeasures to Urban heat Island. Berkeley, USA, 2009. Proceedings ... Disponível em: http://heatisland2009.lbl.gov/docs/221410-jusuf-doc.pdf. Acesso em outubro de 2014.

161. JUSUF, S.K, WONG, N.H., Emlyn, H., A. Roni, and H. Yan. 2007. The influence of land use on the urban heat island in Singapore. Habitat International, 31: 232-42.

162. JUSUF, S.K, WONG, N.H., TAN, E. Urban Climatic Mapping: A Tool to Support Urban Planning and Design in Climate-responsive Cities. In: Third International Conference on Countermeasures to Urban Heat Island. Venice, 2014. Proceedings.... Venice, 2014.

163. KALLARACKAL, J.; SOMEN, C. K. An ecophysiological evaluation of the suitability of Eucalyptus grandis for planting in the tropics. Forest Ecology and Management, 95, 1997, 3-61.

164. KATZSCHNER, L. Open space design strategy based on thermal comfort analysis. In: PLEA 2004 The $21^{\text {st }}$ Conference on Passive and Low Energy Architecture, 2004, Eindhoven. Proceedings... Built environments and Environmental Buildings. Eindhoven: Plea International, 2004. v. 1, p.4752.

165. KATZSCHNER, L. Urban climate studies as tools for urban planning and architecture. In: IV Encontro Nacional de Conforto no Ambiente Construído, 1997, Salvador. Anais... Salvador: FAUUUFBA/LACAM-ANTAC, 1997, p.49-58.

166. KATZSCHNER, Lutz. Urban climate in dense cities. In: NG, Edward (Ed.). Designing high-density cities for social and environmental sustainability. London: Earthscan, 2010. cap. 7, p. 71-78.

167. KNOWLES, Ralph L. The solar envelope: its meaning for energy and buildings. Energy and Buildings, 35 (2003) 15-25.

168. KRATZER, Albert. The Climate of Cities. American Meteorological Society (versão em inglês), 1956. (Das Stadtklima, 1937). Disponível em:< http://www.urban-climate.org/resources/classictexts/. Acesso em: 21 de julho de 2015.

169. KUMAGAI, T.; SAITOH, T. M.; SATO, Y. MOROOKA, T.; MANFROI, O. J.; KURAJI, K.; SUZUKI, M. Transpiration, canopy conductance and the decoupling coefficient of a lowland mixed dipterocarp forest in Sarawak, Borneo: Dry spell effects. Journal of Hydrology. 287, 2004, 237251.

170. LALIC, B., MIHAILOVIC, D. T. An empirical relation describing leaf-area density inside the forest for environmental modelling. Journal of Applied Meteorology, 43(4) 641-645, 2004.

171. LANDSBERG, Helmut. The Urban Climate. Academic Press, 1981.

172. LAMBERT-HABIB et al.. How is climatic adaptation taken into account by legal tools? Introduction of water and vegetation by French town planning documents. Urban Climate, 4, 16-34, June 2013.

173. LEE, Sang-Hyun, BAIK, Jong-Jin. Evaluation of the vegetated urban canopy model (VUCM) and its impacts on urban boundary layer simulation. Asia-Pacific Journal of Atmospheric Sciences. February 2011, Volume 47, Issue 2, pp 151-165 
174. LEE. S.; PARK, S. A Vegetated Urban Canopy Model for Meteorological and Environmental Modelling. Boundary-Layer Meteorology, 2008, 126:73-102.

175. LEITE, Renan Cid Varela. Fortaleza: terra do vento: a influência da mudança nos padrões de ocupação do solo sobre a ventilação natural em cidade de clima tropical úmido. Dissertação (Mestrado em Arquitetura e Urbanismo). São Paulo: FAUUSP, 2010.

176. LEMONSU, A. et al. Inclusion of vegetation in the Town Energy Balance model for modelling urban green areas. Geoscientific Model Development, 5, 1377-1393, 2012.

177. LI, Z., GUO, G. A suitable vegetation index for quantifying temporal variations of LAI in semi-arid mixed grassland. Canadian Journal of Remote Sensing. 36(6): 709-721, 2010.

178. LLOPART, Marta; COPPOLA, Erika; GIORGI, Filippo; ROCHA, Rosmeri P. da; CUADRA, Santiago V. Climate change impact on precipitation for the Amazon and La Plata basins. Climatic Change, v. 125, p.111-125, 2014.

179. LOMBARDO, Magda. Ilha de calor nas metrópoles. São Paulo: Hucitec, 1985.

180. McCARTHY, Mark. Including Cities in Climate Models. In: HEBBERT, Michael; JANKOVIC, Vladimir, WEBB, Brian (ed.). City Weathers. Meteorology and urban design 1950-2010. Proceedings... Manchester, 2011. p.15-20.

181. MAITELLI, Gilda. Abordagem tridimensional de clima urbano em área tropical continental: o exemplo de Cuiabá - MT. 1994. Tese (Doutorado em Geografia) - Faculdade de Filosofia, Letras e Ciências Humanas - Universidade de São Paulo, São Paulo, 1994.

182. MARENGO, José. Caracterização do clima atual e definição das alterações climáticas para o território brasileiro ao longo do Século XXI. Relatório 1. CPTEC/INPE, São Paulo, 2007.

183. MARQUES FILHO et al. Rio de Janeiro's Tropical Urban Climate. Urban Climate News. International Association for Urban Climate, n.32, June, 2009.

184. MARTINS, Rafael; FERREIRA, Leila. Climate change action at the city level: tales from two megacities in Brazil. Management of Environmental Quality: An International Journal. v.22, n.3, 2011, p. 344-357, 2011

185. MASSON, Valéry. A physically-based scheme for the urban energy budget in atmospheric models. Boundary-Layer Meteorology, 94: 357-397, 2000.

186. MASSON, Valéry et al. "Grand Paris": regional landscape change to adapt city to climate warming. Climatic Change, 117, p.769-782, 2013.

187. MATZARAKIS, A; RUTZ F; MAYER, H. Modelling radiation fluxes in simple and complex environments: basics of the RayMan model. International Journal of Biometeorology, v.54, 2010, p.131-139.

188. MAYER, H.; HOPPE, P. Thermal comfort of man in different urban environments. Theoretical and Applied Climatology, n.38, 1987, p.43-49

189. MEADOWS, Donella et al. Limits to Growth, the 30th year update. White River Junction: Chelsea Green, 2004.

190. MEYER, Regina, GROSTEIN, Marta Dora, BIDERMANN, Ciro. São Paulo Metrópole. São Paulo: EDUSP, 2004.

191. MILLS, Gerald et al. Climate Information for Improved Planning and Management of Mega Cities (Needs Perspective). Procedia Environmental Sciences, 1, 2010, 228-246, 2010. 
192. MILLS, Gerald. Cubes and canyons: Different perspectives on the urban climate. In: HEBBERT, Michael; JANKOVIC, Vladimir, WEBB, Brian (ed.). City Weathers. Meteorology and urban design 1950-2010. Proceedings... Manchester, 2011. p.21-24.

193. MILLS, Gerald. Luke Howard, Tim Oke and the study of urban climates. ICUC, Dublin, 2008.

194. MILLS, Gerald. Urban climatology: History, status and prospects. Urban Climate, 10, 479-489, 2014.

195. MIZUNO, M. et al. Effects of land use in urban horizontal atmospheric temperature distributions. Energy and Buildings, n.15-16, 1990/91, p.165-176.

196. MONTEIRO, C. A. F. Teoria e Clima Urbano. Tese (Livre Docência em Geografia), FFLCH/USP, 1976.

197. MONTEIRO, Carlos. A. F. ; ASSIS, E. S. . Entrevista com Carlos Augusto de Figueiredo Monteiro. RUA. Revista de Arquitetura e Urbanismo, v. 9, p. 100-107, 2007.

198. MONTEIRO, Carlos. A. F. et al. A construção da climatologia geográfica no Brasil. São Paulo: Alínea, 2015.

199. MONTEIRO, Carlos A. F.. Some aspects or urban climates in tropical South America: the Brazilian contribution. Technical conference on urban climatology and its applications with special regard to tropical areas. WMO, Cidade do México, 1986. Proceedings.... WMO: Cidade do México, 1986. p. 165-198.

200. MONTEIRO, L. ALUCCI, M. Proposal of an outdoor index: empirical verification in the subtropical climate. In: $27^{\text {th }}$ Conference on Passive and Low Energy Architecture PLEA, 2011, Louvain-laneuve, Belgium. Proceedings... Louvain-la-neuve, July, 2011.

201. MONTEIRO, Leonardo Marques. Modelo adaptativo de conforto para avaliação in loco de espaços urbanos abertos. Ambiente Construído (Online), v. 12, p. 61-79, 2012.

202. MONTEITH, J. L. Evaporation and environment. pp. 205-234. In: G.E. Fogg (ed.) Symposium of the Society for Experimental Biology, The State and Movement of Water in Living Organisms, Vol. 19, Academic Press, Inc., NY, 1965.

203. MUNCK et al. The GREENROOF module (v7.3) for modelling green roof hydrological and energetic performances within TEB 2013. Geoscientific Model Development, 6, 1941-1960, 2013.

204. NG, E. et al. A study on the cooling effects of greening in a high-density city: an experience from Hong Kong. Building and Environment, 47, 2012, p.256-271.

205. NG, Edward (coord.). Urban Climate Map and Standards for Wind Environment - Feasibility Study. Hong Kong: The Chinese University of Hong Kong. School of Architecture. December 2011.

206. NG, Edward (ed). Designing high-density cities. London: Earthscan, 2010.

207. NG, Edward, WONG, Nyuk Hien. Parametric Studies of urban design morphologies and their implied environmental performance. In: BAY, J. B., Ong, B. L. (eds). Tropical Sustainable Architecture: Social and Environmental Dimensions. London, Architectural Press, 2005.

208. NG, Edward; WONG, Nyuk Hien. Better Daylight and Natural Ventilation by Design. In: PLEA 2004. Passive and Low Energy Architecture. Proceedings... Eindhoven, 2004. 
209. NIKOLOPOULOU, Marialena. Designing Open Spaces in the Urban Environment: a Bioclimatic Approach. RUROS: Rediscovering the Urban Real and Open Spaces. CRES - Centre for Renewable Energy Sources, Department of Buildings, Greece, 2004.

210. NOBRE, Carlos A. et al. Vulnerabilidade das Megacidades Brasileiras às Mudanças climáticas: Região Metropolitana de São Paulo. Sumário executivo. 2010.

211. NOBRE, Carlos A.; YOUNG, Andrea F. Vulnerabilidades das megacidades brasileiras às mudanças climáticas: Região Metropolitana de São Paulo. Instituto Nacional de Pesquisas Espaciais, Centro de Ciência do Sistema Terrestre INPE/CCST; Universidade Estadual de Campinas, Núcleo de Estudos de População Unicap/NEPO, 2011.

212. NOWAK, D. J.; MCHALE, P. J.; IBARRA, M.; CRANE, D.; STEVENS, J. C.; LULEY, C. J.1998. Modelling the effects of urban vegetation on air pollution. In: Gryning, Sven-Erik; Chaumerliac, Nadine (ed.). Air pollution modelling and its application XII. New York; Plenum Press: 399-407

213. OJIMA, R. Perspectivas para adaptação frente às mudanças ambientais globais no contexto da urbanização brasileira: cenários para os estudos de população. In: Hogan, Daniel J.; Marandola Jr., Eduardo. (Orgs.). População e Mudança Climática: Dimensões Humanas das Mudanças Ambientais Globais. Campinas: Nepo, 2009, p. 11-24.

214. OKE, T. R. City size and the urban heat island. Atmospheric Environment, v.7, 769-779, 1973.

215. OKE, T. R. Boundary Layer Climates. 2 ed. London; New York: Routledge; John Wiley \& Sons, 1987.

216. OKE, T. R. Canyon geometry and the nocturnal urban heat island: comparison of scale model and field observations. Journal of Climatology, v.1, 237-254, 1981.

217. OKE, T. R. Initial guidance to obtain representative meteorological observations at urban sites. Instruments and observing methods. Report n. 81. WMO/TD-No. 1250,2004.

218. OKE, T. R. Initial guidance to obtain representative meteorological observations at urban sites. Instruments and observing methods. Report n. 81. WMO/TD-No. 1250, 2006.

219. OKE, T. R. Towards better scientific communication in urban climate. Theoretical and Applied Climatology, 2005.

220. OKE, T.R. Towards a prescription for the greater use of climatic principles in settlement planning. Energy and Buildings, 7, 1-10, 1984.

221. OKE, Tim R. The energetic basis of the urban heat island. Quarterly Journal of the Royal Meteorology Society, v. 108, n.455, p.1-24, jan.1982.

222. OLESON, Keith. Contrasts between Urban and Rural Climate in CCSM4 CMIP5 Climate Change Scenarios. Journal of Climate, 25, 1390-1412, 2012.

223. OLGYAY. Design with Climate. Bioclimatic Approach to Architectural Regionalism. Princeton University Press, 1963.

224. OMETO, J. C. Bioclimatologia Vegetal. São Paulo: Agronômica Ceres, 1981.

225. ONG, B. L. Green Plot Ratio and the Role of Greenery in Low Carbon Living. In: Lehmann, Steffen. Low Carbon Cities: Transforming Urban Systems. New York: Routledge, p.349-360, 2015.

226. ONG, B. L. Green Plot Ratio: An Ecological Measure for Architecture and Urban Planning. Landscape and Urban Planning, vol.63, p.197-211, 2002. 
227. ONG, B. L., HO, A., HO, K. H. Green Plot Ratio - Past, Present and Future. In: Tropics 2050. iNTA 2012 - 4th International Network for Tropical Architecture. Proceedings... 2012.

228. ONG, Boon Lay, HES, Dominique, AYE, Lu, FRYD, Ole, TUAN, Duc-Ngo. Towards greater private sector uptake on urban greenery in Melbourne. Disponível na página do autor em: < https://www.mendeley.com/profiles/boon-ong/>. Acesso em 20 de julho de 2015.

229. PBMC. Painel Brasileiro de Mudanças Climáticas. Contribuição do Grupo de Trabalho 1 ao Primeiro Relatório de Avaliação Nacional do Painel Brasileiro de Mudanças Climáticas. Sumário Executivo GT1. Rio de Janeiro, RJ. 2013a.

230. PBMC. Painel Brasileiro de Mudanças Climáticas. Contribuição do Grupo de Trabalho 2 ao Primeiro Relatório de Avaliação Nacional do Painel Brasileiro de Mudanças Climáticas. Sumário Executivo do GT2. Rio de Janeiro, RJ. 2013b.

231. PBMC. Painel Brasileiro de Mudanças Climáticas. Contribuição do Grupo de Trabalho 3 ao Primeiro Relatório de Avaliação Nacional do Painel Brasileiro de Mudanças Climáticas. Sumário Executivo do GT3. Rio de Janeiro, RJ. 2013c.

232. PEPER P.J.; MCPHERSON, E. G. Comparison of five methods for estimating leaf area index of open-grown deciduous trees. Journal of Arboriculture, 24, p.98-111, 1998.

233. PESSACG, Natalia L.; SOLMAN, Silvia A.; SAMUELSON, Patrick; SANCHEZ, Enrique; MARENGO, José; LI, Laurent; REMEDIO, Armelle Reca C.; ROCHA, Rosmeri P. da; MOURÃO, Caroline; JACOB, Daniela. The surface radiation budget over South America in a set of regional climate models from the CLARIS-LPB project. Climate Dynamics, September 2014, v. 43, 5-6, 1221-1239, 2014.

234. PRATA, Alessandra Rodrigues. Dimensionamento do impacto da altura de edifícios nas condições de ventilação natural do meio urbano simulando em túnel de vento: o caso de Santos. 2005. Tese (Doutorado em Arquitetura e Urbanismo) Faculdade de Arquitetura e Urbanismo, Universidade de São Paulo, São Paulo, 2005.

235. PUPPIM DE OLIVEIRA, José Antonio. The implementation of climate change related policies at the subnational level: an analysis of three countries. Habitat International, 33 p. 253-259, 2009.

236. REDON, E. et al. Modelling of Urban Vegetation as a Thermal Regulator and Management of Associated Water Resources for Neighbourhood to City-scale Applications. Third International Conference on Countermeasures to Urban Heat Island. Proceedings, Venezia. October 13-15, 2014. P.850-852.

237. REN, Chao; NG, Edward; KATZCHNER, Lutz. Four Decades of Urban Climatic Map Studies: a Review. In: HEBBERT, Michael; JANKOVIC, Vladimir, WEBB, Brian (ed.). City Weathers. Meteorology and urban design 1950-2010. Proceedings... Manchester, 2011.

238. REVI, A., D.E. SATTERTHWAITE, F. ARAGÓN-DURAND, J. CORFEE-MORLOT, R.B.R. KIUNSI, M. PELLING, D.C. ROBERTS, W. SOLECKI. Urban areas. In: Climate Change 2014: Impacts, Adaptation, and Vulnerability. Part A: Global and Sectoral Aspects. Contribution of Working Group II to the Fifth Assessment Report of the Intergovernmental Panel on Climate Change [Field, C.B., V.R. Barros, D.J. Dokken, K.J. Mach, M.D. Mastrandrea, T.E. Bilir, M. Chatterjee, K.L. Ebi, Y.O. Estrada, R.C. Genova, B. Girma, E.S. Kissel, A.N. Levy, S. MacCracken, P.R. Mastrandrea, and L.L. White (eds.)]. Cambridge University Press, Cambridge, United Kingdom and New York, NY, USA, pp. 535-612.

239. ROBINSON, Darren, BRUSE, Michael. Pedestrian Comfort. In: ROBINSON, Darren. Computer Modeling for Sustainable Urban Design: Physical Principles, Methods and Applications. Routledge, 2011. 
240. ROBINSON, Darren, et al. Building Modelling. In: ROBINSON, Darren. Computer Modeling for Sustainable Urban Design: Physical Principles, Methods and Applications. Routledge, 2011.

241. ROBINSON, Darren. Computer Modeling for Sustainable Urban Design: Physical Principles, Methods and Applications. Routledge, 2011.

242. ROCHA, R. P. da; GONÇALVES, F. L. T.; SEGALIN, B. Fog events and local atmospheric features simulated by regional climate model for the metropolitan area of São Paulo, Brazil. Atmospheric Research (Print), v. 1, p. 1, 2015.

243. ROGERS, Richard, GUMUCHDIIAN, Philip (ed.). Cities for a Small Planet. London: Faber and Faber, 1997.

244. ROSENTHAL, Joyce Klein, KINNEY, Patrick L., METZGER, Kristina B.. Intra-urban vulnerability to heat-related mortality in New York City, 1997-2006. Health \& Place, 30, 45-60, 2014.

245. ROSENTHAL, Joyce Klein. Intra-urban vulnerability to heat-related mortality in New York City. International Association for Urban Climate. Urban Climate News, n.54, December 2014.

246. ROTH, Mathias. Review of urban climate research in (sub)tropical regions. International Journal of Climatology. 27: 1859-1873 (2007)

247. ROTH, Matthias. Thoughts on the state of urban climatology and the IAUC. In: International Association for Urban Climate. Urban Climate News, 2013, p.6-7.

248. SAILOR, D. A green roof model for building energy simulation programs. Energy and Buildings, 40, 2008, 1466-1478.

249. SALDIVA, P. H. N. et al., Association between air pollution and mortality due to respiratory diseases in children in São Paulo, Brazil: a preliminary report. Environmental Research, v.65, p.218-25, 1994.

250. SAMORA, Patricia R. Projeto de habitação em favelas: especificidades e parâmetros de qualidade. Tese (Doutorado em Arquitetura e Urbanismo). Faculdade de Arquitetura e Urbanismo, Universidade de São Paulo, FAUUSP, 2010.

251. SAMPAIO, Antonio Heliodorio Lima. Correlações entre o uso do solo e ilhas de calor no ambiente urbano: o caso de Salvador. 1981. Dissertação (Mestrado em Geografia) - Faculdade de Filosofia, Letras e Ciências Humanas, Universidade de São Paulo, São Paulo, 1981.

252. SANTAMOURIS, M. Cooling the cities - A review of reflective and green roof mitigation technologies to fight heat island and improve comfort in urban environments, Solar Energy, 103, 2014, p. 682-703

253. SANTAMOURIS, M. On the energy impact of urban heat island and global warming on buildings. Energy and Buildings, 82, 2014, p.100-113.

254. SANTAMOURIS, M. (ed). Energy and Climate in the Urban Built Environment. London: James and James, 2001.

255. SANTOS, I. G.; LIMA, H. G.; ASSIS, E. S.; Influência da geometria urbana e da inércia térmica na alteração do clima urbano: uma abordagem preditiva. In: VII ENCAC Curitiba - PR, Brasil 2003. Anais... Curitiba, 2003.

256. SÃO PAULO (Cidade). Atlas ambiental de São Paulo. Secretaria do Verde e do Meio Ambiente SVMA, 2004. Disponível em: <http://atlasambiental.prefeitura.sp.gov.br/> Acesso em: 10 mar 2006. 
257. SÃO PAULO (Cidade). Plano Diretor Estratégico - PDE. São Paulo, 2014. Disponível em: < http://www.prefeitura.sp.gov.br/cidade/secretarias/desenvolvimento urbano/legislacao/plano diretor/index.php>. Acesso em: 23 de julho de 2015.

258. SÃO PAULO (Cidade). Secretaria Municipal de Desenvolvimento Urbano (SMDU). Infocidade, 2009. Disponível em:

<http://infocidade.prefeitura.sp.gov.br/htmls/17_relacao_de_Area_de_terreno_Area_construi_ 2011_452.html>. Acesso em: janeiro de 2012.

259. SÃO PAULO (Cidade). Secretaria Municipal de Habitação. Superintendência de Habitação Popular. A Cidade Informal no Século XXI. São Paulo: Sehab, 2010. Available at: http://www.habisp.inf.br/theke/documentos/publicacoes/catalogo exposicao/index.html, Access May 26 ${ }^{\text {th }}, 2015$.

260. SASS, Ronald L. It's not cool to be hot in Houston. Disponível em: <http://www.ruf.rice.edu/ sass/UHI.html>. Acesso em: 29 julho 2013.

261. SCHILER, Marc. Examples of Glare Remediation Techniques. Four buildings. In: The $26^{\text {rd }}$ Conference on Passive and Low Energy Architecture, Proceedings..., Quebec, 2009.

262. SCHILER, Marc; VALMONT, Elizabeth. Urban Environmental Glare: the Secondary Consequence of Highly Reflective Materials. In: The $23^{\text {rd }}$ Conference on Passive and Low Energy Architecture. Proceedings... Geneva, 2006.

263. SERRA, Geraldo Gomes. Pesquisa em Arquitetura e Urbanismo. Guia prático para o trabalho de pesquisadores em pós-graduação. São Paulo: EDUSP/Mandarim, 2006.

264. SHASHUA-BAR, L.; Hoffman, M. E. Quantitative evaluation of passive cooling of the UCL microclimate in hot regions in summer, case study: urban streets and courtyards with trees. Building and Environment, Oxford, vol. 39, p. 1087-1099, 2004.

265. SHASHUA-BAR, L.; HOFFMAN, M. E. The Green CTTC model for predicting the air temperature in small urban wooded sites. Building and Environment, 37 (2002) 1279-1288.

266. SHASHUA-BAR, L.; HOFFMAN, M. E. Vegetation as a climatic component in the design of an urban street An empirical model for predicting the cooling effect of urban green areas with trees. Energy and Buildings, 31, 2000, p.221-235.

267. SHINZATO, Paula. Impacto da vegetação nos microclimas urbanos em função das interações solo-vegetação-atmosfera. São Paulo: FAUUSP, 2014. Tese (Doutorado em Arquitetura e Urbanismo). Faculdade de Arquitetura e Urbanismo, Universidade de São Paulo. Disponível em: $<$ http://www.teses.usp.br/teses/disponiveis/16/16132/tde-12092014-115829/pt-br.php $>$. Acesso em junho de 2015.

268. SHINZATO, Paula; DUARTE, Denise. Microclimatic Effect of Vegetation for Different Leaf Area Index - LAI. In: PLEA 2012 - Passive and Low Energy Architecture, 2012, Lima. Proceedings... Opportunities, Limits \& Needs. Lima: PUC Peru, 2012. v. 1. p. 1-6.

269. SHINZATO, Paula; DUARTE, Denise; BARROS, Fernanda; MOREIRA, Denise. Intensity and Spatial Influence of Urban Parks: a case study in Sao Paulo, Brazil. In: Sustainable Building Conference, Graz, 2013. Proceedings... International Conference on Sustainable Buildings - Construction Products and Technologies, 2013a.

270. SHINZATO, Paula; DUARTE, Denise; BARROS, Fernanda; MOREIRA, Denise. O impacto da vegetação nos microclimas urbanos: estimativa do índice de área foliar em diferentes grupos arbóreos. In: XII Encontro Nacional de Conforto no Ambiente Construído / VIII Encontro Latinoamericano de Conforto no Ambiente Construído, 2013, Brasília. Anais... Conforto \& Projeto. Brasília: UnB, 2013b. 
271. SHINZATO, Paula. Impacto da vegetação nos microclimas urbanos. Dissertação (Mestrado em Arquitetura e Urbanismo). Faculdade de Arquitetura e Urbanismo, Universidade de São Paulo, 2009.

272. SHINZATO, Paula; DUARTE, Denise. Impact of Vegetation on Urban Microclimates. In: World Sustainable Building Conference. Helsinki, 2011. Proceedings... World Sustainable Building Conference. Helsinski: SB11, 2011. v. 2. p. 239-247.

273. SHINZATO, Paula; DUARTE, Denise. Microclimatic Effect of Vegetation for Different Leaf Area Index - LAI. In: PLEA 2012 - Passive and Low Energy Architecture, 2012, Lima. Opportunities, Limits \& Needs. Proceedings... Lima: PUC Peru, 2012. v. 1. p. 1-6.

274. SHINZATO, Paula; DUARTE, Denise. Quantificação da intensidade e a distribuição espacial dos efeitos microclimáticos da vegetação. In: XI Encontro Nacional e VII Encontro Latino-Americano de Conforto no Ambiente Construído - XI ENCAC e VII ELACAC, 2011, Búzios. Anais...Conforto Ambiental na Arquitetura e no Urbanismo: Uma Reflexão além da Técnica, 2011.

275. SHINZATO, Paula; DUARTE, Denise; BARROS, Fernanda; MOREIRA, Denise. O impacto da vegetação nos microclimas urbanos: estimativa do índice de área foliar em diferentes grupos arbóreos. In: XII Encontro Nacional de Conforto no Ambiente Construído / VIII Encontro Latinoamericano de Conforto no Ambiente Construído, 2013, Brasília. Anais...Conforto \& Projeto. Brasília: UnB, 2013.

276. SHINZATO, Paula; DUARTE, Denise; BARROS, Fernanda; MOREIRA, Denise. Intensity and Spatial Influence of Urban Parks: a case study in Sao Paulo, Brazil. In: Sustainable Building Conference 2013, 2013, Graz. Proceedings... International Conference on Sustainable Buildings Construction Products and Technologies, 2013.

277. SHINZATO, Paula; YOSHIDA, Daniel; DUARTE, Denise. O impacto da vegetação nos microclimas urbanos: estimativa do índice de área foliar - IAF pelo método de fotos hemisféricas (Artigo aceito para o ENCAC 2015).

278. SILVA DIAS, Maria A; DIAS, Juliana; CARVALHO, Leila M; FREITAS, Edmilson; SILVA DIAS, Pedro. Changes in extreme daily rainfall for Sao Paulo, Brazil. Climatic Change, 116, 3-4 705-722, Feb. 2013.

279. SOUZA, Tatiana Moreira de; DUARTE, Denise. Leitura e Representação Gráfica das Condições Ambientais Urbanas. Estudo de caso: Av. Paulista. In: VII Encontro Nacional sobre Conforto no Ambiente Construído e III Conferência Latino-Americana sobre Conforto e Desempenho Energético e Edificações, 2003, Curitiba. Anais... Conforto e Eficiência Energética na Arquitetura Latino-Americana. Curitiba: ANTAC, 2003.

280. SOUZA, Tatiana Moreira de; DUARTE, Denise. Reading and Graphic Representation of the Urban Environmental Conditions. Case study: Paulista Avenue. In: PLEA 2004 - The 21th Conference on Passive and Low Energy Architecture, 2004, Eindhoven. Proceedings... Built environments and Environmental Buildings. Eindhoven: Plea International, 2004. v. 1. p. 565-570.

281. SPANGENBERG, J. Improvement of Urban Climate in Tropical Metropolis - A case study in Maracanã/ Rio de Janeiro. Thesis (Master in Architecture), University of Applied Sciences, Cologne, Germany, 2004. Disponível em: <http://www.basis-id.de/science>. Acesso em: de março 2008.

282. SPANGENBERG, J.; SHINZATO, P.; JOHANSSON, E.; DUARTE, D. (2007). Simulation of the influence of vegetation on microclimate and thermal comfort in the city of São Paulo. Revista da Sociedade Brasileira de Arborização Urbana, RevSBAU, Piracicaba, v.3, n.2, jun. 2008, p. 1-19. 
283. SPANGENBERG, Jörg. Retro-innovating Nature in Megacities. São Paulo/Brazil - a case-Study. Tese (Doutoramento em Arquitetura). USP/Bauhaus, São Paulo/Weimar, 2010.

284. SPRONKEN-SMITH, R. A.; OKE, T. The thermal regime of urban parks in two cities with different summer climates. International Journal of Remote Sensing, 1998, vol. 19, no. 11, 2085-2104.

285. STEEMERS, Koen, STEANE, Mary Ann. Environmental Diversity in Architecture. New York: Spon Press, 2004.

286. STEWART, I. D. A systematic review and scientific critique of methodology in modern urban heat island literature. International Journal of Climatology, 31: 200-217, 2011.

287. STEWART, I. D., OKE, T., KRAYENHOFF, S. Evaluation of the 'local climate zone' scheme using temperature observations and model simulations. International Journal of Climatology, 34: 1062-1080, 2014.

288. STONE Jr., Brian. The city and the coming climate. Climate Changes in the Places we live. New York: Cambridge, 2012.

289. STONE Jr., Brian. Urban and rural temperature trends in proximity of large US cities 1951-2000. International Journal of Climatology, 27, 1801-1807, 2007.

290. SWAID, H.; HOFFMAN M.E. Prediction of urban air temperature variations using the analytical CTTC model. Energy and Buildings, 14, 313-324, 1990.

291. TAESLER, R. Urban climatological methods and data. In: Technical Conference on Urban Climatology and its Applications with Special Regard to Tropical Areas, Geneva. Proceedings... WMO: Geneva, 1986, n.652, 199-236.

292. TAHA, Haider; AKBARI, Hashem; ROSENFELD, Arthur. Residential cooling loads and the urban heat island: the effects of albedo. Building and Environment, 23, 271, 1988.

293. TAHA, Haider. Night Time Air Temperature and the Sky-View Factor : a Case Study in San Francisco, California. Berkeley: Lawrence Berkeley Laboratory, 1988 (LBL- 24009).

294. TAHA, H. et al. (1992) The impact of trees and white surface on residential heating and cooling energy use in four Canadian cities. Energy, v.17, n. 2, 1992, p.141-149.

295. TAN, Puay Yok; SAI, Angela. Leaf Area Index of Tropical Plants. A guidebook on its use in the calculation of green plot ratio. CUGE, 2010.

296. TARIFA, José Roberto, AZEVEDO, Tarik Rezende de. Os climas na cidade de São Paulo. Teoria e prática. São Paulo: Pró-reitoria de Cultura e Extensão. USP: Laboratório de Climatologia. FFLCH, 2001. (GEOUSP - Coleção Novos Caminhos, 4).

297. THE WORLDWATCH INSTITUTE. State of the world. Our Urban Future. A Worldwatch Institute Report on Progress Toward a Sustainable Society. New York; London: WW Norton \& Company, 2007.

298. TOMASELLA J.; ROSSATO, L. Balanço Hídrico. Tópicos em Meio Ambiente e Ciências Atmosférica. INPE. São José dos Campos, 2005.

299. TORRES, Roger et al. Socio-climatic hotspots in Brazil. Climatic Change, 115, p.597-609, 2012.

300. TRICHON, V.; WALTER, J. M. N.; LAUMONIER, Y. Identifying Spatial Patterns in the Tropical Rain Forest Structure using Hemispherical Photograghs. Plant Ecology. 137, 1998, 227-247.

301. ULRICH, R. S. Influences of passive experiences with plants on individual wellbeing and health. In: Relf, D. (ed) The Role of Horticulture in Human Well-Being and Social Development: A National Symposium. Timber Press, Portland, Oregon pp. 93 -105, 1992. 
302. ULRICH, R. S. The therapeutic role of greenspace. Greenspace and Healthy Living National Conference, Manchester, 2002.

303. ULRICH, RS. View through a window may influence recovery from surgery. Science, 224, 1998, pp 420-421.

304. UN/WMO/WHO. United Nations. Heatwaves and Health: Guidance on Warning-System Development. WMO/WHO, 2015. Disponível em: <https://www.wmo.int/media/content/wmowho-issue-guidance-heat-health-warning-systems >. Acesso em: 20 de julho de 2015.

305. UN/DESA - United Nations. Department of Economic and Social Affairs. 2014. World Urbanization Prospects: The 2014 Revision, Highlights. Disponível em: <http://esa.un.org/unpd/wup/Highlights/WUP2014-Highlights.pdf >. Acesso em: 16/01/15.

306. UN-HABITAT. United Nations. Cities and climate change: global report on human settlements. Earthscan, 2011.

307. UNEP. UNITED NATIONS ENVIRONMENT PROGRAMME. Buildings and Climate Change: Status, challenges and opportunities. 2007.

308. VDI 3787. Verein Deutscher Ingenieure. Environmental meteorology, methods for the humanbiometeorological evaluation of climate and air quality for the urban and regional planning at regional level. Part I: Climate. VDI/DIN-Handbuch Reinhaltung der Luft, Düsseldorf, 2008.

309. VERTESSY, R.A.; BENYON, R.G.; O'SULLIVAN, S.K.; GRIBBEN, P.R. Relationships between stem diameter, sapwood area, leaf area and transpiration in a young mountain ash forest. Tree Physiology. 15, 1995, 559-567.

310. VIANNA, Sérgio Besserman; VEIGA, José Eli da; ABRANCHES, Sérgio. A Sustentabilidade do Brasil. In: GIAMBIAGI, BARROS (orgs) Brasil Pós-Crise: Agenda para a próxima década. Campus, p. 305-324, 2009.

311. VOOGT, James A. Urban Heat Islands: Hotter Cities. 2004. Disponível em: <http://www.actionbioscience.org/environment/voogt.html> Acesso em: 9 março de 2006.

312. VOOGT, James A., OKE, T. R. Thermal remote sensing of urban climates. Remote Sensing of Environment, 86, 370-384, 2003.

313. WATSON, D. J. Comparative physiological studies on growth of field crops: I. Variation in net assimilation rate and leaf area between species and varieties, and within and between years. Annals of Botany, v. 11, p. 41-76, 1947.

314. WEISS M., BARET, F., SMITH, G.J., JONCKHEERE, I., COPPIN, P. Review of methods for in situ leaf area index (LAI) determination. Part II. Estimation of LAI, errors and sampling. Agricultural and Forest Meteorology, 121: 37-53, 2004.

315. WEISS, M., BARET, F. CAN-EYE V6.1 "User Manual". EMMAH laboratory (Mediterranena environmentand agro-hydro system modelisation). French National Institute of Agricultural Research (INRA), 2010.

316. WHILE, Aidan, WHITEHEAD, Mark. Cities, Urbanisation and Climate Change. Urban Studies. Special Issue Introduction, 50(7) 1325-1331, May 2013.

317. WILDE, Peter de; COLEY, David. The implications of a changing climate for buildings. Building and Environment, v. 55, p. 1-7, set. 2012.

318. WILMERS F. Effect of Vegetation on Urban Climates and Buildings. Energy and Buildings, n.15, 1991. 
319. WMO. World Meteorological Organization. Guide to Meteorological Instruments and Methods of Observation (WMO, 2008), Part II. Observing Systems, Chapter 11 - Urban Observations, 2008.

320. WMO. World Meteorological Organization. Global Features. Overview. Statement. 2014.

321. WMO. World Meteorological Organization. Warming Trend Continues in 2014. Statement. WMO: 2015. Disponível em: <https://www.wmo.int/media/?q=content/warming-trendcontinues-2014>. Acesso em 02/02/2015.

322. WONG, N. H; CHEN, Y. Tropical Urban Heat Islands. Climate, buildings and greenery. Abingdon: Taylor and Francis, 2009.

323. WONG, N. H. et al. Environmental study of the impact of greenery in an institutional campus in the tropics. Building and Environment, 42, 2007, p.2949-2970.

324. WONG, N. H. et al. The Effects of rooftop garden on energy consumption of a commercial building in Singapore. Energy and Buildings, 35, 2003, p.353-364.

325. WONG, N. H., JUSUF, S. K., TAN, C. L.. Integrated urban microclimate assessment method as a sustainable urban development and urban design tool. Landscape and Urban Planning, 100, 2011, p.386-389.

326. WONG, N. H., JUSUF, S. K.. 2008a. An assessment method for existing greenery conditions in a university campus. Architectural Science Review, 51 (3): 212-22.

327. WONG, N. H., JUSUF, S. K.. 2008b. GIS-based greenery evaluation on campus master plan. Landscape and Urban Planning, 84(2): 166-182.

328. WONG, N. H., JUSUF, S. K.. Development of empirical models for an estate level air temperature prediction in Singapore. In: Second International Conference on Countermeasures to Urban heat Island. Berkeley, USA, 2009. Proceedings ... Disponível em: http://heatisland2009.Ibl.gov/docs/221410-jusuf-doc.pdf. Acesso em outubro de 2014.

329. WONG, Nyuk Hien, CHEN, Yu. The role of urban greenery in High-Density Cities. In: NG, Edward (ed). Designing high-density cities. London: Earthscan, 2010. Chapter 6.

330. WORLD BANK. World Development Indicators: Urbanization. 2014. Disponível em: $<$ http://wdi.worldbank.org/table/3.12>. Acesso em janeiro 2015.

331. WORLD ECONOMIC FORUM, 2015. Global Risks. 10 ${ }^{\text {th }}$ edition. WEF, Geneva, 2015. Disponível em: $<$ www.weforum.org/risks $>$. Acesso em 15/01/15.

332. XAVIER, A. C.; SOARES, J. V.; ALMEIDA, A. C. Variação do Índice de Área Foliar em Clones de Eucalipto ao longo do seu ciclo de crescimento. Árvore, v.26, n.4, 2002.

333. YANG, W. et al. Thermal comfort in outdoor urban spaces in Singapore. Building and Environment, 59 (2013) 426-435.

334. YEANG, Ken. Reinventing the Skyscraper. West Sussex: Wiley-Academy, 2002.

335. YUAN, Chao; NG, Edward. Building porosity for better urban ventilation in high-density cities - a computational parametric study. Building and Environment, 50, 176-189, 2012.

337. ZHANG, Y.; CHEN, J.M.; MILLER, J.R. Determining digital hemispherical photograph exposure for leaf area index estimation. Agricultural and Forest Meteorology, 133, 2005, 166-181. 